INSTITUTO DE BOTÁNICA CARLOS SPEGAZZINI

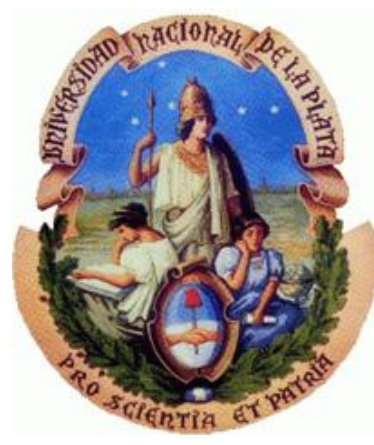

Facultad de Ciencias Naturales y Museo

Universidad Nacional de La Plata

\title{
HONGOS ENTOMOPATÓGENOS: COLONIZACIÓN ENDOFÍTICA Y CONTROL DE INSECTOS PLAGA EN CULTIVOS AGRÍCOLAS
}

Lic. María Leticia Russo

Directores

Dra. Marta N. Cabello

Dr. Sebastián A. Pelizza

La Plata, 2016 


\section{Agradecimientos}

A mis directores Dra. Marta Cabello y Dr. Sebastián Pelizza, por sus innumerables aportes, por su generosidad, por toda la confianza y oportunidades brindadas y por permitir mi integración en el instituto de Botánica "Carlos Spegazzini".

A la Dra. Ana Clara Scorsetti, mi codirectora de beca, por su amabilidad, acompañamiento y apoyo constante durante todo el trabajo de tesis.

Al Consejo Nacional de Investigaciones Científicas y Técnicas (CONICET) y a la Empresa Rizobacter Argentina, por financiar mi estudio de posgrado mediante el otorgamiento de la beca y a la Facultad de Ciencias Naturales y Museo, UNLP, por la formación recibida.

Al Lic. Matías Abalo por su ayuda en los muestreos presentes en mi trabajo de tesis.

Al Dr. Marcelo Barrera por su buena predisposición y ayuda en análisis estadísticos.

A la Ing. María Inés Urrutia por su colaboración en el análisis estadístico.

Al Dr. Sebastián Stenglein por la ayuda brindada y haberme permitido el acceso al Laboratorio de Biología Funcional y Biotecnología (BIOLAB)-CICBA y el uso del mismo para el desarrollo de una parte de mi trabajo.

A Ricardo, Fernando y Celina Marelli por su dedicación, ayuda y permitirme realizar muestreos en sus campos particulares.

A todas mis amigas, muy especialmente a Nati, mi hermana del alma, por formar parte de mi vida, por su compañía, su profunda amistad y por los inolvidables momentos compartidos.

A mis compañeros y amigos del Instituto Spegazzinicon quienes compartimos el día a día durante estos años y por brindar un lugar de trabajo ameno y agradable; a Nati mi gran amiga; a Lore Cami, Ceci, Luz por su buena onda y los lindos momentos 
compartidos; a Gaby, Naty en quienes encontré personas maravillosas y siempre estuvieron dispuestas a ayudar y muy especialmente a Flor por su ayuda, hermosa amistad, paciencia y por tanto que hemos vivido juntas, a Sil porque estuvo presente desde el primer día, porsu generosidad, amistad y consejos en el momento adecuado y a Anita por toda su ayuda, apoyo, amabilidad y cariño.

A mi familia, por su inmenso cariño y confianza, por apoyarme y alentarme día a día.

Y agradecer muy especialmente a Guido, quien me hace muy feliz todos los días de mi vida, porque estuvo y esta siempre a mi lado, por su compañía, ayuda, paciencia y por su inmenso amor. 
A Santi con todo mi amor 


\section{Índice de contenidos}

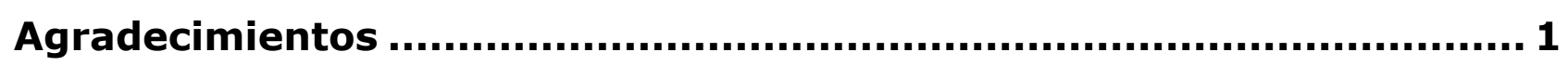

Índice de contenidos .................................................................... 4

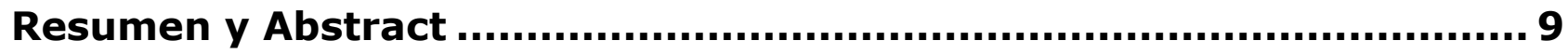

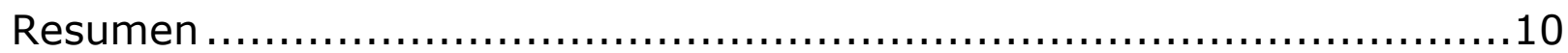

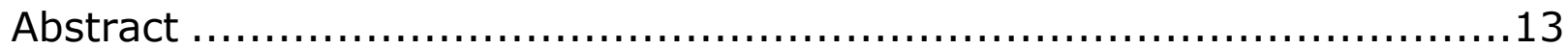

Introducción general y Antecedentes.......................................... 16

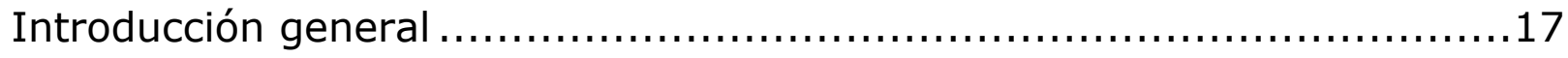

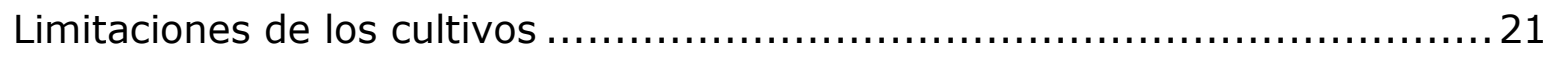

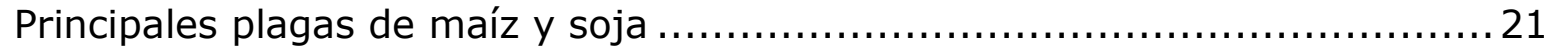

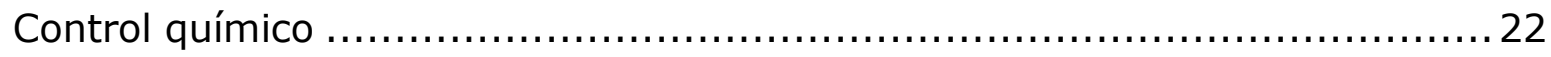

Manejo Integrado de plagas ................................................... 24

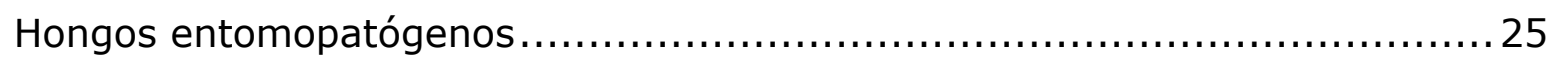

Mecanismo de acción de hongos entomopatógenos ..............................26

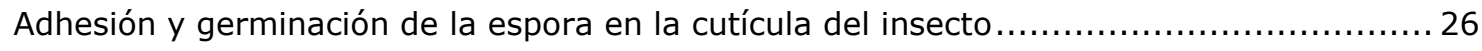

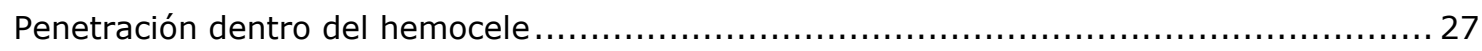

Desarrollo del hongo que resulta en la muerte del insecto $\ldots \ldots \ldots \ldots \ldots \ldots \ldots \ldots \ldots \ldots \ldots \ldots \ldots \ldots \ldots \ldots \ldots \ldots \ldots \ldots \ldots \ldots \ldots$

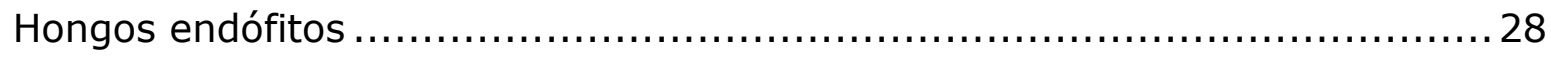

Mecanismo de dispersión y relación hongo-planta ..................................29

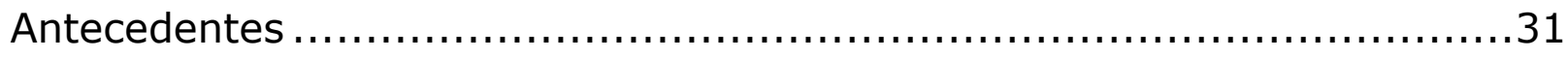

Hongos entomopatógenos como endófitos ........................................ 33

Hipótesis y Objetivos ................................................................ 35

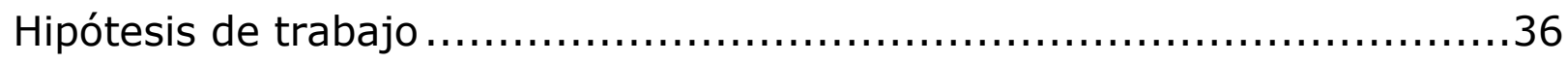

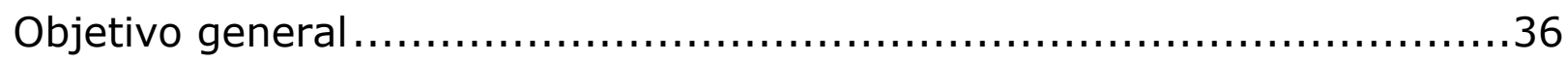

Objetivos específicos........................................................... 


\section{CAPÍTULO I Diversidad de especies de hongos endófitos en cultivos de} maíz y soja.

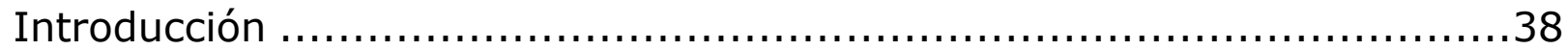

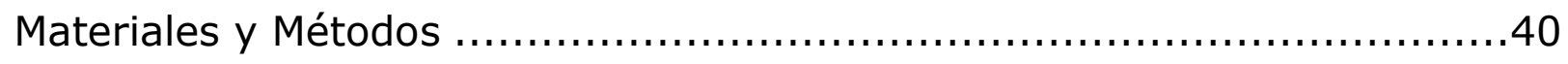

Descripción del sitio de muestreo .............................................40

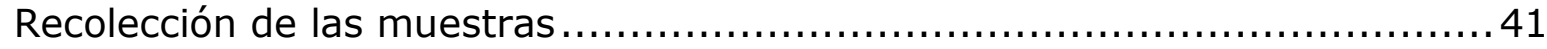

Aislamiento de hongos endófitos ................................................ 43

Identificación de hongos endófitos ........................................... 45

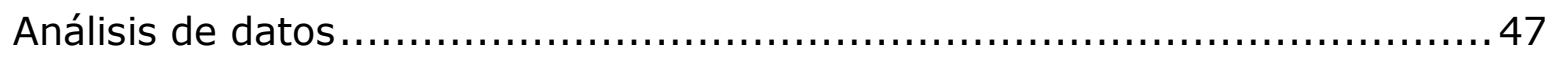

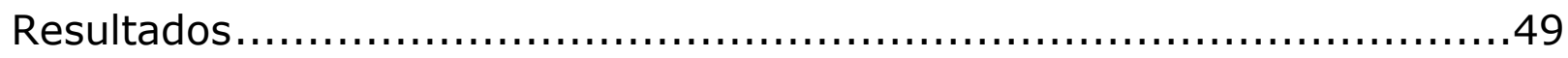

Composición de hongos endófitos en maíz .......................................49

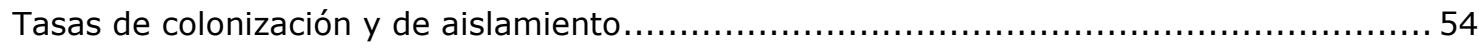

Diversidad de las comunidades de hongos endófitos en las diferentes variedades de maíz . 56

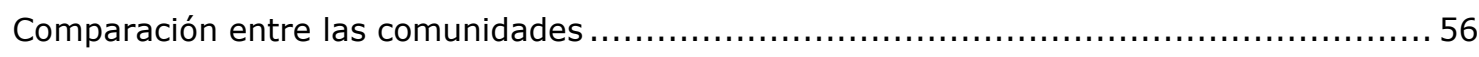

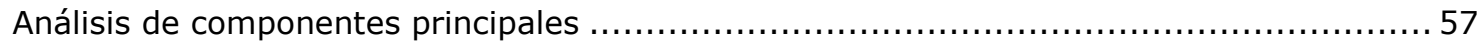

Composición de hongos endófitos en soja .......................................5 59

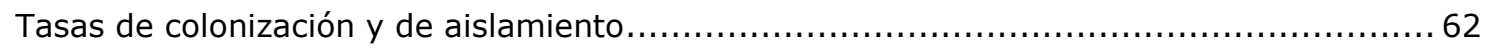

Diversidad de las comunidades de hongos endófitos en las diferentes variedades de soja .. 66

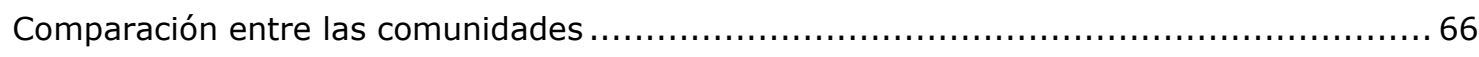

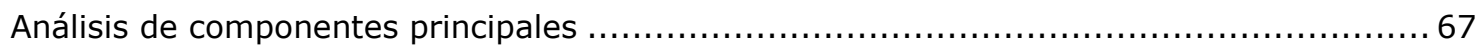

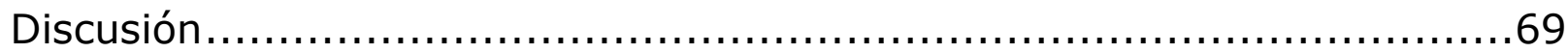

CAPÍTULO II Evaluación de distintas técnicas de inoculación de hongos entomopatógenos en plantas de maíz y soja bajo condiciones de

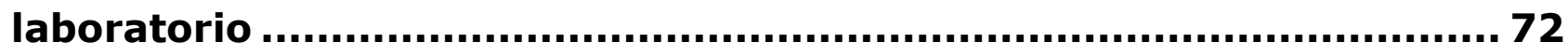

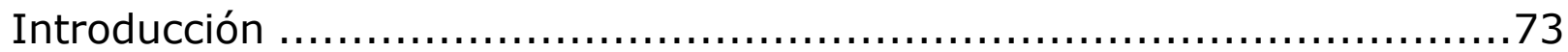

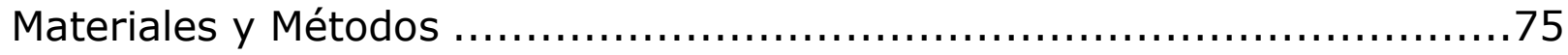

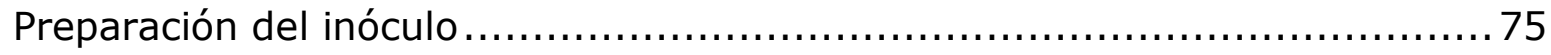

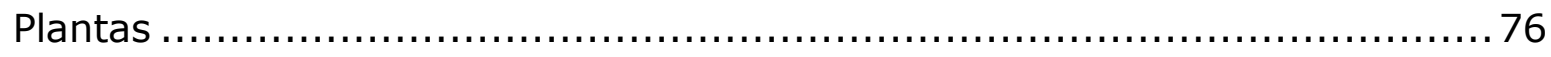

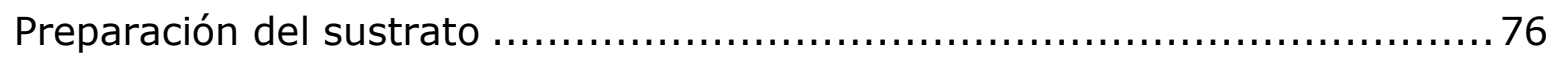

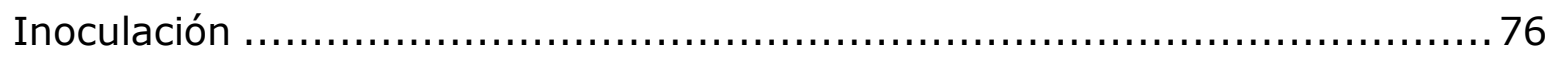


Técnicas de inoculación ......................................................... 77

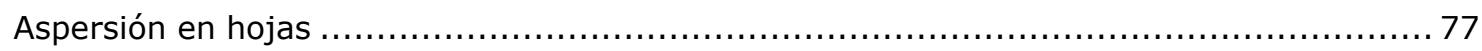

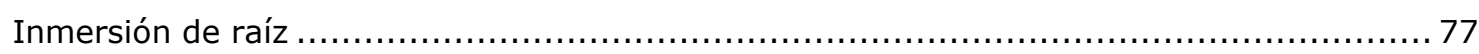

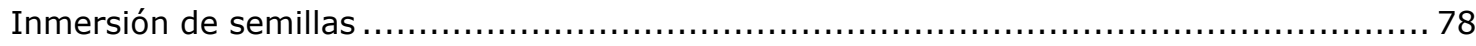

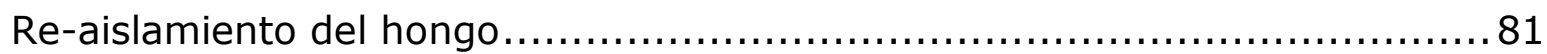

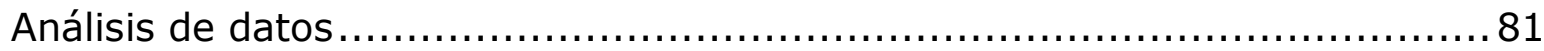

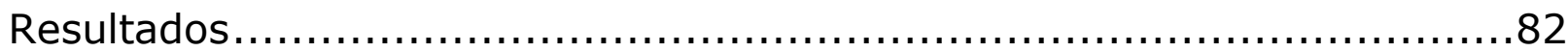

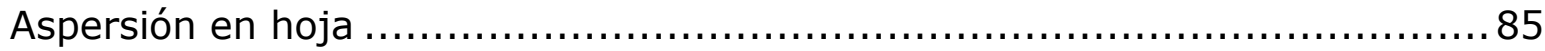

Inmersión de raíz................................................................ 92

Inmersión de semilla .......................................................... 92

Discusión...................................................................... 100

CAPÍTULO III Efecto de Beauveria bassiana como endófito sobre el crecimiento y rendimiento de plantas de maíz y soja ...................... 102

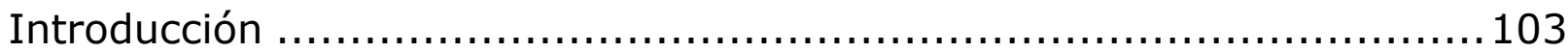

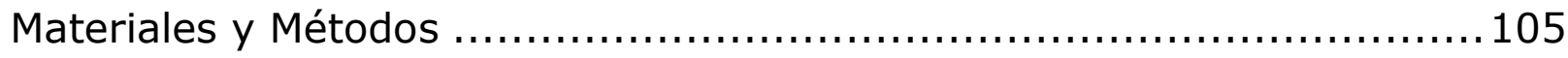

Inoculación de las plantas de maíz y soja y su establecimiento en el campo 105

Crecimiento y rendimiento de las plantas ....................................... 108

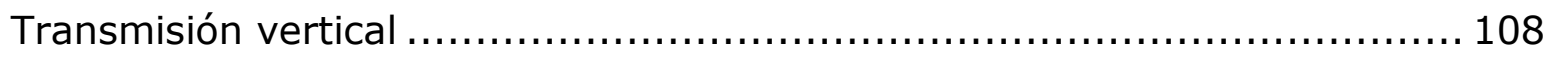

Poder germinativo de las semillas obtenidas.................................. 110

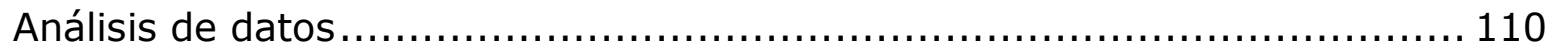

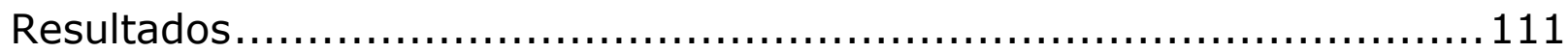

Efecto de $B$. bassiana sobre el crecimiento de las plantas...................... 111

Transmisión vertical de $B$. bassiana y poder germinativo de las semillas

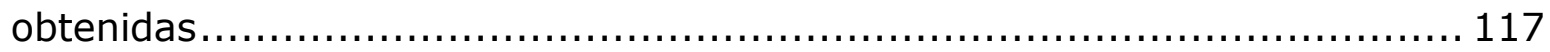

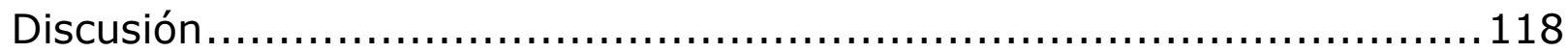

CAPÍTULO IV Efectos de Beauveria bassiana como endófito en plantas de maíz y soja sobre dos especies plaga Spodoptera frugiperda y Helicoverpa gelotopoeon .............................................................. 120

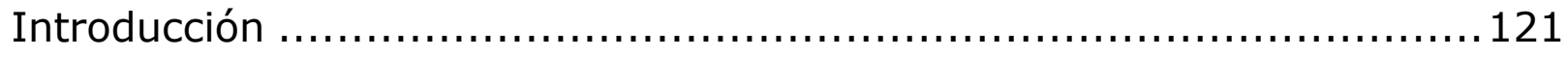


Materiales y Métodos 124

Selección de la cepa fúngica, preparación de la solución fúngica e inoculación de las plantas de maíz y soja. 124

Cría de Lepidópteros 125

Efecto de Beauveria bassiana sobre el crecimiento y la reproducción de los insectos 129

Aspectos biológicos 129

Aspectos reproductivos 129

Parámetros poblacionales 130

Preferencia alimenticia 130

Análisis de los datos

Resultados

Aspectos biológicos y reproductivos de S. frugiperda 133

Parámetros poblacionales 137

Aspectos biológicos y reproductivos de $H$. gelotopoeon 138

Parámetros poblacionales 142

Preferencia alimenticia 143

Discusión 145

Conclusiones generales y perspectivas futuras

Conclusiones generales 148

Perspectivas futuras. 150

Discusión general 151

Discusión general 152

Anexo 155

Cría de Lepidópteros 156

Dieta de larvas 156

S. frugiperda 156

H. gelotopoeon 156

Dieta de adultos 
Esterilización de pupas . 157

Referencias 158

Referencias bibliográficas 159 


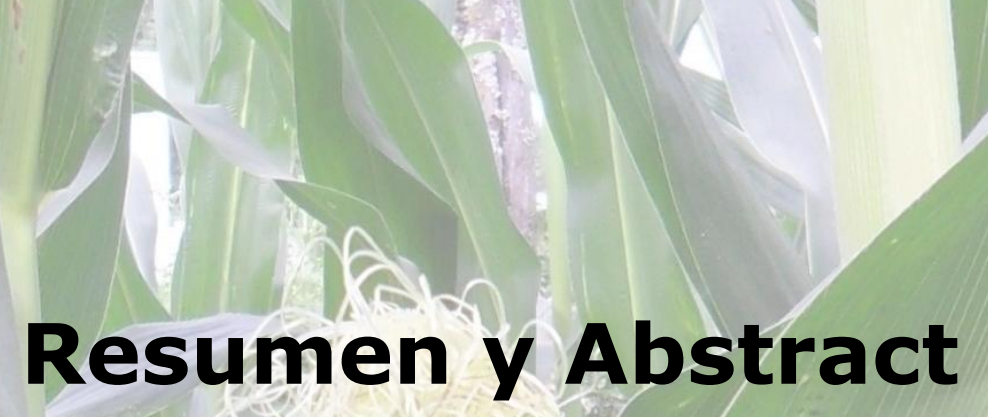




\section{Resumen}

Los hongos entomopatógenos son agentes de control biológico en todo el mundo y han sido objeto de intensa investigación desde hace más de 100 años. La mayoría de las investigaciones con respecto al uso de estos hongos se han centrado en el desarrollo de métodos inundativos, mediante la aplicación masiva con el propósito de que produzcan un efecto inmediato en las poblaciones plaga. El descubrimiento de su naturaleza endofítica se considera como un nuevo enfoque para su uso en la agricultura. El término "endófito" fue acuñado por De Bary (1884) y se utiliza para definir a hongos o bacterias que se encuentran en el interior de tejidos de plantas de manera asintomática. Los hongos endófitos son ubicuos y pertenecen en su mayoría al Phylum Ascomycota. Se ha registrado que el hongo entomopatógeno Beauveria bassiana (Bals-Criv.) Vuill. (Hypocreales: Cordicypitaceae) ha sido aislado como endófito natural de Coffea arabica L. (Gentianales: Rubiaceae), Dactylis glomerata L. (Poales: Poaceae), Datura stramonium L. (Solanales: Solanaceae), Eucalyptus globulus Labill (Myrtales: Mirtaceae), Pinus radiata Don. (Pinales: Pinaceae), Papaver somniferum L. (Ranunculales: Papaveraceae), Quercus ilex L. (Fagales: Fagaceae); en tanto, Metarhizium anisopliae (Metschn.) Sorokin (Hypocreales: Clavicipitaceae) se aisló de Cynodon dactylon (L.) Pers. (Poales: Poaceae); Lecanicillium lecanii (Zimm.) Zare \& Gams (Hypocreales: Cordicypitaceae) de Gossypium hirsutum L. (Malvales: Malvaceae), Carpinus caroliniana Walter (Fagales: Betulaceae), D. glomerata y Tolypocladium cylindrosporum Gams (Hypocreales: Ophiocordycipitaceae) de Festuca rubra L. (Poales: Poaceae) y Holcus lanatus L. (Poales: Poaceae). Además, estos hongos han sido introducidos en estas y otras especies de plantas mediante diversas técnicas (aspersión en hoja, inmersión de raíz, inmersión de semilla, inyección de tallo e inoculación de suelo). Uno de los posibles usos de los hongos entomopatógenos en la agroindustria, radica en la capacidad de producir metabolitos que pueden promover el crecimiento de las plantas, aumentar su rendimiento y establecerse como endófitos en cultivos de importancia económica tales como Brassica napus L. (Brassicales: Brassicaceae), Zea mays L. (Poales: Poaceae), Musa paradisiaca L. (Zingiberales: Musaceae), C. arabica, P. somniferum, Vicia faba L. (Fabales: Fabaceae), Sorghum bicolor L. (Poales: Poaceae), Solanum lycopersicum L. (Solanales: Solanaceae) y G. hirsitum y conferir a las mismas resistencia frente a las plagas. 
Los objetivos de este trabajo de tesis fueron determinar la diversidad de especies de hongos endófitos presentes en raíces, tallos y hojas de siete variedades de maíz (Z. mays) y siete variedades de soja (Glycine max (L.) Merril. (Fabales: Fabaceae) provenientes de diferentes zonas ubicadas dentro de la Región Pampeana Argentina. Determinar si los hongos entomopatógenos B. bassiana, M. anisopliae, Metarhizium robertsii Bisch., Rehner \& Humber (Hypocreales: Clavicipitacea) L. lecanii y T. Cylindrosporum pueden establecerse como endófitos en plantas de maíz y soja mediante aspersión en hoja, inmersión de raíz e inmersión de semilla, determinando así la técnica más eficiente y el aislamiento fúngico con mayor potencialidad para colonizar la planta y comportarse como endófito. Detectar si el aislamiento seleccionado produce algún efecto en el crecimiento y en el rendimiento de las plantas y finalmente, evaluar aspectos biológicos, reproductivos, parámetros poblacionales y la preferencia alimentaria de los insectos plaga Spodoptera frugiperda Smith (Lepidoptera: Noctuidae) y Helicoverpa gelotopoeon Dyar (Lepidoptera: Noctuidae) alimentados con plantas de maíz y soja colonizadas endofiticamente por $B$. bassiana.

A partir de las diferentes variedades de maíz y soja se obtuvieron 1601 y 3992 aislamientos fúngicos respectivamente, los cuales fueron agrupados dentro de los Phyla Ascomycota y Zygomycota.

En maíz, se obtuvieron 1172 aislamientos a partir de tallos, 208 a partir de las raíces y 221 a partir de las hojas. El número de especies fúngicas aisladas a partir del total de las variedades involucradas en este estudio varió entre 10 y 16 en tallos, 6 y 12 en hojas y 9 y 13 en raíces. Las más relevantes por su abundancia fueron Arthrinium sp., Fusarium graminearum Schwabe (Hypocreales: Nectriaceae), Fusarium proliferatum (Matsush.) Nirenberg (Hypocreales: Nectriaceae) y Penicillium rubrum Stoll (Eurotiales: Trichocomaceae) mientras que Fusarium sp. 11 y Trichoderma harzianum Rifai (Hypocreales: Hypocreaceae) sólo fueron aisladas de la variedad NK900 y Fusarium sp. 7 de la variedad DK699.

En soja, se obtuvieron 2787 aislamientos a partir de tallos, 651 a partir de las raíces y 550 a partir de las hojas. El número de especies fúngicas aisladas a partir del total de las variedades involucradas en este estudio varió entre 12 y 18 en tallos, 11 y 15 en hojas y 10 y 15 en raíces. Las más relevantes por su abundancia fueron Aspergillus terreus Thom (Eurotiales: Trichocomaceae), Fusarium sp. 15, Fusarium sp. 17, Macrophomina phaseolina (Tassi) Goid (Botryosphaeriales: Botryosphaeriaceae) y P. rubrum, mientras que Alternaria sp. sólo pudo ser aislada de la variedad DM4913, Bipolaris tetramera (McKinney) Shoemaker (Pleosporales: Pleosporaceae) de la 
variedad DM4670, Nigrospora sp. de la variedad DM4210 y Scopulariopsis brevicaulis (Sacc.) Bainier (Microascales: Microascaceae) de la variedad DM3810.

Tanto en maíz como en soja la composición de las especies fúngicas y el número de aislamientos varió principalmente en función del órgano de la planta estudiado, detectándose diferencias en cuanto a la afinidad de algunas especies hacia la colonización de determinadas variedades vegetales.

Analizando las técnicas de inoculación de hongos entomopatógenos, mediante aspersión en hoja, inmersión de semilla e inmersión de raíz, se logró establecer a las especies $B$. bassiana, M. anisopliae y M. robertsii en plantas de maíz y soja. La técnica de aspersión resultó la más eficiente en introducir a las especies de hongos entomopatógenos como endófitos, produciendo así una relación endofítica entre los hongos y las plantas, que se verificó a través del reaislamiento fúngico hasta 28 días posinoculación. Las cepas probadas de L. lecanii y $T$. cylindrosporum no se establecieron cómo endófitos en ninguna de las plantas dado que no lograron reaislarse en ninguno de los períodos de tiempo estudiados.

En relación a los efectos de los hongos entomopatógenos en los cultivos estudiados y a sus principales insectos plaga, la cepa LPSc 1098 de B. bassiana favoreció el crecimiento y el rendimiento de las plantas; mostró efectos negativos en la supervivencia, fecundidad, fertilidad y en todo el desarrollo de los insectos plaga $S$. frugiperda y $H$. gelotopoeon y disminuyó considerablemente la preferencia alimentaria de estos insectos frente a las plantas de maíz y soja inoculadas con $B$. bassiana.

Estos resultados sugieren que la utilización de los hongos entomopatógenos como endófitos puede constituir una herramienta a tener en cuenta dentro del Manejo Integrado de Plagas. 


\section{Abstract}

Entomopathogenic fungi are biological control agents present all over the world and have been subject of research for over 100 years. Most research regarding the use of these fungi have focused on the development of inundative methods trough massive application intending to produce an immediate effect over plague populations; the discovery of their endophytic nature is considered a new insight on their use in agriculture. The term "endophyte" was defined by De Bary (1884) and is used to define microorganisms (fungi or bacteria) that inhabit the interior of plant tissues in an asymptomatic way. Endophytic fungi are ubiquitous and belong mainly to the Phylum Ascomycota. The entomopathogenic fungi Beauveria bassiana (Bals-Criv.) Vuill. (Hypocreales: Cordicypitaceae) has been recorded as a natural endophyte in plants like Coffea arabica L. (Gentianales: Rubiaceae), Dactylis glomerata L. (Poales: Poaceae), Datura stramonium L. (Solanales: Solanaceae), Eucalyptus globulus Labill (Myrtales: Mirtaceae), Pinus radiata Don. (Pinales: Pinaceae), Papaver somniferum L. (Ranunculales: Papaveraceae), Quercus ilex L. (Fagales: Fagaceae); Metarhizium anisopliae (Metschn) Sorokin (Hypocreales: Clavicipitaceae) has been isolated from Cynodon dactylon (L.) Pers. (Poales: Poaceae); Lecanicillium lecanii (Zimm.) Zare \& Gams (Hypocreales: Cordicypitaceae) from Gossypium hirsutum L. (Malvales: Malvaceae), Carpinus caroliniana Walter (Fagales: Betulaceae), D. glomerata and Tolypocladium cylindrosporum Gams (Hypocreales: Ophiocordycipitaceae) from Festuca rubra L. (Poales: Poaceae) and Holcus lanatus L. (Poales: Poaceae). Also, these fungi had been inoculated in these and other plant species using diverse techniques (leaf spray, root or seed inmersion, stem injection and, soil drench). A possible use of entomopathogenic fungi in agroindustry is the utilization of their capacity to produce metabolites that may promote plant growth, rise yield and establish as endophytes conferring pest resistance in economic importance plants such as Brassica napus L. (Brassicales: Brassicaceae), Zea mays L. (Poales: Poaceae), Musa paradisiaca L. (Zingiberales: Musaceae), C. arabica, P. somniferum, Vicia faba L. (Fabales: Fabaceae), Sorghum bicolor L. (Poales: Poaceae), Solanum lycopersicum L. (Solanales: Solanaceae) and G. hirsitum

The objectives of this thesis were to estimate endophytic fungi species diversity present in roots, stems and leaves of seven corn (Z. mays) varieties and seven 
soybean (Glycine max (L.) Merril (Fabales: Fabaceae)) varieties from different areas belonging to the Pampean Región, Argentina. To determine if the entomopathogenic fungi B. bassiana, M. anisopliae, Metarhizium robertsii Bisch., Rehner \& Humber (Hypocreales: Clavicipitacea), L. lecanii and T. cylindrosporum can establish as endophytes in corn and soybean through leaf spray, root inmersion and, seed inmersion; to determined which technique is the most efficient and which fungi isolate has higher potential to colonize plants and act as endophyte; to detect if the selected fungal isolate affects the growth and yield of plants and finally to evaluate different biological and reproductive aspects, population parameters and, food preference of soybean and corn insect pests Helicoverpa gelotopoeon Dyar (Lepidoptera: Noctuidae) and Spodoptera frugiperda Smith (Lepidoptera: Noctuidae) when fed with plants inoculated and endophytically colonizated with $B$. bassiana.

In corn, 1172 isolations from stems, 208 from roots and, 221 from leaves were obteined. The number of fungic species isolated in stems for all varieties ranged from 10 and 16, in leaves between 6 and 12 and in roots between 9 and 13; the most relevant due to their abundance were Arthrinium sp., Fusarium graminearum Schwabe (Hypocreales: Nectriaceae), Fusarium proliferatum, While (Matsush.) Nirenberg (Hypocreales: Nectriaceae) Penicillium rubrum Stoll (Eurotiales: Trichocomaceae), and Fusarium sp. 11 and Trichoderma harzianun Rifai (Hypocreales: Hypocreaceae) had only been isolated from variety NK900 and Fusarium sp. 7 from variety DK699.

In soybean, 2787 isolations from stems, 651 from roots and 554 from leaves were obteined. The number of fungic species isolated in stems for all varieties ranged from 12 and 18, in leaves between 11 y 15 and in roots between 10 and 15; the most relevant due to their abundance were Aspergillus terreus Thom (Eurotiales: Trichocomaceae), Fusarium sp. 15, Fusarium sp. 17, Macrophomina phaseolina (Tassi) Goid (Botryosphaeriales: Botryosphaeriaceae) and P. rubrum, Alternaria sp. had only been isolated from variety DM4913, Bipolaris tetramera (McKinney) Shoemaker (Pleosporales: Pleosporaceae) from variety DM4670, Nigrospora sp. from DM4210 and Scopulariopsis brevicaulis (Sacc.) Bainier (Microascales: Microascaceae) from variety DM3810.

Both in corn and soybean, the number of fungic species and the number of isolations varied toward the plant organ studied, also differences were detected as regard species affinity to colonize certain varieties.

As regard entomopathogenic fungi inoculation techniques through leaf spray, root inmersion and seed inmersion, B. bassiana, M. anisopliae and, M. robertsii were 
established as endophytes in soybean and corn plants. Leaf spray technique was the most effective when introducing the entomopathogenic fungi species as endophytes, producing an endophytic relationship between fungi and plants. This was verified through fungic reisolation until 28 days postinoculation. The strains of $L$. lecanii and the strain $T$. cylindrosporum were not able to established as endophytes in studied plants as they were not reisolated in any of the periods of time studied.

Regarding entomopathgenic fungi effects over the studied crops and their main insect pests, B. bassiana strain LPSc 1098 favoured growth and yield in plants; showed negative effects on survival, fecundity, fertility and developement of $S$. frugierda and $H$. gelotopoeon and considerably decreased the alimentary preference of these insects towards inoculated corn and soybean plants.

These results suggest that entomopathogenic fungi as endophytes can be taken into account as important tools to consider in Integrated Pest Management systems. 


\section{Introducción general y}

\section{Antecedentes}




\section{Introducción general}

El Reino Fungi está conformado por organismos eucariotas filogenéticamente diversos, portadores de esporas, que no poseen plástidos por lo que son aclorófilos, heterótrofos y se nutren por absorción, se reproducen sexual y asexualmente por esporas; sus estructuras somáticas pueden ser celulares o ramificadas, filamentosas y están rodeadas por paredes celulares quitinosas (Inglis et al. 2001).

En los hongos se reconocen tres modelos nutricionales de acuerdo a la manera que utilizan para explotar los diversos sustratos (Thrower, 1966). Se denominan saprótrofos cuando se nutren degradando sustratos muertos, necrótrofos cuando los tejidos vivos primero son muertos y luego utilizados saprotróficamente y biótrofos cuando sólo obtienen su alimento a partir de células vivas. En la naturaleza, los hongos pueden depender de un solo modo nutricional (carácter obligado) o combinar más de un modo de nutrición en su ciclo de vida.

En su décima edición, en el el Diccionario de los Hongos, Kirk et al. (2008) agrupan a los hongos en seis Phyla: Ascomycota, Basidiomycota, Chytridiomycota, Glomeromycota, Microsporidia y Zygomycota.

Desde el punto de vista del control de plagas agrícolas, el de mayor importancia corresponde al Phylum Ascomycota, ya que agrupa a la mayoría de los hongos patógenos de insectos (Humber 2012 a, b).

Los hongos entomopatógenos son considerados importantes agentes de control biológico en todo el mundo y han sido objeto de intensa investigación desde hace más de 100 años (Vega et al. 2012). Durante los últimos 45 años, los patólogos de insectos han expresado un fuerte optimismo en relación al potencial que presentan los hongos entomopatógenos como controladores de insectos plaga, pero la realidad sin embargo, indica que a pesar de que hubo avances claros y significativos en este campo, todavía no se pueden sortear ciertos obstáculos básicos como las limitaciones de humedad, los rayos ultravioleta y la formulación, que impiden a los hongos patógenos de insectos ser ampliamente adoptados y comercializados (Vega, 2008).

Los cultivos de soja (Glycine max (L.) Merril.) (Fabales: Fabaceae) y maíz (Zea mays L.) (Poales: Poaceae) son los cultivos extensivos más importantes tanto en el mundo, como en Argentina, fundamentalmente si se hace referencia al incremento de superficie sembrada, producción, rentabilidad e ingresos de divisas extranjeras a la economía nacional (Vilella et al. 2010), por otro lado la soja y el maíz constituyen los 
cultivos predominantes de verano en la Región Pampeana, principal zona agrícola de la Argentina (Fernandez et al. 2009).

La soja es originaria de China y pertenece a la familia Fabaceae. Su cultivo es el que mayor crecimiento ha tenido en los últimos años en Argentina, ganando terreno frente a cultivos más tradicionales, como el trigo y el girasol. La práctica de este cultivo pasó de 11 millones de hectáreas en 2001/2002 a 20 millones en la campaña 2014/2015 (SAGPyA, 2015), convirtiéndolo en el de mayor superficie sembrada del país (Figura. 1A). En los últimos 18 años la superficie sembrada de soja aumentó 3,6 veces y la producción creció 4,8 veces. Al mismo tiempo la productividad aumentó aproximadamente un 20\% (Escande, 2012).

La Argentina es el tercer país productor de soja en el mundo, luego de EE.UU y Brasil, siendo el tercer exportador mundial de poroto de soja y el primer exportador de aceite y harinas de soja. La Unión Europea es la principal importadora de granos de soja y una de las más importantes importadora de harinas y otros subproductos junto con otros países asiáticos y africanos. Es por ésto que el complejo exportador de soja es el más relevante para la economía del país, lo que se traduce en un ingreso de 3.500 millones de dólares anuales (Giorda, 1997). La superficie dedicada a este cultivo en la Argentina continúa creciendo y con la aparición de los materiales transgénicos, parecería no existir un techo a su producción, es por ello que la soja ha pasado a ser sin dudas el principal cultivo en nuestro país (Barrios et al. 2014; Ybran y Lacelli, 2015).

Desde finales de los años 90' la adopción de la siembra directa en Argentina, como sistema productivo, ha ido en constante aumento. Esto se vio acompañado por el empleo de un paquete tecnológico que incluye, entre otros, el uso de herbicidas como el glifosato y de semillas de soja genéticamente modificadas, tolerantes a los herbicidas (Barrios, 2011). Por otro lado es importante mencionar que la casi totalidad de la superficie de soja sembrada en nuestro país corresponden a cultivares modificados genéticamente y que gran parte se realiza bajo monocultivo y siembra directa (Carmona, 2014).

Según proyecciones del MAGyP (2012), se estimaba que el sector agrícola evolucionaría con un crecimiento de la superficie sembrada de cereales, leguminosas y cultivos industriales, equivalente a un 9\% entre el año 2010 y el año 2016 (2,8 millones de ha). Con estas proyecciones se alcanzarían cerca de 116 millones de toneladas en el año 2017. 
El maíz pertenece a la familia Poaceae, es originario del continente americano, específicamente de México, Centroamérica y Sudamérica. Es uno de los cereales de mayor importancia, ocupando el tercer lugar en consumo después del arroz y el trigo. En América Latina constituye una de las fuentes principales de nutrición para la población del área (Medina Delgado, 2015).

Es el cereal de grano grueso con mayor superficie sembrada en el continente Americano y el de mayor volumen de producción en toneladas anuales. Sólo en la Argentina se siembran alrededor de 6.000 .000 ha con un volumen de producción de 33.000.000 tn anuales (Figura 1B) (Gimenez Pecci et al. 2002; SAGPyA, 2015).

El maíz es, después del trigo, el cereal más importante en la dieta de humanos y animales en todo el mundo (FAO, 2011). En Argentina, las regiones donde se cultiva principalmente este cereal corresponden a Buenos Aires, Santa Fe y Córdoba y en menor medida la Región del NOA (MAGyP, 2012). En esta última región, también hay razas nativas de maíz, que son cultivadas en granjas pequeñas y se utilizan para el consumo doméstico. Argentina se ha convertido en uno de los cinco mayores productores de maíz en todo el mundo (Tamagno et al. 2015). 


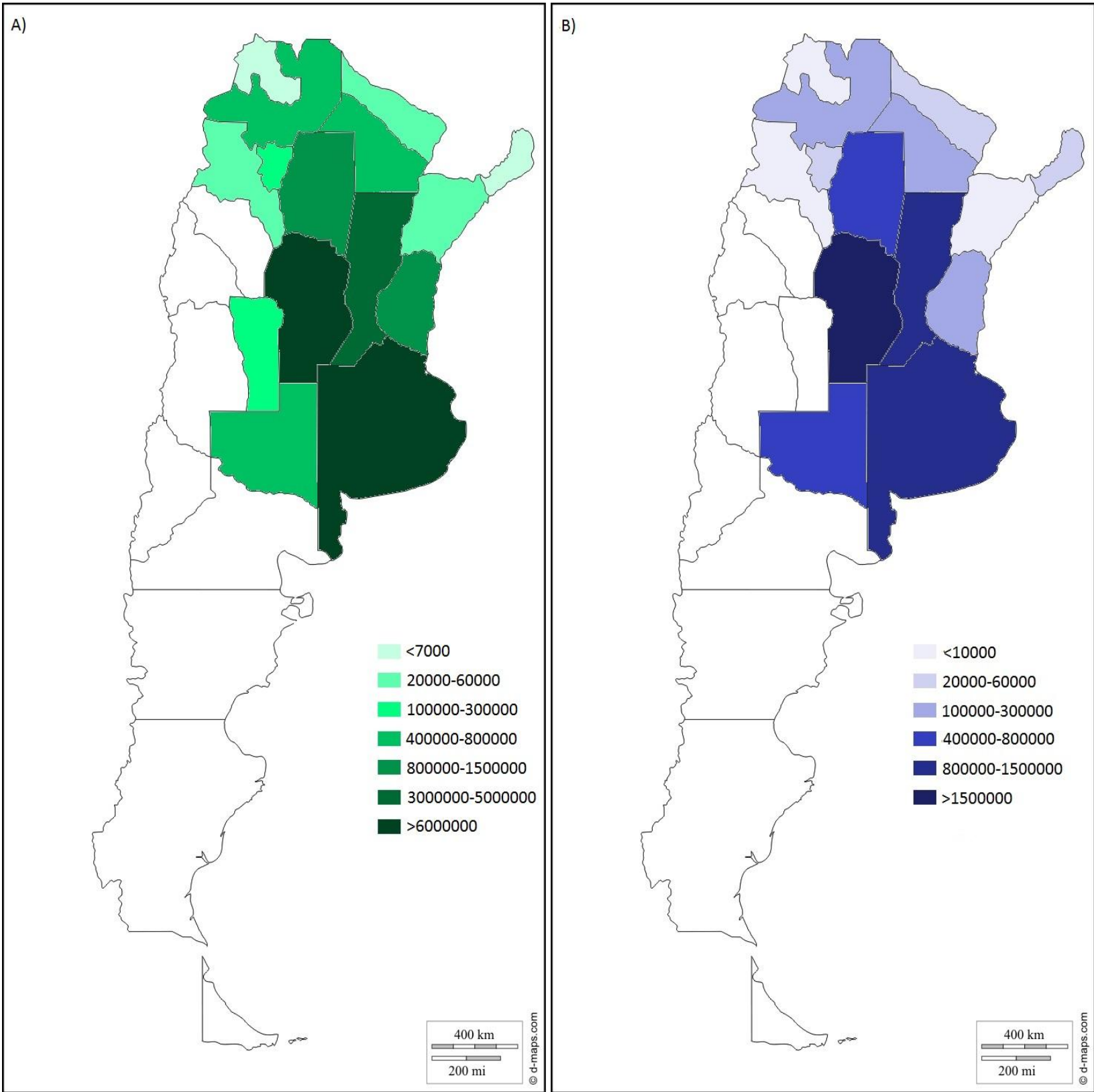

Figura 1. Área sembrada durante la campaña 2014/2015, A) soja B) maíz. (SAGPyA, 2015) 


\section{Limitaciones de los cultivos}

Numerosos son los factores que pueden limitar la producción y la calidad de los granos del cultivo de maíz y soja generando la brecha entre los rendimientos promedios anuales y los potenciales del cultivo. Entre algunos de ellos se puede mencionar deficiencias hídricas, el deterioro de las condiciones fisicoquímicas del suelo, insuficiente uso de fertilizantes, escasas rotaciones e incidencia de las enfermedades, malezas y plagas (Carmona, 2014).

Los cultivos agrícolas son afectados, desde el nacimiento hasta la madurez del grano por una gran diversidad de artrópodos plaga que producen diversos niveles de daños que pueden tener importancia económica por las pérdidas ocasionadas. El conjunto de herbívoros encuentran en estas plantas los recursos indispensables para su vida, señalando como una plaga severa a aquellas que producen un impacto negativo sobre el rendimiento de los granos del cultivo (Chacón Castro, 2008).

Se calcula que las pérdidas producidas por insectos plagas oscilan en promedio entre 10 y 15 \%. En la Argentina, se estima que las pérdidas originadas por las plagas alcanzan valores superiores a las 900.000 toneladas/año, causando un perjuicio económico de más de 250 millones de dólares (FAO, 2010).

\section{Principales plagas de maíz y soja}

El Orden Lepidoptera es el que cuenta con la mayor cantidad de especies plaga para ambos cultivos en la Argentina. Los adultos de la mayoría de las especies plaga son de hábitos nocturnos; las larvas normalmente presentan la cutícula del cuerpo lisa, son de colores apagados, se alimentan del follaje de las plantas, pero algunas tienen hábitos barrenadores y otras consumen frutos (Baudino y Villareal 2007).

Las orugas defoliadoras, son una de las principales plagas del cultivo de soja. Entre las especies de mayor importancia económica se destacan Rachiplusia nu (Guenée) (Lepidoptera: Noctuidae), Anticarsia gemmatalis (Hübner) (Lepidoptera: Noctuidae) y Helicoverpa gelotopoeon (Dyar) (Lepidoptera: Noctuidae), mientras que entre las especies que causan mayores daños al cultivo de maíz y que afectan su rendimiento se pueden mencionar a Diatraea saccharalis (Fab.) (Lepidoptera: Crambidae) y Spodoptera frugiperda (Smith) (Lepidoptera: Noctuidae), considerada la plaga de mayor impacto económico en la región Pampeana de la Argentina (Chacón 
Castro, 2008). La utilización de maíces Bt permitió disminuir las consecuencias del ataque de insectos, pero su eficacia puede verse limitada por la capacidad de los insectos blanco en desarrollar resistencia. La capacidad de este grupo de insectos depende fundamentalmente de factores biológicos, ambientales y genéticos (Parodi, 2011).

El conjunto de insectos plagas mencionados, provocan importantes pérdidas en la producción de cultivos de maíz y soja. Si bien es cierto que no alcanzan todos los años el nivel de daño económico, es común que sus ataques sean más severos en períodos de sequía prolongados, como ocurre frecuentemente en nuestra región productora. Algunos de los perjuicios ocasionados por estas plagas sobre los cultivos de maíz y soja, se ven reflejados en una disminución del área foliar de las plantas lo cual ocasiona menor intercepción de luz, menor capacidad fotosintética, pérdida del material almacenado y acortamiento del período de llenado de granos (Boito et al. 2013).

\section{Control químico}

El método de control de plagas comúnmente utilizado es el uso de insecticidas sintéticos. Existen más de 1500 principios activos que, en distintas mezclas y concentraciones, generan más de 50.000 productos registrados en el mundo como plaguicidas (Sarandon, 2011).

La era de los insecticidas modernos en la agricultura se inició inmediatamente después de terminada la Segunda Guerra Mundial. El descubrimiento de la acción insecticida del dicloro difenil tricloroetano (DDT) (1939) y del hexaclorociclohexano (HCH) (1941) permitió su uso para combatir insectos vectores de enfermedades. Rápidamente su uso se extendió al combate de plagas agrícolas. Años más tarde su uso se había generalizado en casi todos los países del mundo. Los plaguicidas organoclorados (POC) fueron ampliamente utilizados en la Argentina al igual que en el resto del mundo. En la misma época, irrumpieron en el mercado los plaguicidas organofosforados (POF) y los carbámicos (PCar). A partir de los años 70, la producción y el consumo de los agroquímicos aumentó, especialmente en los países productores de granos, acrecentándose los riesgos de efectos adversos a largo plazo en la población en general, en los trabajadores y en el ambiente (Brunstein et al. 
2009). Paulatinamente, se fueron incorporando otras clases de plaguicidas, como los insecticidas piretroides.

En la Argentina el organismo responsable del registro de agroquímicos es, el Servicio Nacional de Sanidad Vegetal y Calidad Agroalimentaria (SENASA), que mediante diferentes resoluciones fue restringiendo y prohibiendo el uso de los POC y ciertos POF y PCar, debido a sus conocidos efectos adversos sobre la salud humana y el ambiente, así como por su elevada persistencia.

A pesar de haber disminuido el empleo de piretroides respecto de 2010, actualmente, los principales insecticidas utilizados en la Argentina son cipermetrina y lambdacialotrina y hubo un crecimiento de insecticidas como el rynaxypyr (diamidas antranílicas) y fipronil (fenil pirazol).

Miles de nuevos productos son investigados anualmente en búsqueda de propiedades pesticidas y algunos de ellos llegan a incorporarse al mercado después de muchos años de experimentación. Las primeras aplicaciones de estos insecticidas modernos fueron tan espectaculares que muchas esperanzas se cifraron en la posibilidad de erradicar las principales plagas. Desafortunadamente después de algo más de cuatro décadas de aquellos resultados extraordinarios se puede comprobar que los problemas de plagas no han desaparecido, por el contrario, en muchos casos se han agravado (Sarandon, 2011).

La continua utilización de los pesticidas trajo consigo fenómenos nuevos, no previstos, entre los cuales se puede mencionar 1) toxicidad en el hombre: los insecticidas, además de ser tóxicos para los artrópodos plaga, son también tóxicos para los vertebrados, incluido el hombre. El personal que trabaja en la fabricación o en la formulación de los productos, los agricultores y operadores que manipulan y aplican los insecticidas, así como el consumidor de los productos vegetales tratados con estos tóxicos, todos están expuestos a intoxicaciones (Sarandon, 2011); 2) desequilibrio en el ecosistema: produciendo efectos directos por la contaminación de las aguas subterráneas (Pimentel, 2005) y por la reducción de abundancia y diversidad de los organismos no blanco, ya que normalmente son más susceptibles que las especies fitófagas, por lo que sus poblaciones son afectadas por las aplicaciones de insecticidas más drásticamente. La destrucción de los controladores biológicos produce dos fenómenos: la rápida resurgencia de la plaga-problema, debido a la eliminación de sus enemigos naturales, que aunque no estaban en proporción satisfactoria para mantener la población de la plaga a niveles bajos, de alguna manera ejercían cierto grado de control. Una vez desaparecido el efecto del insecticida, el insecto, libre de sus enemigos biológicos, se incrementa rápidamente hasta alcanzar 
niveles mayores a los registrados previamente a la aplicación, convirtiéndose en plaga. A su vez, surgen nuevas plagas como consecuencia de la eliminación de enemigos biológicos. Sin este control natural, las poblaciones de insectos, que antes no tenían importancia económica, se incrementan y alcanzan niveles de plagas. La reducción de la diversidad biótica del suelo causada por los pesticidas ocasiona un fuerte impacto en varias funciones biológicas, dentro de las cuales se pueden mencionar la descomposición de la materia orgánica y la disponibilidad de los nutrientes en el suelo, afectando también sus propiedades químicas y físicas (Ferraro et al. 2003); 3) en algunos casos permiten que la plaga desarrolle poblaciones resistentes a los insecticidas, debido a la variabilidad natural que presentan los individuos de una población sobre los efectos de un producto. Normalmente los individuos susceptibles son eliminados y unos pocos individuos son capaces de tolerar las dosis que producen la muerte de la mayoría de la población, ejerciendo una presión de selección por medio de sucesivas aplicaciones (Valerio, 2006; Chacón Castro, 2008). Producto de esta resistencia lograda por las distintas especies de insectos plagas, lo que hacen generalmente los productores es aumentar la dosis del insecticida, lo cual repercute tanto en el medio ambiente, produciendo una mayor contaminación del suelo y del agua, como en los costos de producción (Van Driesche et al. 2007).

Al analizar esta gama de problemas derivados del uso inadecuado y desmedido de estas sustancias químicas, se hace necesario replantear la manera de manejar los sistemas agrícolas y buscar nuevas soluciones para el control de plagas, de manera que se restablezca el equilibrio de los ecosistemas.

\section{Manejo Integrado de plagas}

Desde hace varios años se produjo un aumento indiscriminado en el uso de agroquímicos para el control de insectos plaga. Debido a los efectos negativos mencionados anteriormente y a la necesidad de desarrollar métodos de control más selectivos y compatibles con el ambiente, en las últimas décadas se ha incrementado el interés por el Manejo Integrado de Plagas (MIP). El MIP se define como una herramienta que reúne de manera compatible y simultánea todos los métodos de control posibles (control químico, cultural, biológico y uso de variedades resistentes) para mantener al nivel de la plaga por debajo de los niveles poblacionales que 
produzcan daño económico al cultivo (Pérez Moreno, 2000; Romero, 2004; Sarandon, 2011). El principal objetivo es integrar diferentes estrategias de control de plagas para reducir al mínimo el uso de plaguicidas químicos.

El Control Biológico es un componente muy importante dentro del MIP, ya que además de cuidar y reforzar la acción de los agentes de control que normalmente están presentes en el ecosistema, utiliza enemigos naturales (depredadores, parásitos, parasitoides y patógenos) para reducir la densidad de la población y los efectos de las plagas. El control de plagas utilizando patógenos, es una rama del control biológico conocida como control microbiano y hace referencia al uso de microorganismos como agentes de control, tales como bacterias, nematodos, virus, protozoos y hongos entomopatógenos (Eilenberg et al. 2001; Lord, 2005; González Castillo et al. 2012). Dentro de este grupo de microorganismos, los hongos entomopatógenos son los que han recibido mayor atención por la gran variedad de especies y amplio rango de hospedantes.

\section{Hongos entomopatógenos}

Los hongos entomopatógenos se encuentran en el Reino Fungi, dentro de cinco Phyla: Microsporidia, Chytridiomycota, Zygomycota, Ascomycota y Basidiomycota.

Desde el punto de vista del control de plagas agrícolas, el de mayor importancia corresponde al Phylum Ascomycota, ya que agrupa a la mayoría de hongos patógenos de insectos (Humber, $2012 \mathrm{a}, \mathrm{b}$ ).

Los hongos del Phylum Ascomycota, se caracterizan por presentar hifas septadas y poseer un estado asexual o anamorfo donde las diferentes especies producen gran cantidad de esporas o conidios que sirven para ampliar su dispersión. Los conidióforos surgen desde el micelio y poseen células conidiógenas y diversos tipos de conidios, los cuales corresponden a las estructuras reproductivas asexuales. Estos hongos, se encuentran en la naturaleza mayoritariamente en su estado asexual o conidial (anamorfo) más que en su estado sexual (teleomorfo).

Actualmente, los hongos entomopatógenos más importantes del Phylum Ascomycota, se ubican en el Subphylum Pezizomycotina, Clase Sordariomycetes, Orden Hypocreales, subdividido en tres familias: 1) Familia Clavicipitaceae: se han citado como patógenos los géneros Aschersonia, Hypocrella, Metarhizium, Nomuraea; 2) Familia Cordycipitaceae: se hallan Beauveria, Isaria, Lecanicillium y 3) Familia 
Ophiocordycipitaceae: se encuentran los géneros Ophiocordyces, Hirsutella, Tolypocladium, Hasposporium y Purpureocillium (Sosa-Gómez et al. 2010).

Este grupo de hongos es cosmopolita y se conocen hasta el momento a 700 especies reunidas en 100 géneros (Gonzalez Castillo et al. 2012), entre los géneros más importantes se pueden destacar: Metarhizium, Beauveria, Tolipocladium y Lecanicillium (Roy et al. 2006; García García et al. 2008; Vega et al. 2008). Estos hongos pueden encontrarse en distintas ubicaciones geográficas y climáticas, tanto en suelos cultivados como naturales. Ellos tienen la particularidad de parasitar a diferentes grupos de artrópodos (insectos y ácaros) y producir la muerte del hospedador (Vega et al. 2008; Humber, 2009).

Algunas de las ventajas que presentan los hongos entomopatógenos para ser utilizados en programas de control microbiano de insectos son: alta especificidad, dispersión natural y posibilidad de cultivo in vitro, manteniendo la patogenicidad, inocuidad para vertebrados y la posibilidad de provocar un control permanente una vez establecidos en el ambiente. Otra ventaja importante que presentan estos microorganismos es que la infección generalmente se produce por contacto, a través del tegumento de los insectos, no siendo necesaria su ingesta, siendo este un factor importante en programas de control de insectos. (St. Leger et al. 2011)

\section{Mecanismo de acción de hongos entomopatógenos}

\section{Adhesión y germinación de la espora en la cutícula del insecto}

El paso inicial en la infección de los insectos por medio de hongos patógenos involucra la adhesión de los propágulos infectivos (conidios o esporas) a la cutícula del insecto, lo cual ocurre por las propiedades físicas, químicas y electrostáticas de la superficie del conidio y de la cutícula. Según Duperchy (2003), la adhesión del conidio a la cutícula del huésped, no es específica en muchos casos. Algunas especies de hongos presentan proteínas como las lectinas e hidrofobinas, mucopolisacáridos y/o enzimas (esterasas y lipasas) que favorecen la adhesión de las esporas a sitios específicos de la cutícula. Luego de la adhesión e hidratación de los conidios, ocurre su germinación que involucra el desarrollo de un tubo germinativo $y$, en algunos casos, la formación de un apresorio. La formación del apresorio está relacionada con la capacidad de penetrar la cutícula de los insectos, debido a la presión mecánica o a una actividad enzimática en su ápice. El resultado de la germinación y la penetración 
no depende necesariamente del porcentaje total de germinación sino del tiempo de duración de la germinación, el modo de germinación, la agresividad del hongo, el tipo de espora y la susceptibilidad del hospedador (Figura 2) (Shapiro et al. 2008).

\section{Penetración dentro del hemocele}

Luego se produce la penetración dentro del hemocele en la que participa un mecanismo físico y otro químico, el primero consiste en la presión ejercida por la hifa, la cual rompe las áreas esclerosadas y membranosas de la cutícula, por otro lado el mecanismo químico consiste en una acción enzimática, principalmente de proteasas, lipasas y quitinasas, las cuales causan descomposición del tejido en la zona de penetración (Figura 2) (Pucheta Díaz et al. 2006).

\section{Desarrollo del hongo que resulta en la muerte del insecto}

Después de la penetración, la hifa se ensancha y ramifica dentro del tejido del insecto, colonizándolo completamente y a partir de la cual se forman pequeñas colonias y estructuras fúngicas (García García et al. 2008). En muchos casos este evento es acompañado por la liberación de metabolitos secundarios con actividad insecticida (toxinas peptídicas) que aceleran la muerte del insecto. Es importante destacar que la muerte del insecto se debe a una combinación de tres factores que actúan conjuntamente: la producción de toxinas por parte del hongo, la obstrucción física de la circulación de la hemolinfa por el sistema circulatorio del insecto y la privación de nutrientes (Goettel e Inglis, 1997). El hongo inicia un crecimiento miceliar masivo en el interior del cuerpo del insecto invadiendo los órganos y tejidos. Finalmente, las hifas penetran la cutícula desde el interior del insecto y emergen a la superficie iniciando la formación de conidios, con lo que se puede completar el ciclo infectivo (Figura 2) (Pucheta Díaz et al. 2006). 


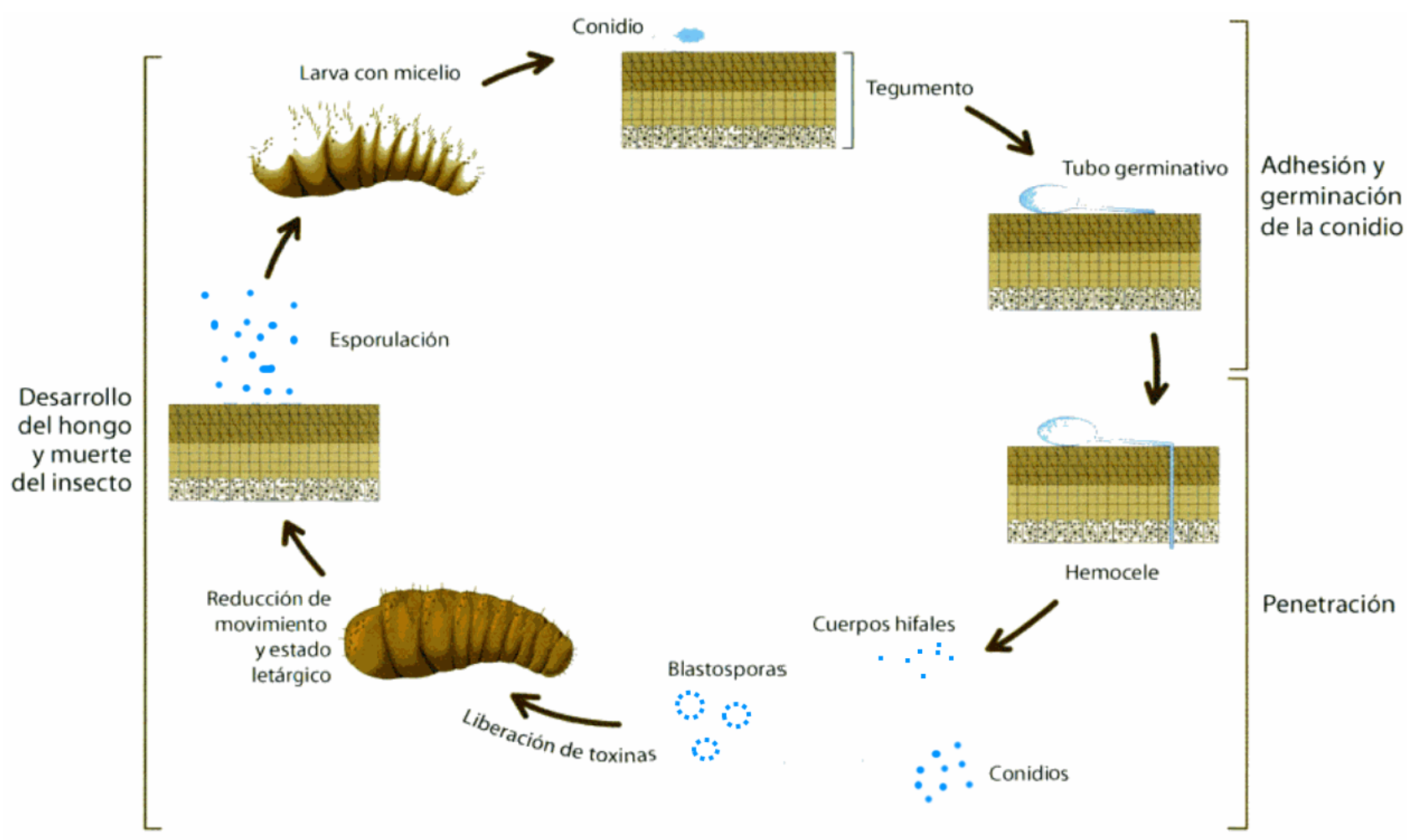

Figura 2. Mecanismo de acción de hongos entomopatógenos (Cañedo y Ames, 2004)

\section{Hongos endófitos}

El término "endófito" fue acuñado por De Bary (1884) y se utiliza para definir a hongos o bacterias que durante todo o gran parte de su ciclo de vida se encuentran en el interior de los tejidos de plantas de manera asintomática (Rodríguez et al. 2009).

Los hongos endófitos son organismos ubicuos que se pueden encontrar en las hojas, pecíolos, estructuras reproductivas, ramas, cortezas y raíces de una amplia gama de especies vegetales (Faeth y Fagan, 2002; Stone et al. 2004; Schulz y Boyle, 2005; Arnold, 2007; Hyde y Soytong, 2008; Rodríguez et al. 2009). Son un grupo muy diverso, polifilético y la mayoría pertenecen al Phylum Ascomycota, aunque también se han encontrado en los Basidiomycota y Zygomycota. (Sánchez Fernández et al. 2013). 


\section{Mecanismo de dispersión y relación hongo-planta}

Estos microorganismos penetran en el tejido de la planta a través de los estomas, raíces, heridas en el tejido vegetal y directamente por la secreción de enzimas hidrolíticas (Esposito y de Azevedo, 2004). Los hongos endófitos se distribuyen a través de los órganos y tejidos de las plantas y se asocian con diversas estructuras tales como: hojas, ramas, tallos, raíces y brotes (Porras Alfaro y Bayman, 2011)

La transmisión de endófitos puede ser horizontal, cuando el inóculo entra en contacto con una planta y la infecta, o vertical, cuando la planta infectada produce semillas infectadas (Krings et al. 2007; Faeth, 2009; Rodríguez et al. 2009; Jani et al. 2010; Faeth y Saari, 2012; Yan et al. 2015).

La relación entre estos hongos endófitos y la planta hospedera involucra desde el mutualismo hasta la patogénesis. Se cree que los hongos endófítos mantienen en ocasiones asociaciones mutualistas con sus hospedadores, establecidas posiblemente gracias a un proceso de coevolución (Hyde y Soytong, 2008). Un ejemplo de ello son las establecidas por especies del género Epichloë, que producen una serie de alcaloides que confieren a las plantas que infectan un aumento de la resistencia al herbivorismo (Schardl et al. 2004). Otras especies de endófitos son conocidas por su capacidad de mejorar la resistencia de sus hospedadores a enfermedades, compitiendo directamente con el patógeno por el espacio y los recursos, o incluso produciendo compuestos nocivos para estos patógenos (Zabalgogeazcoa, 2008). También están involucrados en el proceso de maduración y descomposición de las hojas (Promputtha et al. 2007; Sieber, 2007). Además, estos hongos producen varias enzimas responsables de la descomposición de la materia orgánica de la planta (Sunitha et al. 2013). A su vez, los endófitos pueden garantizar una mayor resistencia del huésped a estreses bióticos y abióticos, incluidos los déficit de agua y salinidad (Bayat et al. 2009; Gundel et al. 2010).

Algunos endófitos pertenecen a géneros que incluyen hongos entomopatógenos, los cuales le confieren protección frente a insectos plaga. En estas relaciones tanto el hongo como la planta producen metabolitos secundarios potencialmente tóxicos. El hongo endófito produce factores de virulencia, mientras que la planta produce defensas, tanto mecánicas como bioquímicas. En consecuencia, para que ambos organismos coexistan se establece entre ellos una relación que depende de la virulencia del hongo y de las defensas de la planta, las cuales varían y 
son influenciadas por los factores ambientales y por la etapa de desarrollo de ambos organismos. Cuando los factores de virulencia del hongo y las defensas de la planta están en equilibrio se establece una relación endofítica y, por el contrario, cuando se presenta la senescencia del hospedero o se encuentra bajo estrés, el balance se torna a favor del hongo y éste se expresa como patógeno, presentándose los síntomas de enfermedad.

Aparte de su taxonomía y filogenia, la mayoría de las investigaciones con hongos entomopatógenos se ha centrado en su desarrollo como bioplaguicidas (Meyling y Eilenberg, 2007; Vega, 2008; Gurulingappa et al. 2010).

Estos hongos presentan un interés particular en aquellos casos en que están involucrados en el control biológico de plagas y enfermedades de las plantas. En este tipo de hongos, se estudia y determina su destino, una vez introducidos como endófitos, incluyendo su distribución, abundancia y las interacciones con otros endófitos dentro de la planta.

Varios géneros de hongos entomopatógenos se han aislado como endófitos en diferentes especies de plantas. Algunos de ellos han sido reportados como endófitos naturales mientras que a otros se los ha logrado introducir artificialmente en la planta utilizando diferentes técnicas (Vega, 2008; Quesada Moraga et al. 2014 a; Greenfield, 2015). 


\section{Antecedentes}

Los hongos entomopatógenos se conocen desde hace dos milenios, cuando en China identificaron la especie Cordyceps (Glare, 2004) sobre especímenes de gusano de seda. En 1836 se presenta un tratado sobre la enfermedad del gusano de seda, causada por el hongo entomopatógeno Beauveria bassiana (Bals-Criv.) Vuill. (Hypocreales: Cordicypitaceae) este hecho marca el inicio de la patología de insectos, aunque el desarrollo y aplicabilidad de estos microorganismos para el control de insectos plagas, se inicia en 1879 con Hagen (García García et al. 2008).

En el año 1878 en Rusia, Metchnikoff, utilizó el hongo Metarhizium anisopliae (Metschn.) Sorokin (Hypocreales: Clavicipitaceae) para el control de Anisoplia austriaca (Herbst) (Coleoptera: Scarabaeidae), conocido vulgarmente como escarabajo de los cereales, con este hecho Metchnikoff se convirtió en la primera persona en utilizar un hongo entomopatógeno como agente de control de plagas (Glare, 2004).

Los hongos entomopatógenos dentro del orden Hypocreales y Entomophthorales han sido aislados y ampliamente evaluados sobre los ordenes Coleoptera, Lepidoptera, Isoptera, Hemiptera y Orthoptera (Rath, 2000; Staples y Milner, 2000; Myles, 2002; Thompson y Brandenburg, 2005; Meyling et al. 2006; Chouvenc et al. 2008; Baverstock et al. 2010); siendo el orden de los Hemiptera, particularmente las familias Coccidae y Aleyrodidae, en las que mayor diversidad de patógenos fúngicos se han documentado (Humber, 2008; Vega et al. 2009).

Numerosas publicaciones registran la presencia de hongos entomopatógenos infectando insectos plaga de la agricultura en Europa (Santamaria y Girbal 1996; Nielsen et al. 2001), en Asia (Humber, 1991; Keller, 1997), en África (Hatting et al. 1999) y en Estados Unidos donde Bing y Lewis (1993) encontraron a B. bassiana infectando a Ostrinia nubilalis Hübner (Lepidoptera: Crambidae) en cultivos de maíz (Pell et al. 2010).

En Chile se encontró el género Entomophthora sobre áfidos (Aruta et al. 1974, 1984), en Uruguay se reportó a Zoophthora radicans (Brefeld) Batko (Zygomycotina: Entomophthorales) para el control de Epinotia aporema Wals. (Lepidoptera: Tortricidae) (Alzugaray et al. 1999).

En Brasil, se encontraron más de 20 géneros que aparecieron naturalmente sobre insectos de importancia económica, entre los que se pueden mencionar a $B$. 
bassiana, Nomuraea rileyi (Pharlow) Samson (Ascomycota: Hypocreales) y Lecanicillium lecanii (Zimm.) Zare \& Gams (Hypocreales: Cordicypitaceae) (Shah y Pell, 2003). También se menciona como muy importante $M$. anisopliae que se encontró infectando a $D$. saccharalis (Rodrigues Destéfano et al. 2004).

En la Argentina las primeras referencias sobre la presencia de hongos entomopatógenos corresponden a la especie $B$. bassiana detectada provocando infecciones naturales en larvas de coleópteros (Spegazzini, 1880) y de Cordyceps unilateralis (Tul. \& C. Tul.) Sacc. (Hypocreales: Ophiocordycipitaceae) en hormigas (Spegazzini, 1913). Posteriormente se conocieron varias publicaciones sobre hongos patógenos de insectos. López Lastra et al. (2006) registraron Entomophthora ferdinandii Keller (Entomophthorales: Entomophthoraceae) causando infecciones naturales en Musca domestica (L.) (Diptera: Muscidae). La especie Entomophaga grylli (Fresen.) Batko (Entomophthorales: Entomophthoraceae) fue registrada infectando diferentes especies de ortópteros en Buenos Aires y en La Pampa (Fresa, 1971; Lange, 1996), también ha sido documentada la presencia de Entomophthorales sobre áfidos (Scorsetti et al. 2007), L. lecanii se ha encontrado infectando a Bemisia tabaci (Gennadius) (Hemiptera: Aleyrodidae) (Scorsetti et al. 2008) en cultivos hortícolas y B. bassiana y M. anisopliae se han aislado a partir de Coleptoros y Hemipteros sobre cultivos de maíz (Toledo et al. 2008) y como agentes de control microbiano contra el picudo del algodonero (Anthonomus grandis (Boheman) (Coleoptera: Curculionidae)) (Nussenbaum y Lecuona, 2012).

En cultivos agrícolas, Entomophthora $s p$. se identificó en la provincia de Buenos Aires como patógeno de R. nu asociado a cultivos de girasol (Fresa, 1979) y como patógeno de R. nu y A. gemmatalis asociado a cultivos de soja (López Lastra y Scorsetti, 2006), mientras que en Córdoba y Santa Fe se aisló de organismos pertenecientes a la subfamilia Plusiinae en soja (Edelstein y Lecuona, 2003).

$N$. rileyi fue aislado de larvas de $A$. gemmatalis en cultivos de soja (Toledo et al. 2004; Edelstein et al. 2005).

Por consiguiente, ciertos hongos entomopatógenos han sido evaluados como agentes de control para una variedad de artrópodos nocivos de la agricultura.

Los primeros registros de la presencia de hongos endófitos provienen del año 1898, en donde los investigadores formularon la hipótesis de que los cuadros toxicológicos observados en animales, se debían al consumo de semillas o partes aéreas de los pastos Lolium temulentum L. (Poales: Poaceae), Lolium arvense With (Poales: Poaceae), Lolium linicolum Braun Schrank (Poales: Poaceae) y Lolium 
remotum (Poales: Poaceae) infectados con hongos. Sin embargo, no se dio continuidad a esta suposición, hasta que Bacon et al. (1977), relacionaron la presencia del hongo Neotyphodium coenophialum (Morgan-Jones \& W. Gams) Glenn, C.W. Bacon \& Hanlin (Hypocreales: Clavicipitaceae) a la alta incidencia de una intoxicación del ganado denominada "síndrome de verano", debida al consumo de pastos de la especie Festuca arundinaceae Schreb. (Poales: Poaceae), sin que ésta presente ningún síntoma. Durante la década del '80 se describió la resistencia al ataque de insectos en pastos infectados con hongos endófitos (Schardl et al. 2004).

Es importante mencionar que los hongos endófitos, se han encontrado desde el ártico hasta los trópicos, como así también en diferentes cultivos agrícolas. De todos los ecosistemas del planeta Tierra, los bosques templados y tropicales presentan una gran biodiversidad de plantas y estas parecen albergar también una cantidad significativa de hongos endófitos (Arnold et al. 2007; Vidal y Jaber, 2015).

Entre las especies de plantas a partir de las cuales se han podido aislar diferentes especies de hongos endófitos, se encuentran algunas de gran importancia económica, como el maíz (Orole y Adejumo, 2009, 2011), el café (Santamaría y Bayman, 2005; Vega et al. 2010), el trigo (Larran et al. 2002 a) y la soja (Larran et al. 2002 b; Pimentel et al. 2006). También se destacan especies arbóreas (Arnold et al. 2003; Arnold y Lutzoni, 2007), palmeras (Frohlich et al. 2000; Pinruan et al. 2010), gramíneas (Tanaka et al. 2012), así como pteridofitas (Zubek et al. 2010), musgos (U'Ren et al. 2010) y líquenes ( $\mathrm{Li}$ et al. 2007). Inclusive algunas plantas acuáticas han sido citadas por albergar hongos endófitos (Stone et al. 2000). En general, son numerosas las especies endófitas asociadas a cada especie vegetal, en varios casos se han identificado decenas e incluso cientos de estas especies endofíticas asociadas a una sola especie vegetal, lo que indica que la micobiota endofítica representa un conjunto de una gran diversidad biológica (Stone et al. 2004; Sánchez Márquez et al. 2007, 2008; Rodriguez et al. 2009).

\section{Hongos entomopatógenos como endófitos}

Hongos pertenecientes a las familias Cordycipitaceae y Ophiocordycipitaceae (antiguos miembros de la familia Clavicipitaceae recientemente reclasificados) que incluyen géneros de hongos considerados tradicionalmente entomopatógenos, han sido también descritos como endófitos naturales, colonizando plantas de naturaleza 
muy diversa, que van desde gramíneas, como el arroz o el maíz, hasta plantas dicotiledóneas, como el cacao o el café. Estos géneros de entomopatógenos endofíticos son Beauveria, Lecanicillium, Isaria, Cladosporium, Metarhizium o Tolypocladium (Vega, 2008; Sánchez Márquez et al. 2012).

Estos géneros también han sido inoculados como endófitos en muchos cultivos agrícolas importantes, como el sorgo (Tefera y Vidal, 2009), plátanos (Pocasangre et al. 2000), algodón, calabaza, frijoles (Gurulingappa et al. 2010), cacao (Cao et al. 2002; Posada y Vega, 2005), tomates (Larran et al. 2001), entre otros.

Todos estos trabajos hacen referencia a diferentes técnicas de inoculación utilizadas para introducir las diferentes especies de hongos entomopatógenos en distintas especies de plantas, sin embargo, poco se conoce acerca del recorrido y alojamiento de estos hongos dentro de la planta. 
Hipótesis y Objetivos 


\section{Hipótesis de trabajo}

Los hongos entomopatógenos inoculados como endófitos en los cultivos de maíz y soja son efectivos para el control biológico de los lepidópteros plaga S. frugiperda y H. gelotopoeon.

\section{Objetivo general}

Estudiar los hongos endófitos naturales presentes en cultivos de soja (Glycine max) y maíz (Zea mays) y conocer la capacidad de los hongos entomopatógenos como microorganismos endófitos para repeler y controlar a los principales insectos plaga de estos cultivos en condiciones experimentales, con la finalidad de disminuir las pérdidas económicas causadas por ellos.

\section{Objetivos específicos}

* Detección e identificación de la diversidad de especies de hongos endófitos en cultivos de maíz y soja de la Región Pampeana Argentina. Capítulo I

* Evaluar distintas técnicas de inoculación de hongos entomopatógenos en plantas de maíz y soja en condiciones de laboratorio. Capítulo II

* Evaluar el efecto de los hongos entomopatógenos como endófitos sobre el crecimiento y rendimiento de plantas de maíz y soja. Capítulo III

* Evaluar aspectos biológicos, reproductivos, los principales parámetros poblacionales y la preferencia alimenticia, de dos especies plaga $S$. frugiperda y $H$. gelotopoeon de los cultivos de maíz y soja respectivamente, que presentan al hongo entomopatógeno como endófito. Capítulo IV 


\section{CAPÍTULO I}

\section{Diversidad de especies de hongos}

endófitos en cultivos de maíz y soja 


\section{Introducción}

El término "endófito" fue acuñado por De Bary (1884) y se utiliza para definir a hongos o bacterias que durante todo o gran parte de su ciclo de vida se encuentran en el interior de los tejidos de plantas.

La colonización interna de los tejidos vegetales por hongos de manera asintomática, es un fenómeno muy extendido y bien documentado. El creciente interés en el rol ecológico que juegan estos hongos ha estimulado la investigación en los últimos años, debido a que algunos hongos endófitos pueden producir compuestos que hacen que los tejidos vegetales sean menos atractivos para los herbívoros actuando de esta manera como agentes de control biológico (Larran et al. 2002 a, b).

Estos microorganismos penetran en los tejidos de las plantas a través de los estomas, raíces, heridas y/o directamente por la secreción de enzimas hidrolíticas (Esposito y de Azevedo, 2004) y se distribuyen claramente en todos los órganos y tejidos de las plantas asociándose con diversas estructuras, tales como hojas, ramas, tallos, raíces y brotes (Porras-Alfaro y Bayman, 2011).

Los hongos endófitos se han encontrado en todas las familias de plantas estudiadas hasta el momento, que representan a muchas especies en diferentes regiones climáticas del mundo. El estudio de la diversidad de los endófitos es de inmensa importancia en la biología de las plantas para comprender y mejorar su productividad (Larran et al. 2002 a, b).

La presencia de endófitos en soja ha sido demostrada por varios autores pero hay muy pocos estudios en relación con las asociaciones de endófitos en Argentina, mientras que para maíz existen escasos trabajos que estudien la diversidad de hongos endófitos, tanto en Argentina como en el mundo.

El conocimiento en general acerca de hongos endófitos es limitado, la mayoría están centrados principalmente en aquellos que se comportan como patógenos y en menor proporción en endófitos que colonizan la parte aérea (Larran et al. 2002 a, b; Pimentel et al. 2006; Impullitti y Malvick, 2013; Leite et al. 2013; Fernandes et al. 2015; Russo et al. 2016). Dalal y Kulkarni (2014) encontraron que ciertos factores como la edad de la planta, las diferentes variedades de las especies y la presencia de cultivos en campo o invernáculo pueden afectar la diversidad y distribución de hongos endófitos en soja. Mientras que Impullitti y Malvick (2013) y Leite et al. (2013) 
mostraron que los métodos utilizados para el aislamiento de hongos endófitos influyen en la abundancia y riqueza de las especies aisladas.

El objetivo de este capítulo fue aislar e identificar endófitos fúngicos de hojas, tallos y raíces de siete variedades del cultivo de soja y siete de maíz que crecen en distintos sitios agrícolas de la Región Pampeana Argentina. 


\section{Materiales y Métodos}

\section{Descripción del sitio de muestreo}

El sitio de muestreo cubrió diferentes puntos de las provincias de Buenos Aires, Santa Fe, La Pampa, Córdoba y Entre Ríos ubicados dentro de la Región Pampeana Argentina. Estos fueron seleccionados ya que representan los puntos más productivos de la región, además fueron aquellos en los que cuyos productores permitieron el acceso (Figuras I.1, 2). En cada uno de los sitios seleccionados se muestreó aquella variedad más utilizada de cada uno de los cultivos. El clima de la región es predominantemente templado-húmedo, con una temperatura media que oscila entre $14^{\circ} \mathrm{C}$ y $17^{\circ} \mathrm{C}$ y mientras que la precipitación media anual varía de 600 a $1.000 \mathrm{~mm}$ aumentando, desde el suroeste al noreste.

La modificación de la cobertura vegetal nativa es casi completa, debido a las actividades productivas. Gracias a sus condiciones edáficas y a su clima, esta zona tiene un carácter predominantemente agrícola.

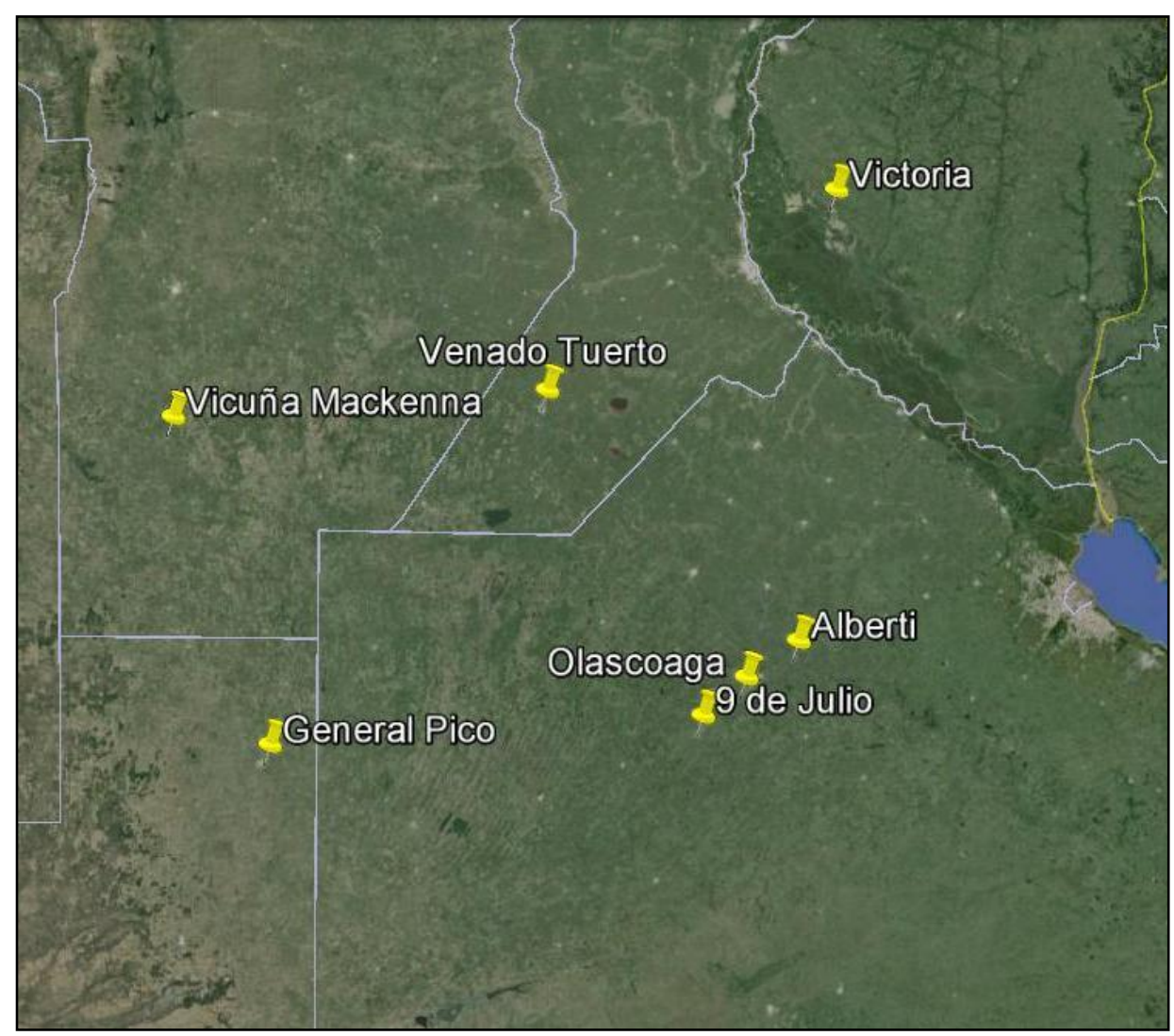

Figura I.1. Sitios de muestreo del cultivo de maíz 


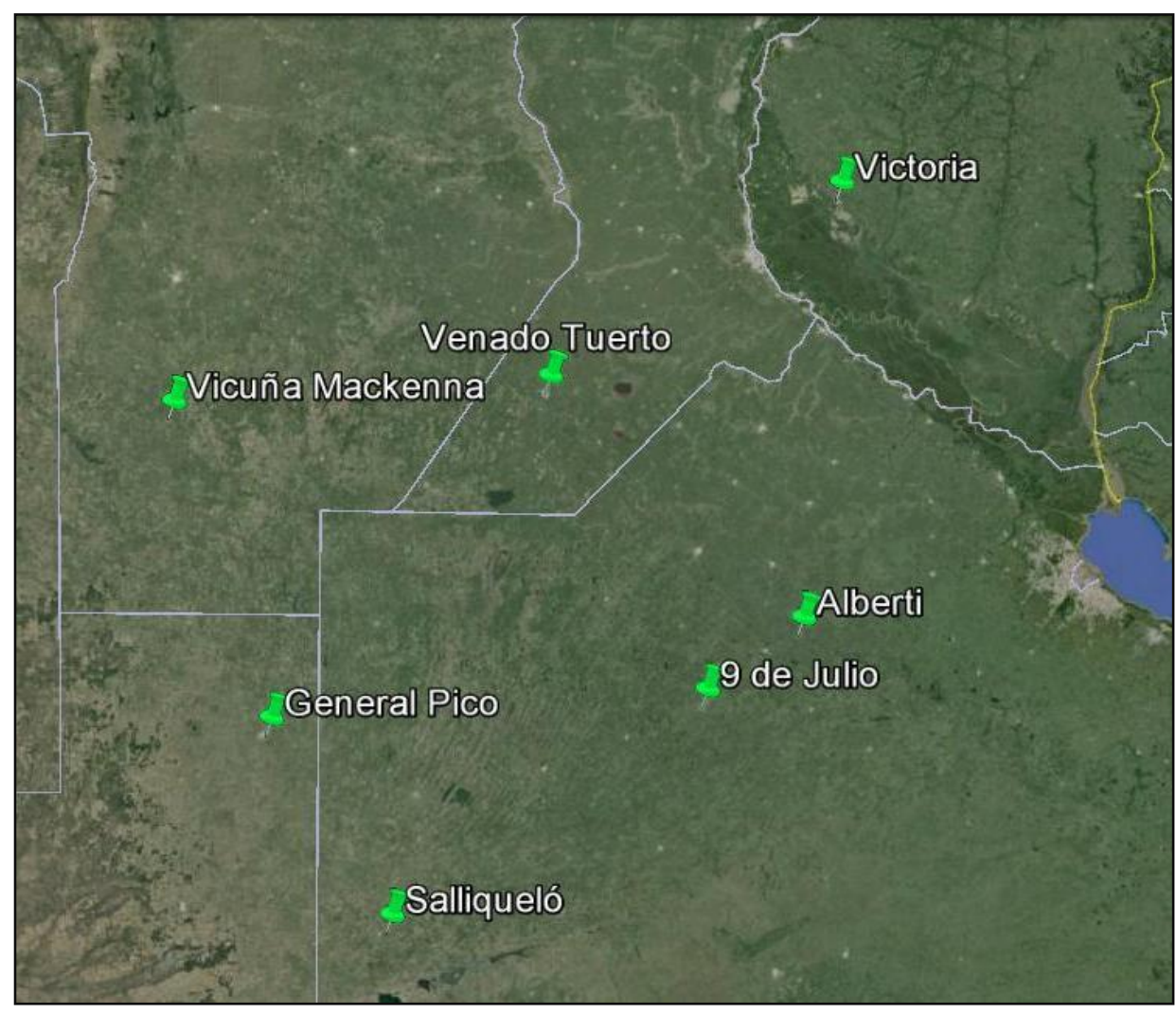

Figura I.2. Sitios de muestreo del cultivo de soja

\section{Recolección de las muestras}

Los muestreos se realizaron durante los meses de diciembre, enero y febrero de la campaña agrícola 2013-2014.

Se seleccionaron siete parcelas de cultivo de maíz y siete parcelas de cultivo de soja situadas dentro del área de estudio (Tabla I.1), donde las plantas de ambas especies crecen en monocultivo.

Tabla I.1. Localidades de muestreo

\begin{tabular}{llll}
\hline \hline \multicolumn{1}{c}{ Soja } & & \multicolumn{1}{c}{ Maíz } \\
\hline Variedad & Localidad & Variedad & Localidad \\
DM3810 & Alberti, Buenos Aires & DK747 & Olascoaga, Buenos Aires \\
DM4210 & 9 de Julio, Buenos Aires & DK699 & Alberti, Buenos Aires \\
DM4913 & Salliqueló, Buenos Aires & NK700 & Venado Tuerto, Santa Fe \\
NA5009 & Victoria, Entre Ríos & DK7210 & 9 de Julio, Buenos Aires \\
DM4612 & Vicuña Mackenna, Córdoba & NK900 & Victoria, Entre Ríos \\
DM4670 & Venado Tuerto, Santa Fe & DK7310 & Vicuña Mackenna, Córdoba \\
DM4214 & General Pico, La pampa & DK7010 & General Pico, La Pampa \\
\hline \hline
\end{tabular}


Las plantas de maíz y soja fueron recolectadas a los dos meses después de la siembra.

En cada una de las 14 localidades de muestreo se delimitaron parcelas de $50 \mathrm{x}$ 50 metros (Figura I.3) y se seleccionaron diez plantas al azar aparentemente sanas sin signos de ataques de insectos y/o enfermedades. Con el fin de evitar lesiones en las raíces, se realizó una perforación delimitando un cilindro que rodeaba a la raíz y se retiró la planta junto con el suelo circundante. Las plantas colectadas fueron embolsadas en forma individual, rotuladas adecuadamente y colocadas inmediatamente en conservadora con hielo para su transporte. Se mantuvieron refrigeradas a $4{ }^{\circ} \mathrm{C}$ hasta el momento en que fueron procesadas, período que no superó las 48h. de acuerdo a Impullitti y Malvick (2013).

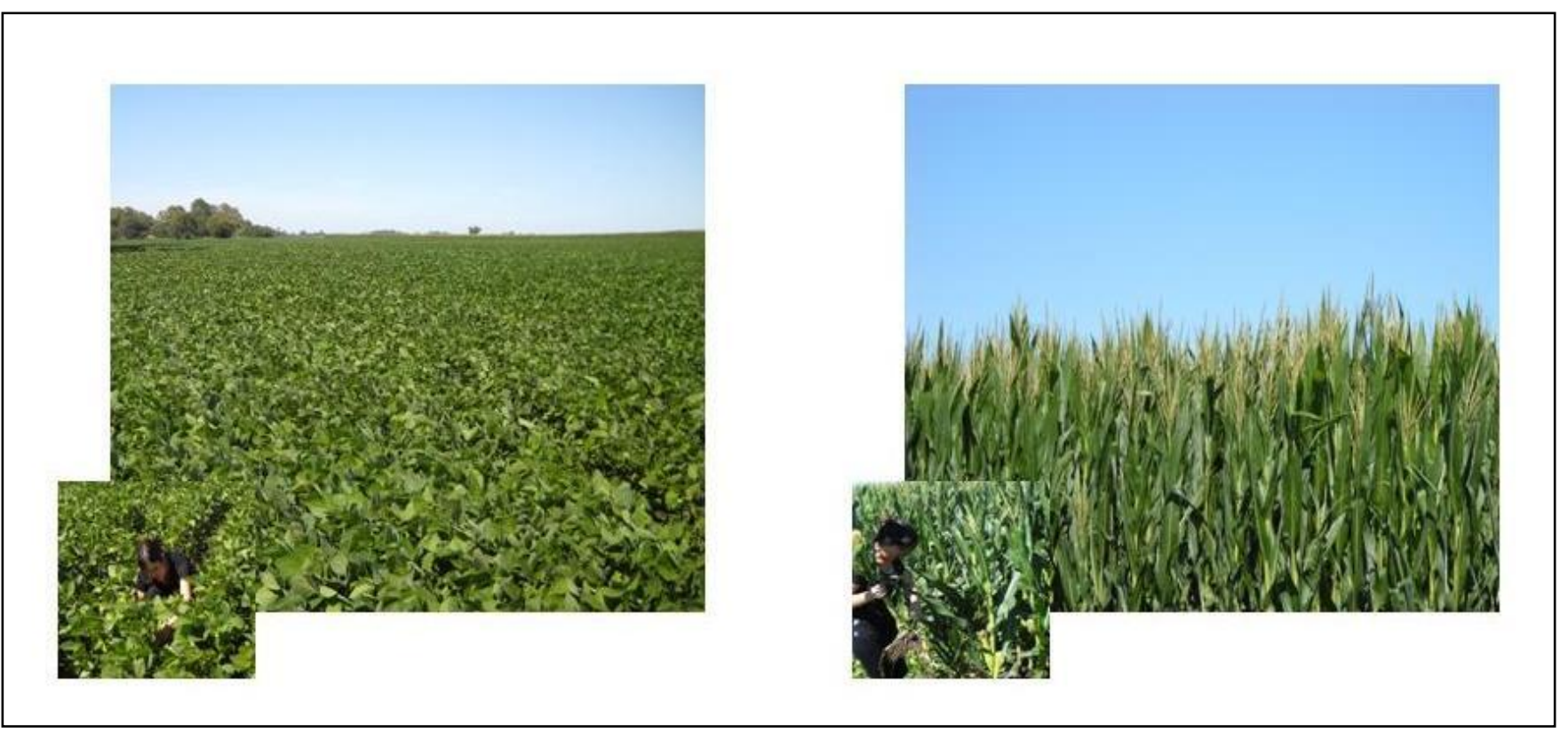

Figura I.3. Muestreo de maíz y soja 


\section{Aislamiento de hongos endófitos}

En el laboratorio, cada planta fue lavada con abundante agua corriente, separada en raíz, tallo y hoja y lavados nuevamente dos veces con agua destilada estéril. De cada porción de raíz, tallo y hoja se seleccionaron al azar 6 fragmentos de $2 \mathrm{~cm}^{2}$ los cuales fueron esterilizados superficialmente por inmersión durante 1 minuto en $70 \%(\mathrm{v} / \mathrm{v})$ de etanol, 4 minutos en hipoclorito de sodio $3 \%(\mathrm{v} / \mathrm{v})$ de cloro disponible y por último se realizaron tres lavados con agua destilada estéril.

Luego de la esterilización superficial, las muestras fueron reducidas, con un bisturí estéril a fragmentos de $1 \mathrm{~cm}^{2}$, eliminando así los bordes de las muestras y transferidas a placas que contenían agar papa glucosado (APG) (Britania ${ }^{\circledR}$ ) con antibiótico $(0,5 \mathrm{~g}$ estreptomicina- $0,25 \mathrm{~g}$ cloranfenicol) para suprimir el crecimiento bacteriano (Figura I.4). Alícuotas del último lavado fueron sembradas en APG para comprobar eficacia de la esterilización superficial (Pimentel et al. 2006).

Los fragmentos correspondientes a una misma planta fueron colocados en una misma caja de Petri. Se sembraron un total de 2520 fragmentos (18 de cada una de las 140 plantas investigadas). Para facilitar el aislamiento de hongos endófitos, las placas se incubaron a $25^{\circ} \mathrm{C}$ en oscuridad durante 10 días. Las placas fueron observadas periódicamente para verificar crecimiento hifal proveniente del interior de cada fragmento, conforme se fueron observando, se aislaron, purificaron (Figuras I.5, 6) y luego se mantuvieron a $4^{\circ} \mathrm{C}$ en tubos con APG para su posterior identificación (Figura I.7). 


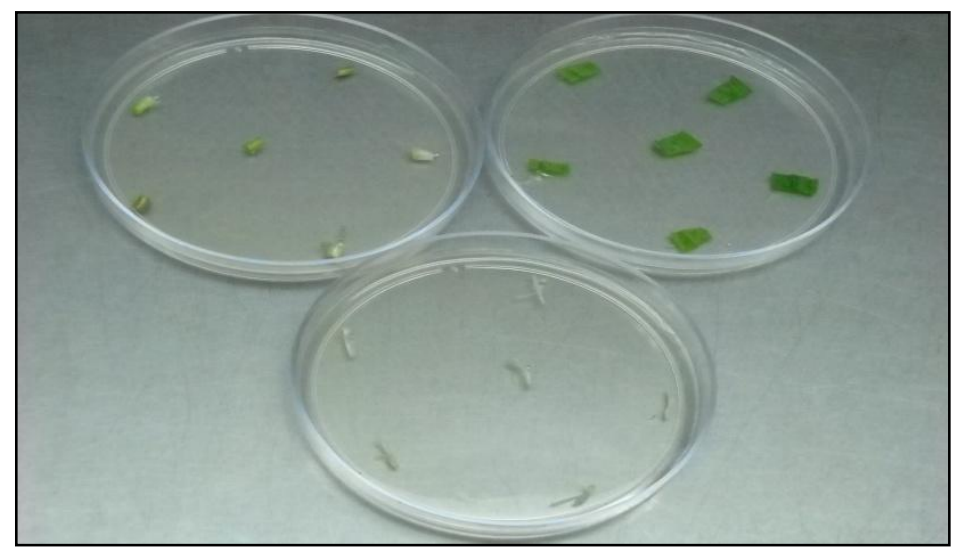

Figura I.4. Disposición de los fragmentos de raíz, tallo y hoja

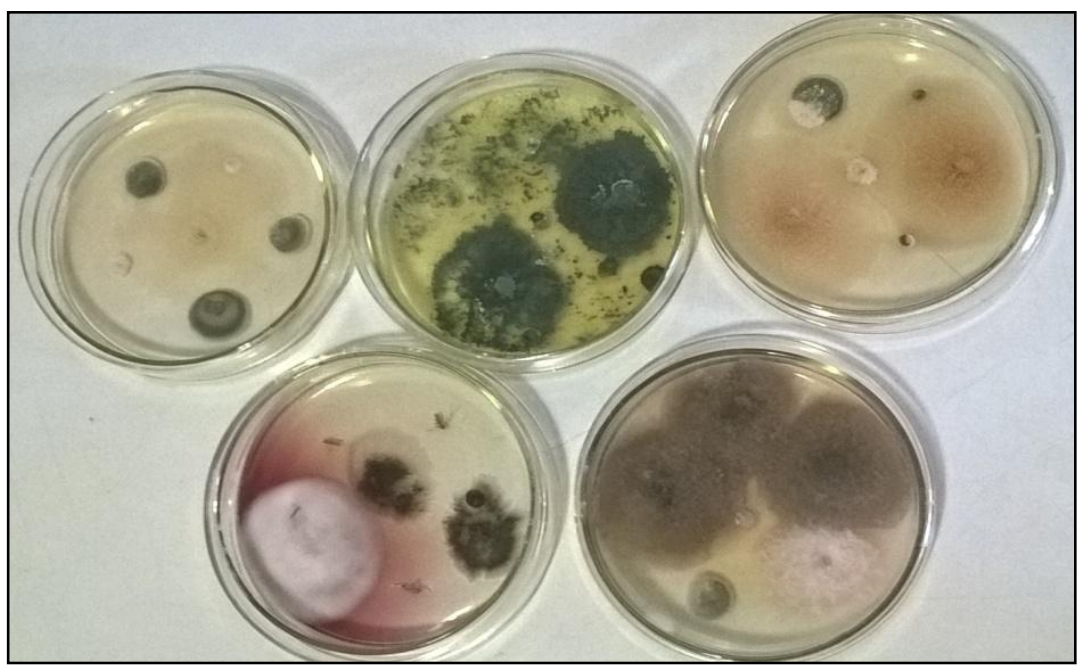

Figura I.5. Colonización de hongos endófitos
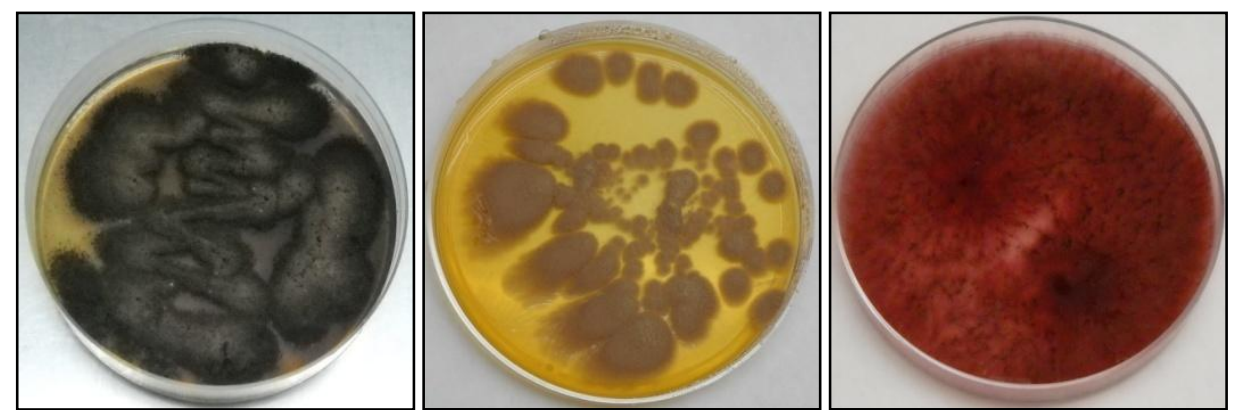

Figura I.6. Purificación de los hongos aislados 


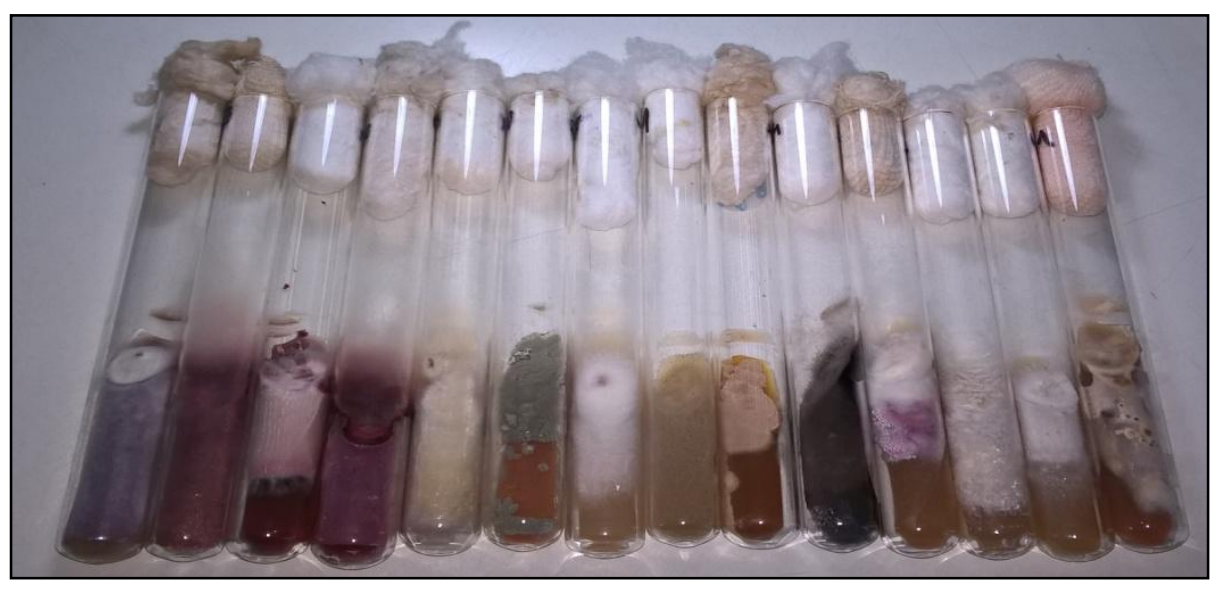

Figura I.7. Conservación de hongos aislados

\section{Identificación de hongos endófitos}

Cabe mencionar que en esta tesis se empleó en adelante dos términos, los cuales se definen a continuación:

-cepa: Un grupo de células de una sola especie, propagadas clonalmente (Kirk et al. 2008)

-aislamiento: obtención de una especie fúngica proveniente de un sustrato animal o vegetal, sobre un medio de cultivo.

La identificación morfológica de los distintos aislamientos fúngicos se realizó mediante la observación de las estructuras reproductivas asexuales o sexuales bajo microscopía óptica, utilizando claves taxonómicas. Las especies fueron identificados de acuerdo con Leslie y Summerell (2006) y Domsch et al. (2007).

Por otro lado, para corroborar las identificaciones morfológicas se realizaron identificaciones moleculares de los aislamientos fúngicos. Para ello se obtuvo ADN genómico de los cultivos monospóricos de acuerdo con Stenglein y Balatti (2006). Luego, por medio de una reacción en cadena de la polimerasa (PCR), se amplificó la región ITS del ADNr, usando pares de cebadores ITS5 (5'-3'GGAAGTAAAAGTCGTAACAAG G) e ITS4 (5'-TCCTCC GCT TATTGATATGC-3 ') (White et al 1990). Las PCR fueron realizadas en un termociclador XP (Bioer Tecnología Co, Hangzhou, China). Para la confirmación de algunas especies de Fusarium se usó el factor de elongación (EF-1a) utilizando los cebadores EF1 (5'-ATGGGTAAGGA (A / G) GACAAGAC-3 ') y EF2 (5'-GGA (A / G) GTACCAGT (G / C) ATCATGTT-3 ') (O'Donnell 
et al. 1998). Las reacciones de PCR, purificaciones de fragmentos y secuenciación se realizaron según Stenglein et al. (2010) y Canel et al. (2013).

Las secuencias nucleotíidicas obtenidas fueron comparadas con aquellas depositadas en el banco de genes National Center for Biotechnology Information (NCBI) (www.ncbi.nlm.nih.gov) utilizando la herramienta bioinformática BLAST, de comparación y búsqueda de secuencias. 


\section{Análisis de datos}

La ocurrencia de hongos endófitos se evaluó mediante la frecuencia porcentual de colonización, la tasa de colonización y la tasa de aislamiento por variedad de cultivo considerada (Saucedo García et al. 2014).

El porcentaje de colonización se definió para cada especie de hongos aislada como el número total de fragmentos colonizados en relación con el número total de fragmentos sembrados x 100 (Fisher y Petrini, 1992).

La tasa de colonización se calculó como el número total de segmentos de órganos infectados por uno o más hongos, divididos por el número total de segmentos incubados (Petrini et al. 1982) y fueron expresadas como porcentajes.

La tasa de aislamiento se determinó como el número de aislamientos obtenidos dividido por el número total de segmentos incubados.

Los hongos aislados se clasificaron en categorías de frecuencias, según el criterio propuesto por Yadav y Madelin (1968) (Tabla I.2).

Tabla I.2. Clasificación según Yadav y Madelin en base a frecuencia de aislamientos

\begin{tabular}{ll}
\hline \hline \multicolumn{2}{c}{ Clasificación } \\
\hline Muy común & $80-100 \%$ \\
Común & $61-80 \%$ \\
Frecuente & $41-60 \%$ \\
Ocasional & $21-40 \%$ \\
Raro & $0,1-20 \%$ \\
\hline \hline
\end{tabular}

Para comparar la estructura de las comunidades de hongos endófitos en estudio se consideraron los componentes alfa y beta. La diversidad alfa permite realizar un análisis a escala de comunidad y la beta compara la diversidad entre diferentes comunidades.

La diversidad alfa, se determinó a través del índice de diversidad de ShannonWeaner $\left(\mathrm{H}^{\prime}\right)$. Este índice combina dos componentes de diversidad, la riqueza de especies y la equidad. Fue calculado con la siguiente ecuación: $\mathrm{H}^{\prime}=-\Sigma$ pi In pi, donde pi es la abundancia relativa de las especies comparado con el total de especies identificadas en la muestra (Magurran, 1988). 
La Diversidad beta, se calculó a través del coeficiente de similitud de Jaccard. Este tiene en cuenta la cantidad de especies presentes exclusivamente en comunidades distintas y la cantidad de especies comunes (Kumar y Hyde, 2004). Fue calculado con la siguiente ecuación JI $=a /(a+b+c)$, donde a representa al número de especies presentes sólo en la comunidad $A ; b$ representa al número de especies presentes solo en la comunidad $B$, y c representa al número de especies presentes en las comunidades $A$ y $B$.

Los valores de este índice varían entre 0, cuando no hay especies compartidas entre ambas comunidades hasta 1 , cuando los dos sitios tienen la misma composición de especies.

Las variedades de plantas muestreadas fueron ordenadas de acuerdo a sus composición de hongos endófitos, a través de un análisis de componentes principales $(A C P)$. Este análisis multivariado permite una representación de las diferencias de composición entre muestras a través de su ordenamiento sobre ejes sucesivos. Sólo se analizaron los ejes sobre los que se observaron tendencias consistentes de variación entre las diferentes muestras. El programa utilizado fue el MVSP 3.1 (Program Multi-Variate Statistical Package) (Kovach, 1999).

Los valores del índice de $\mathrm{H}^{\prime}$, se diferenciaron estadísticamente mediante un análisis de la varianza y si se observaban diferencias significativas las medias fueron comparadas utilizando el test de Tukey con niveles de significancia de 0,05, utilizando el programa InfoStat (2004). 


\section{Resultados}

\section{Composición de hongos endófitos en maíz}

Se obtuvieron 1601 aislamientos fúngicos a partir de los 1260 fragmentos de maíz analizados, de los cuales 420 correspondieron a raíces, 420 a tallos y 420 a hojas.

Estos aislamientos se agruparon en 34 taxa en base a caracteres morfológicos, 19 de ellos se identificaron a nivel de género y 15 a nivel de especie. La identificación de 7 aislamientos fue corroborada mediante la utilización de técnicas moleculares.

La especies Fusarium sp. 11 y Trichoderma harzianun Rifai (Hypocreales: Hypocreaceae) sólo fueron aisladas de la variedad NK900 y Fusarium sp. 7 de la variedad DK699.

Todos los aislamientos fúngicos obtenidos pertenecen a los Phyla Ascomycota y Zygomycota. Los Ascomycota se agruparon en tres Clases, (Dothideomycetes, Sordariomycetes y Eurothiomycetes), en 8 Órdenes y en más de 10 Familias (Tabla I.3). 
Tabla I.3. Número de aislamientos ( $\mathrm{n}$ ) y frecuencia de colonización (\%) de hongos endófitos en las distintas variedades de maíz.

\begin{tabular}{|c|c|c|c|c|c|c|c|c|c|c|c|c|c|c|c|c|}
\hline \multirow[t]{2}{*}{ HONGOS AISLADOS } & \multicolumn{2}{|c|}{ NK700 } & \multicolumn{2}{|c|}{ DK747 } & \multicolumn{2}{|c|}{ DK699 } & \multicolumn{2}{|c|}{ DK7310 } & \multicolumn{2}{|c|}{ DK7210 } & \multicolumn{2}{|c|}{ NK900 } & \multicolumn{2}{|c|}{ DK7010 } & \multirow[t]{2}{*}{ FAMILIA } & \multirow[t]{2}{*}{ ORDEN } \\
\hline & $\mathrm{n}$ & $\%$ & $\mathrm{n}$ & $\%$ & $\mathrm{n}$ & $\%$ & $\mathrm{n}$ & $\%$ & $\mathrm{n}$ & $\%$ & $\mathrm{n}$ & $\%$ & $\mathrm{n}$ & $\%$ & & \\
\hline Alternaria alternata & 10 & 5,6 & 12 & 6,7 & 28 & 15,6 & - & - & 7 & 3,9 & - & - & - & - & Pleosporaceae & Pleosporales \\
\hline Alternaria sp.1 & - & - & - & - & 13 & 7,2 & - & - & - & - & 15 & 8,3 & - & - & Pleosporaceae & Pleosporales \\
\hline Alternaria sp.2 & - & - & - & - & - & - & 15 & 8,3 & - & - & 8 & 4,4 & 9 & 5,0 & Pleosporaceae & Pleosporales \\
\hline Arthrinium phaeospermun & 36 & 20 & - & - & 24 & 13,3 & - & - & - & - & - & - & - & - & Apiosporaceae & insertidae sedis \\
\hline Arthrinium $s p$. & 38 & 21,1 & - & - & 23 & 12,8 & 23 & 12,8 & - & - & 10 & 5,6 & 8 & 4,4 & Apiosporaceae & insertidae sedis \\
\hline Aspergillus flavus & - & - & 26 & 14,4 & - & - & - & - & 12 & 6,7 & - & - & - & - & Trichocomaceae & Eurotiales \\
\hline Aspergillus niger & 35 & 19,4 & 18 & 10,0 & 14 & 7,8 & 14 & 7,8 & 19 & 10,6 & 9 & 5,0 & 7 & 3,9 & Trichocomaceae & Eurotiales \\
\hline Aspergillus terreus & - & - & 40 & 22,2 & - & - & 6 & 3,3 & - & - & - & - & - & - & Trichocomaceae & Eurotiales \\
\hline Bipolaris tetramera & - & - & 19 & 10,6 & - & - & - & - & - & - & 15 & 8,3 & 12 & 6,7 & Pleosporaceae & Pleosporales \\
\hline Chaetomium globosum & 14 & 7,8 & 15 & 8,3 & - & - & - & - & - & - & - & - & - & - & Bionectriaceae & Hypocreales \\
\hline Drechslera sp. & - & - & - & - & - & - & - & - & 6 & 3,3 & 14 & 7,8 & 6 & 3,3 & Pleosporaceae & Pleosporales \\
\hline Fusarium graminearum & 32 & 17,8 & 30 & 16,7 & 18 & 10,0 & 20 & 11,1 & - & - & - & - & - & - & Nectriaceae & Hypocreales \\
\hline Fusarium proliferatum & - & - & 59 & 32,8 & 12 & 6,7 & 10 & 5,6 & - & - & - & - & - & - & Nectriaceae & Hypocreales \\
\hline Fusarium sp.1 & 20 & 11,1 & - & - & - & - & - & - & - & - & - & - & 13 & 7,2 & Nectriaceae & Hypocreales \\
\hline Fusarium sp.2 & 13 & 7,2 & - & - & - & - & - & - & - & - & - & - & 10 & 5,6 & Nectriaceae & Hypocreales \\
\hline Fusarium sp.3 & 24 & 13,3 & - & - & - & - & - & - & - & - & - & - & 20 & 11,1 & Nectriaceae & Hypocreales \\
\hline Fusarium sp.4 & 18 & 10,0 & - & - & - & - & - & - & - & - & - & - & 18 & 10,0 & Nectriaceae & Hypocreales \\
\hline Fusarium sp.5 & - & - & 30 & 16,7 & 42 & 23,3 & 10 & 5,6 & - & - & - & - & - & - & Nectriaceae & Hypocreales \\
\hline Fusarium sp.6 & - & - & - & - & 28 & 15,6 & 9 & 5,0 & - & - & - & - & - & - & Nectriaceae & Hypocreales \\
\hline Fusarium sp.7 & - & - & - & - & 18 & 10,0 & - & - & - & - & - & - & - & - & Nectriaceae & Hypocreales \\
\hline Fusarium sp.8 & - & - & - & - & 15 & 8,3 & 3 & 1,7 & 9 & 5,0 & - & - & - & - & Nectriaceae & Hypocreales \\
\hline Fusarium sp.11 & - & - & - & - & - & - & - & - & - & - & 15 & 8,3 & - & - & Nectriaceae & Hypocreales \\
\hline Mucor circinelloides & - & - & 15 & 8,3 & - & - & - & - & 9 & 5,0 & - & - & - & - & Mucoraceae & Mucorales \\
\hline Mucor mucedo & 10 & 5,6 & 8 & 4,4 & 13 & 7,2 & - & - & - & - & 12 & 6,7 & 15 & 8,3 & Mucoraceae & Mucorales \\
\hline Nigrospora & - & - & - & - & 30 & 16,7 & - & - & 10 & 5,6 & - & - & 7 & 3,9 & Trichosphaeriaceae & Trichosphaeriales \\
\hline Penicillium rubrum & 11 & 6,1 & 23 & 12,8 & - & - & 21 & 11,7 & 13 & 7,2 & - & - & 33 & 18,3 & Trichocomaceae & Eurotiales \\
\hline Penicillium sp.1 & - & - & 14 & 7,8 & - & - & - & - & - & - & - & - & 9 & 5,0 & Trichocomaceae & Eurotiales \\
\hline Penicillium sp.2 & 25 & 13,9 & 7 & 3,9 & - & - & - & - & - & - & - & - & 6 & 3,3 & Trichocomaceae & Eurotiales \\
\hline Scopulariopsis brevicaulis & 20 & 11,1 & - & - & - & - & - & - & - & - & 20 & 11,1 & - & - & Microascaceae & Microascales \\
\hline Trichoderma harzianum & - & - & - & - & - & - & - & - & - & - & 21 & 11,7 & - & - & Hypocreceae & Hypocreales \\
\hline Trichoderma saturnisporum & - & - & - & - & 26 & 14,4 & 26 & 14,4 & - & - & - & - & - & - & Hypocreceae & Hypocreales \\
\hline Ulocladium $s p$ & - & - & - & - & - & - & - & - & 18 & 10,0 & 13 & 7,2 & 8 & 4,4 & Pleosporaceae & Pleosporales \\
\hline TOTAL DE AISLAMIENTOS & 306 & & 316 & & 333 & & 170 & & 111 & & 184 & & 181 & & & \\
\hline TOTAL DE ESPECIES & 14 & & 14 & & 16 & & 12 & & 10 & & 13 & & 15 & & & \\
\hline
\end{tabular}


Las especies Aspergillus flavus Link (Eurotiales: Trichocomaceae), Aspergillus terreus Thom (Eurotiales: Trichocomaceae), Bipolaris tetramera (McKinney) Shoemaker (Pleosporales: Pleosporaceae), Clonostachys rosea (Preuss) Mussat (Hypocreales: Bionectriaceae), Fusarium graminearum Schwabe (Hypocreales: Nectriaceae), Fusarium proliferatum (Matsush.) Nirenberg (Hypocreales: Nectriaceae) y Mucor circinelloides Tiegh (Mucorales: Mucoraceae) fueron identificadas mediante análisis molecular y sus secuencias nucleotídicas fueron ingresadas en el banco de genes del NCBI bajo sus respectivos números de acceso KF753952, KF753943, KF753950, KF753951, KF753955, KF753956 y KF753949. Se obtuvo como resultado para todos los aislamientos un $\%$ de ID y cobertura del $100 \%$ y e-value $=0.0$

El número de aislamientos obtenidos varió principalmente en función al órgano de la planta estudiado, independientemente de la variedad de maíz estudiada, si bien el número más alto de aislamientos se obtuvo en la variedad DK699 (333 aislamientos) y el menor en la variedad DK7210 (111 aislamientos). Para todas las variedades de maíz, el mayor número de aislamientos fue obtenido en el tallo de las plantas más que en raíces y en hojas (Figura I.8).

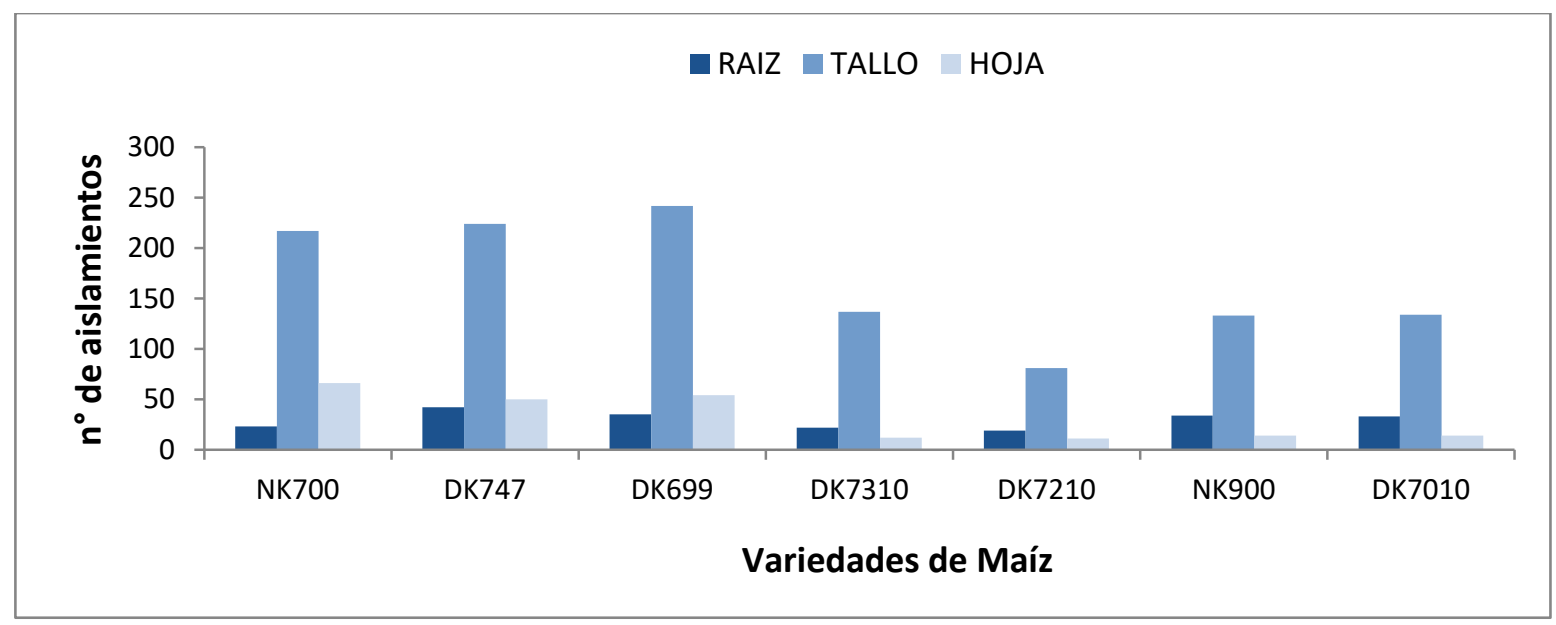

Figura I.8. Número de aislamientos obtenidos en raíces, tallos y hojas de cada una de las siete variedades de maíz.

El número de especies fúngicas aisladas en los tallos de las plantas varió entre 10 y 16 (registrándose en este órgano el mayor número de especies), en hojas entre 6 y 12 y en raíces entre 9 y 13, para todas las variedades de maíz. Por otro lado el mayor número de especies fue obtenido de la variedad DK699 y el menor de la variedad DK7210 (Figura I.9). 


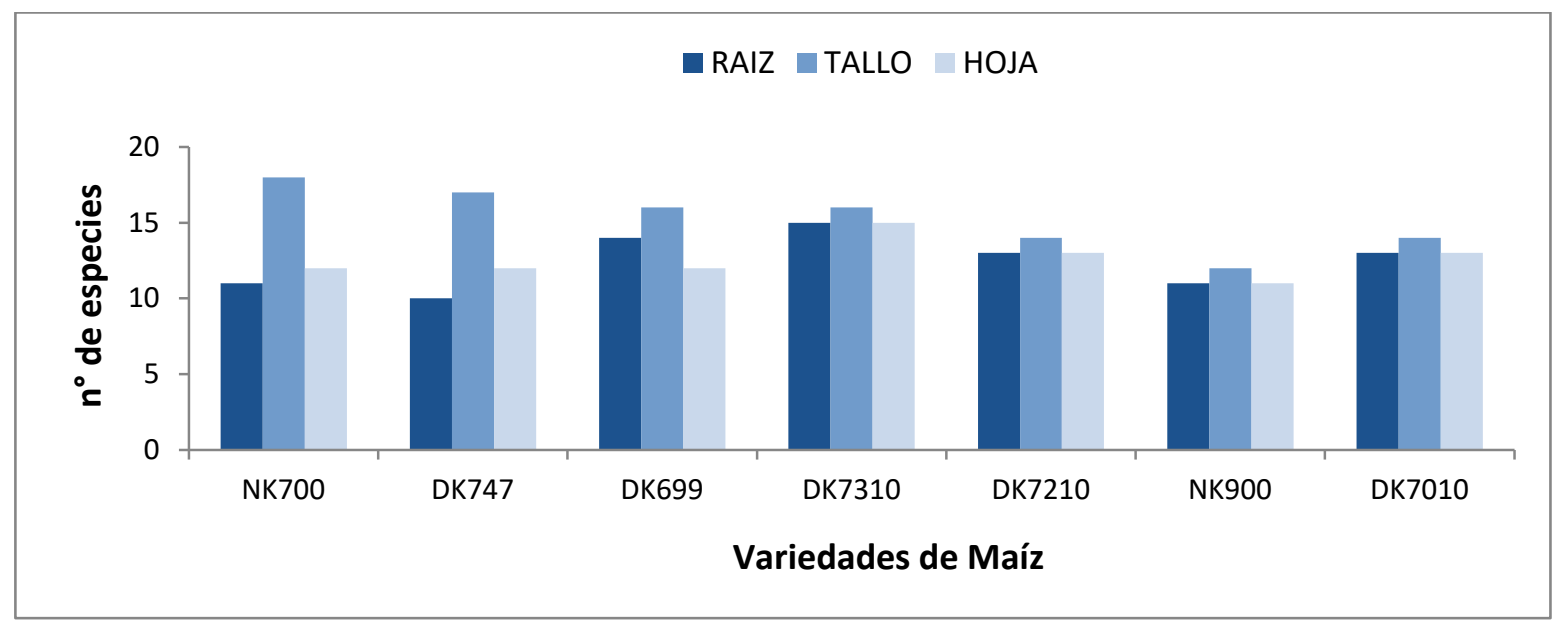

Figura I.9. Número de especies de hongos endófitos aislados e identificados en cada una de las variedades de maíz.

La comunidad fúngica presente en los distintos órganos de la planta en cada variedad de maíz varió según las frecuencias porcentuales de colonización de las especies aisladas (Tabla I.4).

La categorización de los taxa aislados, según categorías de frecuencias se observa en la Tabla I.2.

En hojas y raíces todas las variedades presentaron solamente especies raras u raras y ocasionales. En los tallos, las variedades NK700, DK747 y DK699 mostraron especies de hongos raras, ocasionales y frecuentes, mientras que en los tallos del resto de las variedades sólo presentaron especies raras y ocasionales.

Los tallos, en general, agruparon los porcentajes más altos de colonización de cada especie en cada variedad; en dicho órgano ninguna variedad de maíz presentó especies comunes ni muy comunes, mientras que todas las variedades presentaron especies frecuentes (Tabla I.4). 
Tabla I.4. Frecuencia de colonización (\%) en raíz, tallo y hoja de cada variedad de maíz

\begin{tabular}{|c|c|c|c|c|c|c|c|c|c|c|c|c|c|c|c|c|c|c|c|c|c|}
\hline \multirow[t]{3}{*}{ Hongos aislados } & \multicolumn{21}{|c|}{ Frecuencia de colonización (\%) } \\
\hline & \multicolumn{3}{|c|}{ NK700 } & \multicolumn{3}{|c|}{ DK747 } & \multicolumn{3}{|c|}{ DK699 } & \multicolumn{3}{|c|}{ DK7310 } & \multicolumn{3}{|c|}{ DK7210 } & \multicolumn{3}{|c|}{ NK900 } & \multicolumn{3}{|c|}{ DK7010 } \\
\hline & raíz & tallo & hoja & raíz & tallo & hoja & raíz & tallo & hoja & raíz & tallo & hoja & raíz & tallo & hoja & raíz & tallo & hoja & raíz & tallo & hoja \\
\hline Alternaria alternata & 3,3 & 13,3 & - & 1,7 & 16,7 & 1,7 & 3,3 & 40,0 & 3,3 & - & - & - & 1,7 & 8,3 & 1,7 & - & - & - & - & - & - \\
\hline Alternaria sp.1 & - & - & - & - & - & - & 1,7 & 20,0 & - & - & - & - & - & - & - & 5,0 & 16,7 & 3,3 & - & - & - \\
\hline Alternaria sp.2 & - & - & - & - & - & - & - & - & - & 3,3 & 18,3 & 3,3 & - & - & - & - & 13,3 & - & - & 15,0 & - \\
\hline Arthrinium phaeospermun & 3,3 & 35,0 & 21,7 & - & - & - & 3,3 & 36,7 & - & - & - & - & - & - & - & - & - & - & - & - & - \\
\hline Arthrinium sp. & 3,3 & 50,0 & 10,0 & - & - & - & 1,7 & 26,7 & 10,0 & 5,0 & 30,0 & 3,3 & - & - & - & 3,3 & 13,3 & - & - & 13,3 & - \\
\hline Aspergillus flavus & - & - & - & 8,3 & 35,0 & - & - & - & - & - & - & - & 1,7 & 18,3 & - & - & - & - & - & - & - \\
\hline Aspergillus niger & 6,7 & 31,7 & 20,0 & 3,3 & 21,7 & 5,0 & 5,0 & 16,7 & 1,7 & 5,0 & 18,3 & - & 6,7 & 23,3 & 1,7 & 3,3 & 11,7 & - & 1,7 & 10,0 & - \\
\hline Aspergillus terreus & - & - & - & 8,3 & 30,0 & 28,3 & - & - & - & - & 10,0 & - & - & - & - & - & - & - & - & - & - \\
\hline Bipolaris tetramera & - & - & - & - & 31,7 & - & - & - & - & - & - & - & - & - & - & 6,7 & 15,0 & 3,3 & 5,0 & 11,7 & 3,3 \\
\hline Chaetomium globosum & - & 23,3 & - & - & 25,0 & - & - & - & - & - & - & - & - & - & - & - & - & - & - & - & - \\
\hline Drechslera sp. & - & - & - & - & - & - & - & - & - & - & - & - & 3,3 & 6,7 & - & 5,0 & 18,3 & - & - & 10,0 & - \\
\hline Fusarium graminearum & 8,3 & 33,3 & 11,7 & 6,7 & 38,3 & 5,0 & 8,3 & 20,0 & 1,7 & 6,7 & 23,3 & 3,3 & - & - & - & - & - & - & - & - & - \\
\hline Fusarium proliferatum & - & - & - & 26,7 & 43,3 & 28,3 & 3,3 & 13,3 & 1,7 & - & 16,7 & - & - & - & - & - & - & - & - & - & - \\
\hline Fusarium sp.1 & 1,7 & 21,7 & 10,0 & - & - & - & - & - & - & - & - & - & - & - & - & - & - & - & - & 21,7 & - \\
\hline Fusarium sp.2 & - & 16,7 & 5,0 & - & - & - & - & - & - & - & - & - & - & - & - & - & - & - & - & 16,7 & - \\
\hline Fusarium sp.3 & - & 28,3 & 11,7 & - & - & - & - & - & - & - & - & - & - & - & - & - & - & - & 8,3 & 16,7 & 8,3 \\
\hline Fusarium sp.4 & 3,3 & 18,3 & 8,3 & - & - & - & - & - & - & - & - & - & - & - & - & - & - & - & 10,0 & 18,3 & 1,7 \\
\hline Fusarium sp.5 & - & - & - & 10,0 & 36,7 & 3,3 & 3,3 & 36,7 & 30,0 & 5,0 & 8,3 & 3,3 & - & - & - & - & - & - & - & - & - \\
\hline Fusarium sp.6 & - & - & - & - & - & - & 13,3 & 28,3 & 5,0 & 3,3 & 10,0 & 1,7 & - & - & - & - & - & - & - & - & - \\
\hline Fusarium sp.7 & - & - & - & - & - & - & - & 30,0 & - & - & - & - & - & - & - & - & - & - & - & - & - \\
\hline Fusarium sp.8 & - & - & - & - & - & - & 3,3 & 16,7 & 5,0 & 1,7 & 5,0 & - & 3,3 & 8,3 & 3,3 & - & - & - & - & - & - \\
\hline Fusarium sp.9 & - & - & - & - & - & - & - & 21,7 & 6,7 & - & - & - & - & - & - & 5,0 & 23,3 & - & - & - & - \\
\hline Fusarium sp.10 & - & - & - & - & - & - & 3,3 & 11,7 & 5,0 & 1,7 & 20,0 & - & 3,3 & 8,3 & 1,7 & 3,3 & 20,0 & 1,7 & - & - & - \\
\hline Fusarium sp.11 & - & - & - & - & - & - & - & - & - & - & - & - & - & - & - & 8,3 & 15,0 & 1,7 & - & - & - \\
\hline Mucor circinelloides & - & - & - & - & 25,0 & - & - & - & - & - & - & - & 3,3 & 11,7 & - & - & - & - & - & - & - \\
\hline Mucor mucedo & - & 15,0 & 1,7 & 1,7 & 8,3 & 3,3 & 3,3 & 13,3 & 5,0 & - & - & - & - & - & - & 5,0 & 13,3 & 1,7 & 6,7 & 15,0 & 3,3 \\
\hline Nigrospora sp. & - & - & - & - & - & - & 5,0 & 28,3 & 16,7 & - & - & - & 3,3 & 13,3 & - & - & - & - & 3,3 & 6,7 & 1,7 \\
\hline Penicillium rubrum & 1,7 & 13,3 & 3,3 & 1,7 & 33,3 & 3,3 & - & - & - & 1,7 & 31,7 & 1,7 & 5,0 & 13,3 & 3,3 & - & - & - & 15,0 & 36,7 & 3,3 \\
\hline Penicillium sp.1 & - & - & - & 1,7 & 18,3 & 3,3 & - & - & - & - & - & - & - & - & - & - & - & - & 3,3 & 10,0 & 1,7 \\
\hline Penicillium sp.2 & 1,7 & 36,7 & 3,3 & - & 10,0 & 1,7 & - & - & - & - & - & - & - & - & - & - & - & - & - & 10,0 & - \\
\hline Scopulariopsis brevicaulis & 5,0 & 25,0 & 3,3 & - & - & - & - & - & - & - & - & - & - & - & - & 8,3 & 20,0 & 5,0 & - & - & - \\
\hline Trichoderma harzianum & - & - & - & - & - & - & - & - & - & - & - & - & - & - & - & 3,3 & 28,3 & 3,3 & - & - & - \\
\hline Trichoderma saturnisporum & - & - & - & - & - & - & - & 43,3 & - & 3,3 & 36,7 & 3,3 & - & - & - & - & - & - & - & - & - \\
\hline Ulocladium $s p$ & - & - & - & - & - & - & - & - & - & - & - & - & - & 23,3 & 6,7 & 5,0 & 13,3 & 3,3 & 1,7 & 11,7 & - \\
\hline Total de especies & 10 & 14 & 12 & 10 & 14 & 10 & 13 & 16 & 12 & 10 & 12 & 7 & 9 & 10 & 6 & 12 & 13 & 8 & 9 & 15 & 7 \\
\hline
\end{tabular}




\section{Tasas de colonización y de aislamiento}

En general la tasa de colonización y de aislamiento de hongos endófitos recuperados de raíces y hojas fue mayor en las variedades DK7477 y NK700 respectivamente, mientras que la tasa de colonización de los tallos fue la más alta de los tres tipos de órganos, alcanzando en la mayoría de las variedades el 100\%, mientras que la tasa de aislamiento fue mayor en las variedades DK699 y DK747 (Tabla I.5). 
Tabla I.5. Tasa de colonización (TC) y tasa de aislamiento (TA) en siete variedades de maíz comúnmente cultivadas en la Región Pampeana, Argentina. Campaña agrícola 2013-2014.

\begin{tabular}{|c|c|c|c|c|c|c|c|c|c|c|c|c|c|c|c|c|c|c|c|c|c|c|c|c|c|c|c|c|c|}
\hline & \multicolumn{4}{|c|}{ NK700 } & \multicolumn{4}{|c|}{ DK747 } & \multicolumn{4}{|c|}{ DK699 } & \multicolumn{4}{|c|}{ DK7310 } & \multicolumn{4}{|c|}{ DK7210 } & \multicolumn{4}{|c|}{ NK900 } & \multicolumn{5}{|c|}{ DK7010 } \\
\hline & raíz & tallo & hoja & planta & raíz & tallo & hoja & planta & raíz & tallo & hoja & planta & raíz & tallo & hoja & planta & raíz & tallo & hoja & planta & raíz & tallo & hoja & planta & raíz & tallo & hoja & planta & total \\
\hline $\mathrm{N}^{\circ}$ de segmentos incubados & 60 & 60 & 60 & 180 & 60 & 60 & 60 & 180 & 60 & 60 & 60 & 180 & 60 & 60 & 60 & 180 & 60 & 60 & 60 & 180 & 60 & 60 & 60 & 180 & 60 & 60 & 60 & 180 & 1260 \\
\hline $\begin{array}{l}\mathrm{N}^{\circ} \text { de segmentos colonizados } \\
\text { con una o más sp. }\end{array}$ & 30 & 60 & 42 & 132 & 41 & 60 & 38 & 139 & 27 & 60 & 40 & 127 & 24 & 57 & 12 & 93 & 18 & 57 & 11 & 86 & 36 & 60 & 12 & 108 & 39 & 60 & 14 & 113 & 798 \\
\hline $\mathrm{N}^{\circ}$ de aislamientos & 23 & 218 & 66 & 307 & 42 & 225 & 50 & 317 & 35 & 242 & 54 & 331 & 22 & 137 & 12 & 171 & 19 & 81 & 11 & 111 & 34 & 133 & 14 & 181 & 33 & 136 & 14 & 183 & 1601 \\
\hline TC (\%) & 50 & 100 & 70 & 73 & 68 & 100 & 63 & 77 & 45 & 100 & 67 & 71 & 40 & 95 & 20 & 52 & 30 & 95 & 18 & 48 & 60 & 100 & 20 & 60 & 65 & 100 & 23 & 63 & \\
\hline TA & 0,4 & 3,6 & 1,1 & 1,7 & 0,7 & 3,7 & 0,8 & 1,8 & 0,6 & 4,0 & 0,9 & 1,8 & 0,4 & 2,3 & 0,2 & 0,9 & 0,3 & 1,3 & 0,2 & 0,6 & 0,6 & 2,2 & 0,2 & 1,0 & 0,5 & 2,3 & 0,2 & 1,0 & \\
\hline
\end{tabular}




\section{Diversidad de las comunidades de hongos endófitos en las diferentes variedades de maíz}

La diversidad de hongos endófitos, mostró diferencias significativas entre las siete comunidades, las variedades NK700 y DK699, mostraron los valores más altos (Tabla I.6).

Tabla I.6. Índice de diversidad de Shannon

\begin{tabular}{lccccccc}
\hline \hline & NK700 & DK747 & DK699 & DK7310 & DK7210 & NK900 & DK7010 \\
\hline Índice Shannon (H') & $2,67 \pm 0,46 a$ & $2,08 \pm 0,75 b$ & $2,72 \pm 0,31 a$ & $1,78 \pm 0,54 b$ & $2,03 \pm 0,56 b$ & $1,89 \pm 0,65 b$ & $1,77 \pm 0,36 b$ \\
ANOVA & & $F=5,46$ & $d f=6$ & $p<0,0001$ & & \\
\hline \hline
\end{tabular}

\section{Comparación entre las comunidades}

Para comparar las distintas comunidades se calculó el coeficiente de similitud de Jaccard. La Tabla I.7 muestra las comparaciones realizadas y el valor que tomó este índice para cada una.

Tabla I.7. Índice de similitud de Jaccard

\begin{tabular}{llllllll}
\hline \hline & NK700 & DK747 & DK699 & DK7310 & DK7210 & NK900 & DK7010 \\
\hline NK700 & 1 & & & & & & \\
DK747 & 0,270 & 1 & & & & & \\
DK699 & 0,200 & 0,208 & 1 & & & & \\
DK7310 & 0,190 & 0,300 & 0,444 & 1 & & & \\
DK7210 & 0,143 & 0,200 & 0,238 & 0,222 & 1 & & \\
NK900 & 0,125 & 0,130 & 0,261 & 0,190 & 0,211 & 1 & \\
DK7010 & $\mathbf{0 , 5 0 0}$ & 0,261 & 0,154 & 0,174 & 0,250 & 0,333 & 1 \\
\hline \hline
\end{tabular}

El valor más alto del Índice de Jaccard está dado por las variedades DK7010 y NK700 $(\mathrm{JI}=0,500)$, la similitud del grupo de hongos endófitos entre otras variedades de maíz resultó más baja (Tabla I.7). 


\section{Análisis de componentes principales}

El análisis de componentes principales explicó el 55\% de la variabilidad total en los dos primeros ejes, siendo que el 34,4\% está relacionado al primer eje y el 20,9\% al segundo eje (Tabla I.8). En la Figura I.10 los vectores representan las variedades de maíz, observándose además los aislamientos de hongos endófitos obtenidos.

La proyección de los tratamientos en el plano de los dos primeros ejes permite diferenciar tres grupos ( $A, B, C, D)$, cada uno de ellos formado por una de las siete variedades de maíz. El grupo A, formado por la variedad DK7010 asociada con las especies Fusarium sp. 1, Fusarium sp. 2, Fusarium sp. 3 y Fusarium sp. 4. El grupo B, formado por la variedad NK900 asociado con las especies Scopulariopsis brevicaulis (Sacc.) Bainier (Microascales: Microascaceae), Fusarium sp. 11 y T. harzianun. El grupo C formado por la variedad DK7210 asociada con las especies Arthrinium phaeospermun (Corda) Ellis (Apiosporaceae), Arthrinium sp., A. flavus, $M$. circinelloides, A. terreus, Nigrospora sp. y Alternaria alternata (Fr.) Keissl. (Pleosporales: Pleosporaceae) y el grupo D formado por la variedad DM699 asociada con las especies Trichoderma saturnisporum Hammill (Hypocreales: Hypocreaceae), Fusarium sp. 6 y Fusarium sp. 8.

Tabla I.8. Análisis de componentes principales

\begin{tabular}{lll}
\hline \hline Eigenvalores & & \\
\hline & Eje 1 & Eje 2 \\
Eigenvalores & 1,7 & 1,5 \\
Percentaje & 34,4 & 20,9 \\
Percentaje acumulado & 24,4 & 55,2 \\
\hline \hline
\end{tabular}




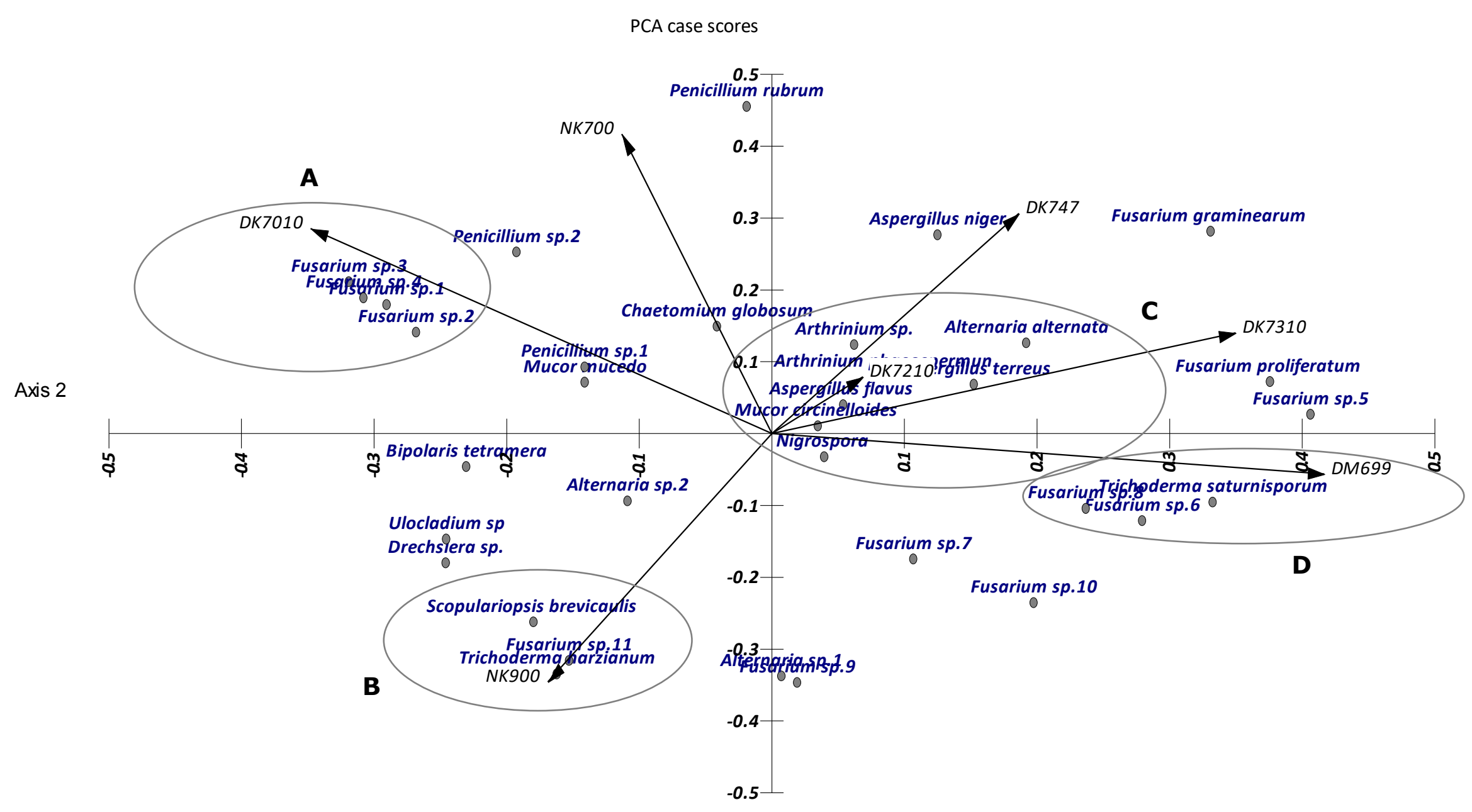

Vector scalina: 0,76

Axis 1

Figura I.10. Análisis de componentes principales. 


\section{Composición de hongos endófitos en soja}

A partir de 1260 fragmentos, se obtuvieron 3992 aislamientos, de los cuales 651 correspondieron a raíces, 2787 a tallos y 554 a hojas.

Entre los aislamientos se obtuvieron 36 taxa, 20 a nivel genérico y 16 a nivel específico. Nueve de los aislamientos fueron identificados mediante análisis moleculares, por ser aquellos que pudieron identificarse a nivel de especie pero generaron dudas en el análisis morfológico y a su vez, registraron alta frecuencia de colonización.

Hubo cuatro taxa que pudieron ser aislados sólo de una sola variedad de soja, a saber: Alternaria sp. de la variedad DM4913, B. tetramera de la variedad DM4670, Nigrospora sp. de la variedad DM4210 y S. brevicaulis de la variedad DM3810.

Todos los aislamientos pertenecieron a los Phyla Ascomycota y Zygomycota. Los Ascomycota se agruparon en tres clases, (Dothideomycetes, Sordariomycetes y Eurothiomycetes), en 8 órdenes y en más de 10 familias (Tabla I.9). 
Tabla I.9. Número de aislamientos ( $\mathrm{n}$ ) y frecuencia de colonización de hongos endófitos (\%) en las distintas variedades de soja

\begin{tabular}{|c|c|c|c|c|c|c|c|c|c|c|c|c|c|c|c|c|}
\hline \multirow[t]{2}{*}{ HONGOS AISLADOS } & \multicolumn{2}{|c|}{ DM3810 } & \multicolumn{2}{|c|}{ DM4210 } & \multicolumn{2}{|c|}{ DM4670 } & \multicolumn{2}{|c|}{ NA5009 } & \multicolumn{2}{|c|}{ DM4612 } & \multicolumn{2}{|c|}{ DM4214 } & \multicolumn{2}{|c|}{ DM4913 } & \multirow[t]{2}{*}{ FAMILIA } & \multirow[t]{2}{*}{ ORDEN } \\
\hline & $\mathrm{n}$ & $\%$ & $\mathrm{n}$ & $\%$ & $\mathrm{n}$ & $\%$ & $\mathrm{n}$ & $\%$ & $\mathrm{n}$ & $\%$ & $\mathrm{n}$ & $\%$ & $\mathrm{n}$ & $\%$ & & \\
\hline Alternaria alternata & - & - & 31 & 17,2 & 24 & 13,3 & 25 & 13,9 & - & - & 48 & 26,7 & 50 & 27,8 & Pleosporaceae & Pleosporales \\
\hline Alternaria sp.1 & - & - & - & - & - & - & - & - & - & - & - & - & 49 & 27,2 & Pleosporaceae & Pleosporales \\
\hline Alternaria sp.2 & - & - & - & - & - & - & - & - & - & - & 56 & 31,1 & 9 & 5,0 & Pleosporaceae & Pleosporales \\
\hline Arthrinium phaeospermun & 15 & 8,3 & 32 & 17,8 & 29 & 16,1 & - & - & - & - & - & - & - & - & Apiosporaceae & Incertae sedis \\
\hline Aspergillus flavus & - & - & - & - & 32 & 17,8 & 37 & 20,5 & 32 & 17,8 & - & - & - & - & Trichocomaceae & Eurotiales \\
\hline Aspergillus niger & 29 & 16,1 & 33 & 18,3 & - & - & 42 & 23,3 & - & - & - & - & - & - & Trichocomaceae & Eurotiales \\
\hline Aspergillus terreus & - & - & 25 & 13,9 & 22 & 12,2 & 60 & 33,3 & - & - & 53 & 29,4 & 54 & 30,0 & Trichocomaceae & Eurotiales \\
\hline Bipolaris tetramera & - & - & - & - & 24 & 13,3 & - & - & - & - & - & - & - & - & Pleosporaceae & Pleosporales \\
\hline Clonostachys rosea & 10 & 5,5 & - & - & 27 & 15,0 & - & - & - & - & - & - & - & - & Bionectriaceae & Hypocreales \\
\hline Curvularia lunata & 32 & 17,8 & 23 & 12,8 & - & - & 32 & 17,8 & 32 & 17,8 & - & - & - & - & Pleosporaceae & Pleosporales \\
\hline Fusarium equiseti & 35 & 19,4 & - & - & - & - & - & - & - & - & - & - & - & - & Nectriaceae & Hypocreales \\
\hline Fusarium graminearum & 39 & 21,7 & 26 & 14,4 & 30 & 16,7 & - & - & - & - & - & - & - & - & Nectriaceae & Hypocreales \\
\hline Fusarium oxysporum & 19 & 10,6 & - & - & 25 & 13,9 & - & - & - & - & - & - & - & - & Nectriaceae & Hypocreales \\
\hline Fusarium sp.1 & 23 & 12,8 & - & - & - & - & 32 & 17,8 & 27 & 15,0 & 55 & 30,6 & 49 & 27,2 & Nectriaceae & Hypocreales \\
\hline Fusarium sp.2 & 27 & 15,0 & - & - & - & - & - & - & - & - & 56 & 31,1 & 55 & 30,5 & Nectriaceae & Hypocreales \\
\hline Fusarium sp.3 & 31 & 17,2 & - & - & - & - & - & - & 32 & 17,8 & - & - & 6 & 3,3 & Nectriaceae & Hypocreales \\
\hline Fusarium sp.4 & 30 & 16,7 & - & - & - & - & - & - & - & - & - & - & - & - & Nectriaceae & Hypocreales \\
\hline Fusarium sp.5 & 26 & 14,4 & - & - & - & - & - & - & 32 & 17,8 & - & - & - & - & Nectriaceae & Hypocreales \\
\hline Fusarium sp.6 & 23 & 12,8 & - & - & - & - & - & - & 32 & 17,8 & - & - & - & - & Nectriaceae & Hypocreales \\
\hline Fusarium sp.7 & 23 & 12,8 & - & - & - & - & 41 & 22,8 & 32 & 17,8 & 6 & 3,3 & - & - & Nectriaceae & Hypocreales \\
\hline Fusarium sp. 8 & - & - & - & - & 54 & 30,0 & 49 & 27,2 & - & - & - & - & - & - & Nectriaceae & Hypocreales \\
\hline Fusarium sp.9 & - & - & 26 & 14,4 & 54 & 30,0 & 46 & 25,6 & - & - & - & - & - & - & Nectriaceae & Hypocreales \\
\hline Fusarium sp.10 & 17 & 9,4 & 34 & 18,9 & 54 & 30,0 & 38 & 21,1 & - & - & - & - & - & - & Nectriaceae & Hypocreales \\
\hline Fusarium sp.11 & 23 & 12,8 & 26 & 14,4 & 54 & 30,0 & 43 & 23,9 & - & - & - & - & - & - & Nectriaceae & Hypocreales \\
\hline Fusarium sp.12 & - & - & 43 & 23,9 & 54 & 30,0 & 44 & 24,4 & - & - & - & - & - & - & Nectriaceae & Hypocreales \\
\hline Fusarium sp.13 & - & - & 22 & 12,2 & - & - & 47 & 26,1 & - & - & - & - & - & - & Nectriaceae & Hypocreales \\
\hline Fusarium sp.14 & - & - & 44 & 24,4 & - & - & 46 & 25,6 & 36 & 20,0 & - & - & 64 & 35,6 & Nectriaceae & Hypocreales \\
\hline Fusarium sp.15 & 23 & 12,8 & - & - & - & - & - & - & 44 & 24,4 & 54 & 30,0 & 62 & 34,4 & Nectriaceae & Hypocreales \\
\hline Fusarium sp.16 & - & - & 24 & 13,3 & - & - & - & - & 32 & 17,8 & 54 & 30,0 & 62 & 34,4 & Nectriaceae & Hypocreales \\
\hline Fusarium sp.17 & - & - & 24 & 13,3 & - & - & 38 & 21,1 & 38 & 21,1 & 54 & 30,0 & 55 & 30,5 & Nectriaceae & Hypocreales \\
\hline Macrophomina phaseolina & 64 & 35,5 & - & - & 31 & 17,2 & - & - & 58 & 32,0 & 54 & 30,0 & 52 & 28,9 & Botryosphaeriaceae & Botryosphaeriales \\
\hline Mucor mucedo & - & - & - & - & - & - & - & - & - & - & 54 & 30,0 & 51 & 28,3 & Mucoraceae & Mucorales \\
\hline Nigrospora sp. & - & - & 18 & 10,0 & - & - & - & - & - & - & - & - & - & - & Trichosphaeriaceae & Trichosphaeriales \\
\hline Penicillium rubrum & 18 & 10,0 & 25 & 13,9 & 25 & 13,9 & - & - & 58 & 32,0 & 49 & 27,2 & - & - & Trichocomaceae & Eurotiales \\
\hline Scopulariopsis brevicaulis & 25 & 13,9 & - & - & - & - & - & - & - & - & - & - & - & - & Microascaceae & Microascales \\
\hline Trichoderma saturnisporum & - & - & 18 & 10,0 & - & - & 32 & 17,8 & 32 & 17,8 & - & - & 56 & 31,1 & Hypocreceae & Hypocreales \\
\hline TOTAL DE AISLAMIENTOS & 532 & & 474 & & 539 & & 659 & & 521 & & 593 & & 674 & & & \\
\hline TOTAL DE ESPECIES & 20 & & 17 & & 15 & & 16 & & 14 & & 12 & & 14 & & & \\
\hline
\end{tabular}


Las especies A. alternata, Aspergillus niger Tiegh (Eurotiales: Trichocomaceae), A. phaeospermun, Curvularia lunata (Wakker) Boedijn (Pleosporales: Pleosporales), Fusarium equiseti (Corda.) Sacc. (Hypocreales: Nectriaceae), Fusarium oxysporum Schltdl (Hypocreales: Nectriaceae), Macrophomina phaseolina (Tassi) Goid (Botryosphaeriales: Botryosphaeriaceae), S. brevicaulis y T. saturnisporum fueron identificadas mediante análisis molecular y sus secuencias nucleotídicas fueron depositadas en la base de datos del NCBI bajo sus respectivos números de acceso KF753947, KF753944, KF753946, KF753941，KF753953，KF753954， KF753946, KF753948 y KF753942. Se obtuvo como resultado para todos los aislamientos un \% ID y de cobertura del $100 \%$ y e-value $=0.0$

El número de aislamientos varió en función del órgano de la planta estudiado más que con la variedad. El mayor número de aislamientos se obtuvo a partir de los tallos mientras que en raíces y en hojas el número de aislamientos fue menor (Figura I.11). En cuanto a las variedades, el mayor número de aislamientos (674 aislamientos) se obtuvo en la variedad DM4913 y el menor número de aislamientos (474 aislamientos) se obtuvo en la variedad DM4210 (Tabla I.9).

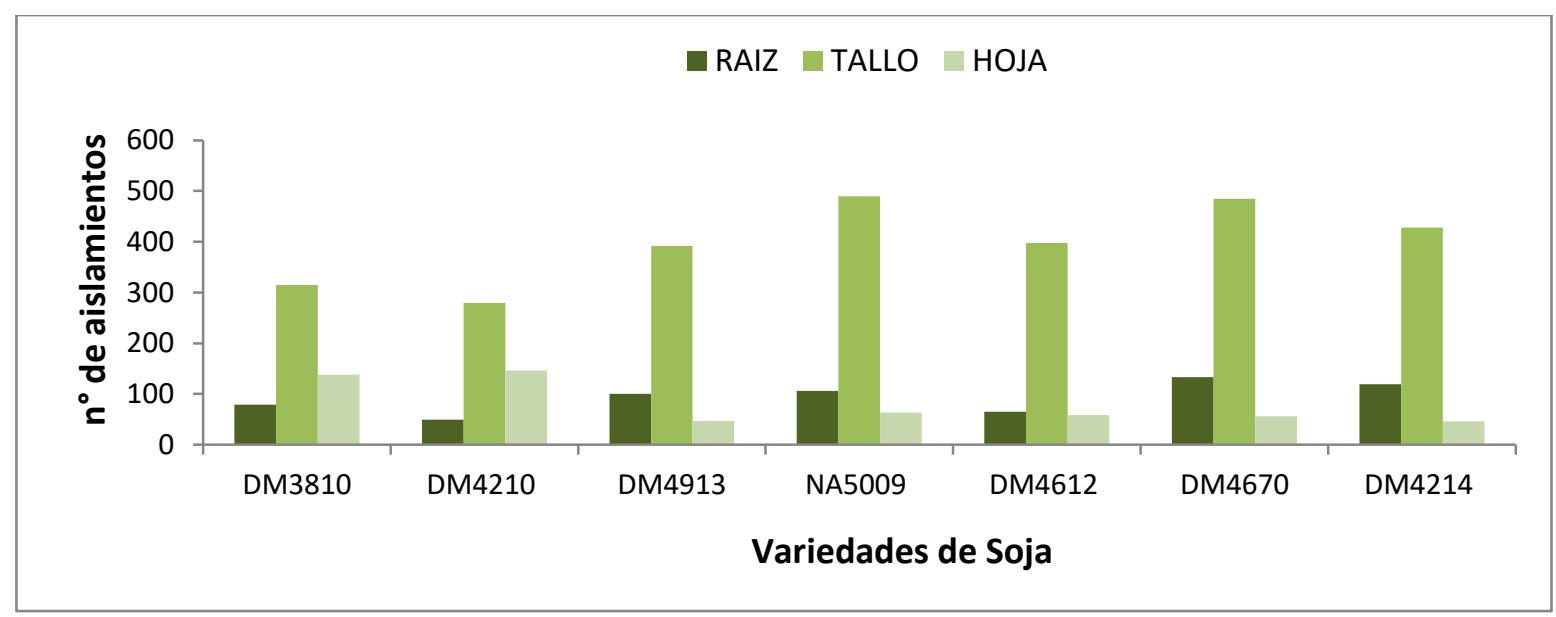

Figura I.11. Número de aislamientos obtenidos en raíces, tallos y hojas de cada una de las siete variedades de soja.

El número de especies aisladas en tallos varió entre 12 y 18 , en hojas entre 11 y 15 , y en raíces entre 10 y 15 en todas las variedades de soja. Al igual que el número de aislamientos, el mayor número de especies fue obtenido en los tallos de todas las variedades (Figura I.12). Es importante mencionar que a diferencia de lo ocurrido con el número de aislamientos, en este caso las variedades en las que se 
obtuvieron el mayor y menor número de especie fúngicas fueron la DM3810 (20 especies) y la DM4214 (12 especies) respectivamente.

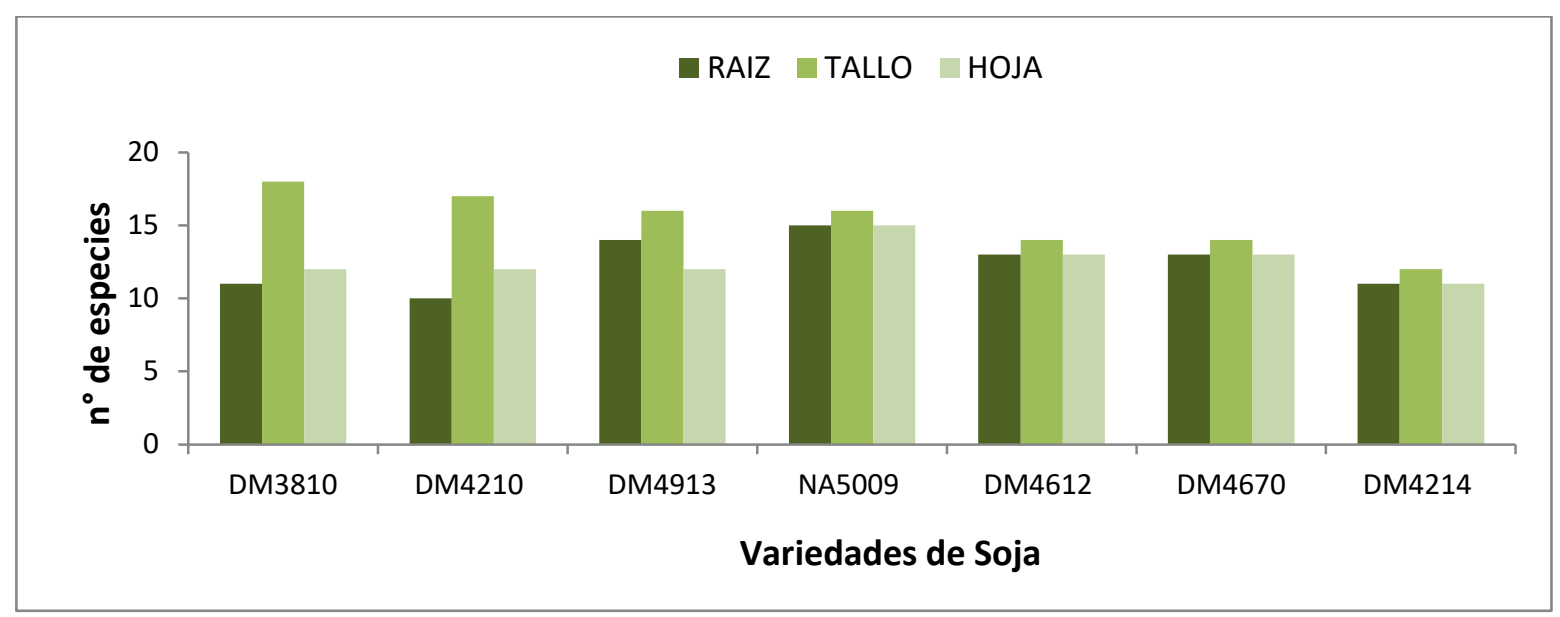

Figura I.12. Número de especies de hongos endófitos aislados e identificados en cada una de las variedades de soja.

La comunidad fúngica en los distintos órganos de la planta en cada variedad de soja varió según las frecuencias porcentuales de colonización de las especies aisladas (Tabla I.10).

En hojas y raíces todas las variedades presentaron solamente especies raras o raras y ocasionales (ver Tabla I.2 para categorías)

En los tallos las variedades DM3810 y DM4670 mostraron especies de hongos ocasionales, frecuentes y comunes; en las variedades DM4913 y DM4214, presentaron especies raras, frecuentes y comunes; en las variedades DM4612 y NA5009 se pudieron aislar especies frecuentes y comunes, mientras que la variedad DM4210 presentó especies ocasionales y frecuentes.

Los tallos, en general, agruparon los porcentajes más altos de colonización de cada especie en cada variedad (Tabla I.10), en dicho órgano ninguna variedad de soja presentó especies muy comunes, mientras que todas las variedades presentaron especies frecuentes.

\section{Tasas de colonización y de aislamiento}

A partir de los tallos se obtuvieron las mayores tasas de colonización, las cuales variaron entre el 85 y el $100 \%$ en las diferentes variedades, alcanzando el $100 \%$ en las variedades DM3810, NA5009, DM4913 Y DM4214. La tasa de aislamiento se 
comportó de la misma manera, debido a que fueron los tallos quienes registraron los valores más altos. Los valores de dicha tasa variaron entre 4,7 (variedad DM4210) y 8,2 (variedad NA5009), las otras variedades registraron valores intermedios (Tabla I.11).

En cuanto a la tasa media de colonización fue mayor $(77,8 \%)$ en la variedad DM3810 indicando de esta manera que hubo un mayor número de segmentos colonizados, mientras que la tasa media de aislamiento fue mayor $(3,7)$ en la variedades NA5009 y DM4913 (Tabla I.11). 
Tabla I.10. Frecuencia de colonización (\%) en raíz, tallo y hoja de cada variedad de soja

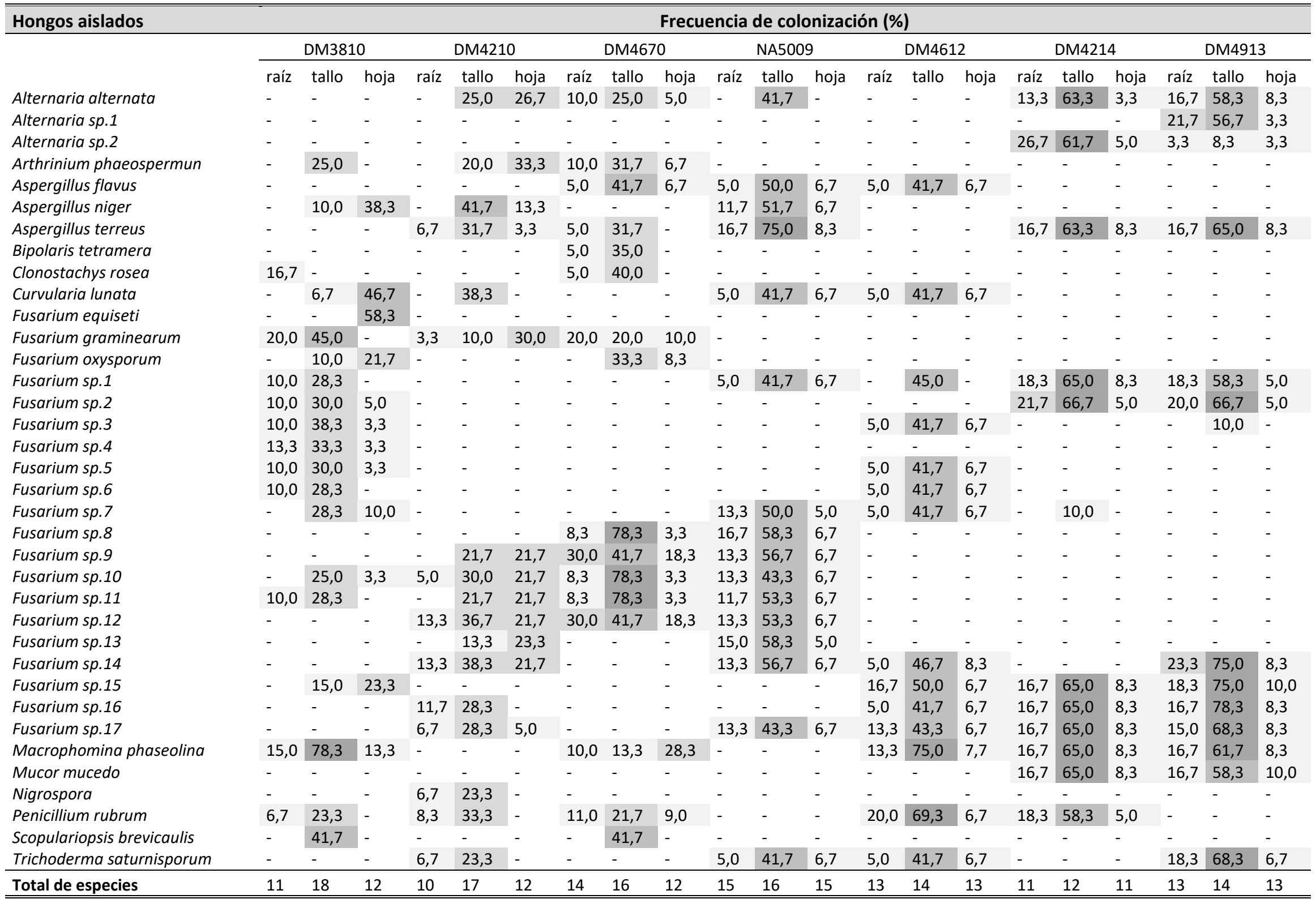

\begin{tabular}{l|l|l|l|l|l|} 
Clasificación & $0,1 \%-20 \%$ & $21 \%-40 \%$ & $41 \%-60 \%$ & $61 \%-80 \%$ & $81 \%-100 \%$
\end{tabular} 
Tabla I.11. Tasa de colonización (TC) y tasa de aislamiento (TA) en siete variedades de soja comúnmente cultivadas en la Región Pampeana, Argentina. Campaña agrícola 2013-2014.

\begin{tabular}{|c|c|c|c|c|c|c|c|c|c|c|c|c|c|c|c|c|c|c|c|c|c|c|c|c|c|c|c|c|c|}
\hline & \multicolumn{4}{|c|}{ DM3810 } & \multicolumn{4}{|c|}{ DM4210 } & \multicolumn{4}{|c|}{ DM4670 } & \multicolumn{4}{|c|}{ NA5009 } & \multicolumn{4}{|c|}{ DM4612 } & \multicolumn{4}{|c|}{ DM4913 } & \multicolumn{5}{|c|}{ DM4214 } \\
\hline & raíz & tallo & hoja & planta & raíz & tallo & hoja & planta & raíz & tallo & hoja & planta & raíz & tallo & hoja & planta & raíz & tallo & hoja & planta & raíz & tallo & hoja & planta & raíz & tallo & hoja & planta & total \\
\hline $\mathrm{N}^{\circ}$ de segmentos incubados & 60 & 60 & 60 & 180 & 60 & 60 & 60 & 180 & 60 & 60 & 60 & 180 & 60 & 60 & 60 & 180 & 60 & 60 & 60 & 180 & 60 & 60 & 60 & 180 & 60 & 60 & 60 & 180 & 1260 \\
\hline $\begin{array}{l}\mathrm{N}^{\circ} \text { de segmentos colonizados } \\
\text { con una o más sp. }\end{array}$ & 54 & 60 & 26 & 140 & 47 & 51 & 16 & 114 & 45 & 56 & 16 & 117 & 26 & 60 & 19 & 105 & 30 & 58 & 16 & 104 & 41 & 60 & 27 & 128 & 45 & 60 & 30 & 135 & 843 \\
\hline $\mathrm{N}^{\circ}$ de aislamientos & 79 & 315 & 138 & 532 & 49 & 279 & 146 & 474 & 100 & 392 & 47 & 539 & 106 & 490 & 63 & 659 & 65 & 398 & 58 & 521 & 133 & 485 & 56 & 674 & 119 & 428 & 46 & 593 & 3992 \\
\hline TC (\%) & 90 & 100 & 43,3 & 77,8 & 78,3 & 85 & 26,6 & 63,3 & 75 & 93,3 & 26,6 & 65 & 43,3 & 100 & 31,6 & 58,3 & 50 & 96,6 & 26,6 & 57,7 & 68,3 & 100 & 45 & 71,1 & 75 & 100 & 50 & 75 & \\
\hline TA & 1,3 & 5,3 & 2,3 & 3,0 & 0,8 & 4,7 & 2,4 & 2,6 & 1,7 & 6,5 & 0,8 & 3,0 & 1,8 & 8,2 & 1,1 & 3,7 & 1,1 & 6,6 & 1,0 & 2,9 & 2,2 & 8,1 & 0,9 & 3,7 & 2,0 & 7,1 & 0,8 & 3,3 & \\
\hline
\end{tabular}




\section{Diversidad de las comunidades de hongos endófitos en las diferentes variedades de soja}

La diversidad de hongos endófitos, no mostró diferencias significativas entre las siete variedades de soja (Tabla I.12).

Tabla I.12. Índice de diversidad de Shannon

\begin{tabular}{lccccccc}
\hline \hline & DM3810 & DM4210 & DM4670 & NA5009 & DM4612 & DM3812 & DM4214 \\
\hline Indice Shannon $\left(H^{\prime}\right)$ & $3,7 \pm 0,28 a$ & $3,28 \pm 0,43 a$ & $3,34 \pm 0,35 a$ & $3,33 \pm 1,33 a$ & $3,19 \pm 1,16 a$ & $3,65 \pm 0,07 a$ & $3,45 \pm 0,06 a$ \\
ANOVA & & $F=0,98$ & $d f=6$ & $p=0,44$ & & \\
\hline
\end{tabular}

\section{Comparación entre las comunidades}

Para comparar las distintas comunidades se calculó el coeficiente de similitud de Jaccard. La Tabla I.13 muestra las comparaciones realizadas y el valor que tomó este índice para cada una.

Tabla I.13. Índice de similitud de Jaccard

\begin{tabular}{llllllll}
\hline \hline & DM3810 & DM4210 & DM4670 & NA5009 & DM4612 & DM4214 & DM4913 \\
\hline DM3810 & 1 & & & & & & \\
DM4210 & 0,233 & 1 & & & & & \\
DM4670 & 0,296 & 0,391 & 1 & & & & \\
NA5009 & 0,200 & 0,571 & 0,348 & 1 & & & \\
DM4612 & 0,360 & 0,240 & 0,115 & 0,250 & 1 & & \\
DM4214 & 0,231 & 0,208 & 0,174 & 0,217 & 0,368 & 1 & \\
DM4913 & 0,172 & 0,240 & 0,115 & 0,250 & 0,333 & $\mathbf{0 , 6 4 7}$ & 1 \\
\hline \hline
\end{tabular}

El valor más alto del Índice de Jaccard estuvo dado entre las variedades DM4913 y DM4214 (JI=0,647); la similitud del grupo de hongos endófitos de otras variedades fue más bajo (Tabla I.13). 


\section{Análisis de componentes principales}

El análisis de componentes principales explicó el 62\% de la variabilidad total en los dos primeros ejes, el 35,24\% correspondió al primer eje y el $26,76 \%$ al segundo eje (Tabla I.14). En la Figura I.13 los vectores representan las variedades de soja, y se observan además los aislamientos de hongos endófitos obtenidos.

La proyección de los tratamientos en el plano de los dos primeros ejes permite diferenciar tres grupos $(A, B, C)$, cada uno de ellos formado por una de las siete variedades de soja. El grupo A, formado por la variedad DM3810 asociada con las especies Fusarium sp. 3, Fusarium sp. 4, Fusarium sp. 5, Fusarium sp. 6, F. equiseti y S. brevicaulis. El grupo B, formado por la variedad DM4612 asociada con las especies Fusarium sp. 2, Fusarium sp. 15, M. phaseolina y $P$. rubrum y el grupo C formado por la variedad DM4670 asociada con las especies Fusarium sp. 8, Fusarium sp. 9, Fusarium sp. 10, Fusarium sp. 11 y Fusarium sp. 12 (Figura I.13).

Tabla I.14. Análisis de componentes principales

\begin{tabular}{lll}
\hline \hline Eigenvalores & & \\
\hline & Eje 1 & Eje 2 \\
Eigenvalores & 2,114 & 1,606 \\
Percentaje & 35,239 & 26,764 \\
Percentaje acumulado & 35,239 & 62,003 \\
\hline \hline
\end{tabular}




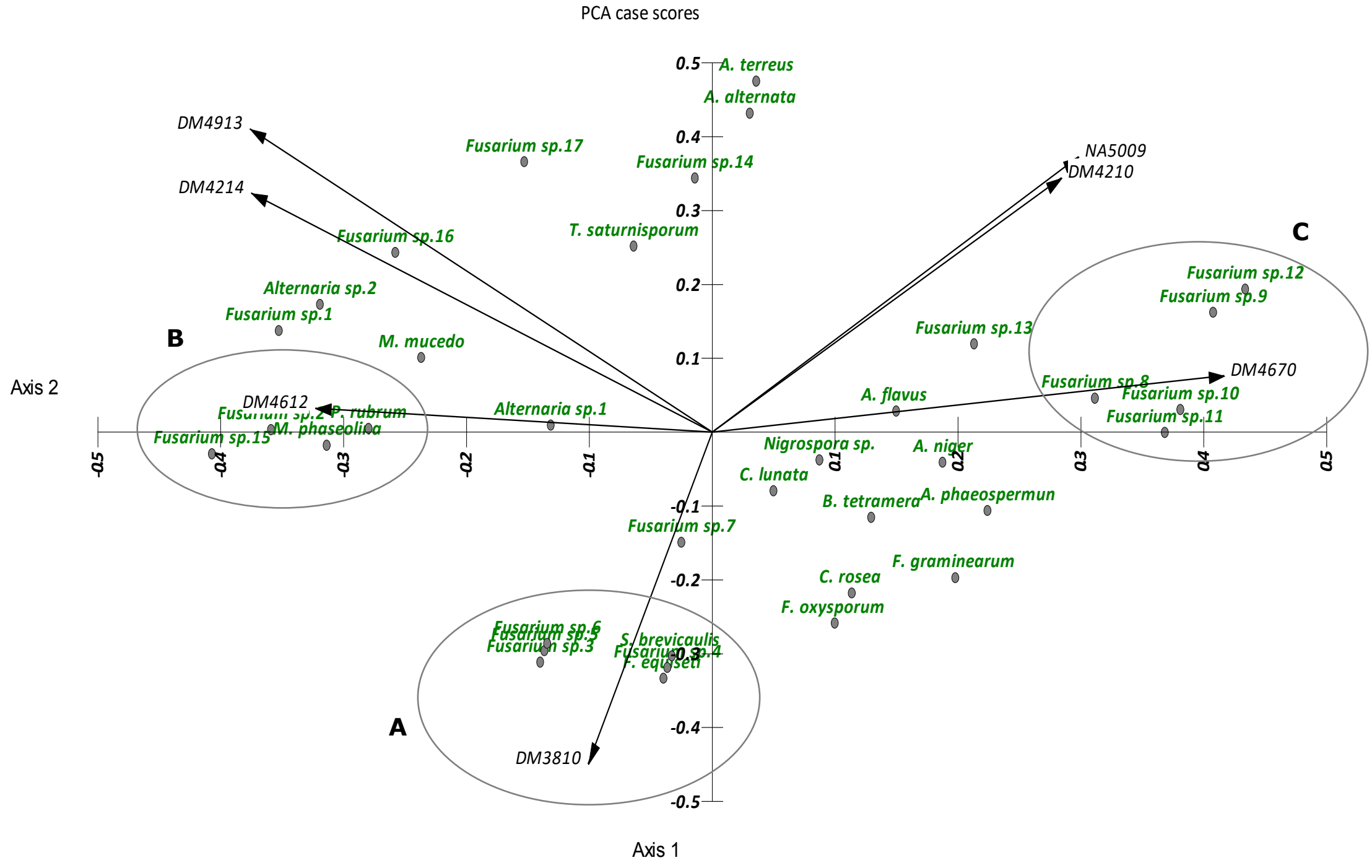

Vector scalina: 0,91

Figura I.13. Análisis de componentes principales. 


\section{Discusión}

En este capítulo se estudió la composición de las comunidades fúngicas presentes en raíces, tallos y hojas de siete variedades de maíz ( $Z$. mays) y siete variedades de soja (G. max), provenientes de diferentes zonas ubicadas dentro de la Región Pampeana Argentina, constituyendo este, el primer estudio de diversidad de hongos endófitos en plantas de maíz (Russo et al. 2016). En cultivos de soja Larran et al. (2002 b) estudiaron previamente la composición de los endófitos en hojas mientras que como resultado de este trabajo de tesis se incorporan registros de endófitos colonizando la raíz y el tallo también (Russo et al. 2016). Si bien a nivel mundial existen varios trabajos en la temática (Fisher et al. 1992; Pimentel et al. 2006; Impullitti y Malvick, 2013; Leite et al. 2013; Nur, 2013; Tenguria y Firodiya 2013; Fernandes et al. 2015), esta contribución amplía el entendimiento de hongos endófitos considerando que algunos de los aislamientos obtenidos son conocidos por ser patógenos de soja y/o maíz. Aunque es importante mencionar que ninguna de las plantas muestreadas en este estudio mostró síntomas de enfermedad. Cabe destacar que algunas de las especies fúngicas identificadas no son conocidas como patógenos y las asociaciones funcionales entre estos hongos y las plantas utilizadas permaneces aun desconocidas.

Dos factores son importantes para garantizar el éxito en el aislamiento de hongos endófitos, uno de ellos es la correcta desinfección de la superficie de las hojas para eliminar los microorganismos epífitos que pudieran existir y el otro es que las plantas utilizadas se encuentren libres de síntomas de enfermedades (Sun y Guo, 2012). A su vez, el tamaño de los fragmentos utilizados de cada planta y el número de muestras influyen en el aislamiento y la diversidad de la comunidad de endófitos fúngico (Sun y Guo, 2012).

La metodología seleccionada para obtener los aislamientos fúngicos a partir de los diferentes órganos en las diferentes variedades de maíz y de soja, permitió corroborar que los hongos crecieron efectivamente desde el interior, siendo estos identificados utilizando caracteres morfológicos y/o moleculares. Estas especies pertenecen a los órdenes Hypocreales, Pleosporales y Eurotiales. Nuestros hallazgos coinciden con Fernandes et al. (2015), quienes registraron en cultivos de soja, endófitos pertenecientes a los Órdenes Hypocreales, Pleosporales y Eurotiales, 
aunque dichos autores también mencionan la presencia de endófitos pertenecientes a los órdenes Xylariales, Sordariales y Diaporthales.

Al igual que Impullitti y Malvick (2013), nuestros resultados mostraron que en todas las variedades estudiadas el mayor número de especies de hongos como la mayoría de aislamientos se obtuvieron a partir de los tallos. Por otra parte, Pimentel et al. (2006) observaron que el mayor número de aislamientos en soja se encontró en las hojas.

En esta investigación la comparación entre las poblaciones de hongos endófitos y el número de aislamientos obtenidos en hojas, tallos y raíces de diferentes variedades en las plantas de maíz y soja reveló una tendencia de ciertas especies de hongos para colonizar diferentes regiones de la planta, como así también una mayor tendencia para colonizar ciertas variedades. En soja, se aislaron los géneros $A$. alternata y Curvularia sp. coincidiendo con los resultados de Larran et al. (2002 b) y Leite et al. (2013). En tanto Aspergillus sp. y Fusarium sp. también fueron identificados como endófitos (Pimentel et al. 2006; Leite et al. 2013). Fernandes et al. (2015), identificaron especies de Chaetomiun sp., F. oxysporum y M. phaseolina. En esta tesis, en tallos de soja se identificaron especies de A. alternata, Fusarium sp. y Trichoderma $s p$. Estos resultados coinciden con los hallazgos de Impullitti y Malvick (2013). En este estudio se aislaron especies de Aspergillus sp. y Penicillium sp en tallo. En raíces, se obtuvieron mayormente aislamientos de Alternaria sp. y Fusarium $s p .$, un hallazgo que coincide con los resultados de Fernandes et al. (2015).

El caso de Fusarium spp. es particularmente interesante porque muchas cepas fueron encontradas con frecuencia como endófitos de diferentes plantas (Gotz et al. 2006; Sun et al. 2014). Especies de Fusarium se han aislado de diversas partes de la planta de soja (Roy et al. 2000; Pimentel et al. 2006; Impullitti y Malvick, 2013; Kumar y Kaushik, 2013; Leite et al. 2013; Rathod y Pawar, 2013; Fernandes et al. 2015). Sin embargo, en ningún caso se determinó si estos aislamientos son patógenos, inocuos o beneficiosos para la planta.

Según Implullitti y Malvick (2013) y Fernandes et al. (2015) géneros tales como, Cladosporium, Diaporthe y Phoma fueron muy representativos entre sus aislamientos, mientras en este estudio, en coincidencia con el llevado a cabo por Pimentel et al. (2006) S. brevicaulis fue aislado de tallos. Sólo una especie del Phylum Zygomycota (Mucor mucedo L. (Mucorales: Mucoraceae) fue aislada en este estudio, también encontrada como endófito en plantas de Tripterygium wilfordii Hook (Celastrales: Celastraceae) (Kumar y Hyde, 2004). 
En maíz, este estudio concuerda con los realizados por Fisher et al. (1992) y Nur (2013) quienes entre los aislamientos de hongos endófitos de raíz encontraron especies de Fusarium, Aspergillus, Penicillium y Trichoderma, mientras que en tallos y hojas aislaron frecuentemente A. alternata, F. graminearum y Trichoderma sp.

Las especies de hongos endófitos detectados en las plantas pueden estar influenciadas por varios factores, haciendo a veces difícil establecer una relación directa entre los hongos aislados y los descriptos en otros estudios, incluyendo el tipo de órgano de la muestra, las variedades, el clima en el que crecieron las plantas, si las plantas se cultivaron en un monocultivo o policultivo, edad de la planta, la historia de cultivos del campo, el número de muestras, el estado nutricional y la cantidad de agua de la planta (Fernandes et al. 2015).

Fisher et al. (1992) detectó que la menor incidencia de infección y colonización fúngica en algunos órganos de la planta (como ser en hojas y raíces) podía deberse probablemente a que estas partes de las plantas tenían una mayor densidad de bacterias, las cuales podrían inhibir la colonización fúngica. Mayor número de hongos endófitos como en los tallos, también se observaron en estudios de soja en Brasil (Pimentel et al. 2006). Estos estudios también sugieren que los endófitos pueden colonizar exclusivamente ciertos tejidos, por ejemplo, Colletotrichum sp. solamente pudo ser aislada a partir de hojas de soja y no de los tallos de las plántulas de soja cultivadas en Brasil. En este estudio, F. equiseti solamente fue aislado de las hojas en plantas de soja y $S$. brevicaulis sólo a partir de tallos.

Los hongos endófitos pueden ser organismos importantes para la mejora de la producción sustentable de cultivos, aunque sus identidades y funciones en una amplia gama de plantas están comenzando a ser reveladas. En el futuro deberían llevarse a cabo más investigaciones para determinar cuál de estos hongos endófitos naturales podría ser utilizado para la promoción del crecimiento de las plantas y para el control biológico, aumentando la resistencia a la herbivoría a través de la producción de alcaloides y/o micotoxinas. 


\section{CAPÍTULO II}

Evaluación de distintas técnicas de inoculación de hongos entomopatógenos en plantas de maíz y soja bajo condiciones de laboratorio 


\section{Introducción}

Los hongos entomopatógenos son utilizados como agentes de control biológico en todo el mundo y han sido objeto de intensa investigación desde hace más de 100 años (Vega et al. 2012). Si bien, la mayoría de las investigaciones con respecto al uso de estos hongos se han centrado en el desarrollo de métodos inundativos, el descubrimiento de su comportamiento endofítico demuestra que la ecología de estos microorganismos se extiende más allá de la interacción hongo-insecto y plantea un nuevo enfoque para el uso de los hongos entomopatógenos en la agricultura (Vega et al. 2009; Roy et al. 2010).

B. bassiana, M. anisopliae, M. robertsii, L. lecanii y T. cylindrosporum son ampliamente conocidos a nivel mundial como hongos entomopatógenos y como endófitos pueden vivir dentro de las plantas, sin causar, en general, daño evidente para el huésped (Van Bael et al. 2005). Tanto B. bassiana, M. anisopliae, L. lecanii y T. cylindrosporum se han aislado como endófitos naturales en diferentes especies vegetales (Vega et al. 2008; Sánchez Márquez et al. 2010; Miles et al. 2012; Sánchez Márquez et al. 2012, Quesada-Moraga et al. 2014), mientras que B. bassiana, $M$. anisopliae, M. robertsii, $L$. lecanii y $T$. cylindrosporum han sido inoculadas artificialmente utilizando suspensiones concentradas de conidios a través diferentes técnicas (Vega, 2008; Quesada-Moraga et al. 2014), demostrado así, el éxito de su capacidad endofítica (Wagner y Lewis, 2000; Gomez-Vidal et al. 2006; QuesadaMoraga et al. 2006; Ownleyet al. 2008; Tefera y Vidal, 2009; Biswas et al. 2012).

$B$. bassiana es el hongo entomopatógeno mejor estudiado y hasta la fecha se ha introducido como endófito en diferentes especies vegetales como café (Coffea arabica L. (Gentianales: Rubiaceae)), yute (Corchorus olitorius L. (Malvales: Malvaceae)), banana (Musa sp.), adormidera (Papaver somniferum L. (Ranunculales: Papaveraceae)), palmera (Phoenix dactylifera L. (Arecales: Arecaceae)), pino (Pinus radiata Don. (Pinales: Pinaceae)), sorgo (Sorghum bicolor L. (Poales: Poaceae)), cacao (Theobroma cacao L. (Malvales: Malvaceae)), maíz (Z. mays), tomate, (Solanun lycopersicum L. (Solanales: Solanaceae)) y judía (Phaseolus vulgaris L. (Fabales: Fabaceae)) (Leckie, 2002; Ownley et al. 2004; Posada y Vega, 2005, 2006; GómezVidal et al. 2006, 2009; Quesada-Moraga et al. 2006; Akello et al. 2007; Gurulingappa et al. 2010; Brownbridge et al. 2012; Parsa et al. 2013). En tanto M. anisopliae, fue introducido endofiticamente en S. lycopersicum (García et al. 2011). M. 
robertsii en Panicum virgatum L. (Poales: Poaceae) y P. vulgaris (Sasan y Bidochka 2012). L. lecanii, fue inoculado en plantas de Gossypium hirsutum L. (Malvales: Malvaceae) (Anderson et al. 2007) y T. cylindrosporum en S. lycopersicum y $P$. vulgaris (Herrero et al. 2012).

El objetivo de este ensayo fue determinar si los hongos entomopatógenos $B$. bassiana, M. anisopliae, $M$. robertsii, L. lecanii y $T$. cylindrosporum pueden establecerse como microorganismos endófitos en plantas de maíz y soja mediante diferentes técnicas de inoculación: aspersión en hoja, inmersión de raíz e inmersión de semilla, y así determinar que técnica de inoculación es la más efectiva para cada especie vegetal. 


\section{Materiales y Métodos}

\section{Preparación del inóculo}

Para este ensayo fueron utilizados aislamientos fúngicos provenientes de la Colección Micológica del Instituto Carlos Spegazzini (LPSC), La Plata, Buenos Aires, Argentina. Los aislamiento fúngicos utilizados fueron los siguientes: $B$. bassiana LPSc 902, LPSc 1060, LPSc 1061, LPSc 1062, LPSc 1063, LPSC 1066, LPSc 1067, LPSc 1080, LPSc 1081, LPSc 1082, LPSc 1083, LPSc 1086, LPSc 1098, LPSc 1156; M. anisopliae LPSc 907; M. robertsii LPSc 963; L. lecanii LPSc 1035, LPSc 1069 y LPSc 1070; T. cylindrosporum LPSc 1065. Estas cepas fueron seleccionadas debido a su comprobada eficacia contra insectos plaga y a sus altos valores de actividad enzimática (proteolítica, quitinolítica y lipolítica) de acuerdo a los trabajos llevados a cabo por Pelizza et al.(2012 a, b).

Para obtener la suspensión de conidios, las diferentes cepas de cada especie se cultivaron en cajas de Petri con agar papa dextrosa (APG) (Britania ${ }^{\circledR}$ ) y se mantuvieron a $25^{\circ} \mathrm{C}$ en la oscuridad. Luego de 15 días, se obtuvieron los conidios raspando la superficie de las cajas y se colocaron en $10 \mathrm{ml}$ de Tween 80 (polyoxyethylene sorbitan monolaurate) $\left(\right.$ Merck $^{\circledR}$ ) al 0,01 \% (v/v). La suspensión se filtro a través de varias capas de gasas para eliminar restos de hifas y para homogeneizarla se la agitó durante 10 minutos. La concentración de conidios se determinó utilizando una cámara de Neubauer y se ajustó a 1 x $10^{8}$ conidios $/ \mathrm{ml}$ según Gurulingappa et al. (2010). 


\section{Plantas}

Las semillas utilizadas en este ensayo fueron obtenidas de productores agrícolas de la zona de estudio, correspondieron a la variedad DM3810 de soja y al híbrido DK747 de maíz.

La superficie de las semillas de ambas especies utilizadas para cada una de las técnicas de inoculación probada, fue esterilizada mediante la inmersión en una solución de alcohol 70 \% durante 2 minutos y luego lavadas 2 veces con agua estéril. Posteriormente fueron colocadas durante 24 horas en agua destilada estéril (Brownbridge et al. 2012).

\section{Preparación del sustrato}

El sustrato utilizado consistió en una mezcla de tierra-perlita-vermiculita en partes iguales (1:1:1). Este sustrato, luego de preparado, fue tindalizado en autoclave durante períodos de una hora, con intervalos de 24 h en 3 días consecutivos.

Las semillas de cada uno de los cultivos fueron sembradas en macetas de plástico de $330 \mathrm{~cm}^{3}$ de volumen con dicho sustrato.

\section{Inoculación}

Se probaron tres métodos de inoculación en cada una de las especies: aspersión en hoja, inmersión de raíz e inmersión de semillas. Para cada una de estas técnicas se hicieron 10 repeticiones con 10 plantas testigo. Se sembraron 4 semillas por maceta y se descartaron 3 plantas después de la germinación.

Las plantas (Figura II.1) se mantuvieron en invernáculo a $25^{\circ} \mathrm{C}$ y $12 \mathrm{~h}(\mathrm{~L}: \mathrm{O}) \mathrm{de}$ fotoperíodo y fueron regadas cuando lo requirieron. 


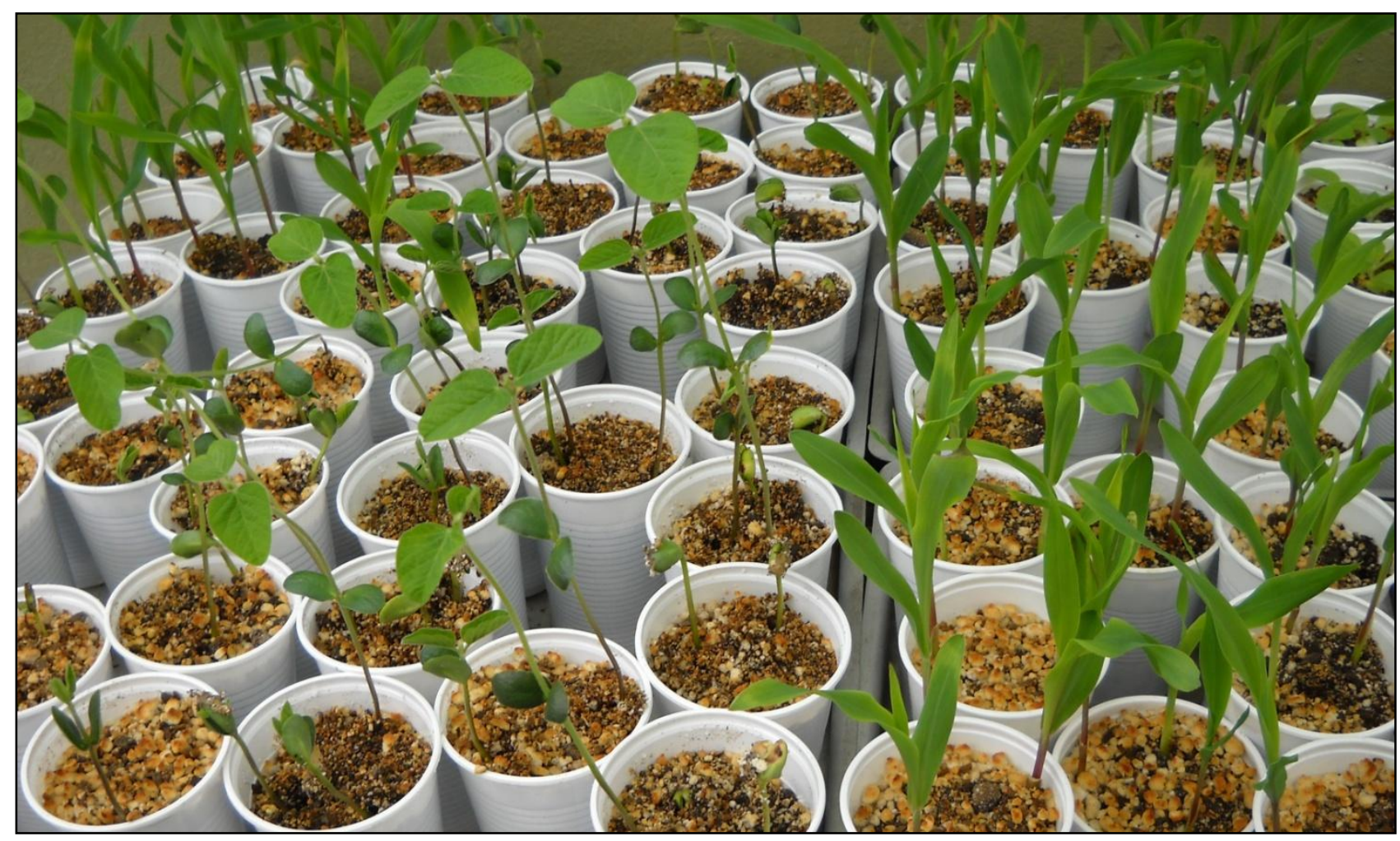

Figura II.1. Plantas de maíz y soja

\section{Técnicas de inoculación}

\section{Aspersión en hojas}

Las plántulas de soja fueron inoculadas a las 2 semanas de edad, momento en el cual presentaban 4 hojas verdaderas, mientras que las de maíz se inocularon a las 2 semanas de edad, cuando presentaron 2 hojas verdaderas.

El suelo de cada una de las macetas fue cubierto con papel de aluminio para evitar el escurrimiento de los conidios (Tefera y Vidal, 2009). Para esta técnica se utilizó un atomizador manual con el cual se pulverizaron $2 \mathrm{ml}$ de suspensión de conidios por planta (Figuras II.2a, 3a), rociando la superficie de todas las hojas. Las plantas controles fueron pulverizadas de la misma manera con una solución de agua estéril con $2 \mathrm{ml}$ Tween 80 al 0,01\% (v/v), libre de conidios.

\section{Inmersión de raíz}

Tanto las plantas de maíz como las de soja fueron inoculadas con esta técnica a las 3 semanas posteriores a la siembra, transcurrido ese lapso de tiempo cada planta 
fue retirada de la maceta, se enjuagó 3 veces con agua destilada estéril, se cortaron los extremos de las raíces para obtener una mejor absorción y luego fueron colocadas individualmente en tubos de ensayo con $2 \mathrm{ml}$ de suspensión de conidios $\left(1 \times 10^{8}\right.$ conidios/ml) (Figuras II.2b, 3b). De esta manera las raíces de todas las plantas quedaron totalmente sumergidas. Los controles fueron colocados de la misma manera pero se sumergieron en una solución de Tween 80 al 0,01\%. Finalmente se cubrió cada tubo con papel de aluminio y se dejaron durante $24 \mathrm{~h}$ a $25^{\circ} \mathrm{C}, 12 \mathrm{~h}$ (L: O) de fotoperíodo en cámara de cría (Semedic, I-219PF). Luego las plantas tratadas y las controles fueron colocadas sobre papel de filtro estéril hasta que se escurrieran completamente y se plantaron en las mismas macetas en las que se encontraban creciendo previamente.

\section{Inmersión de semillas}

Ciento veinte semillas de cada una de las especies de plantas estudiadas se colocaron dentro de una caja de Petri y se sumergieron en $120 \mathrm{ml}$ de una suspensión de $1 \times 10^{8}$ conidios/ml (Figuras II.2c, 3c). Las semillas utilizadas para las plantas control se sumergieron en una solución de agua estéril con tween 80 al 0,01\%. Tanto las semillas tratadas como las control se matuvieron en estas condiciones durante 24 $\mathrm{h}$ a $25^{\circ} \mathrm{C}, 12 \mathrm{~h}$ (L: O) de fotoperíodo en cámara de cría. Transcurrido este lapso de tiempo se escurrieron sobre un papel de filtro estéril durante $30 \mathrm{~min}$. (Tefera y Vidal, 2009) y se sembraron en macetas a $4 \mathrm{~cm}$ de profundidad que se mantuvieron en invernáculo a $25^{\circ} \mathrm{C}$ con un fotoperíodo de $12 \mathrm{~h}$. 

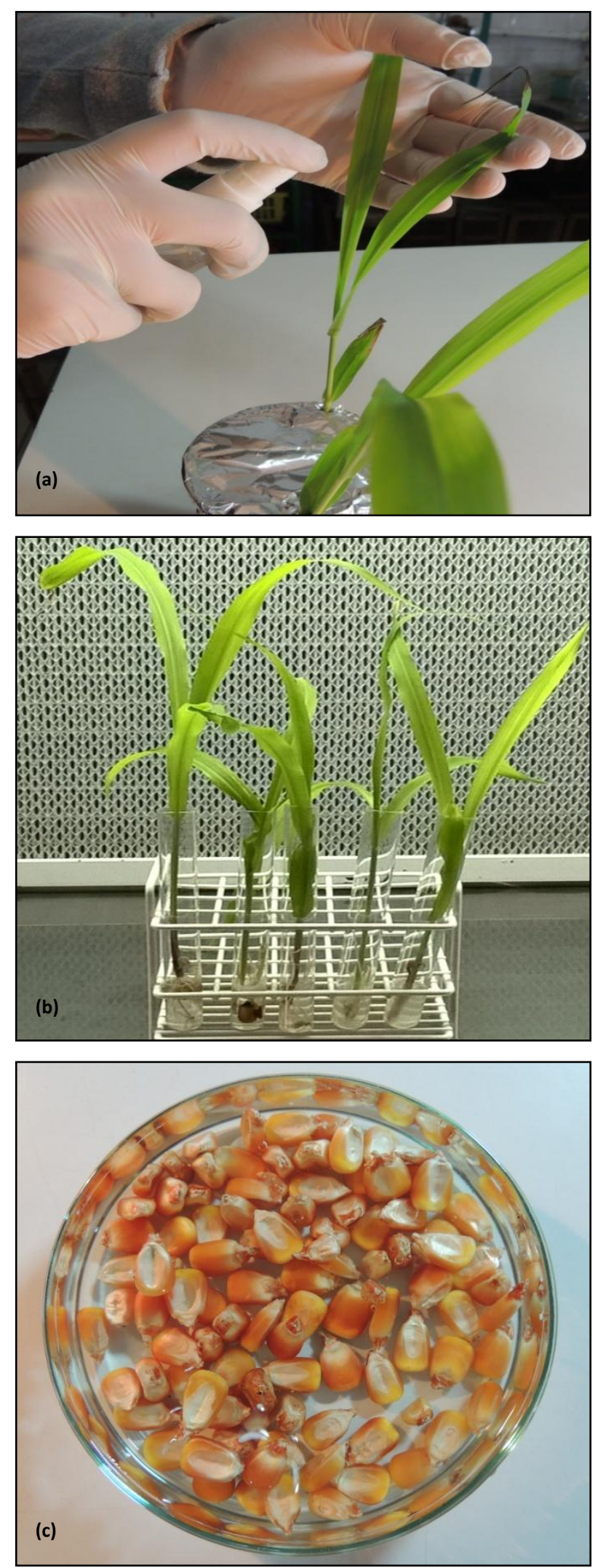

Figura II.2. Técnicas de inoculación en maíz: a) Aspersión en hoja, b) Inmersión de raíz, c) Inmersión de semilla. 

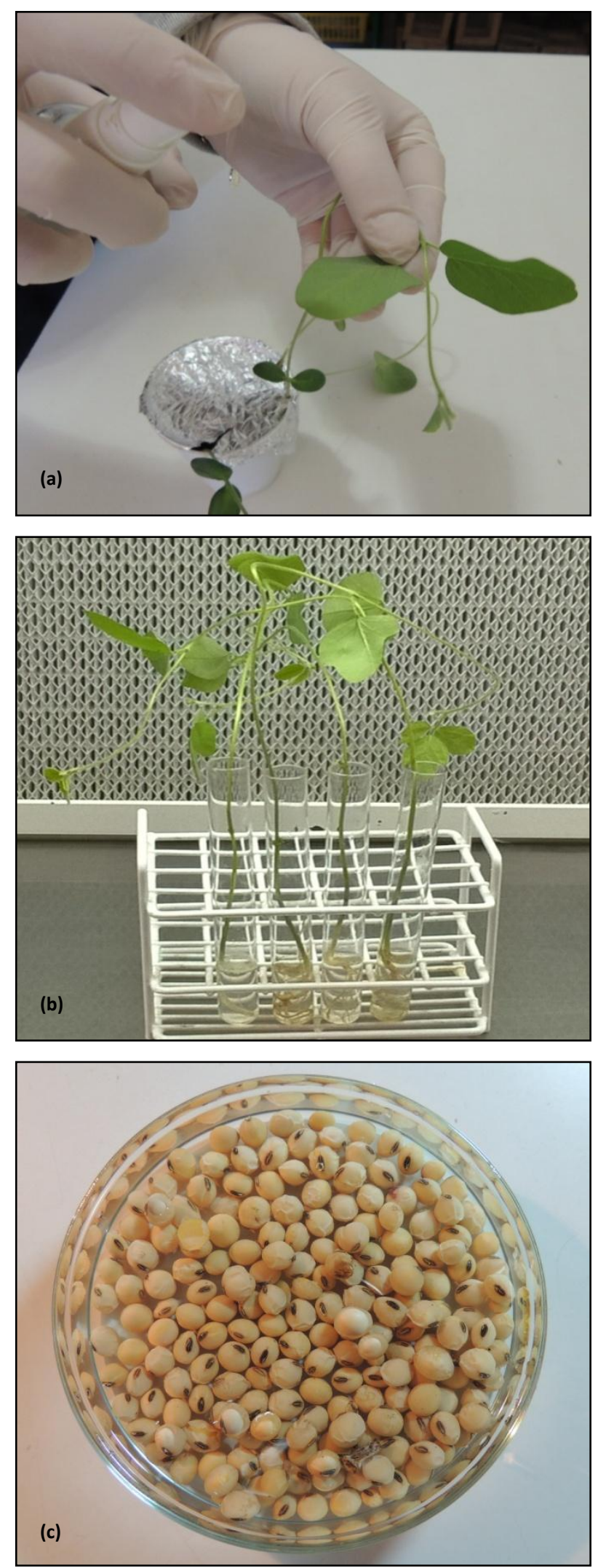

Figura II.3. Técnicas de inoculación en soja: a) Aspersión en hoja, b) Inmersión de raíz, c) Inmersión de semilla. 


\section{Re-aislamiento del hongo}

La colonización de las plantas por las diferentes cepas de hongos se evaluó a los 7, 14, 21 y 28 días posteriores a la inoculación para las técnicas de inmersión de raíz y aspersión en hojas, mientras que los resultados de la técnica de inmersión de semillas fueron evaluados luego de tres semanas posteriores a la siembra de las mismas.

Para cada técnica se utilizaron 10 plantas por fecha y 10 plantas testigo, cada una se separó en raíz, tallo y hoja, se esterilizaron en superficie por inmersión sucesiva en alcohol $70 \%$ durante 2 minutos, en hipoclorito de sodio (lavandina comercial $55 \mathrm{~g} \mathrm{Cl} / \mathrm{L}$ ) durante 2 minutos y finalmente se enjuagaron 2 veces con agua destilada estéril y la eficacia de la esterilización se evaluó pipeteando alícuotas del enjuague final y sembrándolo en medio de cultivo sólido (Posada y vega, 2005; Tefera y Vidal, 2009; Parsa et al. 2013; Vidal y Jaber, 2015 y Greenfield et al. 2016). Cada órgano de la planta se cortó con bisturí estéril en segmentos de $1 \times 1 \mathrm{~cm}$, los cuales se colocaron en cajas de Petri (6 segmentos por caja) con $20 \mathrm{ml}$ de APG y $2 \mathrm{ml}$ de antibiótico (0,5g estreptomicina-0,25g cloranfenicol) (Vega et al. 2008). Todas las cajas se colocaron en estufa a $25^{\circ} \mathrm{C}$ y se evaluaron pasados los 10 días.

Se examinaron 120 plantas y 2160 fragmentos de plantas por cada cepa inoculada, evaluándose en total 2400 plantas y 43200 fragmentos. Esto se repitió tanto para maíz como para soja.

\section{Análisis de datos}

Los datos fueron expresados como frecuencias de colonización: frecuencia de colonización $=$ (número de fragmentos de plantas colonizadas / número total de fragmentos de plantas) x 100 (Tefera y Vidal, 2009).

Las diferencias entre las técnicas de inoculación, los órganos de las plantas, el tiempo y la frecuencia de colonización para las distintas cepas de hongos fueron analizadas por medio de un Análisis de la Varianza (ANOVA) de tres vías y sus medias fueron comparadas por medio de un test de Tukey $(p<0,05)$ utilizando el programa InfoStat versión 2004. Los valores porcentuales fueron transformados a arcoseno para estabilizar la varianza. 


\section{Resultados}

Tanto en maíz como en soja, no se registró crecimiento de ninguna de las especies de hongos entomopatógenos en los controles no inoculados (datos no mostrados). El método de esterilización resultó ser eficaz ya que no se observó crecimiento de ninguna de las cepas probadas al sembrar el último enjuague de la esterilización y las técnicas de inmersión de semila e inmersión de raíz no redujeron la germinación de las semilas o el crecimiento de las plántulas y tampoco se observaron raíces enfermas (datos observados y no mostrados). Todas las técnicas de inoculación utilizadas lograron introducir con éxito a todas las cepas de $B$. bassiana en las dos especies de plantas estudiadas. M. anisopliae y M. robertsii pudieron establecerse en las plantas excepto mediante la técnica de inmersión de semilla, mientras que las tres cepas de $L$. lecanii y la cepa de $T$. cylindrosporum no fueron capaces de establecerse en maíz y soja a través de ninguna de las técnicas estudiadas.

El análisis estadístico realizado para cada cepa mostró diferencias significativas $(p<0,0001)$ en cuanto a la eficacia entre las diferentes técnicas de inoculación, como así también en las interacciones triples, demostrando que los tres factores (técnica, órgano y tiempo) son importantes en la recuperación de cada cepa fúngica (Tablas II.1, 2). 
Tabla II.1. Resultado de análisis de la varianza (ANOVA) en maíz

\begin{tabular}{|c|c|c|c|c|}
\hline & Maíz & $\mathbf{F}$ & df & $\mathbf{p}$ \\
\hline \multirow{7}{*}{$\begin{array}{l}\text { B. bassiana } \\
1098\end{array}$} & Técnica & 1169,98 & 2 & $<0,0001$ \\
\hline & Órgano & 54,25 & 2 & $<0,0001$ \\
\hline & Tiempo & 386,28 & 3 & $<0,0001$ \\
\hline & técnica*órgano & 290,46 & 4 & $<0,0001$ \\
\hline & técnica*tiempo & 20,07 & 6 & $<0,0001$ \\
\hline & órgano*tiempo & 25,96 & 6 & $<0,0001$ \\
\hline & técnica*órgano*tiempo & 10,08 & 12 & $<0,0001$ \\
\hline \multirow{8}{*}{$\begin{array}{l}\text { B. bassiana } \\
1086\end{array}$} & Maíz & $\mathbf{F}$ & df & $\mathbf{p}$ \\
\hline & Técnica & 114,07 & 2 & $<0,0001$ \\
\hline & Órgano & 2,99 & 2 & 0,0515 \\
\hline & Tiempo & 101,21 & 3 & $<0,0001$ \\
\hline & técnica*órgano & 22,71 & 4 & $<0,0001$ \\
\hline & técnica*tiempo & 31,93 & 6 & $<0,0001$ \\
\hline & órgano*tiempo & 1,59 & 6 & 0,1481 \\
\hline & técnica*órgano*tiempo & 4,25 & 12 & $<0,0001$ \\
\hline \multirow{8}{*}{$\begin{array}{l}\text { B. bassiana } \\
1063\end{array}$} & Maíz & $\mathbf{F}$ & df & $\mathbf{p}$ \\
\hline & Técnica & 295,28 & 2 & $<0,0001$ \\
\hline & Órgano & 19,86 & 2 & $<0,0001$ \\
\hline & Tiempo & 615,88 & 3 & $<0,0001$ \\
\hline & técnica*órgano & 294,55 & 4 & $<0,0001$ \\
\hline & técnica*tiempo & 59,73 & 6 & $<0,0001$ \\
\hline & órgano*tiempo & 32,17 & 6 & $<0,0001$ \\
\hline & técnica*órgano*tiempo & 63,89 & 12 & $<0,0001$ \\
\hline \multirow{8}{*}{$\begin{array}{l}\text { B. bassiana } \\
1156\end{array}$} & Maíz & $\mathbf{F}$ & df & $p$ \\
\hline & Técnica & 47,71 & 2 & $<0,0001$ \\
\hline & Órgano & 5,24 & 2 & 0,0057 \\
\hline & Tiempo & 163,1 & 3 & $<0,0001$ \\
\hline & técnica*órgano & 59,08 & 4 & $<0,0001$ \\
\hline & técnica*tiempo & 4,87 & 6 & 0,0001 \\
\hline & órgano*tiempo & 2,15 & 6 & 0,0472 \\
\hline & técnica*órgano*tiempo & 7,81 & 12 & $<0,0001$ \\
\hline \multirow{8}{*}{$\begin{array}{l}\text { B. bassiana } \\
1061\end{array}$} & Maíz & $\mathbf{F}$ & df & $p$ \\
\hline & Técnica & 27,63 & 2 & $<0,0001$ \\
\hline & Órgano & 6,45 & 2 & 0,0018 \\
\hline & Tiempo & 242,91 & 3 & $<0,0001$ \\
\hline & técnica*órgano & 45,92 & 4 & $<0,0001$ \\
\hline & técnica*tiempo & 7,58 & 6 & $<0,0001$ \\
\hline & órgano*tiempo & 8,42 & 6 & $<0,0001$ \\
\hline & técnica*órgano*tiempo & 8,02 & 12 & $<0,0001$ \\
\hline \multirow{8}{*}{$\begin{array}{l}\text { B. bassiana } \\
1082\end{array}$} & Maíz & $\mathbf{F}$ & df & $p$ \\
\hline & Técnica & 78,19 & 2 & $<0,0001$ \\
\hline & Órgano & 2,04 & 2 & 0,1315 \\
\hline & Tiempo & 151,16 & 3 & $<0,0001$ \\
\hline & técnica*órgano & 36,22 & 4 & $<0,0001$ \\
\hline & técnica*tiempo & 5,11 & 6 & $<0,0001$ \\
\hline & órgano*tiempo & 4,18 & 6 & 0,0005 \\
\hline & técnica*órgano*tiempo & 2,72 & 12 & 0,0016 \\
\hline \multirow{8}{*}{$\begin{array}{l}\text { B. bassiana } \\
1081\end{array}$} & Maíz & $\mathbf{F}$ & df & $p$ \\
\hline & Técnica & 65,9 & 2 & $<0,0001$ \\
\hline & Órgano & 1,3 & 2 & 0,2734 \\
\hline & Tiempo & 168,19 & 3 & $<0,0001$ \\
\hline & técnica*órgano & 29,28 & 4 & $<0,0001$ \\
\hline & técnica*tiempo & 3,1 & 6 & 0,0057 \\
\hline & órgano*tiempo & 3,22 & 6 & 0,0044 \\
\hline & técnica*órgano*tiempo & 2,98 & 12 & 0,0006 \\
\hline \multirow{8}{*}{$\begin{array}{l}\text { M. anisopliae } \\
907\end{array}$} & Maíz & $\mathbf{F}$ & df & $p$ \\
\hline & Técnica & 570,7 & 2 & $<0,0001$ \\
\hline & Órgano & 14,59 & 2 & $<0,0001$ \\
\hline & Tiempo & 446,71 & 3 & $<0,0001$ \\
\hline & técnica*órgano & 281,92 & 4 & $<0,0001$ \\
\hline & técnica*tiempo & 112,37 & 6 & $<0,0001$ \\
\hline & órgano*tiempo & 17,19 & 6 & $<0,0001$ \\
\hline & técnica*órgano*tiempo & 35,42 & 12 & $<0,0001$ \\
\hline
\end{tabular}

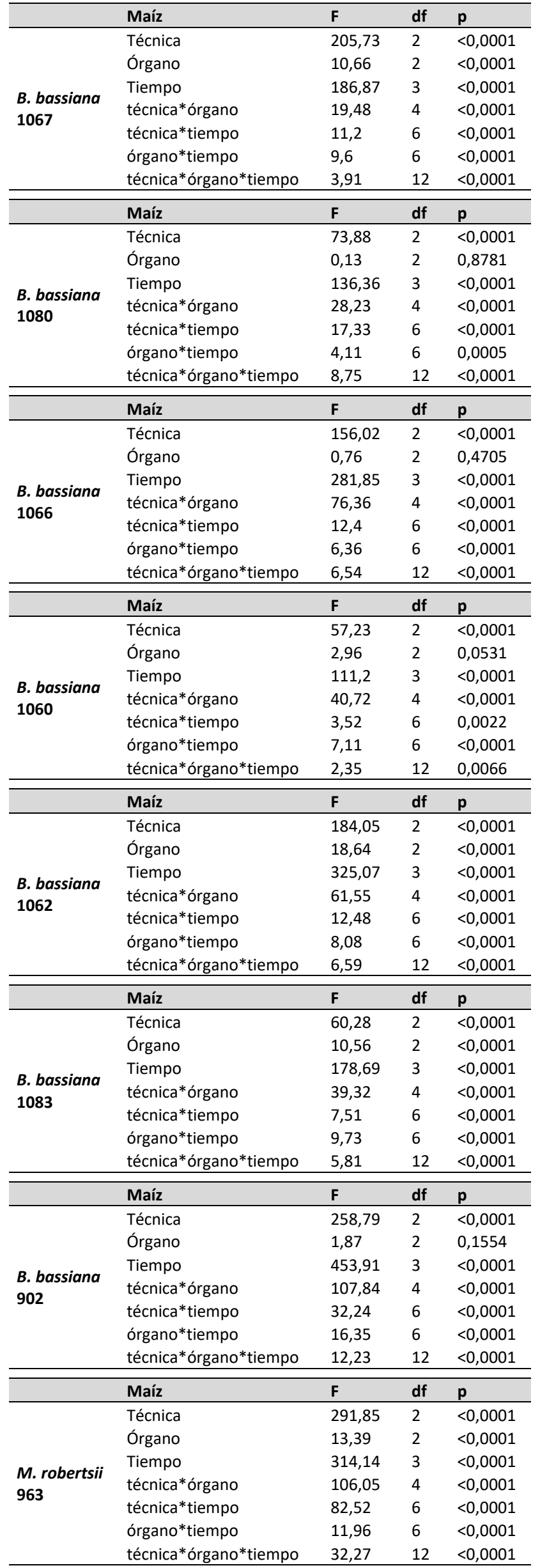


Tabla II.2. Resultado de análisis de la varianza (ANOVA) en soja

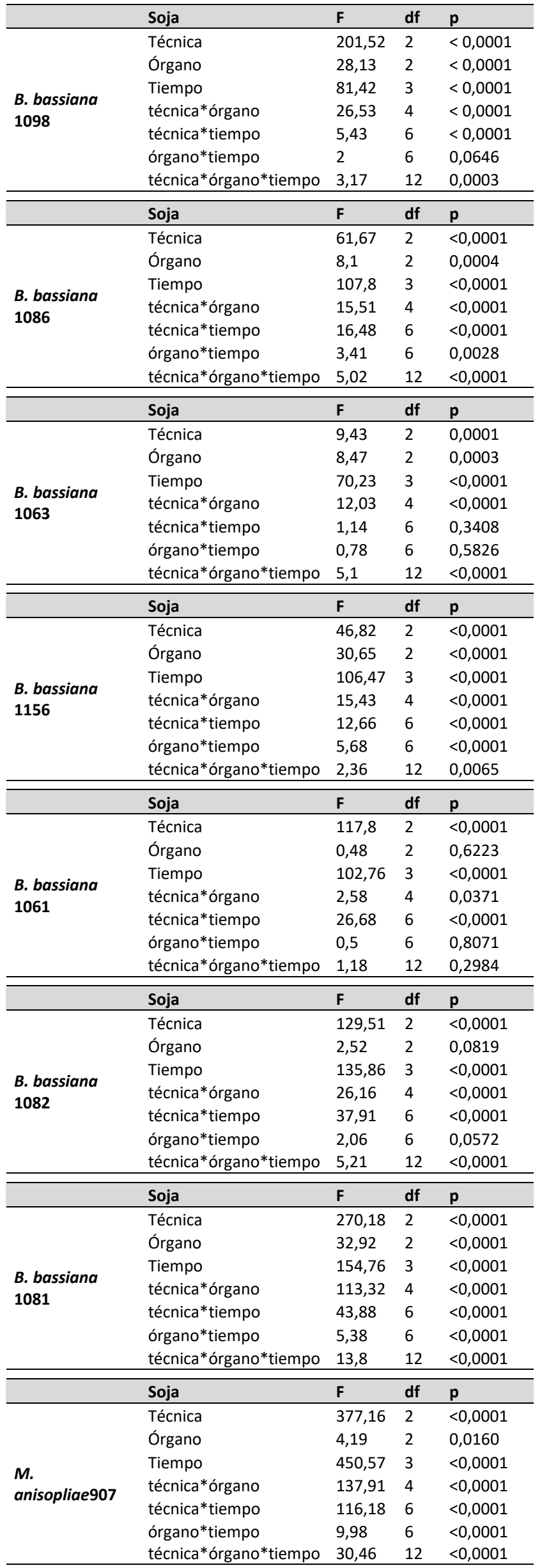

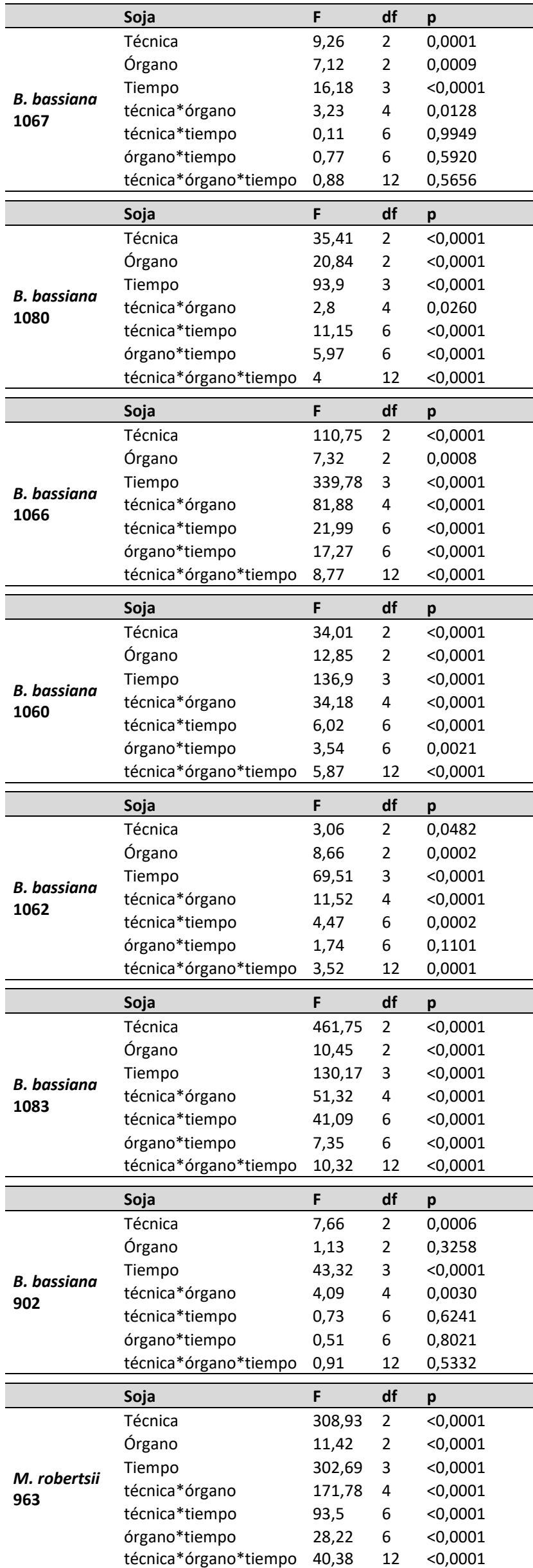




\section{Aspersión en hoja}

En maíz y soja todas las plantas inoculadas fueron colonizadas por todas las cepas de $B$. bassiana, y por la cepa 907 de M. anisopliae y la 963 de M. robertsii.

El mayor número de aislamientos se obtuvo a partir de las hojas a los 7 días posteriores a la inoculación, observándose, en general, una disminución significativa en el porcentaje de fragmentos colonizados a través del tiempo en ambas especies vegetales.

Se pudo demostrar claramente que la cepa de $B$. bassiana LPSc 1098 fue la más exitosa ya que a los 7 días la recuperación en las hojas de soja fue del $100 \%$ (Figura II.20). En lo que respecta a las plantas de maíz la recuperación del 100\% también pudo lograrse a los 7 días, no registrándose diferencias significativasa los 14, 21 y 28 días (Figura II.4). En los tallos de las plántulas de maíz y soja se pudo recuperar esta cepa fúngica en el $90 \%$ de los casos a los 7 días, resultados que no pudieron obtenerse con ninguna de las otras cepas estudiadas. Por otro lado, se observó que en soja la cepa $B$. bassiana LPSc 1081 (Figura II.32) no pudo recuperarse de las raíces en ninguno de los tiempos analizados.

El establecimiento de las tres especies de hongos como endófito en raíces, tallo y hojas mostró una disminución significativa en el porcentaje de colonización a través del tiempo.

Tanto para maíz como para soja, las dos especies de Metarhizium fueron reaisladas de cada uno de los órganos analizados, observándose tasas de colonización que no superaron el $60 \%, 40 \%$ y $16 \%$ en hojas, tallos y raíces respectivamente (Figuras II.18, 19, 34, 35), mostrando una menor colonización cuando se las compara con las obtenidas para $B$. bassiana. 


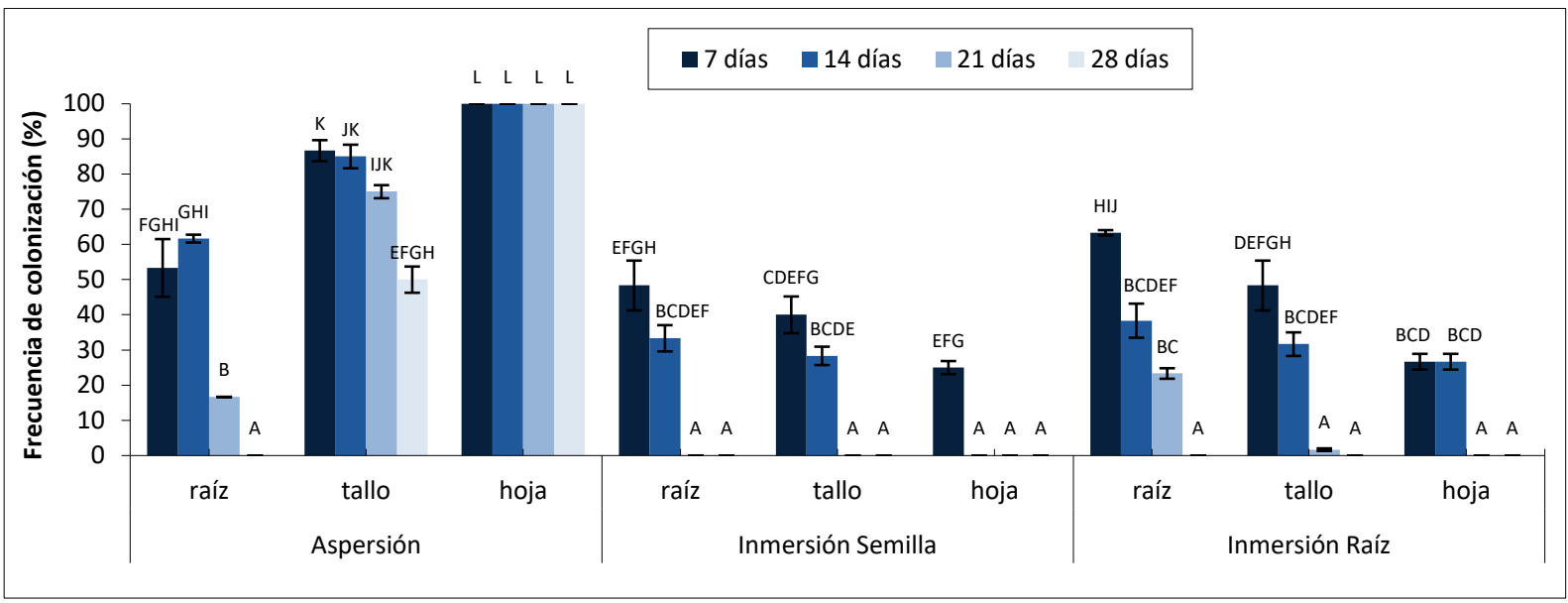

Figura II.4. Porcentaje de recuperación de B. bassiana LPSc 1098 en raíz, tallo y hoja; con diferentes técnicas de inoculación en plantas de maíz. Letras distintas indican diferencias significativas de acuerdo a test de Tukey $(p<0,05)$. Las barras indican el error estándar de la media.

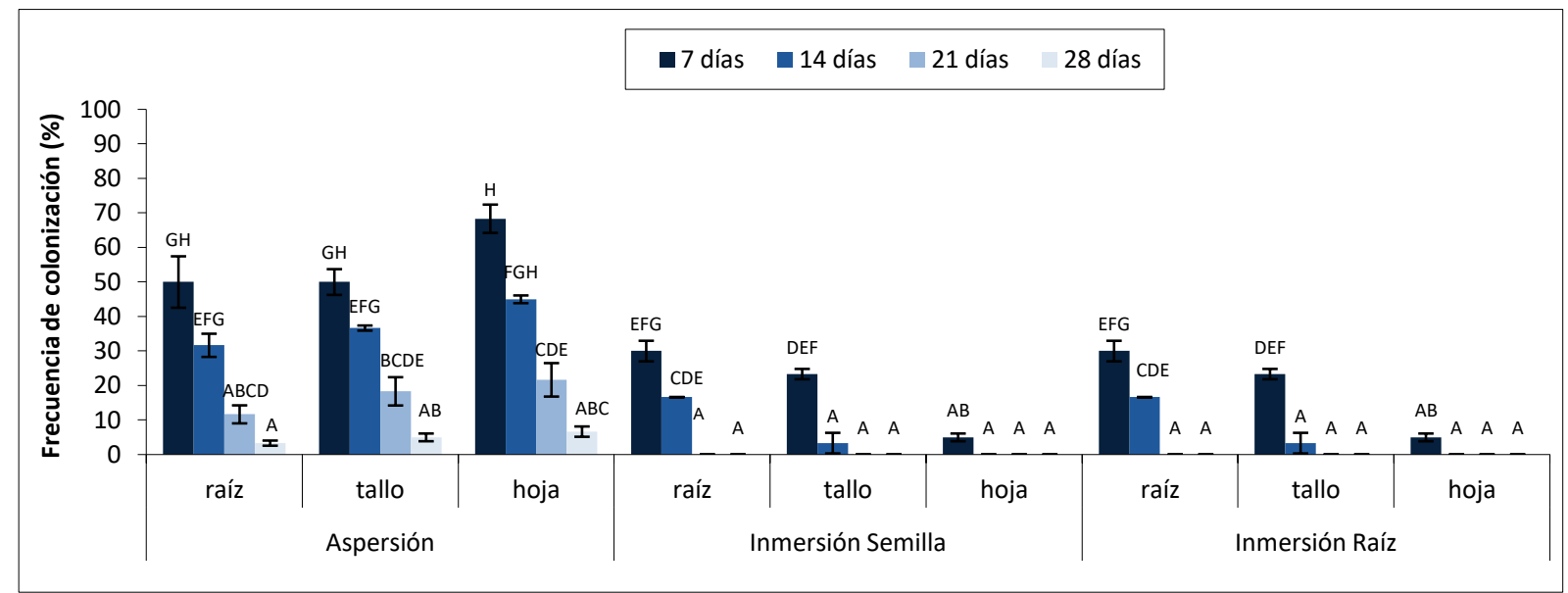

Figura II.5. Porcentaje de recuperación de B. bassiana LPSc 1067 en raíz, tallo y hoja; con diferentes técnicas de inoculación en plantas de maíz. Letras distintas indican diferencias significativas de acuerdo a test de Tukey $(p<0,05)$. Las barras indican el error estándar de la media.

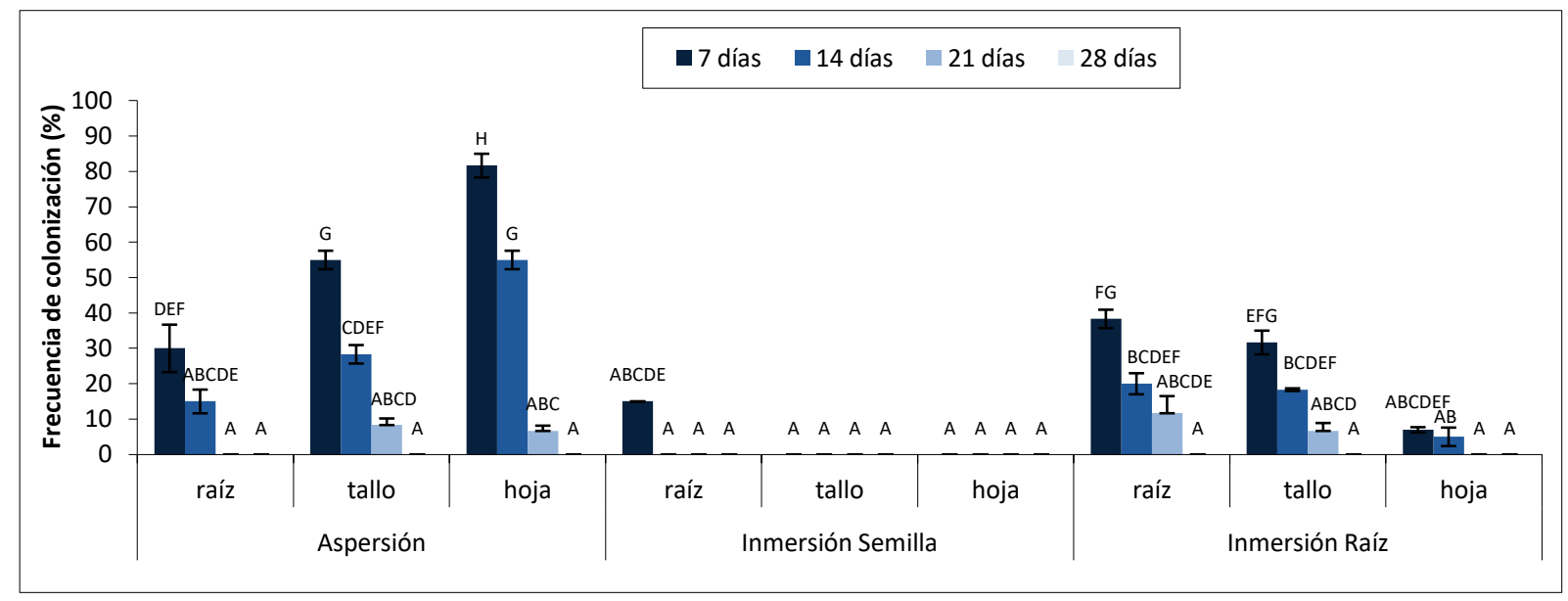

Figura II.6. Porcentaje de recuperación de B. bassiana LPSc 1086 en raíz, tallo y hoja; con diferentes técnicas de inoculación en plantas de maíz.Letras distintas indican diferencias significativas de acuerdo a test de Tukey $(p<0,05)$. Las barras indican el error estándar de la media. 


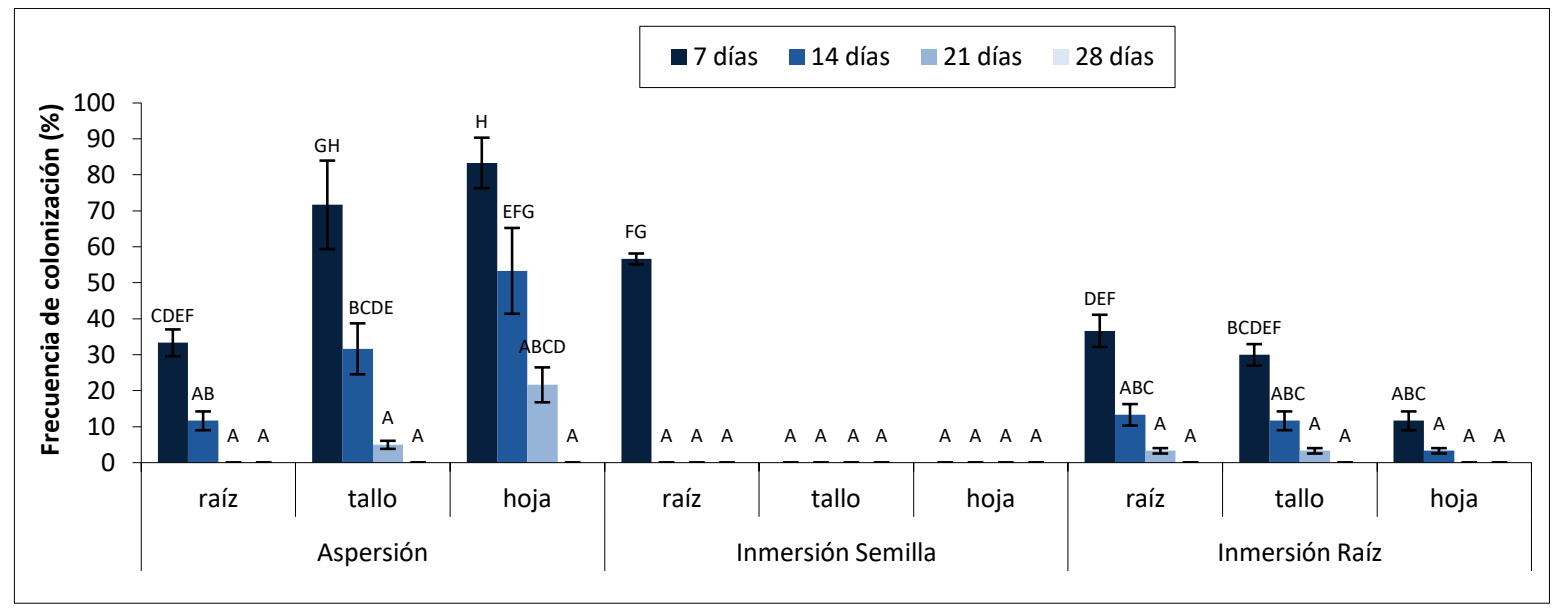

Figura II.7. Porcentaje de recuperación de B. bassiana LPSc 1080 en raíz, tallo y hoja; con diferentes técnicas de inoculación en plantas de maíz. Letras distintas indican diferencias significativas de acuerdo a test de Tukey $(p<0,05)$. Las barras indican el error estándar de la media.

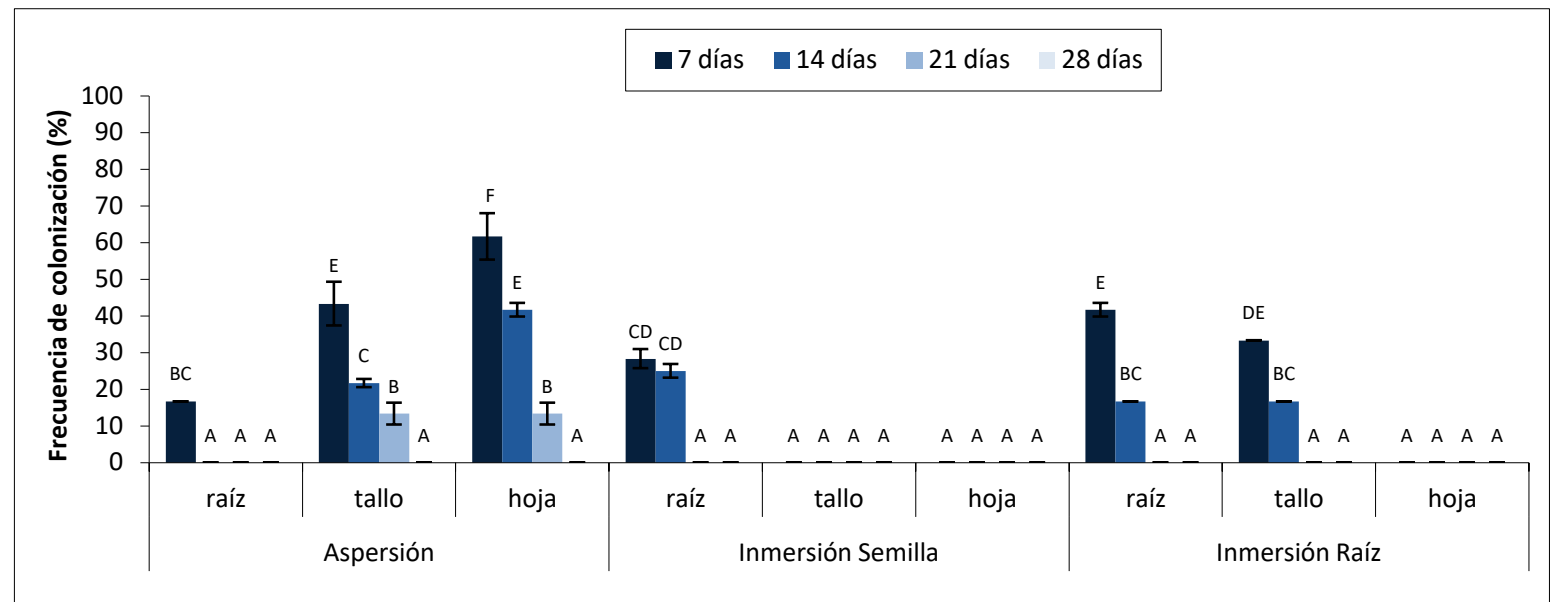

Figura II. 8. Porcentaje de recuperación de B. bassiana LPSc 1063 en raíz, tallo y hoja; con diferentes técnicas de inoculación en plantas de maíz. Letras distintas indican diferencias significativas de acuerdo a test de Tukey $(p<0,05)$. Las barras indican el error estándar de la media.

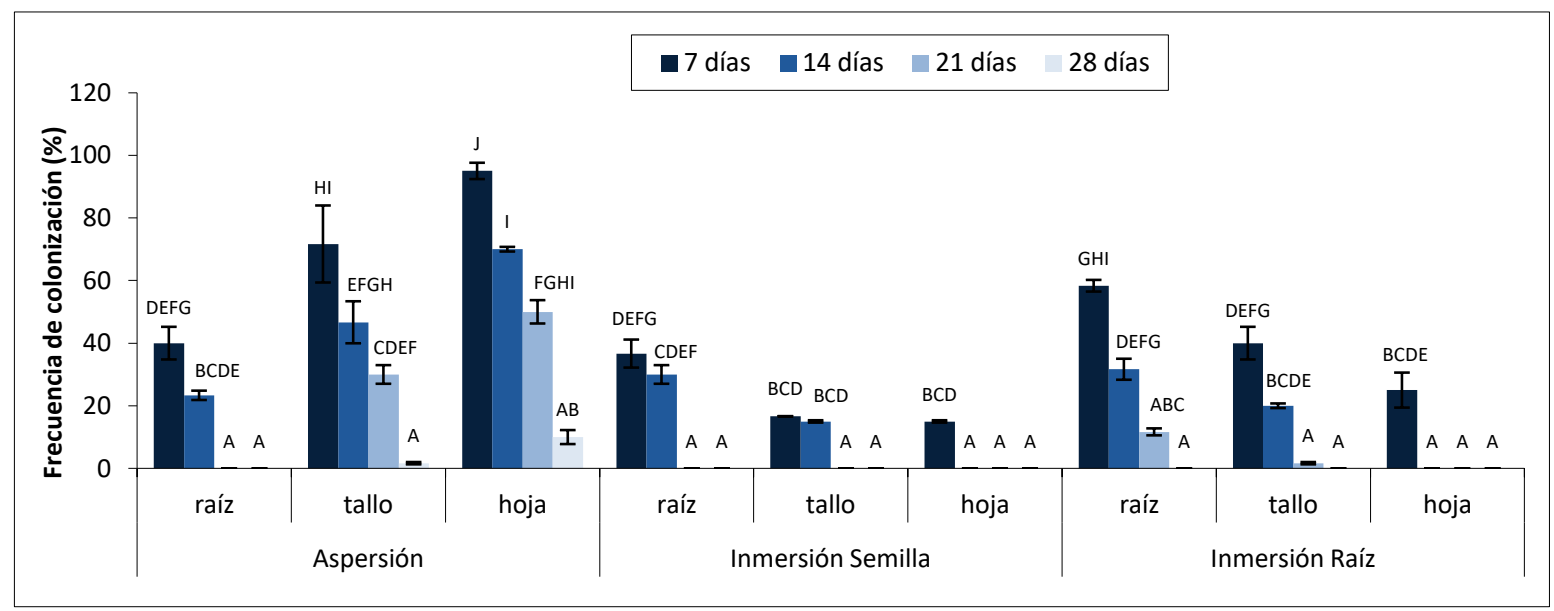

Figura II. 9. Porcentaje de recuperación de $B$. bassiana LPSc 1066 en raíz, tallo y hoja; con diferentes técnicas de inoculación en plantas de maíz.Letras distintas indican diferencias significativas de acuerdotest de Tukey $(p<0,05)$. Las barras indican el error estándar de la media. Las barras indican el error estándar de la media. 


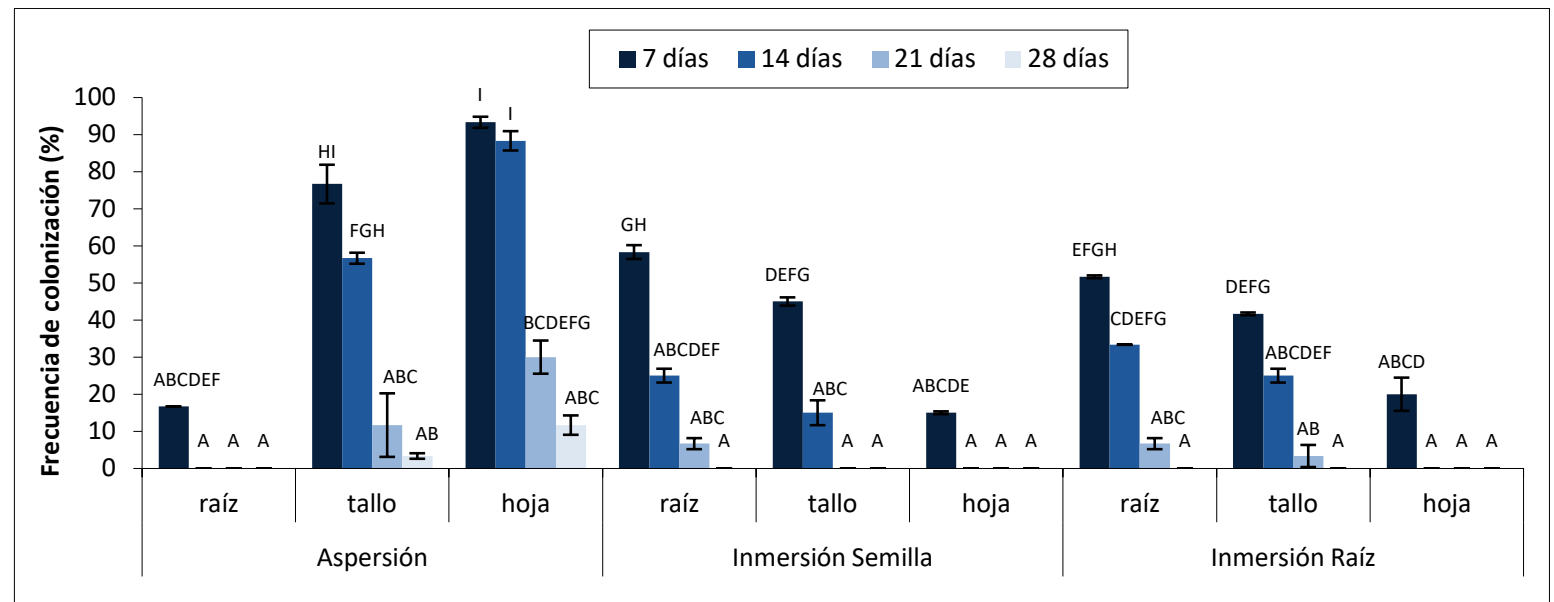

Figura II.10. Porcentaje de recuperación de B. bassiana LPSc 1156 en raíz, tallo y hoja; con diferentes técnicas de inoculación en plantas de maíz. Letras distintas indican diferencias significativas de acuerdo a test de Tukey $(p<0,05)$. Las barras indican el error estándar de la media.

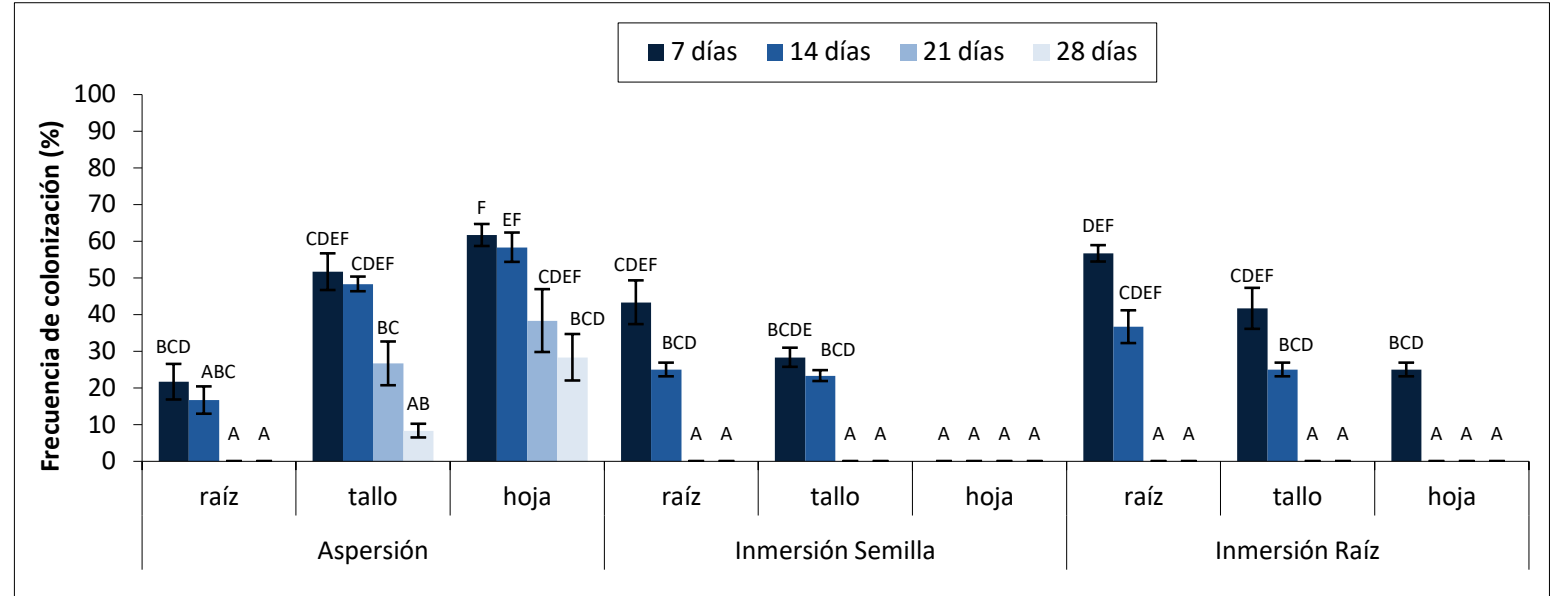

Figura II.11. Porcentaje de recuperación de B. bassiana LPSc 1060 en raíz, tallo y hoja; con diferentes técnicas de inoculación en plantas de maíz. Letras distintas indican diferencias significativas de acuerdo a test de Tukey $(p<0,05)$. Las barras indican el error estándar de la media.

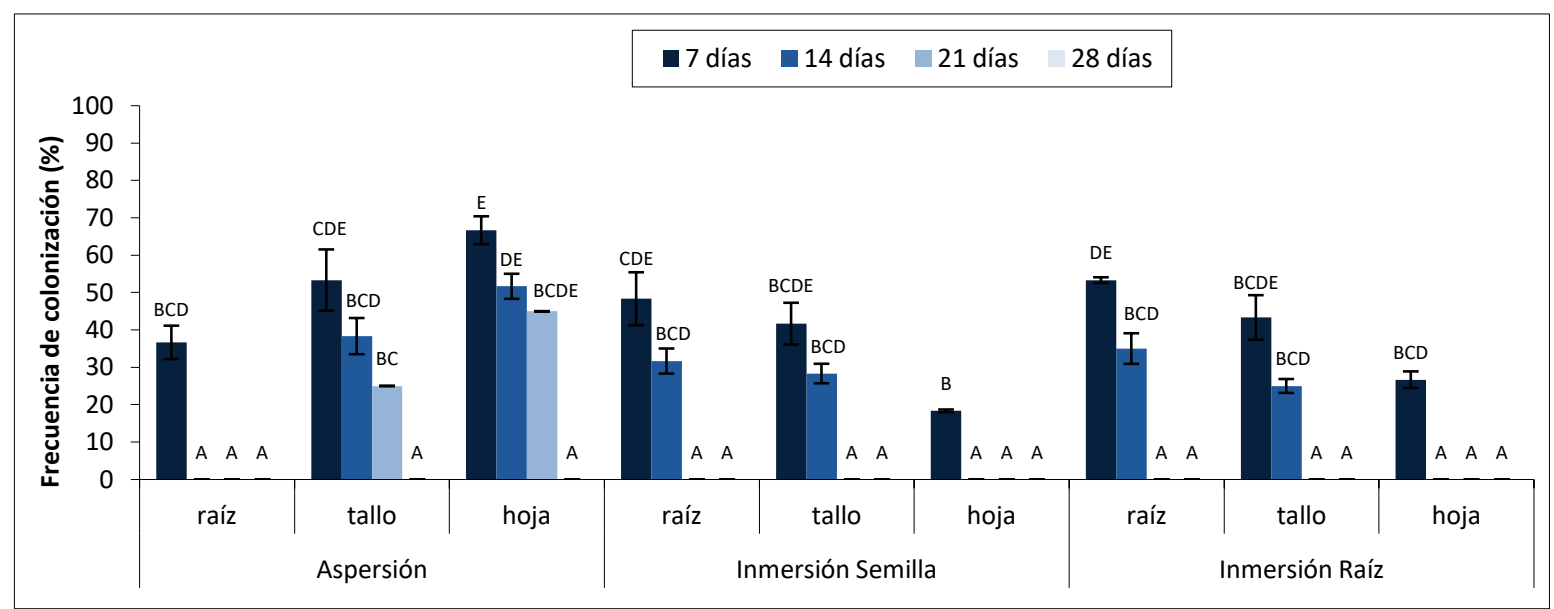

Figura II.12. Porcentaje de recuperación de B. bassianaLPSc 1061 en raíz, tallo y hoja; con diferentes técnicas de inoculación en plantas de maíz.Letras distintas indican diferencias significativas de acuerdo a test de Tukey $(p<0,05)$. Las barras indican el error estándar de la media. 


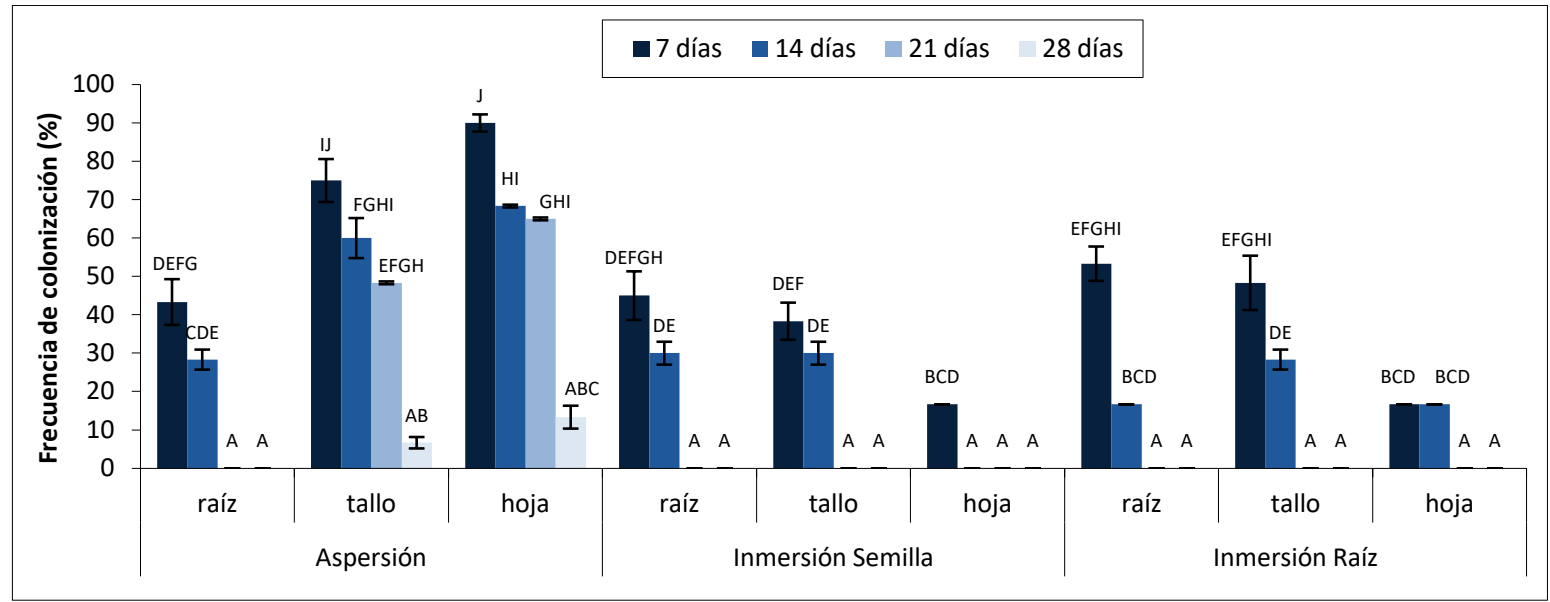

Figura II.13. Porcentaje de recuperación de B. bassiana LPSc 1062 en raíz, tallo y hoja; con diferentes técnicas de inoculación en plantas de maíz. Letras distintas indican diferencias significativas de acuerdo a test de Tukey $(p<0,05)$. Las barras indican el error estándar de la media.

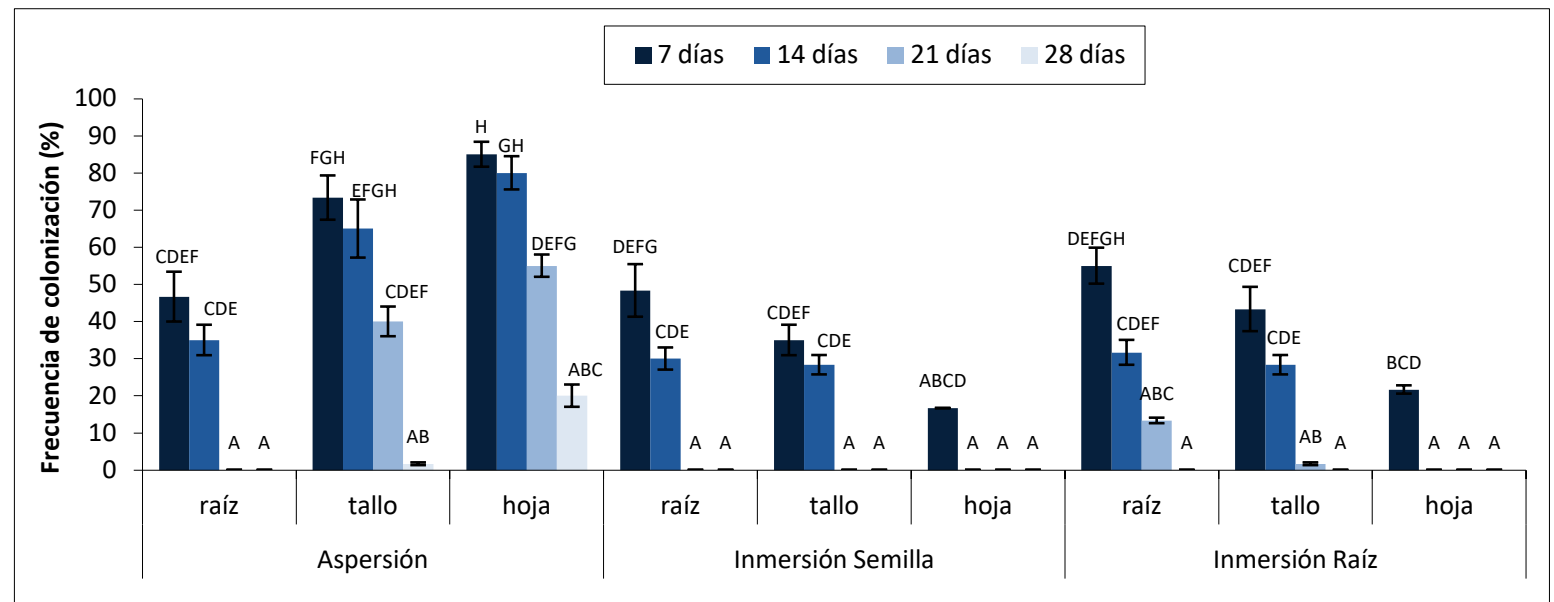

Figura II.14. Porcentaje de recuperación de B. bassiana LPSc 1082 en raíz, tallo y hoja; con diferentes técnicas de inoculación en plantas de maíz. Letras distintas indican diferencias significativas de acuerdo a test de Tukey $(p<0,05)$. Las barras indican el error estándar de la media.

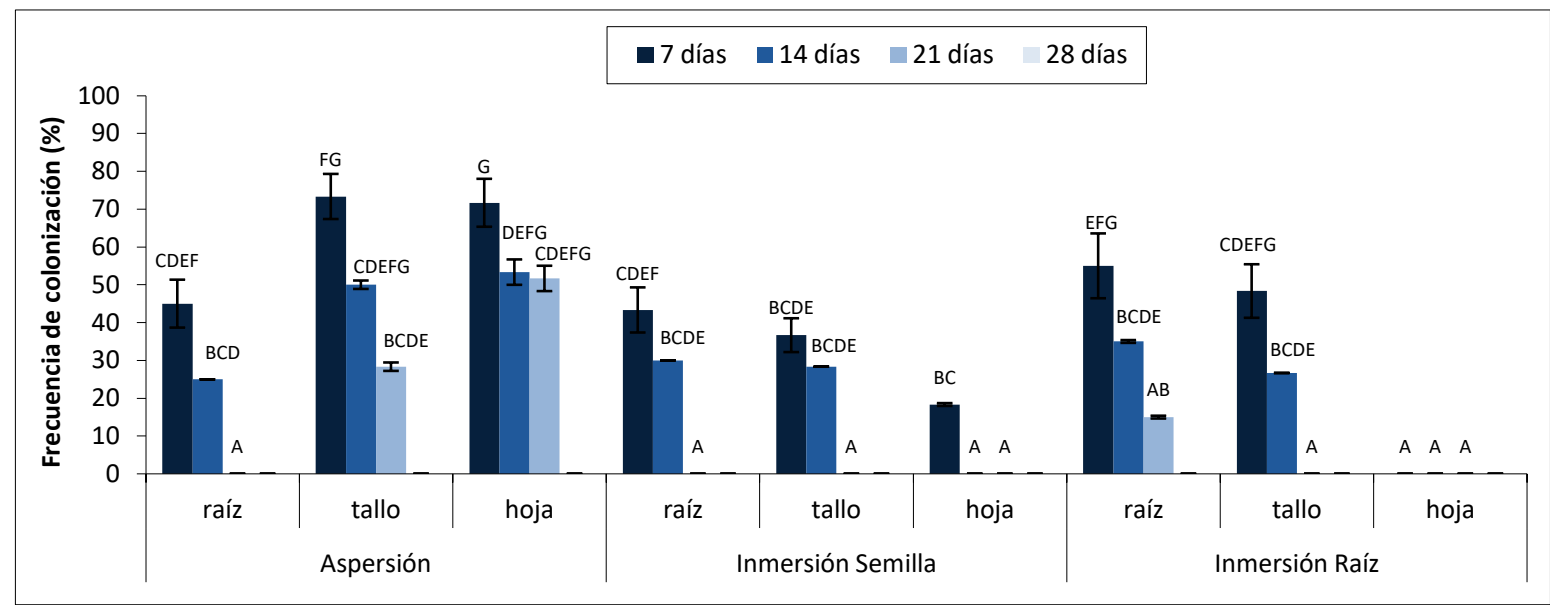

Figura II.15. Porcentaje de recuperación de B. bassiana LPSc 1083 en raíz, tallo y hoja; con diferentes técnicas de inoculación en plantas de maíz. Letras distintas indican diferencias significativas de acuerdo a test de Tukey $(p<0,05)$. Las barras indican el error estándar de la media. 


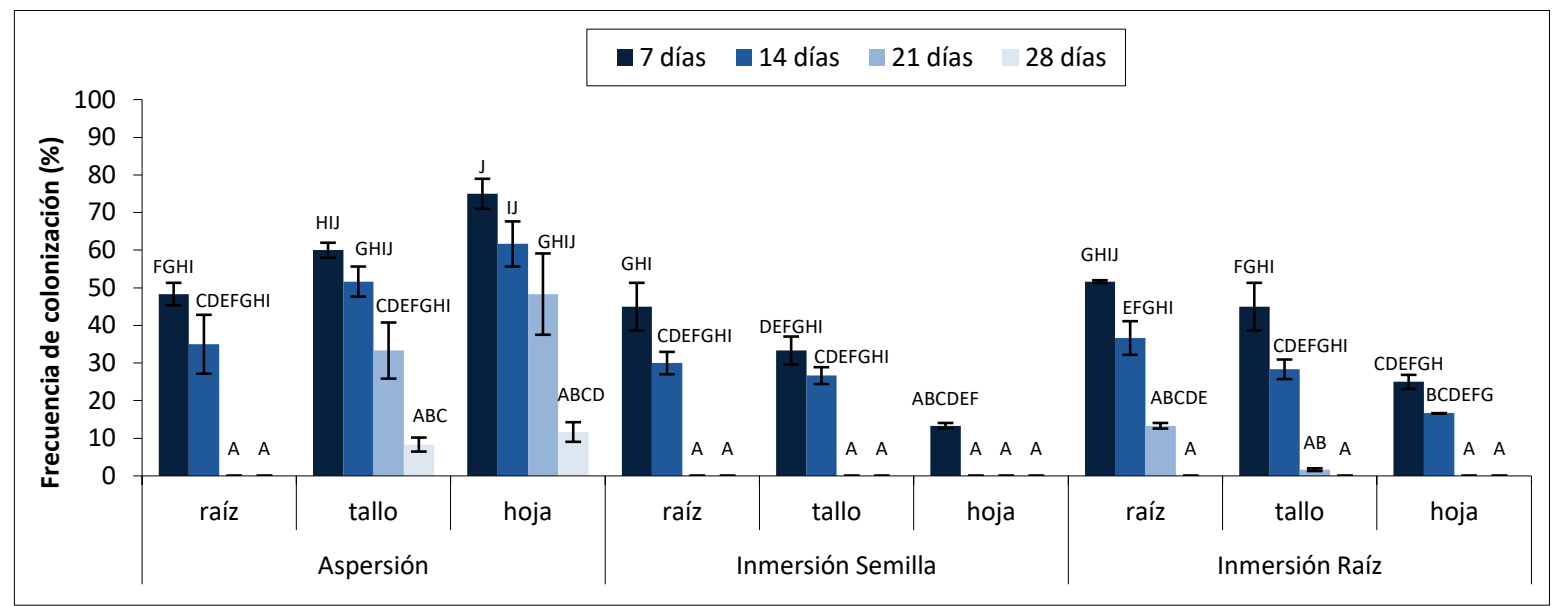

Figura II.16. Porcentaje de recuperación de B. bassiana LPSc 1081 en raíz, tallo y hoja; con diferentes técnicas de inoculación en plantas de maíz. Letras distintas indican diferencias significativas de acuerdo a test de Tukey $(p<0,05)$. Las barras indican el error estándar de la media.

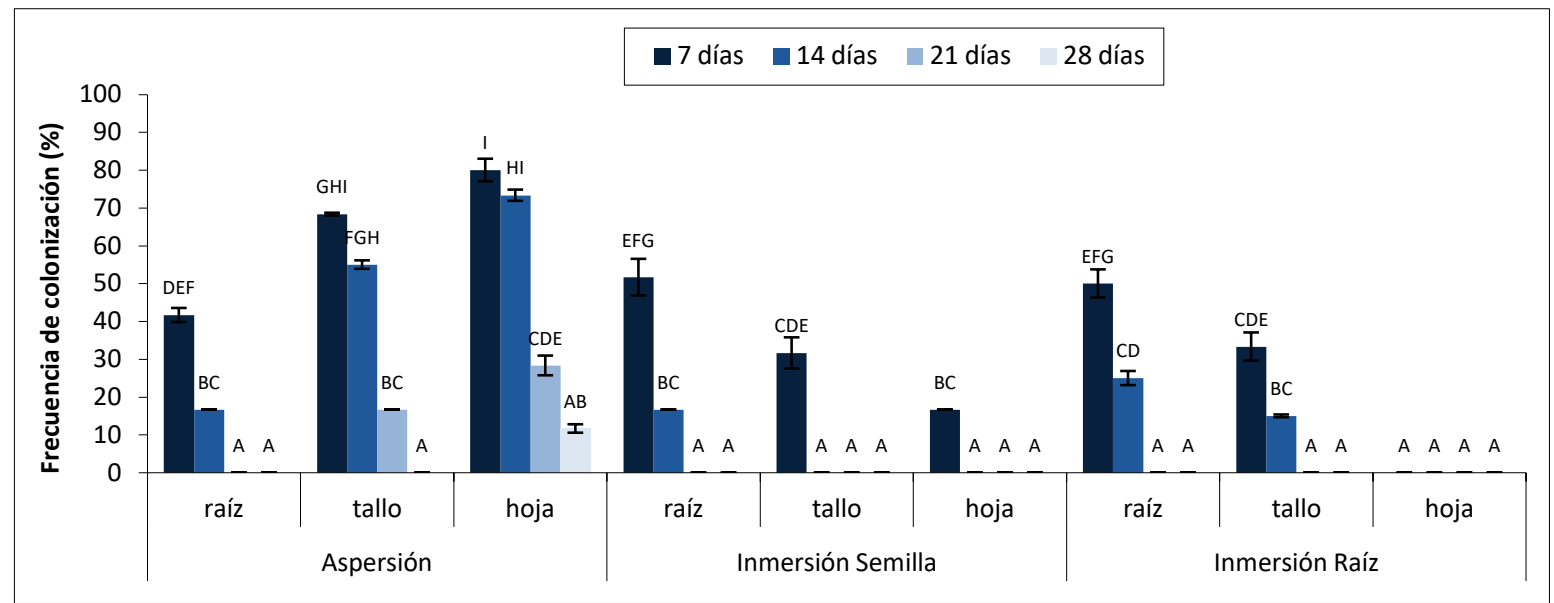

Figura II.17. Porcentaje de recuperación de B. bassianaLPSc 902 en raíz, tallo y hoja; con diferentes técnicas de inoculación en plantas de maíz. Letras distintas indican diferencias significativas de acuerdo a test de Tukey $(p<0,05)$. Las barras indican el error estándar de la media.

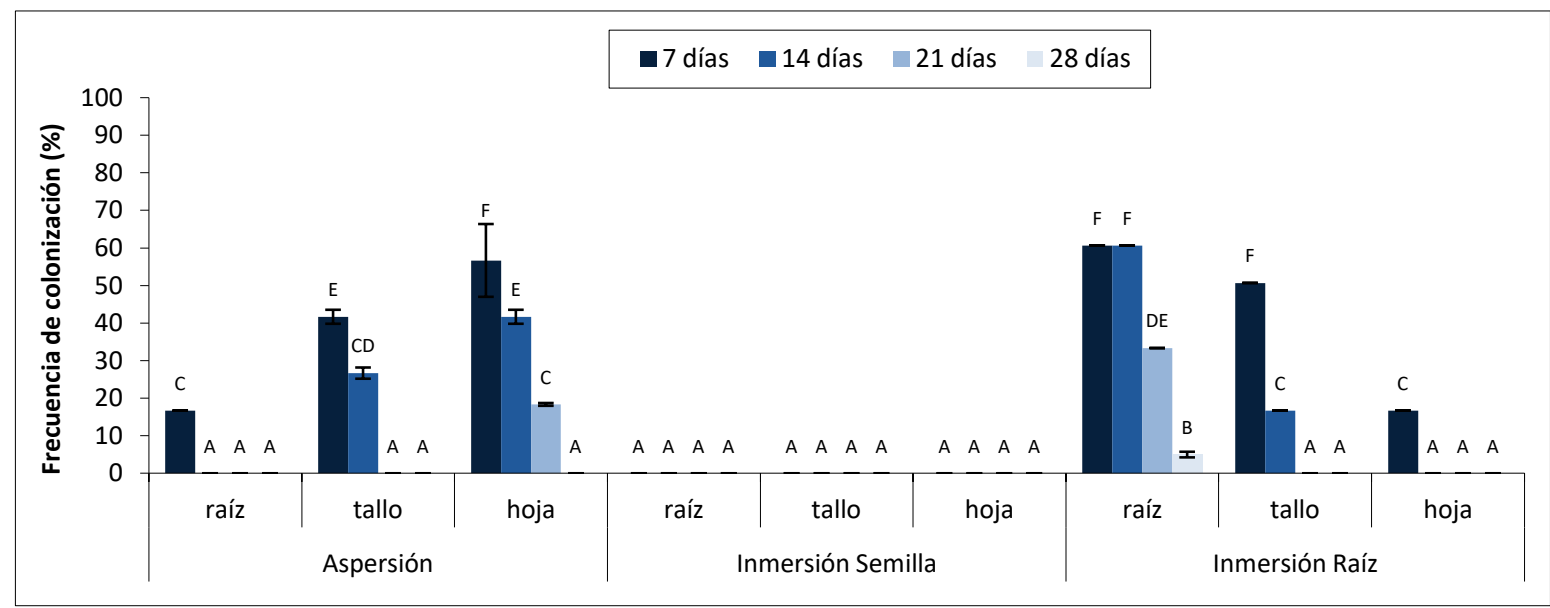

Figura II.18. Porcentaje de recuperación de M. anisopliae LPSC 907 en raíz, tallo y hoja; con diferentes técnicas de inoculación en plantas de maíz.Letras distintas indican diferencias significativas de acuerdo a test de Tukey $(p<0,05)$. Las barras indican el error estándar de la media. 


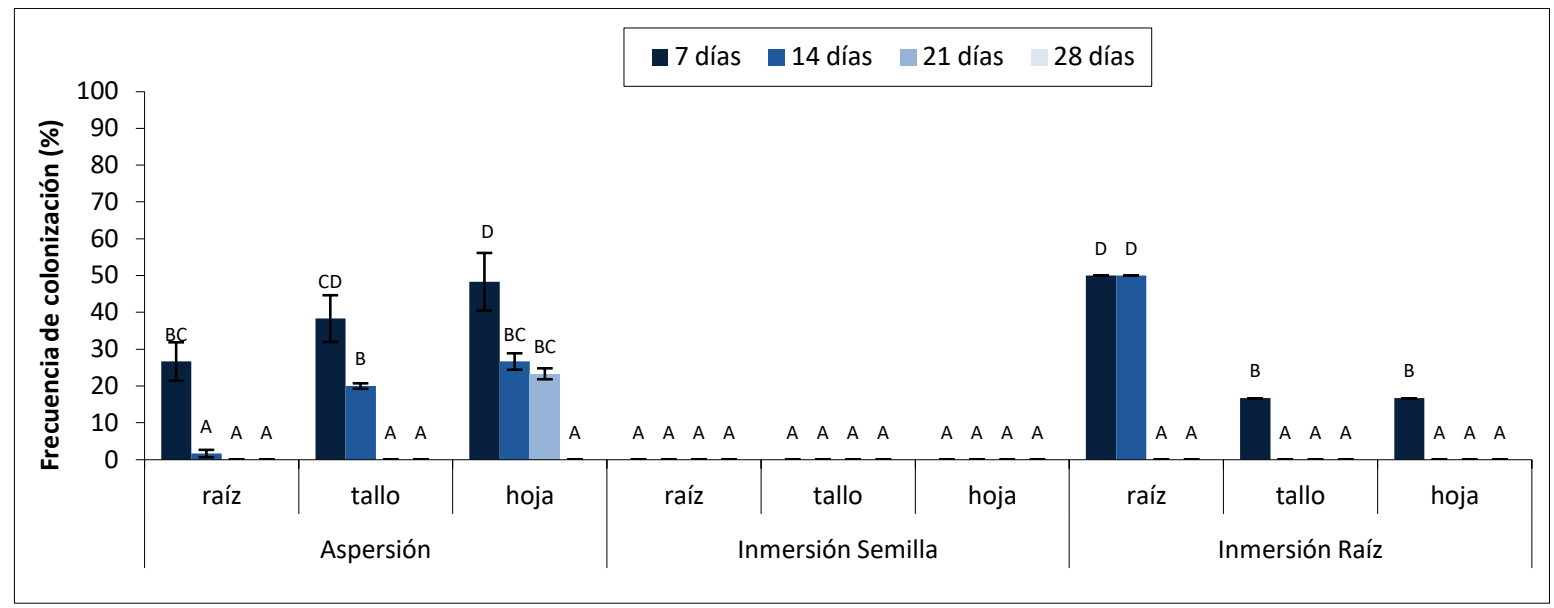

Figura II.19. Porcentaje de recuperación de M. robertsii LPSC 963 en raíz, tallo y hoja; con diferentes técnicas de inoculación en plantas de maíz. Letras distintas indican diferencias significativas de acuerdo a test de Tukey $(p<0,05)$. Las barras indican el error estándar de la media. 


\section{Inmersión de raíz}

Todas las cepas de $B$. bassiana y ambas especies de Metarhizium lograron colonizar endofíticamente mediante esta técnica de inoculación a ambas especies de plantas.

En maíz, los mayores porcentajes de reaislamientos se obtuvieron de las raíces a los 7 días luego de la inoculación siendo 63,3\% el mayor porcentaje de colonización obtenido, el cual fue registrado para la cepa B. bassiana LPSc 1098 (Figura II.4). Posteriormente observamos un descenso en el reaislamiento a medida que transcurrió el tiempo.

En soja, en cambio, con las cepas B. bassiana LPSc 1080 (Figura II.23), B. bassiana LPSc 1156 (Figura II.26), B. bassiana LPSc 1061 (Figura II.28), B. bassiana LPSC 1060 (Figura II.27), B. bassiana LPSC 1082 (Figura II.30), B. bassiana LPSC 1083 (Figura II.31), B. bassiana LPSc 902 (Figura II.33) y con ambas especies de Metarhizium LPSc 963 y LPSc 907 (Figuras II.34, 35) se obtuvieron los mayores porcentajes de reaislamientos en raíces a los 7 días posteriores a la inoculación. En tanto, en las cepas B. bassiana LPSc 1098 (Figura II.20), B. bassiana LPSc 1067 (Figura II.21), B. bassiana LPSc 1086 (Figura II.22), B. bassiana LPSc 1063 (Figura II.24), B. bassiana LPSc 1066 (Figura II.25) y B. bassiana LPSc 1062 (Figura II.29), el análisis estadístico no mostró diferencias significativas entre raíces y tallo a los 7 días. La cepa B. bassiana LPSc 1062 (Figura II.29) fue la que mayor frecuencia de colonización mostró en las hojas.

Es importante destacar, que con esta técnica no se registró ningún aislamiento de hongo entomopatógeno a los 28 días posteriores a la inoculación en ambas especies de plantas (Figuras II.4 a la 35).

\section{Inmersión de semilla}

Las especies de Metarhizium inoculadas mediante esta técnica no pudieron ser reaisladas de ninguno de los órganos de las plantas estudiadas. Por el contrario, $B$. bassiana pudo establecerse dentro de las plantas de ambas especies, mostrando variación entre las diferentes cepas y observándose que el porcentaje de colonización se registró a los 7 días posteriores a la inoculación. 
En plantas de maíz, las cepas B. bassiana LPSc 1080 (Figura II.7), B. bassiana LPSc 1063 (Figura II.8) y B. bassiana LPSc 1086 (Figura II.6) sólo fueron reaisladas de raíz. El resto de las cepas fueron reaisladas de raíz, tallo y hoja. La mayor y menor frecuencia de colonización fue observada en las cepas B. bassiana LPSc 1156 (Figura II.10) y B. bassiana LPSc 1086 (Figura II.6) con frecuencias de colonización del 56\% y $15 \%$ respectivamente en raíz a los 7 días posteriores a la inoculación.

En soja, las cepas B. bassiana LPSc 1081 (Figura II.32), B. bassiana LPSc 1082 (Figura II.30), B. bassiana LPSc 1061 (Figura II.28) y B. bassiana LPSc 1086 (Figura II.22) pudieron ser reaisladas en raíces y tallos a los 7 días posteriores a la inoculación con un porcentaje promedio en raíz y tallo de $40 \%$ y $16,6 \%$ respectivamente, mostrando en cada cepa diferencias significativas $(p<0,0001)$ entre ambos órganos. Las cepas B. bassiana LPSc 1063 (Figura II.24), B. bassiana LPSc 1066 (Figura II.25), B. bassiana LPSc 1060 (Figura II.27) y B. bassiana LPSC 1083 (Figura II.31), no pudieron establecerse en las hojas, aunque si lo hicieron en raíces y tallos a los 7, 14 y 21 días posteriores a la inoculación, alcanzando porcentajes de colonización mayores que las cepas mencionadas anteriormente. Las cepas fúngicas restantes lograron introducirse y permanecer en las hojas. Es importante mencionar que la cepa $B$. bassiana LPSc 1067 (Figura II.21) fue la única que pudo reaislarse a los 28 días posteriores a la inoculación.

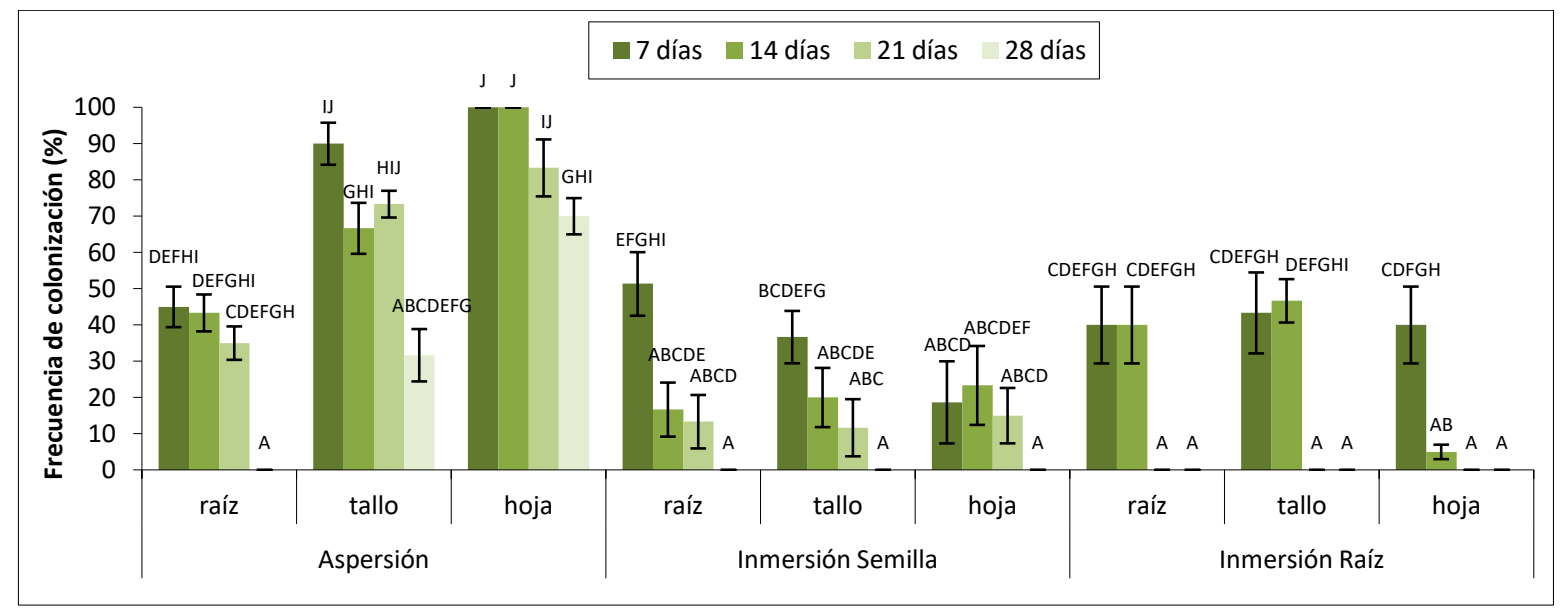

Figura II.20. Porcentaje de recuperación de B. bassiana LPSc 1098 en raíz, tallo y hoja, con diferentes técnicas de inoculación en plantas de soja.Letras distintas indican diferencias significativas de acuerdo a test de Tukey $(p<0,05)$. Las barras indican el error estándar de la media. 


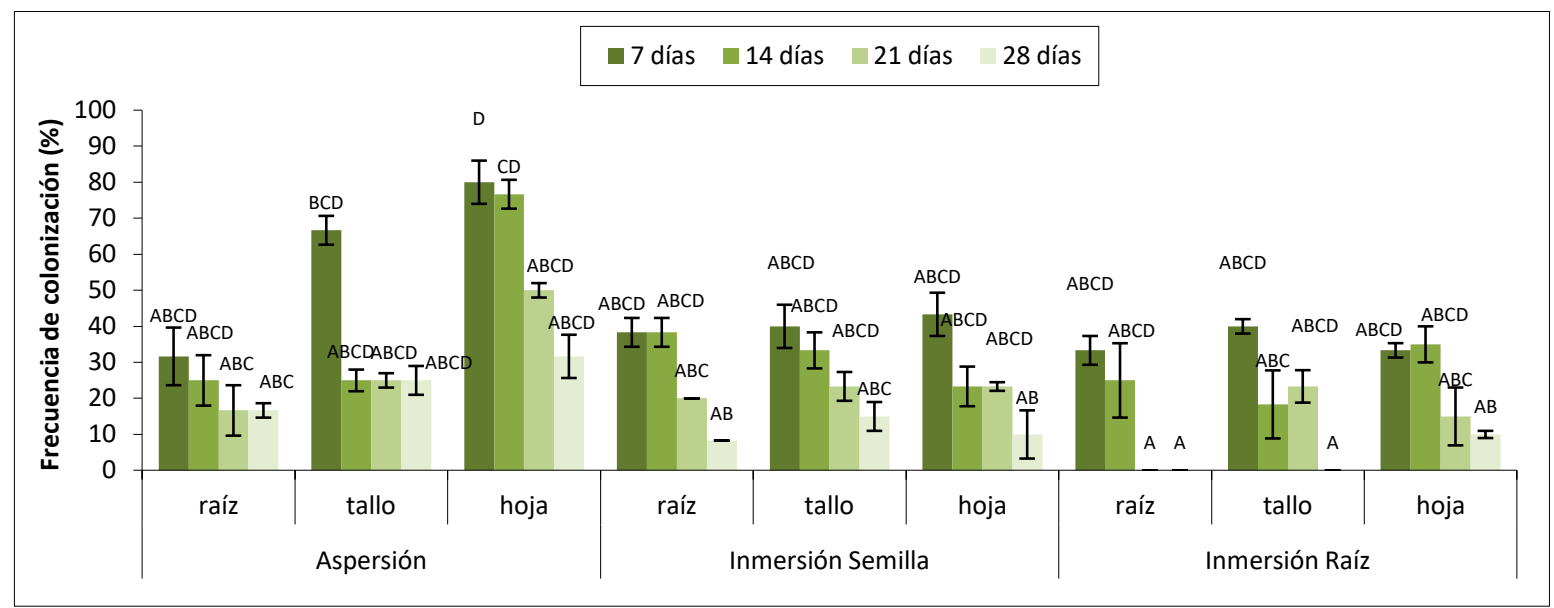

Figura II.21. Porcentaje de recuperación de B. bassiana LPSc 1067 en raíz, tallo y hoja, con diferentes técnicas de inoculación en plantas de soja.Letras distintas indican diferencias significativas de acuerdo a test de Tukey $(p<0,05)$. Las barras indican el error estándar de la media.

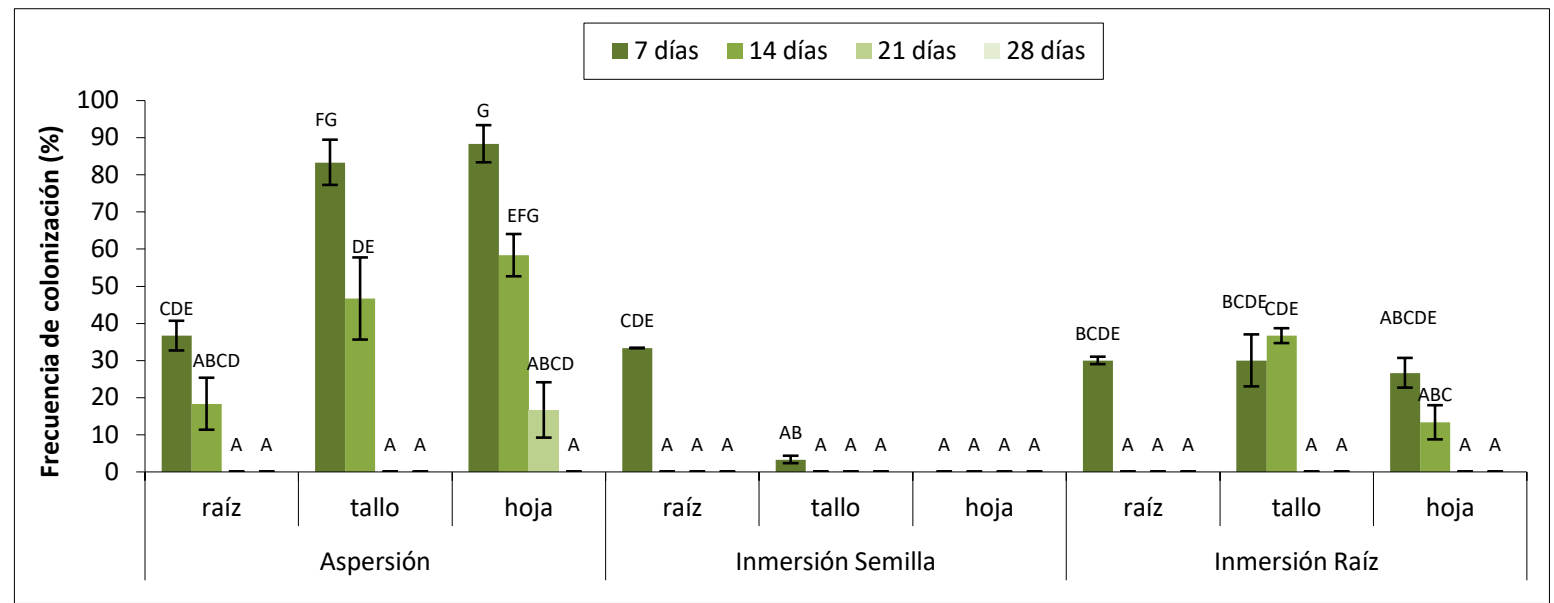

Figura II.22. Porcentaje de recuperación de B. bassiana LPSc 1086 en raíz, tallo y hoja, con diferentes técnicas de inoculación en plantas de soja.Letras distintas indican diferencias significativas de acuerdo a test de Tukey $(p<0,05)$. Las barras indican el error estándar de la media.

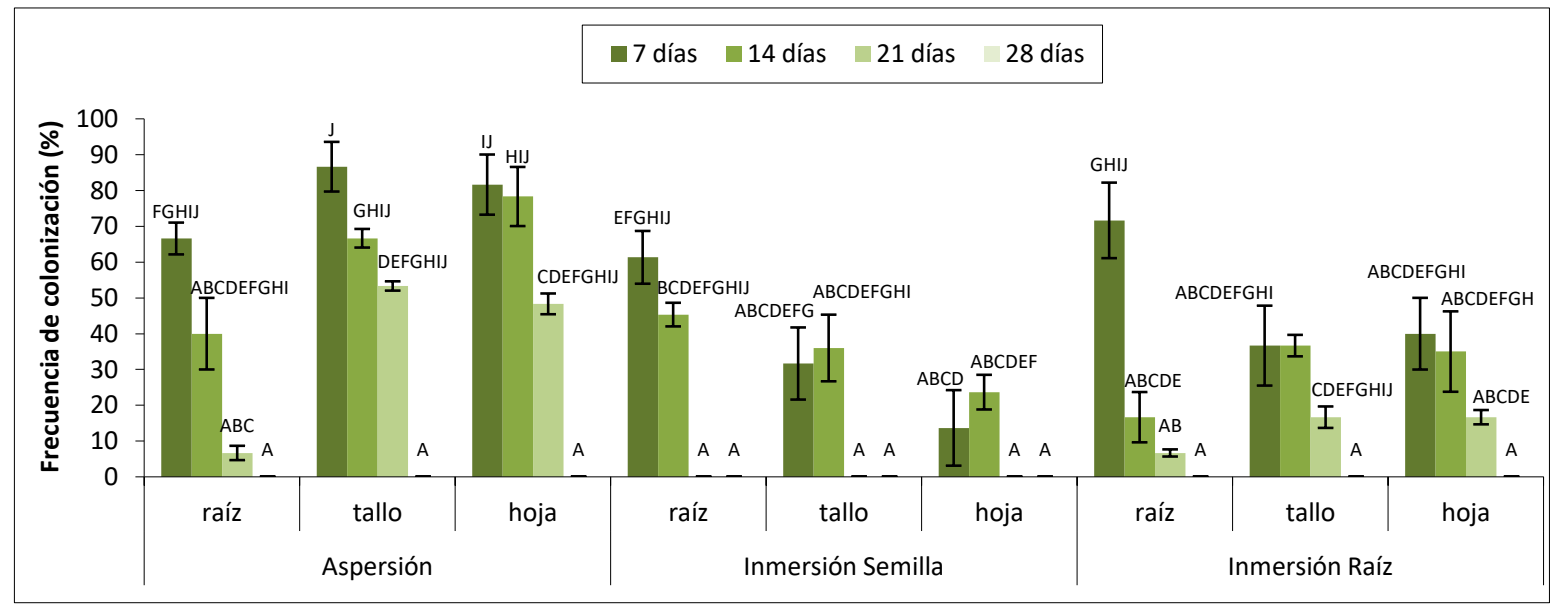

Figura II.23. Porcentaje de recuperación de B. bassiana LPSc 1080 en raíz, tallo y hoja, con diferentes técnicas de inoculación en plantas de soja.Letras distintas indican diferencias significativas de acuerdo a test de Tukey $(p<0,05)$. Las barras indican el error estándar de la media. 


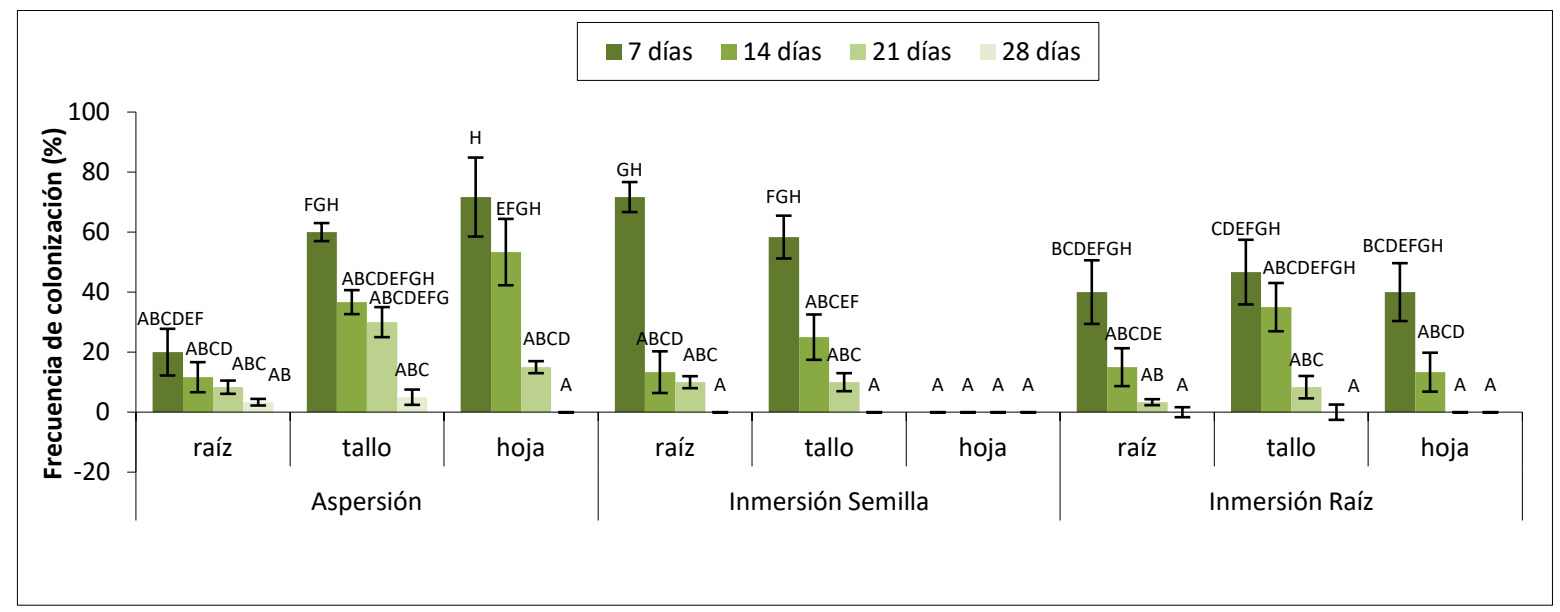

Figura II.24. Porcentaje de recuperación de B. bassiana LPSc 1063 en raíz, tallo y hoja, con diferentes técnicas de inoculación en plantas de soja.Letras distintas indican diferencias significativas de acuerdo a test de Tukey $(p<0,05)$. Las barras indican el error estándar de la media.

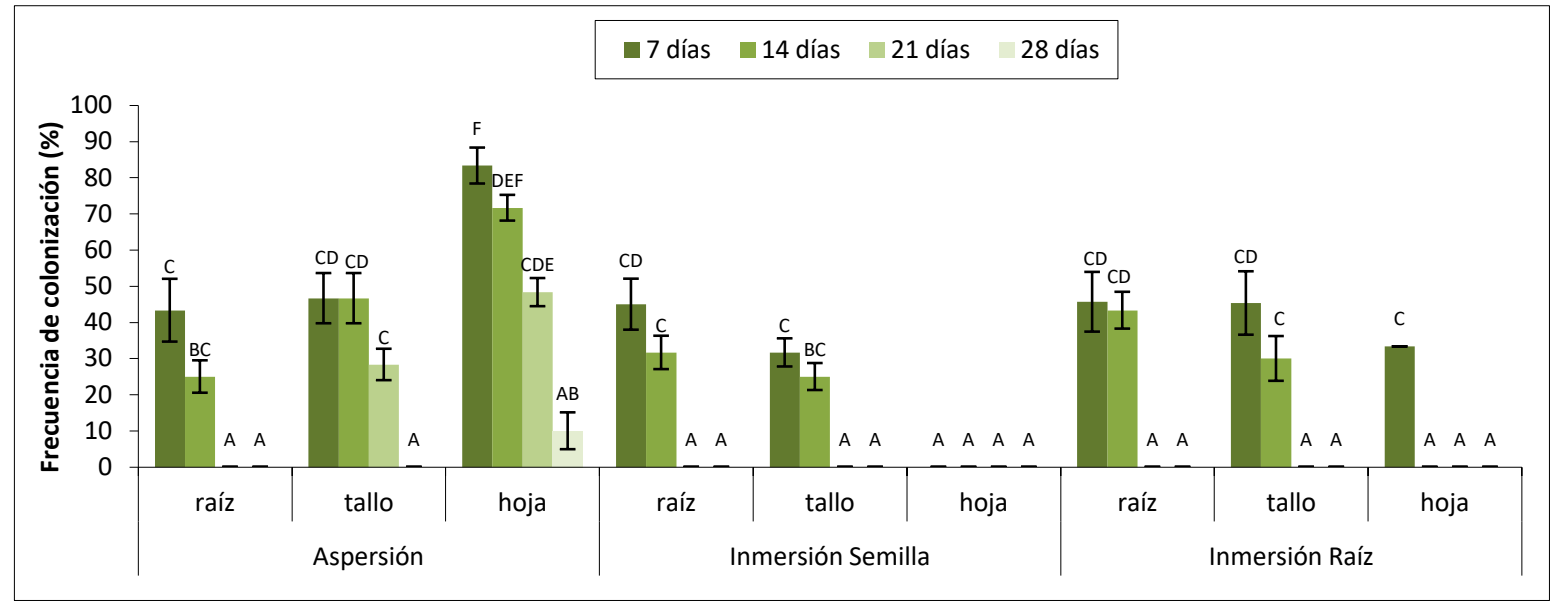

Figura II.25. Porcentaje de recuperación de B. bassiana LPSc 1066 en raíz, tallo y hoja, con diferentes técnicas de inoculación en plantas de soja.Letras distintas indican diferencias significativas de acuerdo a test de Tukey $(p<0,05)$. Las barras indican el error estándar de la media.

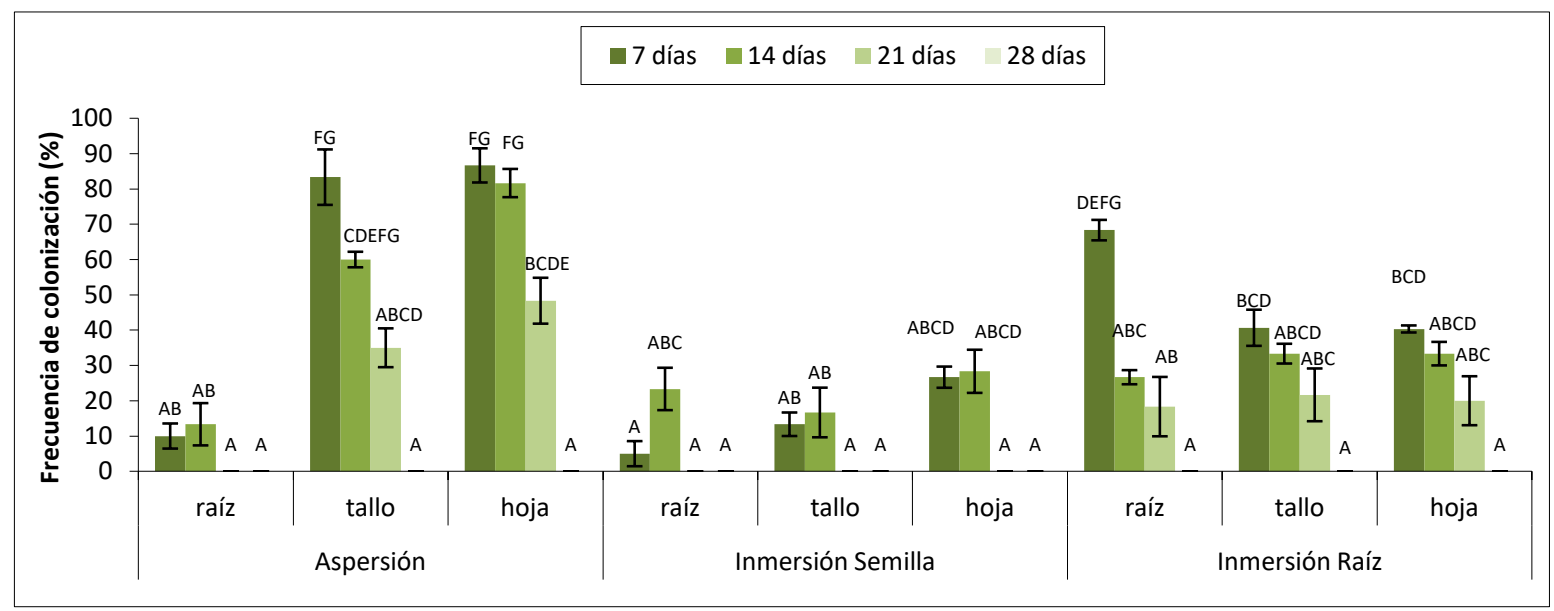

Figura II.26. Porcentaje de recuperación de B. bassiana LPSc 1156 en raíz, tallo y hoja, con diferentes técnicas de inoculación en plantas de soja.Letras distintas indican diferencias significativas de acuerdo a test de Tukey $(p<0,05)$. Las barras indican el error estándar de la media. 


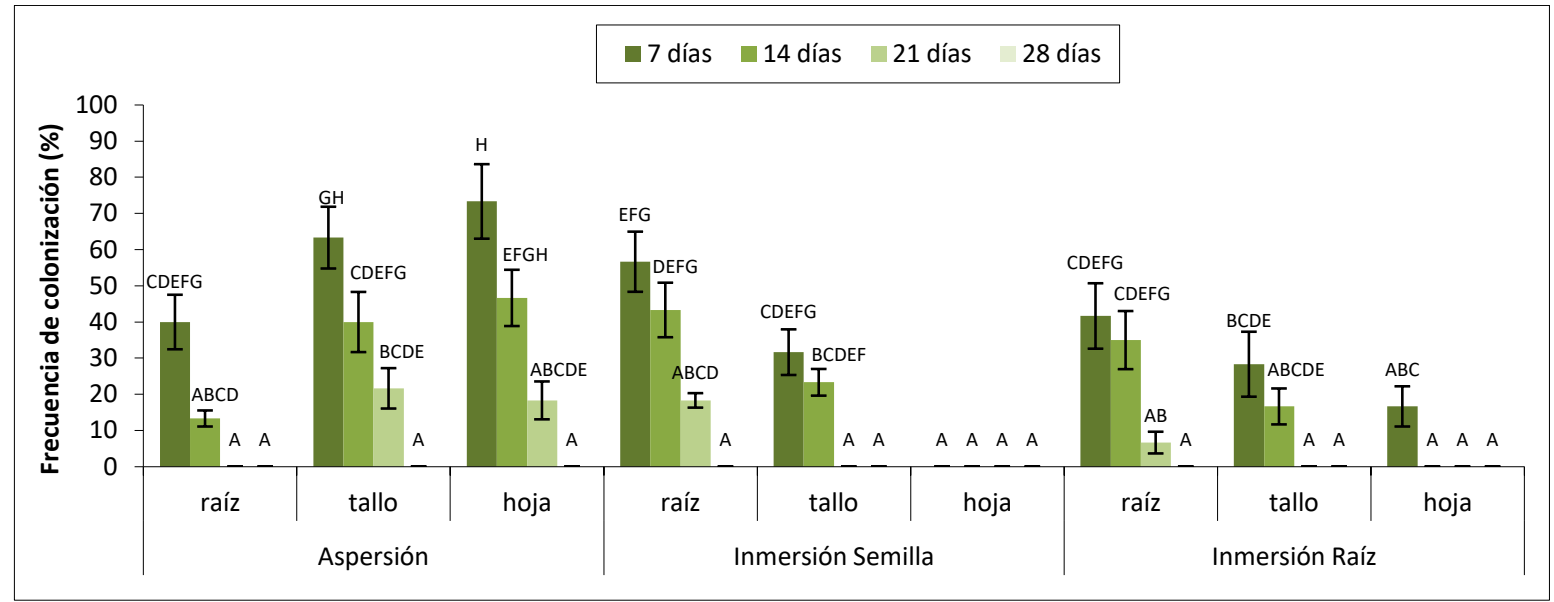

Figura II.27. Porcentaje de recuperación de B. bassiana LPSc 1060 en raíz, tallo y hoja, con diferentes técnicas de inoculación en plantas de soja.Letras distintas indican diferencias significativas de acuerdo a test de Tukey $(p<0,05)$. Las barras indican el error estándar de la media.

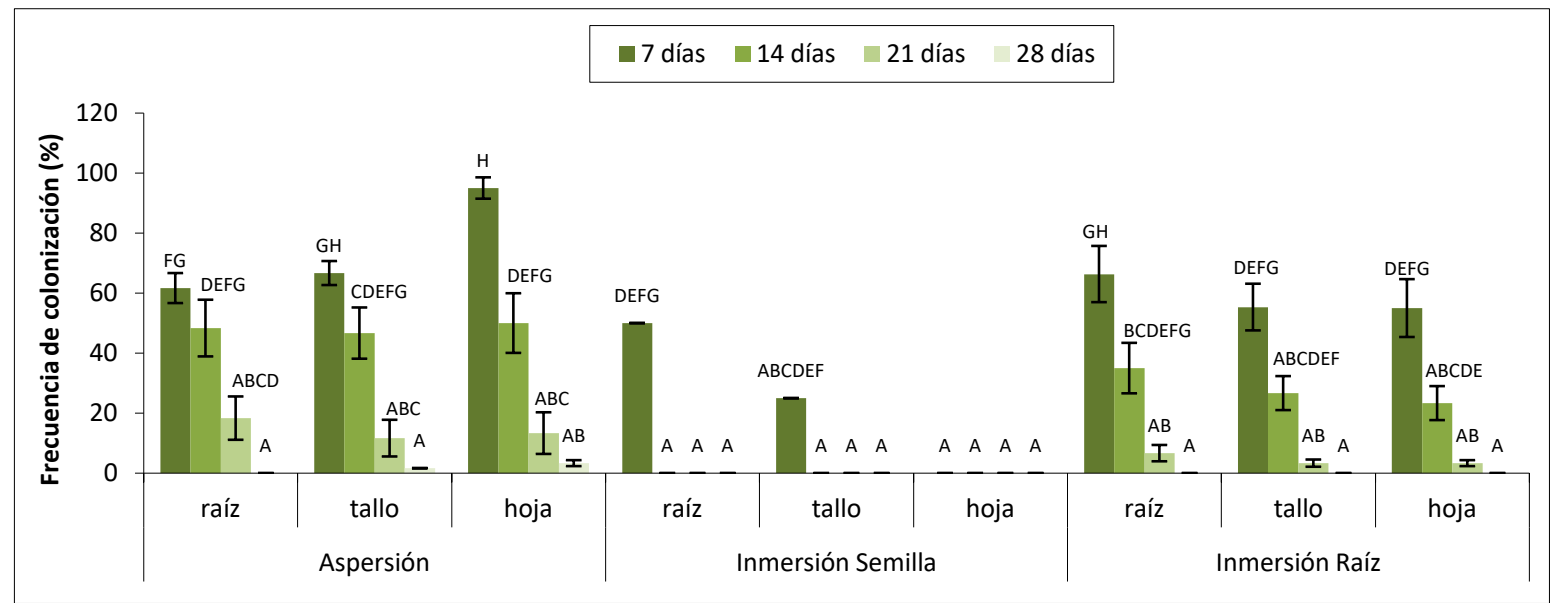

Figura II. 28. Porcentaje de recuperación de B. bassiana LPSc 1061 en raíz, tallo y hoja, con diferentes técnicas de inoculación en plantas de soja.Letras distintas indican diferencias significativas de acuerdo a test de Tukey $(p<0,05)$. Las barras indican el error estándar de la media.

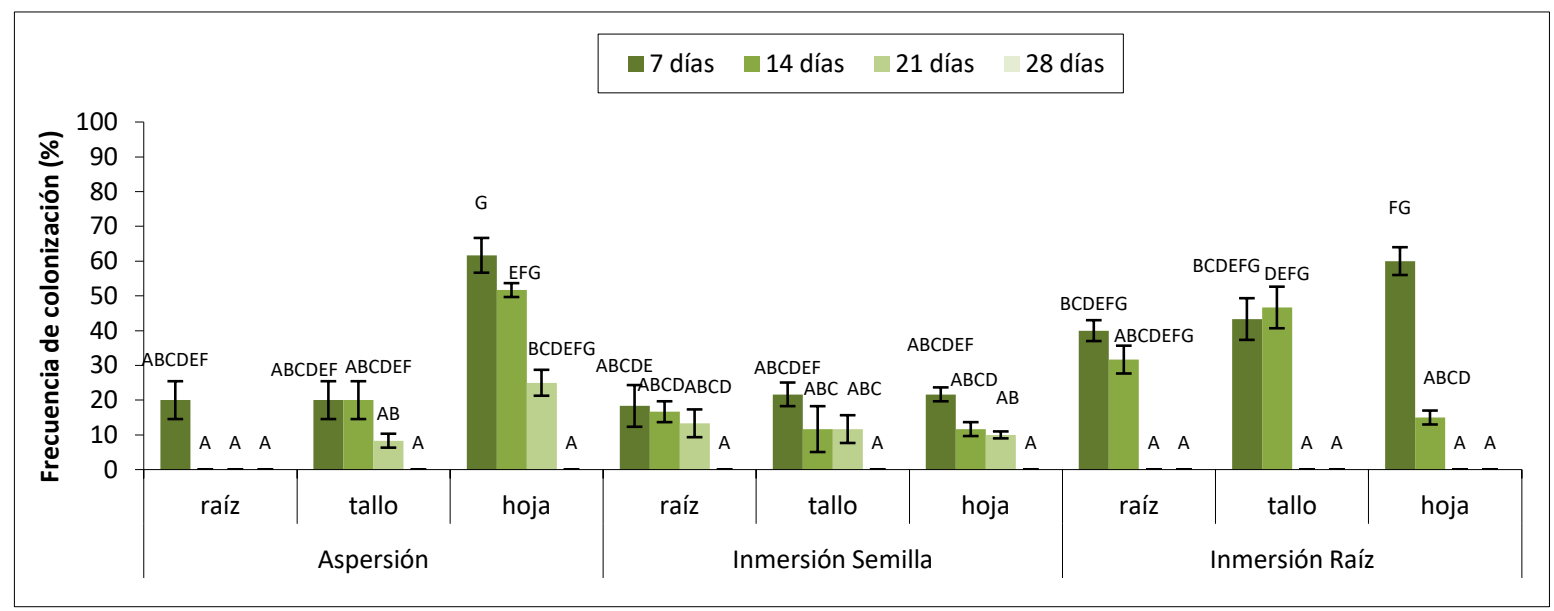

Figura II.29. Porcentaje de recuperación de B. bassiana LPSc 1062 en raíz, tallo y hoja, con diferentes técnicas de inoculación en plantas de soja.Letras distintas indican diferencias significativas de acuerdo a test de Tukey $(p<0,05)$. Las barras indican el error estándar de la media. 


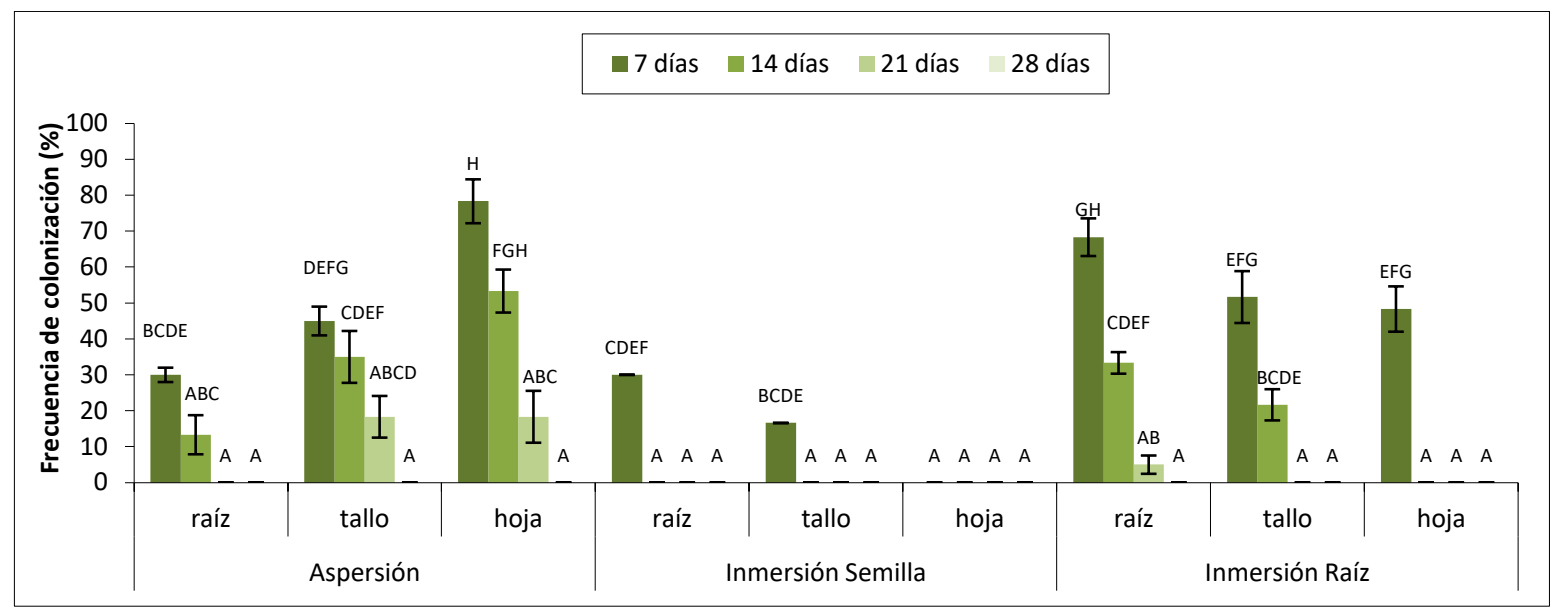

Figura II.30. Porcentaje de recuperación de B. bassiana LPSc 1082 en raíz, tallo y hoja, con diferentes técnicas de inoculación en plantas de soja.Letras distintas indican diferencias significativas de acuerdo a test de Tukey $(p<0,05)$. Las barras indican el error estándar de la media.

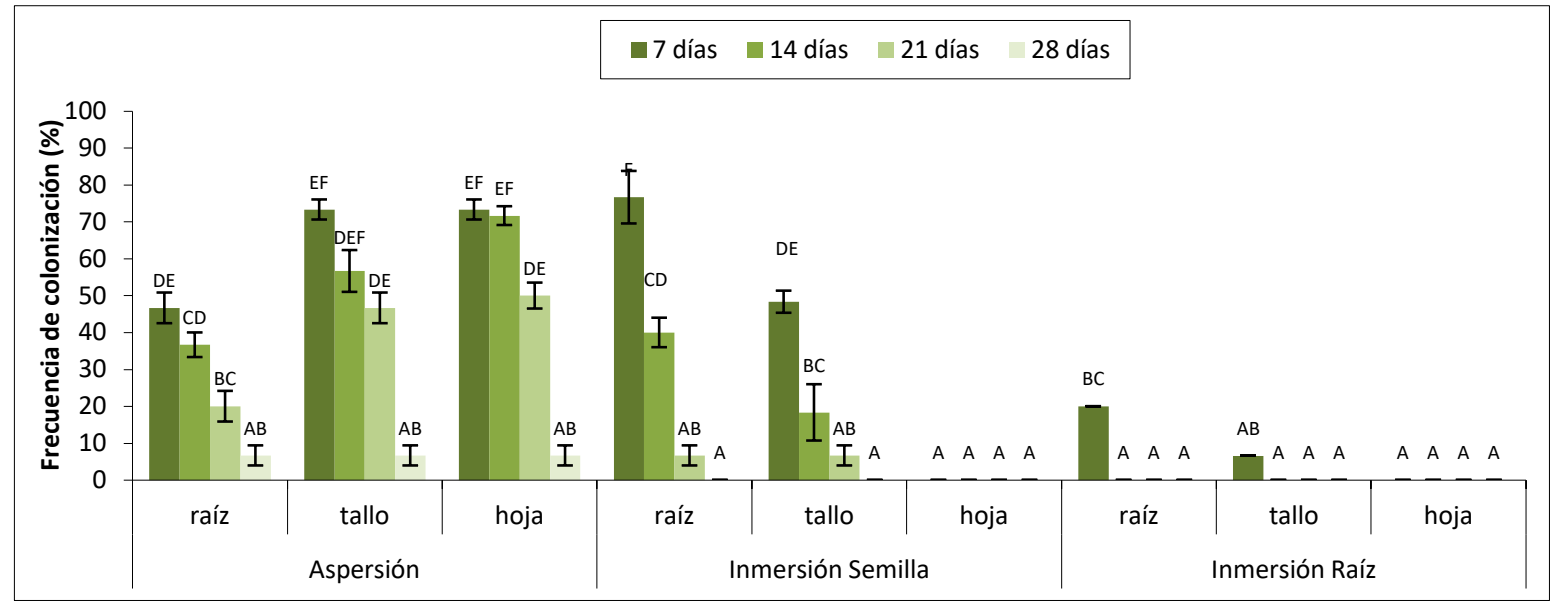

Figura II.31. Porcentaje de recuperación de B. bassiana LPSc 1083 en raíz, tallo y hoja, con diferentes técnicas de inoculación en plantas de soja.Letras distintas indican diferencias significativas de acuerdo a test de Tukey $(p<0,05)$. Las barras indican el error estándar de la media.

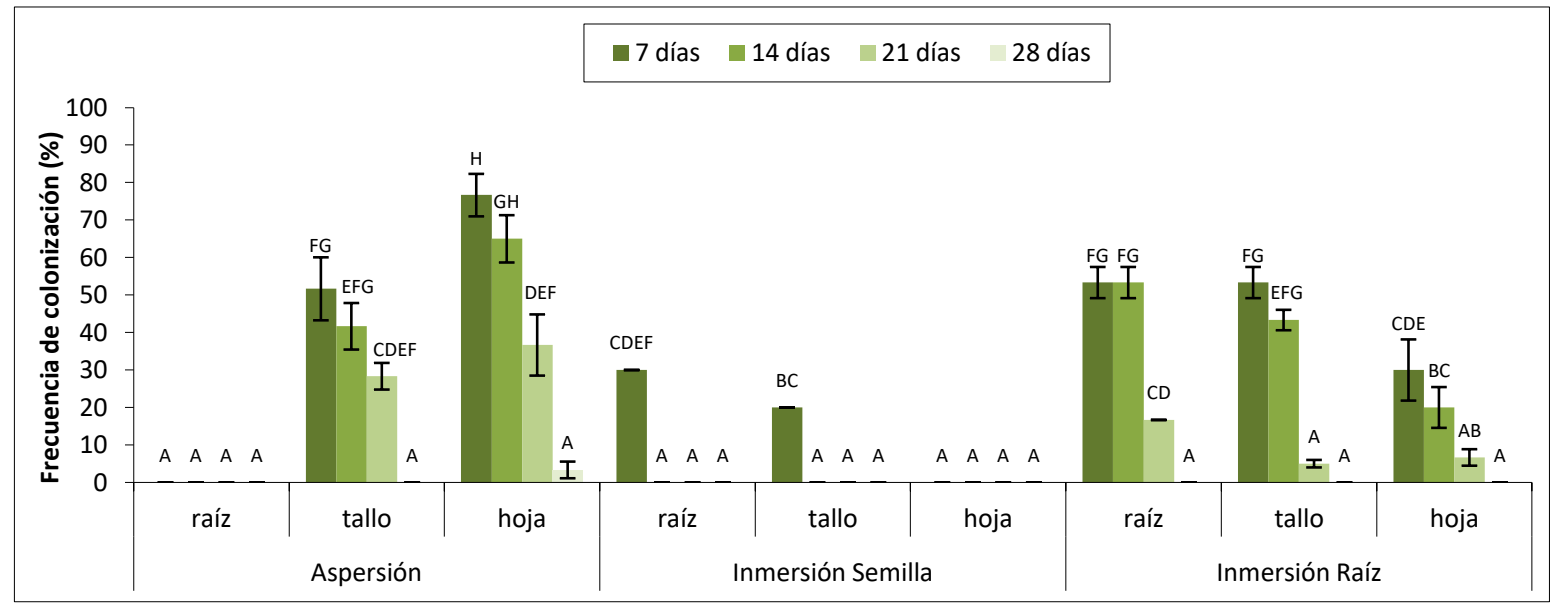

Figura II.32. Porcentaje de recuperación de B. bassiana LPSc 1081 en raíz, tallo y hoja, con diferentes técnicas de inoculación en plantas de soja.Letras distintas indican diferencias significativas de acuerdo a test de Tukey $(p<0,05)$. Las barras indican el error estándar de la media. 


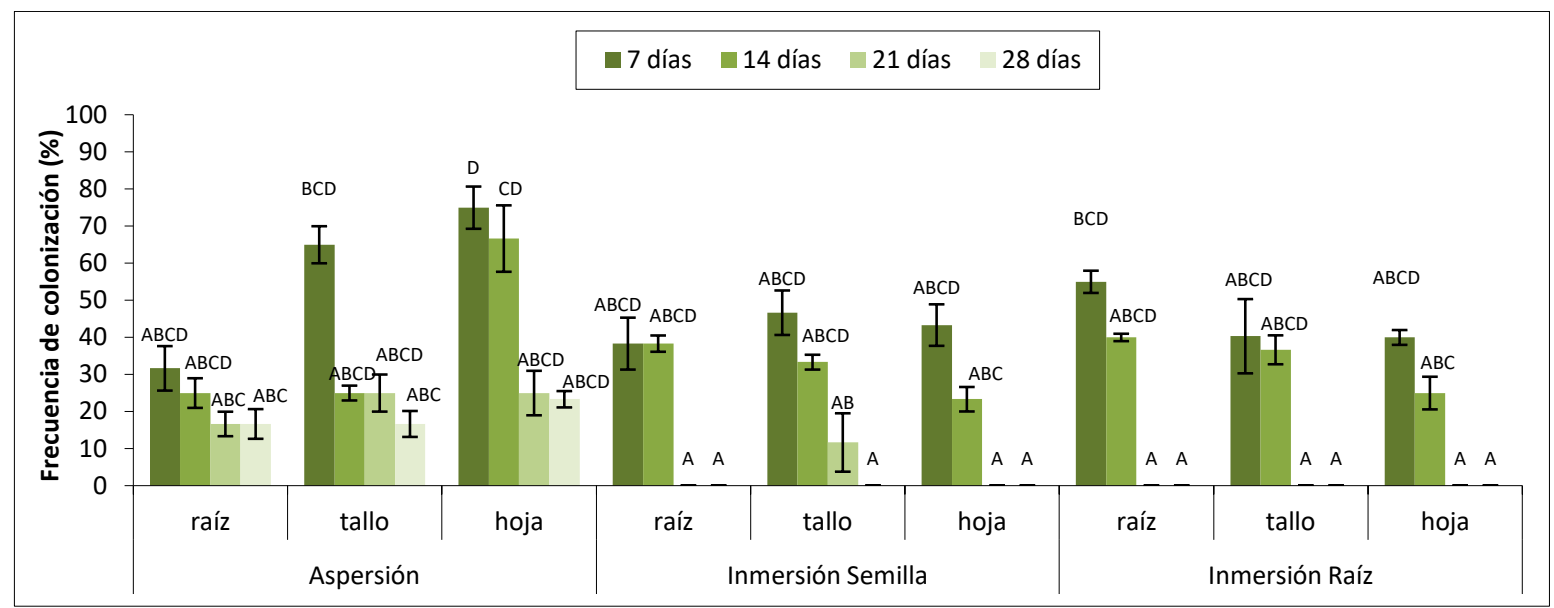

Figura II.33. Porcentaje de recuperación de $B$. bassiana LPSc 902 en raíz, tallo y hoja, con diferentes técnicas de inoculación en plantas de soja.Letras distintas indican diferencias significativas de acuerdo a test de Tukey $(p<0,05)$. Las barras indican el error estándar de la media.

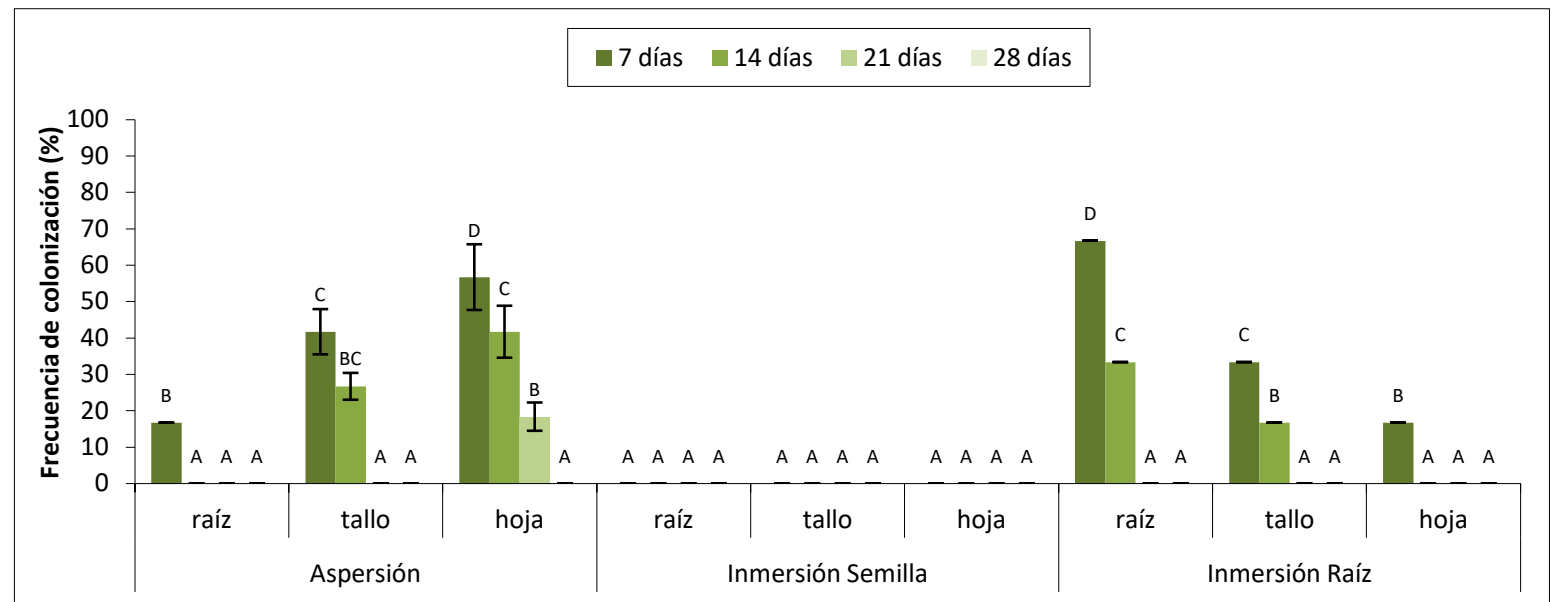

Figura II.34. Porcentaje de recuperación de M. anisopliae LPSc 907 en raíz, tallo y hoja, con diferentes técnicas de inoculación en plantas de soja.Letras distintas indican diferencias significativas de acuerdo a test de Tukey $(p<0,05)$. Las barras indican el error estándar de la media.

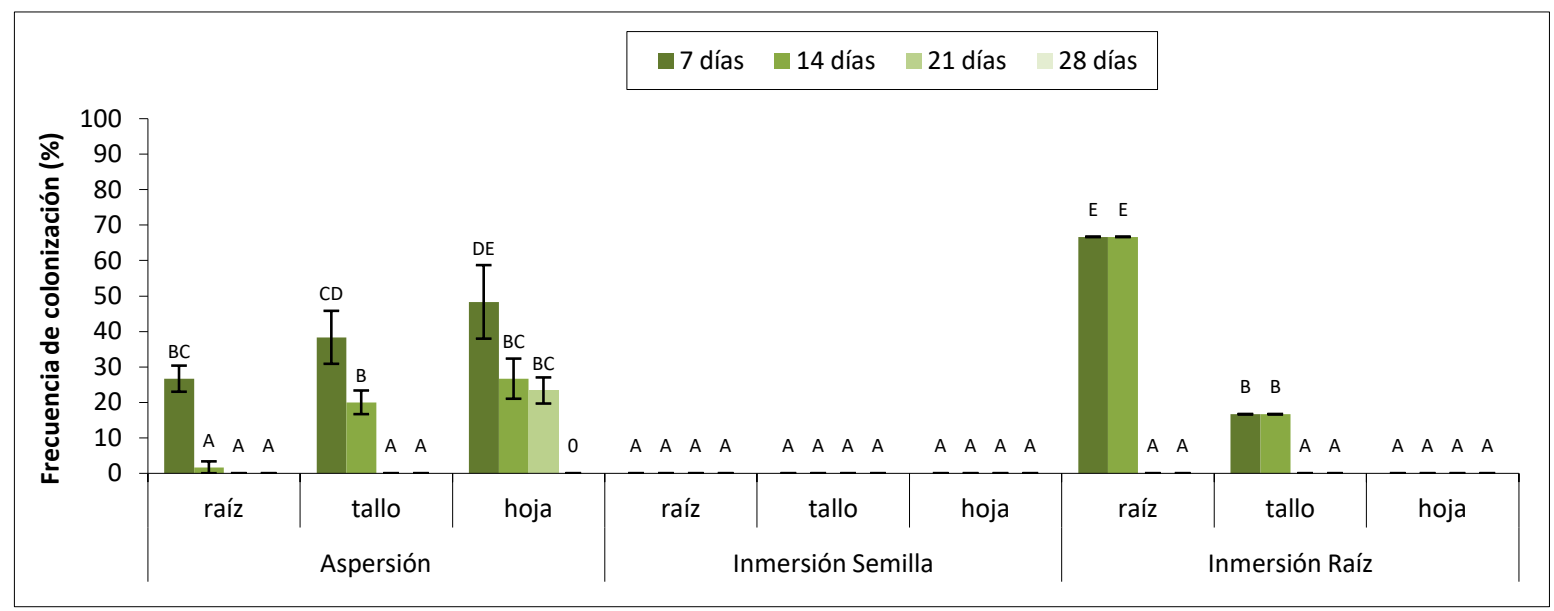

Figura II.35. Porcentaje de recuperación de M. robertsii LPSc 963 en raíz, tallo y hoja, con diferentes técnicas de inoculación en plantas de soja.Letras distintas indican diferencias significativas de acuerdo a test de Tukey $(p<0,05)$. Las barras indican el error estándar de la media. 
En síntesis, las tres técnicas de inoculación utilizadas demostraron ser efectivas para la introducción de $B$. bassiana, siendo la cepa LPSC 1098 y la técnica de aspersión en hoja la más exitosa tanto para maíz como para soja (Figuras II.36 a, b). Con las técnicas de inmersión de semilla e inmersión de la raíz se pudo demostrar que la presencia de los hongos entomopatógenos como endófitos son capaces de desplazarse a través de los tejidos de las plantas de maíz y soja, entrando por las raíces y las semillas para luego ser aisladas en tallos y hojas.

De igual manera, la técnica de aspersión en hoja demostró la capacidad de los hongos entomopatógenos de entrar por medio de este órgano hacia el interior de las plantas, desplazarse por los distintos tejidos, para luego poder ser aislados a partir de tallo, raíz y las mismas hojas.
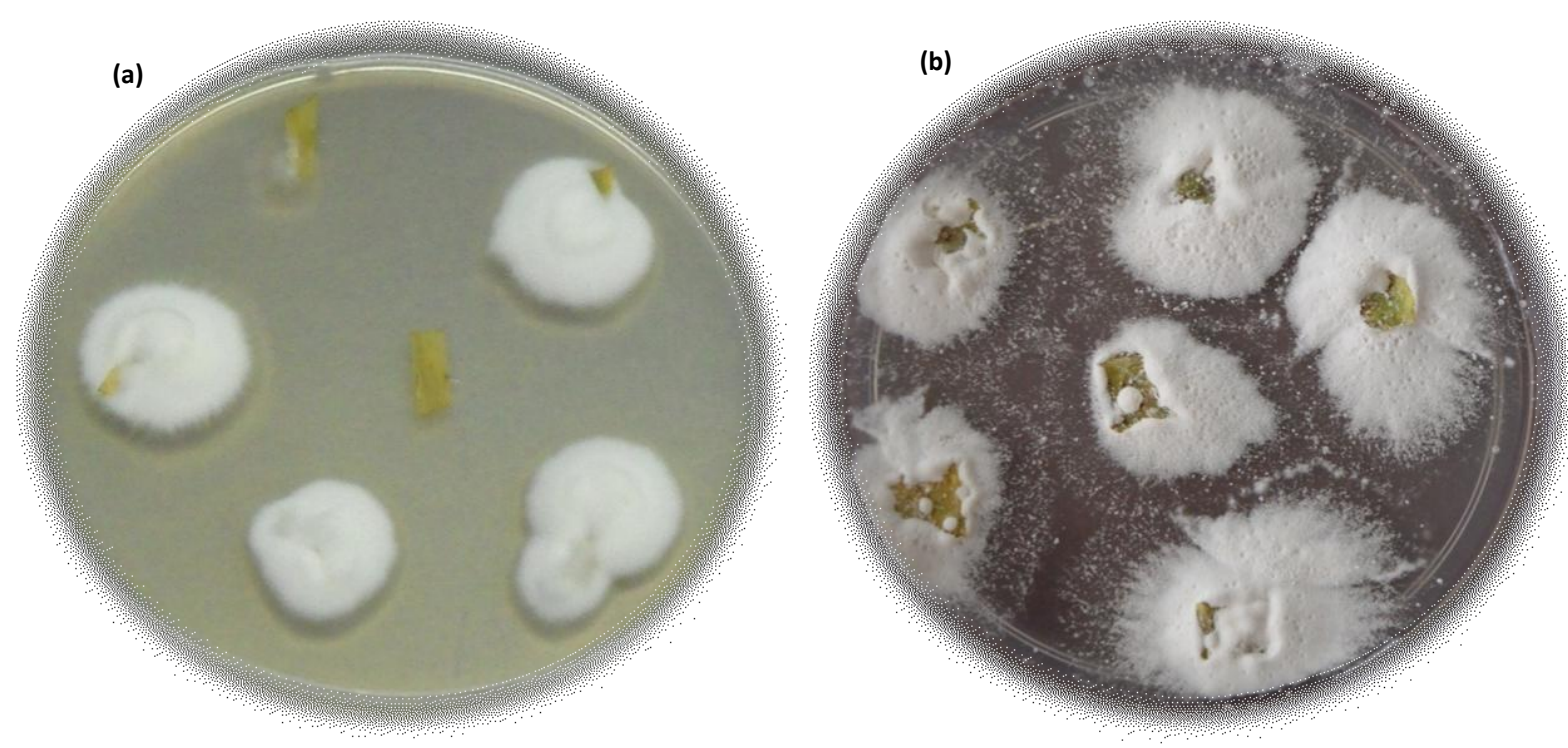

Figura II.36. Reaislamiento de la cepa B. bassiana LPSc 1098 a) maíz, b) soja 


\section{Discusión}

Este estudio demuestra que las tres técnicas de inoculación (aspersión foliar, inmersión de raíz e inmersión de semilla) fueron efectivas para introducir las diferentes cepas de $B$. bassiana en las plantas de maíz y soja. Por el contrario, las cepas de $M$. anisopliae y $M$. robertsii pudieron establecerse únicamente mediante las técnicas de aspersión foliar e inmersión de raíz, mientras que las cepas probadas de $L$. lecanii y la cepa de $T$. cylindrosporum no se incorporaron en las plantas de maíz y soja, por ninguna de las tres técnicas de inoculación mencionadas anteriormente.

En este estudio la eficacia de la esterilización se evaluó pipeteando alícuotas del enjuague final del procedimiento de esterilización y sembrándolo en medio de cultivo sólido (Posada y vega, 2005; Tefera y Vidal, 2009; Parsa et al. 2013; Vidal y Jaber, 2015 y Greenfield et al. 2016), a diferencia de otros estudios que comprobaron la eficacia de esterilización marcando la impronta del tejido vegetal esterilizado sobre un medio sólido (McKinnon et al. 2017).

Es importante mencionar que la colonización endofítica de estos hongos entomopatógenos depende de varios factores, como lo son el método de inoculación, la concentración del inóculo, la edad de la planta y de las especies de plantas estudiadas (Fernandes et al. 2015).

Al igual que en plantas de maíz (Gurulingappa et al. 2010), amapola (Quesada Moraga et al. 2006), habas (Parsa et al. 2013) y sorgo (Tefera y Vidal, 2009), en este estudio, la mejor técnica para la introducción de las distintas cepas fúngicas fue la aspersión foliar. Se observó además que la mayor recuperación de B. bassiana y de las diferentes especies de Metarhizium utilizadas en este estudio, ocurrió en hojas, a los 7 días posteriores a la inoculación.

Por otro lado, cuando la inoculación de las plantas se realizó en las raíces o semillas, la mayor cantidad de aislamientos se obtuvieron de raíces y en menor proporción en hojas, debido a que más probable la colonización por el hongo aplicado en la parte de la planta que estaba en contacto directo con el inoculo y menos probable o ausente en las partes de la planta distantes del lugar de aplicación (Greenfield et al. 2016). Es importante mencionar que el porcentaje de aislamiento fue disminuyendo a medida que transcurrió el tiempo. Estos resultados coinciden con los realizados por Parsa et al. (2013) en habas, Greenfield et al. (2016) en mandioca y Brownbridg et al. (2012) en pino. Por el contrario un estudio llevado a cabo por 
Batta (2013) en plantas de colza, demostró que los hongos entomopatógenos Metarhizium sp. y Beauveria $s p$. fueron mayormente aislados a las 4 semanas posteriores a la inoculación.

Sin embargo, en contraste con el éxito de la inoculación de hojas que se pudo observar que en este estudio, algunos trabajos indican que la hoja no sería una vía adecuada de entrada del hongo para colonizar plantas como el café (Posada et al. 2007) y el tomate (Qayyum et al. 2015), donde la mayor recuperación de B. bassiana después de la inoculación se produjo a partir de las plantas de café inoculadas por inyección directa y de las de tomate inoculadas a través de la raíz.

B. bassiana, M. anisopliae y M. robertsii pudieron establecerse como endófito en plantas de maíz y soja. Al igual que lo registrado por Parsa et al. (2013) y Brownbridg et al. (2012), el tratamiento de semillas o raíz con estos hongos entomopatógenos, no redujo la germinación de las semillas o el crecimiento de las plántulas y tampoco se observaron raíces enfermas (datos observados y no mostrados).

En coincidencia con estos resultados, Tefera y Vidal (2009) y Posada y Vega (2005), demostraron que la colonización de Beauveria y Metarhizium fue diferente entre las distintas partes de la planta. La razón para una mayor colonización de las hojas y tallos no está clara, pero podría reflejar las diferentes condiciones fisiológicas en los órganos de la planta y diferencias en contenidos microbianos, ya que, más allá de utilizar sustrato estéril y esterilizar las semillas no se garantiza que las plantas estén libres de endófitos naturales. (Posada y Vega, 2005; Vega, 2008; Quesada Moraga et al. 2009). La colonización de las diferentes partes de la planta indica que el hongo se mueve dentro de ella de manera sistémica (Ownley et al. 2008; Quesada Moraga et al. 2009; Akutse et al. 2013).

Con respecto a las posibles razones para explicar la baja recuperación del inóculo a los 28 días posteriores a la inoculación se pueden mencionar: a) el métodos utilizado para aislar los diferentes hongos que puede no ser lo suficientemente sensibles para asegurar la recuperación del inóculo, b) la competencia de otros hongos y bacterias en el sistema, c) la respuesta del huésped al hongo no permitiendo el establecimiento de un equilibrio en la coexistencia (relación endofítica) de ambos organismos, conduciendo de esta manera a la inhibición del crecimiento de Beauveria y Metarhizium (Posada et al. 2007). También es posible que el método de esterilización haya tenido consecuencias inhibiendo la aparición, teniendo en cuenta que se utilizaron pequeñas secciones de la planta, el procedimiento elegido debe ser optimizado para la planta huésped con respecto al tipo de tejido y a su sensibilidad, tal como lo ha referido Brownbridg et al. (2012). 


\section{CAPÍTULO III}

Efecto de Beauveria bassiana como endófito sobre el crecimiento y rendimiento de plantas de maíz y

$$
\text { soja }
$$




\section{Introducción}

El hongo entomopatógeno $B$. bassiana ha sido probado como agente de control biológico contra diversas plagas. Como endófito, se ha encontrado de forma natural en varias especies de plantas (Vega, 2008) mientras que en otras se han introducido artificialmente (Gurulingappa et al. 2010; Brownbridge et al. 2012; Akello y Sikora, 2012; Parsa et al. 2013; Quesada-Moraga et al. 2014b; López y Sword, 2015; Russo et al. 2015), colonizando a las plantas de forma sistémica (Quesada-Moraga et al. 2006; Gurulingappa et al. 2010; Russo et al. 2015) o localizada (Wearn et al. 2012; Yan et al. 2015).

Los hongos entomopatógenos como endófitos son importantes debido a que producen diversos metabolitos con una amplia gama de posibles usos en la agricultura como el ácido oxálico, la beauvericina, efrapeptinas y destruxinas (Selim et al. 2012; Qayyum et al. 2015). Recientemente, se ha demostrado que ciertos hongos entomopatógenos pueden desempeñar otra función en la naturaleza como agentes promotores del crecimiento de plantas mediante el aumento de ciertos parámetros, como el largo de la raíz, el peso seco, peso fresco, área foliar, germinación de las semillas, altura y rendimiento de las plantas, e incluso mejorar su nutrición (Kabaluk y Ericsson, 2007; Ownley et al. 2008; Vega, 2008; Vega et al. 2009; Sasan y Bidochka, 2012; García López et al. 2013; Maag et al. 2013; Liao et al. 2014; Sánchez Rodríguez et al. 2015).

En diferentes cultivos, donde las plantas fueron inoculadas con hongos entomopatógenos, se comprobó que han producido aumentos significativos en el crecimiento y rendimiento: en cultivos de maíz y cebollas (Kabaluk y Ericsson 2007), en tomate y algodón (Ownley et al. 2004; Griffin et al. 2005; Ownley et al. 2008, Castillo Lopez y Sword 2015; Qayyum et al. 2015), en sorgo (Tefera y Vidal 2009), en mandioca (Greenfield et al. 2016) y en banana (Akello et al. 2008 a, b). Una de las ventajas de la utilización de hongos endófitos promotores del crecimiento vegetal sería la disminución del uso de fertilizantes químicos, los cuales poseen elevadas cantidades de nitrógeno, fósforo y potasio, que en general sólo son absorbidas por las plantas entre un $10 \%$ y un $40 \%$ del total del fertilizante aplicado por el productor, el resto se pierde provocando la contaminación del agua, el aire, la tierra y afectando directamente al hombre. La visión innovadora de la producción agrícola atrae a la creciente demanda de fertilizantes orgánicos basados en productos biológicos, donde 
los hongos surgen como una alternativa a los productos químicos (Bhardwaj et al. 2014).

El objetivo de este capítulo fue utilizar la técnica de inoculación más eficiente (probada en el capítulo II), es decir, la aspersión de plantas jóvenes y el aislamiento fúngico que con mayor frecuencia se pudo aislar de las plantas inoculadas bajo condiciones de laboratorio, para evaluar si produce algún efecto en el crecimiento y rendimiento de las plantas de maíz y soja. 


\section{Materiales y Métodos}

\section{Inoculación de las plantas de maíz y soja y su establecimiento en el campo}

Se utilizó la cepa LPSc 1098 de $B$. bassiana, que fue seleccionada en función de su alta capacidad de esporulación y principalmente a su alta tasa de colonización vegetal, tal como se pudo observar en el capítulo II. Para obtener la suspensión de conidios, este aislamiento fúngico se cultivó en cajas de Petri con agar papa dextrosa (APG) mantenidas durante 15 días a $25^{\circ} \mathrm{C}$ en oscuridad. La concentración de conidios fue preparada según Gurulingappa et al. (2010), la cual se determinó utilizando una cámara de Neubauer y se ajustó a $1 \times 10^{8}$ conidios/ml.

Las plantas se obtuvieron siguiendo la metodología descriptas en el capítulo II. Se mantuvieron en invernáculo a $25{ }^{\circ} \mathrm{C}$ y $12 \mathrm{~h}$ de fotoperíodo y fueron regadas diariamente. Transcurridas dos semanas todas las plantas fueron inoculadas (dentro del invernáculo para evitar el deterioro de los conidios mediante la exposición a los rayos UV) a través del método de aspersión que demostró previamente ser la técnica más efectiva para introducir la cepa de $B$. bassiana como endófito en ambas especies de plantas.

Dos semanas después de efectuarse la inoculación tanto las plantas tratadas como las controles de ambas especies fueron trasplantadas a campo de manera aleatorea, para ellos se sembraron dos parcelas, una de 12 × $12 \mathrm{~m}$. para el maíz y otra de 10 × $10 \mathrm{~m}$. para la soja, respetando la época de siembra de cada cultivo (Figuras III.1, 4). Las plantas de maíz se distribuyeron en la parcela formando seis surcos de diez plantas cada uno distanciados 0,75 m. entre sí. En cada uno de ellos las plantas estuvieron separadas a $0,50 \mathrm{~m}$. de distancia. Por otro lado, las plantas de soja se distribuyeron en la parcela formando seis surcos de diez plantas cada uno distanciados a 0,50 m. entre sí. En cada uno de ellos las plantas estuvieron separadas a $0,35 \mathrm{~m}$. de distancia.

Este ensayo se realizó en la localidad de Alberti, ubicada en el Noroeste de la provincia de Buenos Aires, siendo la precipitación media anual de $1000 \mathrm{~mm}$ y su temperatura media de $16^{\circ} \mathrm{C}$ (www.trigoklein.com.ar/estacion-meteorológica). Ambas especies forman parte de sus cultivos principales, características que aseguraron que las plantas lleguen a su madurez fisiológica en óptimas condiciones (Figuras III.2, 5). 


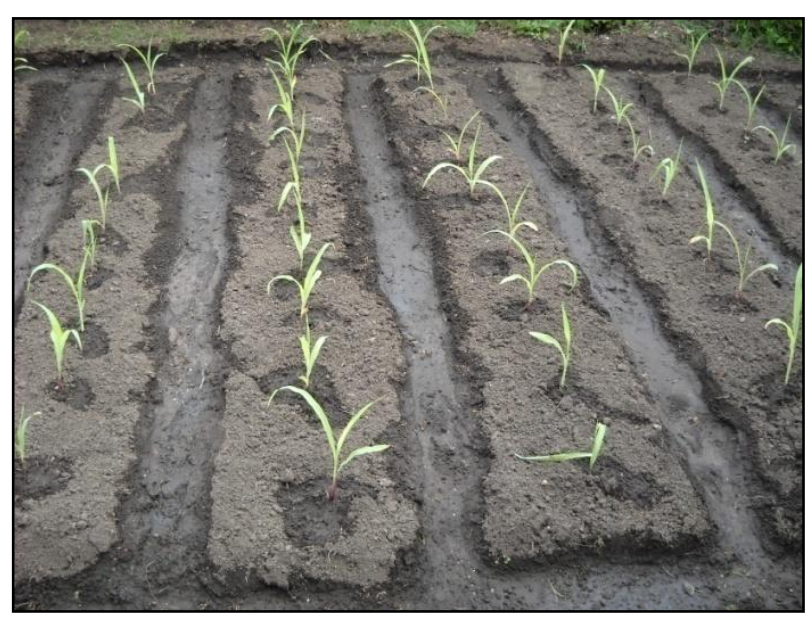

Figura III.1. Plantas de maíz trasplantadas a condiciones de campo

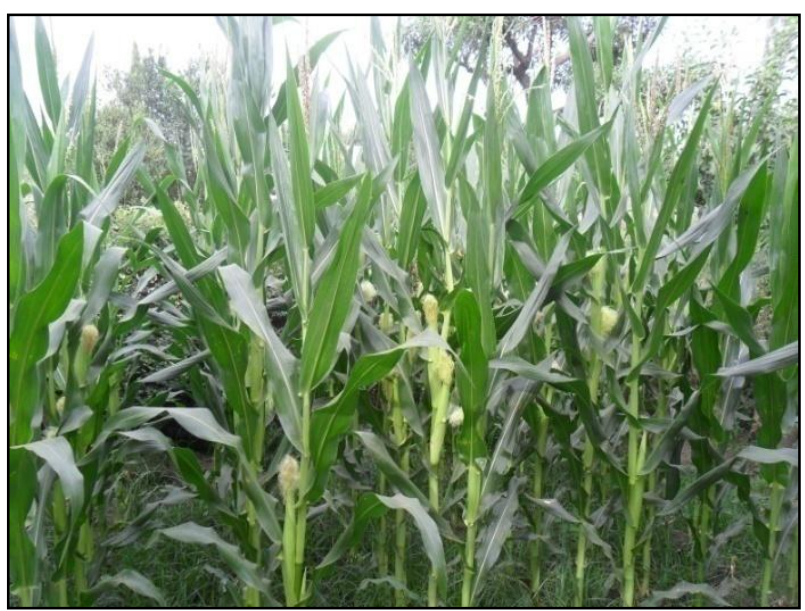

Figura III.2. Plantas de maíz alcanzando su madurez fisiológica

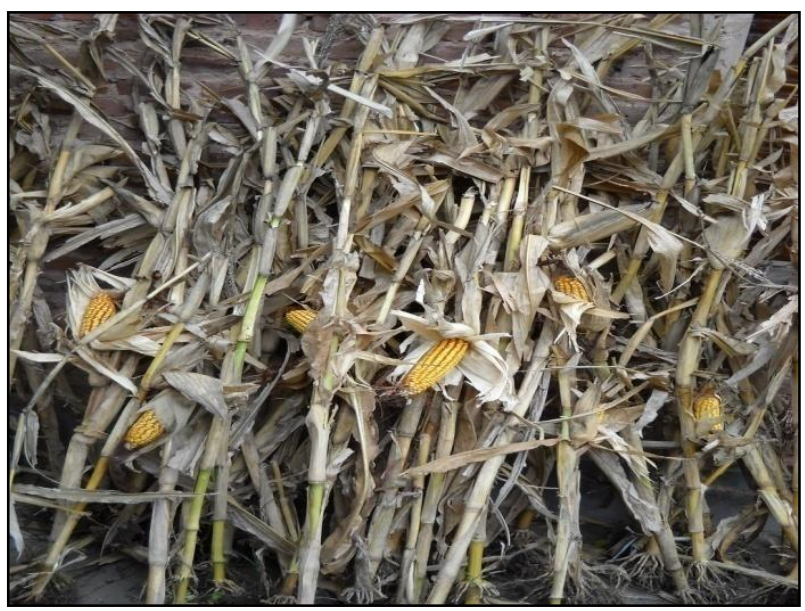

Figura III.3. Plantas de maíz que han completado su ciclo 


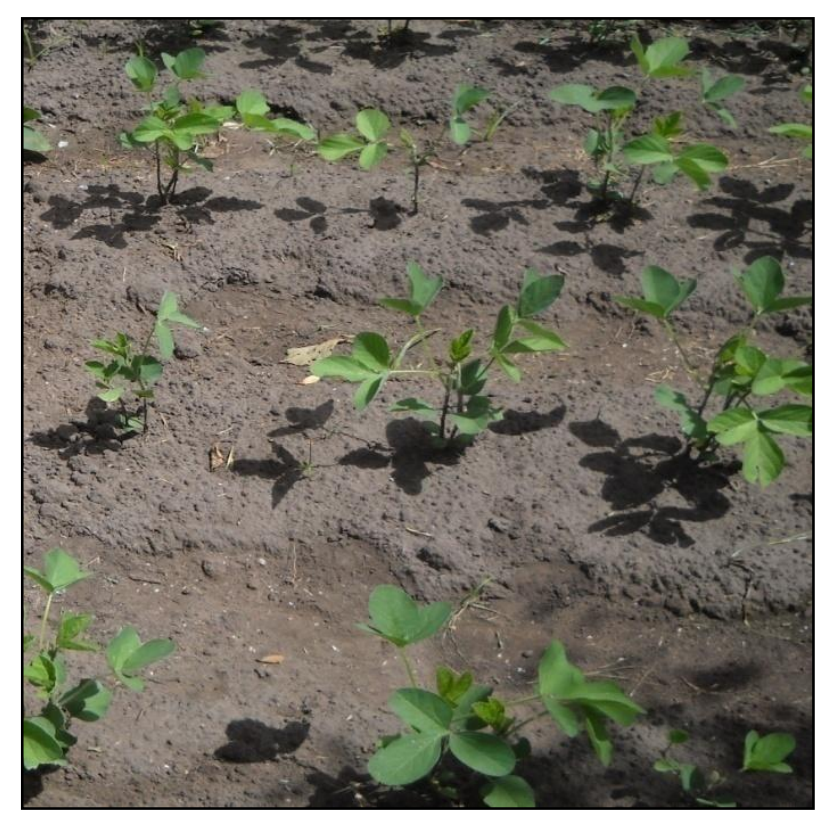

Figura III.4. Plantas de soja trasplantadas a condiciones de campo

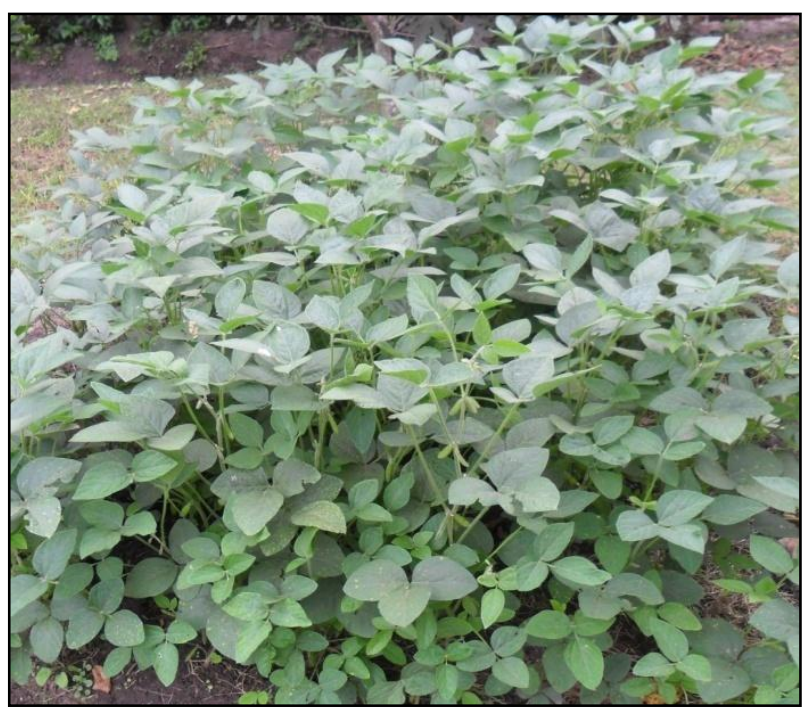

Figura III.5. Plantas de soja alcanzando su madurez fisiológica

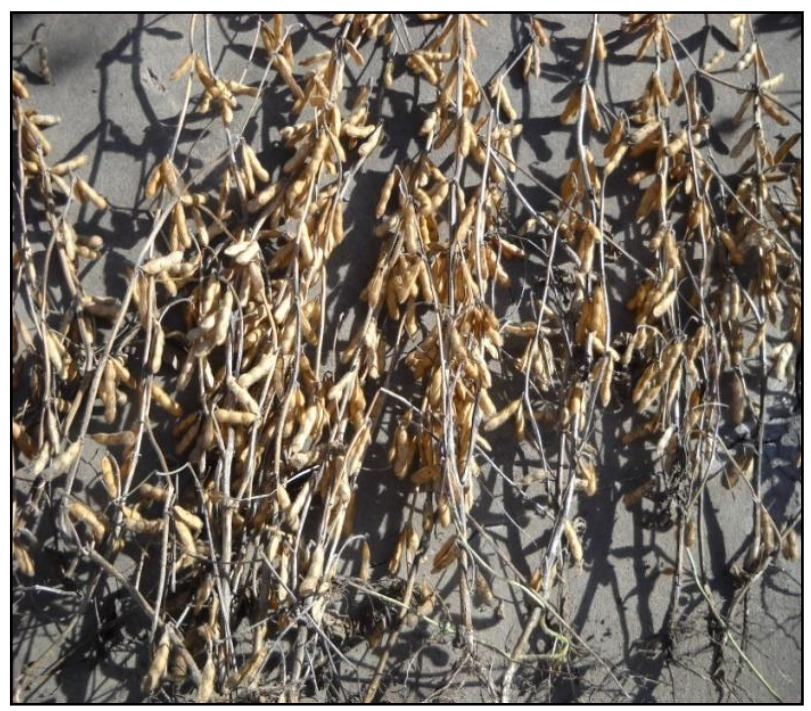

Figura III.6. Plantas de soja que han completado su ciclo 


\section{Crecimiento y rendimiento de las plantas}

El efecto producido por B. bassiana LPSc 1098 actuando como endófito sobre el crecimiento de las plantas se determinó al cabo de 5 meses, cuando las mismas habían completado su ciclo (Figuras III.3, 6).

Para las plantas de maíz se determinó: altura de la planta, número de hojas, altura y número de nudo en dónde emerge la primer mazorca, cantidad de hileras de granos por mazorca y cantidad de granos por hilera, peso de granos por planta, número de mazorcas por planta y rendimiento que fue calculado según Diestéfano et al. (2010).

Para las plantas de soja se determinó la altura de la planta, cantidad de ramas por planta, cantidad de vainas por rama y por planta, peso de vainas por rama y por planta, cantidad de semillas por vaina, por rama y por planta, peso de semillas por rama y por planta y el rendimiento según Diestéfano y Gadbán (2010).

En este experimento se utilizaron 30 plantas inoculadas y 30 plantas controles para cada cultivo. Los controles tuvieron el mismo tratamiento pero fueron inoculados con una solución de tween 80 ( $\left.\operatorname{Merck}^{\circledR}\right)$ al 0,01\% (v/v) sin el agregado de inoculo fúngico.

\section{Transmisión vertical}

Para evaluar si existe transmisión vertical (de planta a semilla), se tomaron 10 semillas de cada planta tratada y 10 semillas de cada planta control, se esterilizaron superficialmente según la técnica de Akello y Sikora (2012), se cortaron y colocaron en cajas de Petri con medio de cultivo selectivo para hongos entomopatógenos (Posada et al. 2012) (Figuras III.7a, b). Las cajas se mantuvieron en cámaras incubadoras (Semedic, I-219PF) a $25^{\circ} \mathrm{C}$ y oscuridad durante un período de 10 días.

También se tomaron otras 10 semillas de cada planta tratada $(n=300)$ y 10 controles $(n=300)$ y se sembraron en macetas con sustrato estéril. Las macetas se mantuvieron en invernáculo bajo condiciones controladas de temperatura, humedad y fotoperíodo $\left(24^{\circ} \mathrm{C}, 75 \% \mathrm{HR}, 14: 10 \mathrm{~L}\right.$ : O). Para confirmar la presencia del hongo como endófito, se realizaron cortes de $10 \times 10 \mathrm{~mm}$ de tejido vegetal de las hojas de cada una de las plantas tratadas y controles. Estas porciones de tejido vegetal fueron esterilizadas superficialmente mediante baños sucesivos en hipoclorito de sodio $0.5 \%$, 
etanol $70 \%$, agua destilada estéril y luego se colocaron sobre papel de filtro estéril y se dejaron secar bajo condiciones de esterilidad en cámara de flujo laminar. Posteriormente fueron depositados en cajas de Petri que contenían medio de cultivo Agar Papa Glucosa (APG) más antibiótico (0,5g estreptomicina-0,25g cloranfenicol). Se mantuvieron en condiciones controladas de temperatura ( $25^{\circ} \mathrm{C}$ ) y en oscuridad, durante 10 días.
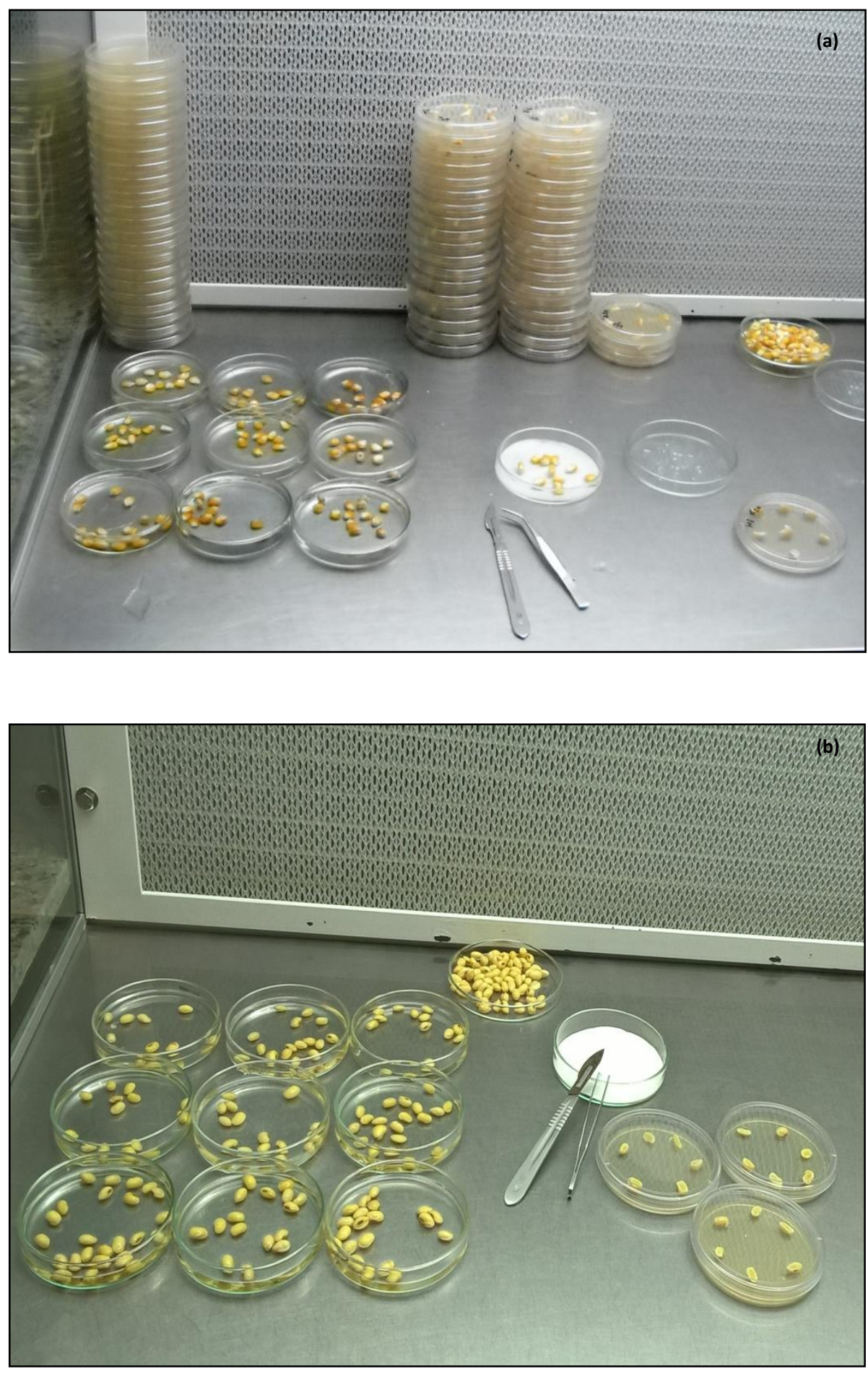

Figura III.7. Evaluación de la transmisión vertical de $B$. bassiana a) maíz, b) soja 


\section{Poder germinativo de las semillas obtenidas}

Tanto para las plantas de soja como para las de maíz se calculó el poder germinativo de las semillas obtenidas tanto de las plantas tratadas como de las controles. El poder germinativo (PG) se determinó según normas de la Asociación Internacional de Análisis de Semillas (ISTA, 2007), siguiendo el protocolo de Luna y Iannone, (2013) modificado, para ello se utilizaron 3 muestras de 100 semillas por repetición de cada uno de los tratamientos ensayados. Como sustrato se empleó arena esterilizada y humedecida. La germinación de las semillas se realizó en cámara a $25^{\circ} \mathrm{C}$ y 12 horas de luz. El recuento se efectuó a los 8 días, registrándose el número de plántulas normales, anormales y las semillas muertas. El poder germinativo se calculó como el porcentaje (\%) de semillas que han logrado germinar y producir plántulas que pueden ser categorizadas como normales al final del período del ensayo de laboratorio.

\section{Análisis de datos}

El poder germinativo, el rendimiento y cada uno de los parámetros de crecimiento registrados para las plantas de maíz y soja inoculadas con $B$. bassiana y las no inoculadas (controles) fueron comparadas por mediode un test de $t$. 


\section{Resultados}

\section{Efecto de $B$. bassiana sobre el crecimiento de las plantas}

El hongo entomopatógeno $B$. bassiana promovió el desarrollo de las plantas. Los parámetros de crecimiento evaluados en las plantas de maíz inoculadas con $B$. bassiana fueron significativamente mayores que en las plantas controles: altura de la planta ( $T=5,49 ; g l=58 ; p<0,0001)$, número de hojas $(T=6,83 ; g l=58 ; p<0,0001)$, altura donde emerge la primer mazorca $(T=2,85 ; g l=58 ; p=0,0064)$, número de nudo donde emerge la primer mazorca $(T=3,87 ; g l=58 ; p=0,0003)$, cantidad de hileras de granos por mazorca $(T=6,49 ; g l=58 ; p<0,0001)$, cantidad de granos por hilera $(T=5,83 ; g l=58 ; p<0,0001)$, número de mazorcas por planta $(T=4,20 ; g l=58$; $p<0,0001)$, peso de semillas por planta $(T=5,56 ; g l=58 ; p<0,0001)$ y rendimiento $(T=5,73 ; g l=4 ; p=0,0046)$.

También en las plantas de soja los parámetros de crecimiento evaluados fueron significativamente mayores con respecto a las plantas controles: altura de las plantas $(T=4,49 ; \quad g l=58 ; \quad p<0,0001)$, número de ramas por planta $(T=4,38 ; g l=58$; $p<0,0001)$, peso de vainas por rama $(T=3,71 ; g l=58 ; p=0,0005)$, peso de vainas por planta $(T=4,85 ; \mathrm{gl}=58 ; \mathrm{p}<0,0001)$, número de vainas por rama $(T=2,87 ; \mathrm{gl}=58$; $p=0,0057)$, número de vainas por planta $(T=4,32 ; \mathrm{gl}=58 ; \mathrm{p}<0,0001)$, cantidad de semillas por vaina $(T=3,48 ; g l=58 ; p=0,0009)$, cantidad de semillas por rama ( $T=4,54 ; \mathrm{gl}=58 ; \mathrm{p}<0,0001)$, cantidad de semillas por planta $(T=4,88 ; \mathrm{gl}=58$; $p<0,0001)$, peso de semillas por rama $(T=1,57 ; g l=58 ; p=0,05)$, peso de semillas por planta $(T=4,17 ; g l=58 ; p<0,0001)$ y rendimiento $(T=2,67 \mathrm{gl}=4 ; p=0,0456)$.

Los valores medios de cada uno de los parámetros evaluados para las plantas tratadas y controles de maíz y soja se muestran en las Figuras III.8, 9 respectivamente. 

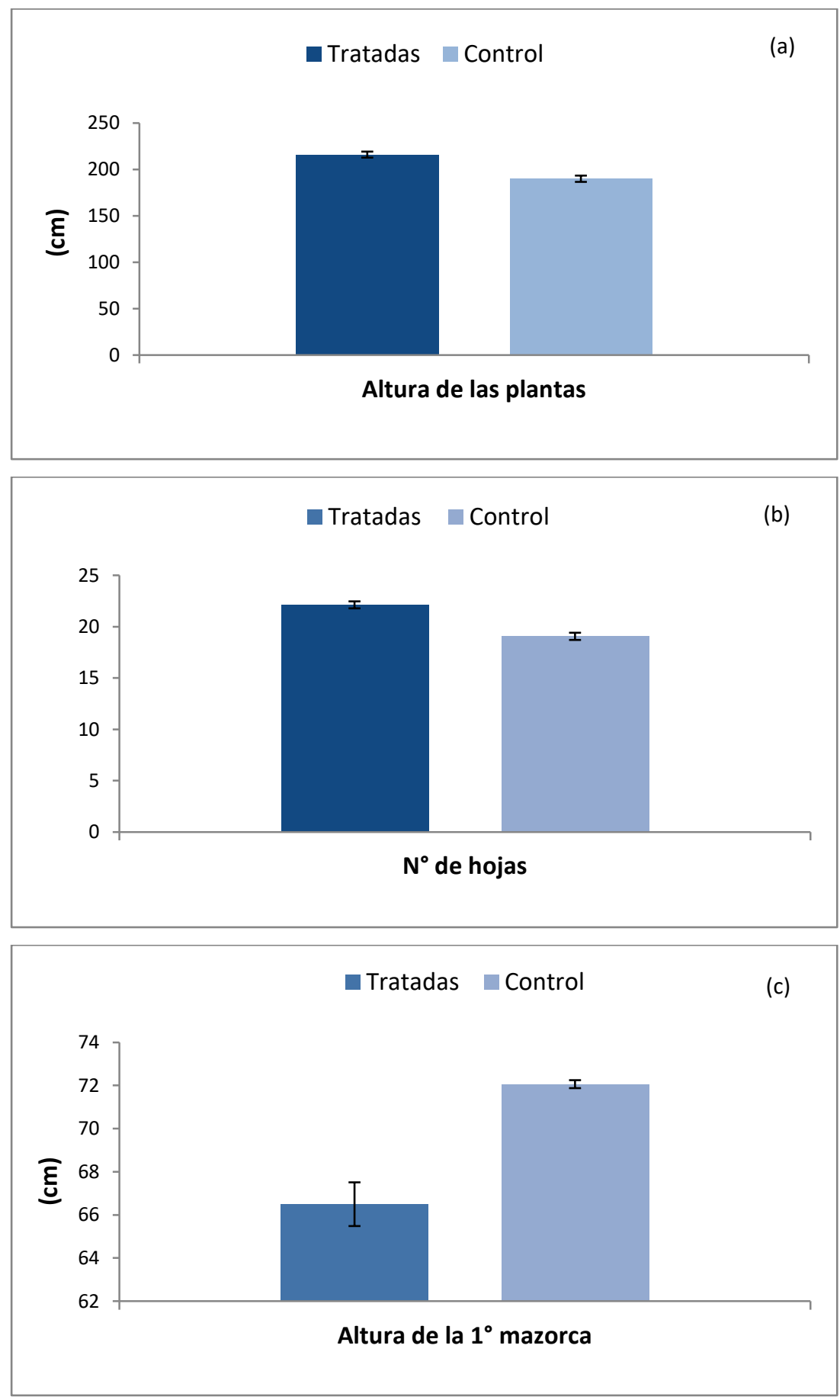

- Tratadas Control

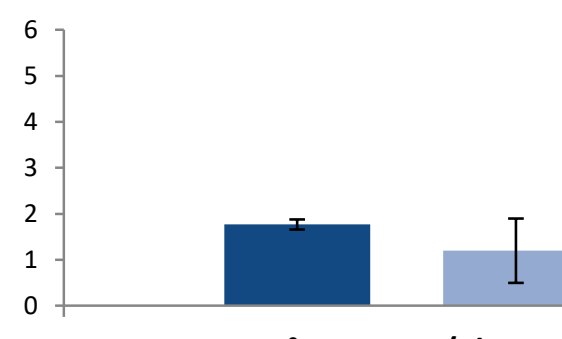

$N^{\circ}$ mazorcas/planta

$N^{\circ}$ de nudo de la primer mazorca 

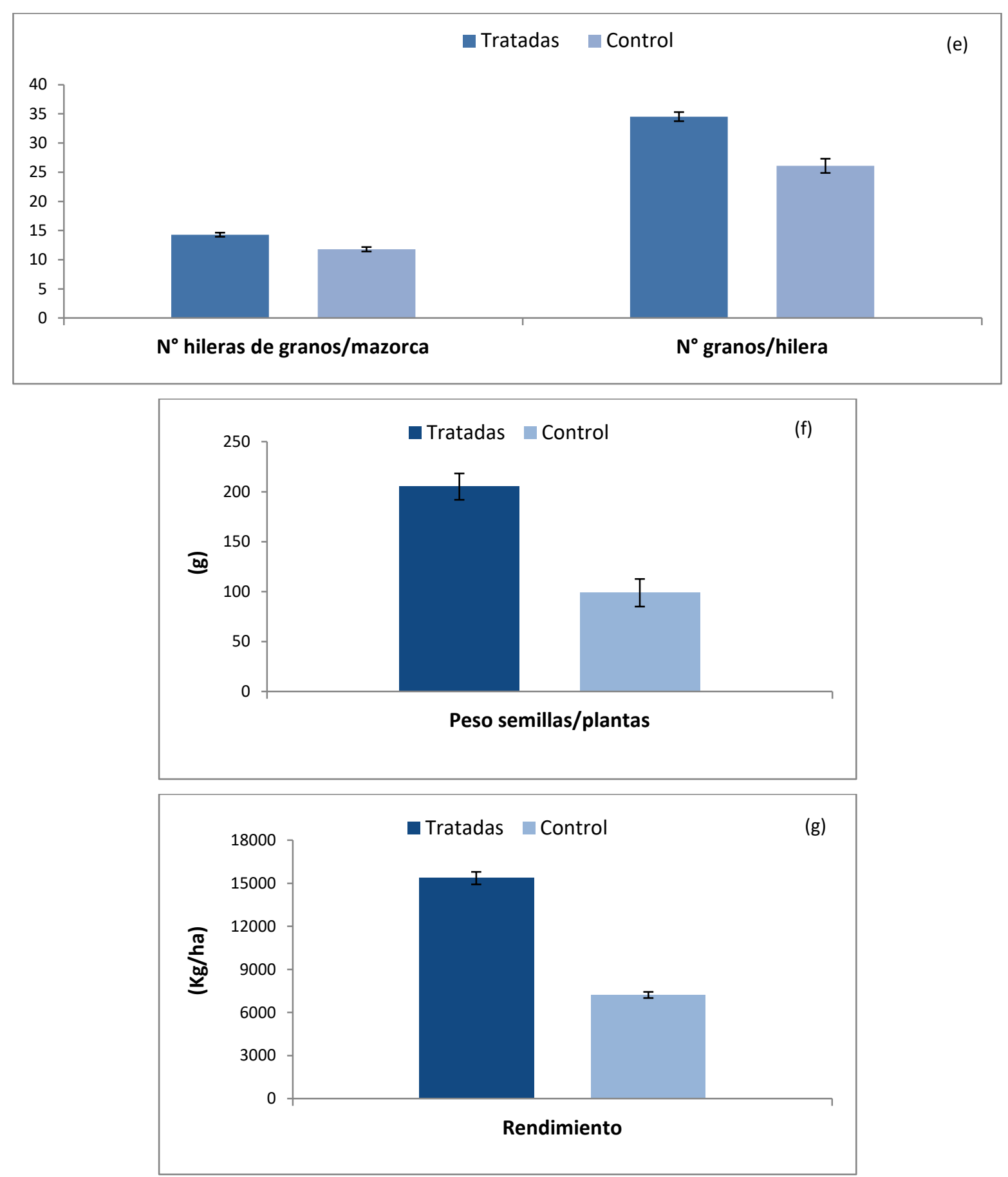

Figura III.8. Parámetros de crecimiento evaluados en plantas de maíz: a) Altura de la planta $(\mathrm{cm}), \mathrm{b}) \mathrm{N}^{\circ}$ de hojas, c) Altura de la primer mazorca $\left.(\mathrm{cm}), \mathrm{d}\right) \mathrm{N}^{\circ}$ de mazorcas/planta y $\mathrm{N}^{\circ}$ nudo de la primer mazorca, e) $\mathrm{N}^{\circ}$ hilera de grano/mazorca y $\mathrm{N}^{\circ}$ granos/hilera, f) Peso semillas/planta $(\mathrm{g}), \mathrm{g})$ Rendimiento $(\mathrm{Kg} / \mathrm{ha})$. Las barras indican el error estándar de la media. 

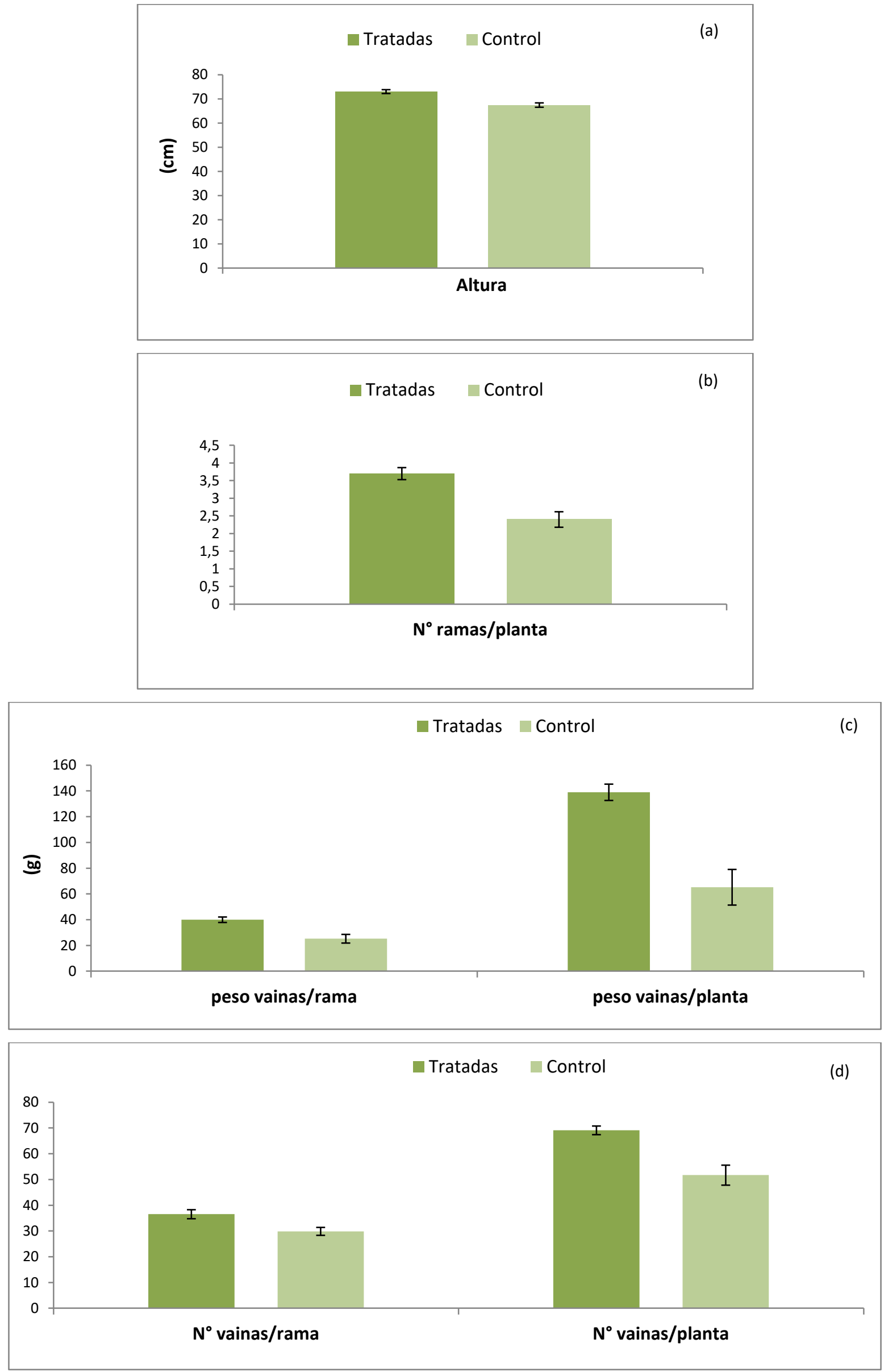

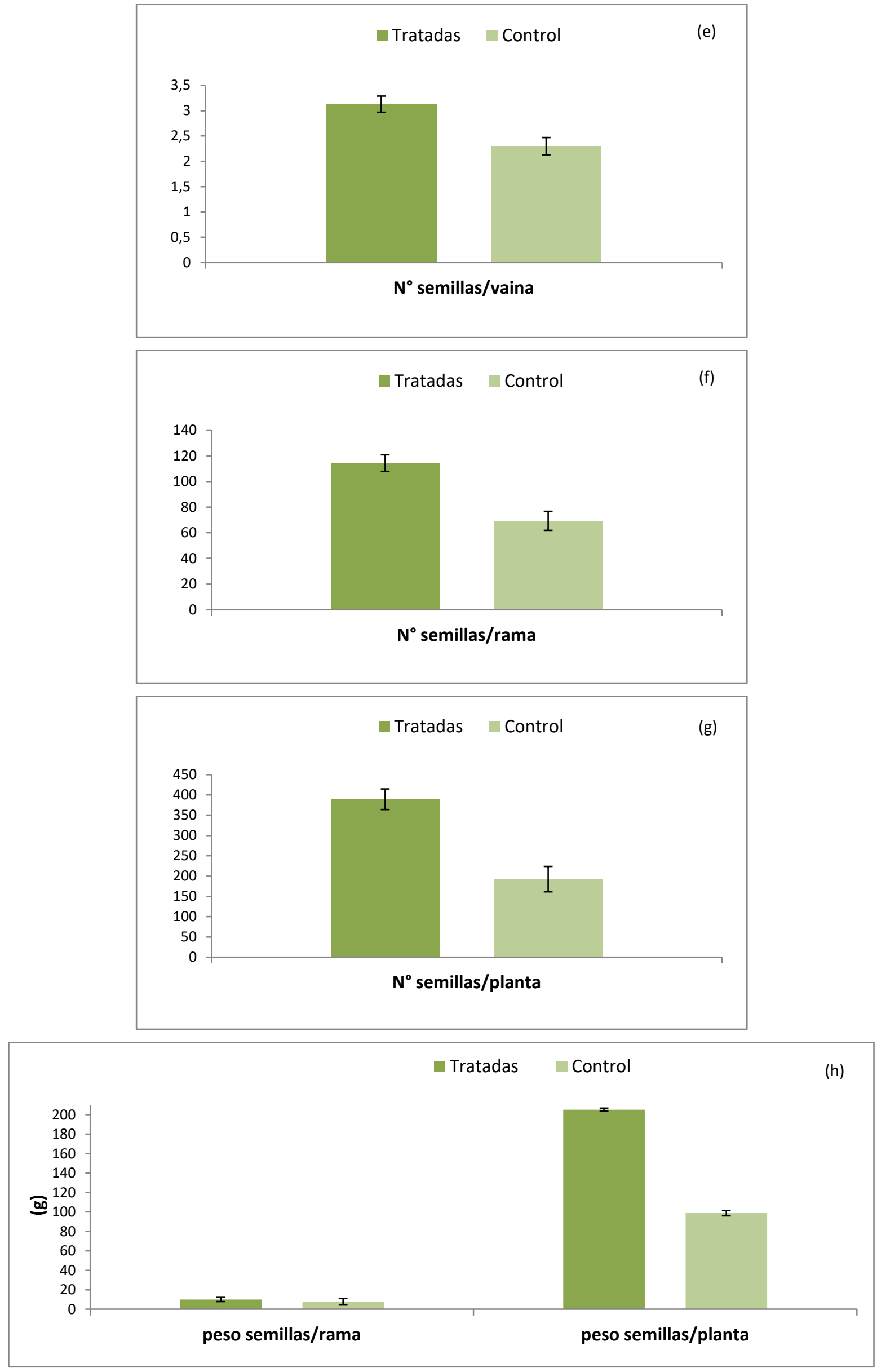


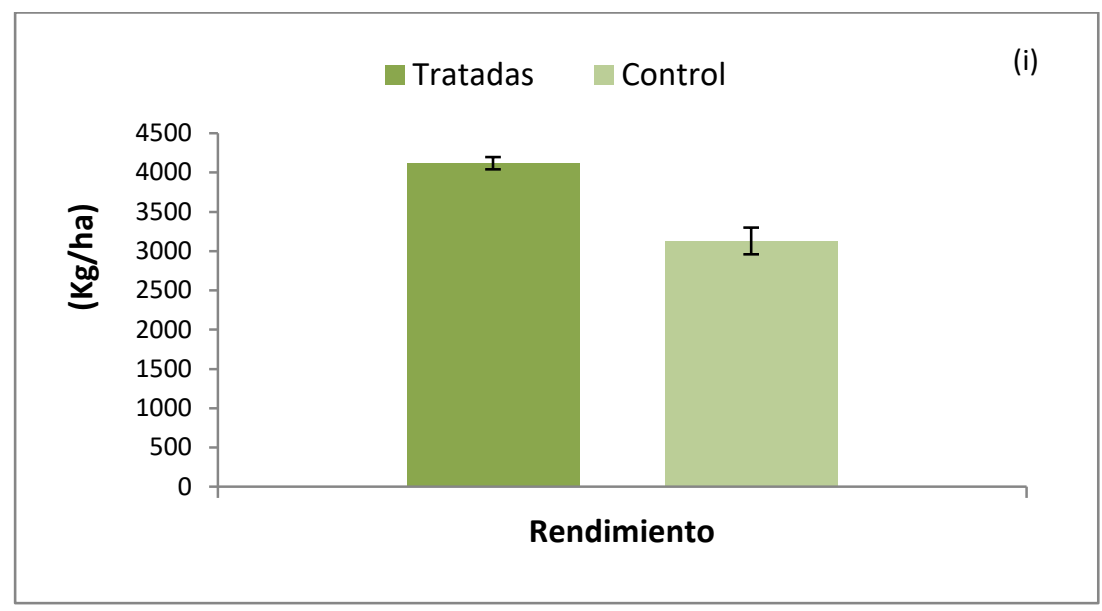

Figura III.9. Parámetros de crecimiento evaluados en plantas de soja: a) Altura de la planta $(\mathrm{cm}), \mathrm{b}) \mathrm{N}^{\circ}$ de ramas/planta, c) peso vainas/rama y peso vainas/planta $\left.(\mathrm{g}), \mathrm{d}\right) \mathrm{N}^{\circ}$ de vainas/rama y número de vainas/planta, e) número de semillas/vaina, f) número de semillas/rama, g) $N^{\circ}$ de semillas/planta, h) peso de semillas/rama y peso de semillas/planta $(\mathrm{g}), \mathrm{i})$ Rendimiento $(\mathrm{Kg} / \mathrm{ha})$. Las barras indican el error estándar de la media. 


\section{Transmisión vertical de $B$. bassiana y poder germinativo de las semillas obtenidas}

Los resultados de este estudio demostraron que la cepa LPSc 1098 de $B$. bassiana no se transmitió verticalmente a través de las plantas de la generación parental.

No obstante, cuando se analizó el poder germinativo de las semillas obtenidas de las plantas tratadas y controles, los valores medios obtenidos para las plantas de maíz demostraron que en aquellas plantas tratadas el poder germinativo fue significativamente menor $(T=3,01, g l=4, p<0,0395)$ que en las plantas controles. En cambio, en el caso de las plantas de soja, el poder germinativo de las plantas tratadas fue significativamente mayor $(T=8,55, g l=4, p<0,0010)$ en relación al de las plantas controles. (Tabla III.1).

Tabla III.1. Poder germinativo de las semillas obtenidas de las plantas tratadas y controles

\begin{tabular}{lcccc}
\hline \hline & \multicolumn{2}{c}{ Soja } & \multicolumn{2}{c}{ Maíz } \\
\hline & Tratadas & Control & Tratadas & Control \\
Poder germinativo (\%) & $99 \pm 0,5 \mathrm{a}$ & $86 \pm 1 \mathrm{~b}$ & $77 \pm 5,5 \mathrm{a}$ & $89 \pm 2 \mathrm{~b}$ \\
\hline \hline
\end{tabular}

Letras distintas indican diferencias significativas

Los efectos de la inoculación de la cepa LPSc 1098 de $B$. bassiana tanto en las plantas de maíz como en las de soja fueron positivos con respecto a las plantas controles (sin tratar), promoviendo de esta manera el crecimiento de las mismas. A pesar de que no se registraron efectos adversos en ninguna de las plantas inoculadas, cabe destacar que el poder germinativo de las plantas de maíz inoculadas disminuyó con respecto a los controles, siendo este el único efecto adverso encontrado a lo largo del ensayo. 


\section{Discusión}

Los resultados mostraron que el hongo entomopatógeno $B$. bassiana afectó positivamente todos los parámetros de crecimiento evaluados tanto en las plantas de maíz como en las de soja. Posada y Vega (2006) registraron resultados similares en plántulas de café, sin observar signos perjudiciales en la salud de las plantas, mientras que Ownley et al. (2004), Griffin et al. (2005) y Ownley et al. (2008), observaron que la aplicación de $B$. bassiana como endófito en plantas de tomate y algodón produjo un aumento significativo en la altura de dichos cultivos.

Castillo López y Sword (2015), demostraron una mejora en el crecimiento de plantas de algodón en respuesta a la inoculación con $B$. bassiana y Purpureocillium lilacinum (Thom) Samson (Hypocreales: Ophiocordycipitaceae), observando un aumento en el peso seco de la planta y un aumento en el tamaño de las estructuras reproductivas. De la misma manera Greenfield et al. (2016) demostraron un mayor crecimiento de las plantas de mandioca cuando fueron inoculadas con $B$. bassiana y M. anisopliae.

En tanto la investigación realizada por Qayyum et al. (2015) en plantas de tomate inoculadas con dos cepas distintas de $B$. bassiana, demostró que una de ellas, promovió el crecimiento de las plantas a diferencia de la otra que produjo un retraso en el crecimiento y el desarrollo de las plantas y una reducción en el tamaño de los frutos.

Por otro lado Lewis et al. (2002) reportaron que no hubo diferencias en el crecimiento en plantas de maíz inoculadas con $B$. bassiana y tampoco observaron una reducción en la germinación de las semillas o el desarrollo de las plántulas. De la misma manera Tefera y Vidal (2009) tampoco notaron efectos adversos ni cambios en el crecimiento en plantas de sorgo.

En este estudio se observó que el rendimiento aumentó significativamente en ambas especies de plantas tratadas, en coincidencia con resultados similares de estudios a campo llevados a cabo en cultivos de maíz y cebollas tratados con hongos entomopatógenos (Kabaluk y Ericsson, 2007).

A diferencia de Quesada-Moraga et al. (2014 b), quienes constataron en plantas de amapola que $B$. bassiana se puede transferir verticalmente, los resultados de este estudio no pudieron demostrar tal efecto, aunque si, se pudo observar en soja que el poder germinativo de las semillas obtenidas en plantas inoculadas con $B$. bassiana, 
aumentó considerablemente en relación a las plantas no tratadas. Este resultado no se observó en las plantas de maíz inoculadas con la misma cepa fùngica.

En cuanto a los mecanismos que subyacen en la mejora del crecimiento de las plantas, estudios previos postulan que podría deberse a que el hongo entomopatógeno $B$. bassiana reduce los daños ocasionados por insectos plaga y/o actúa de manera antagónica frente a ciertos patógenos, favoreciendo de esta manera el mayor desarrollo de las plantas (Ownley et al. 2008). Mientras que otros estudios realizados principalmente con hongos endófitos, no entomopatógenos, han demostrado que dichos efectos pueden ser ya sea debido a la fijación de los nutrientes del suelo o la producción de hormonas de crecimiento (auxinas, giberelinas y citoquininas) (Castillo López y Sword, 2015).

Aunque la presente investigación no tuvo como objetivo dilucidar el mecanismo por el cual se produjo una mejora en el crecimiento de las plantas de maíz y soja que presentaban al hongo entomopatógeno $B$. bassiana como endófito, si brindó evidencias de un notable incremento en el crecimiento y rendimiento de estas plantas tratadas, sin mostrar efectos adversos en su desarrollo. Para las plantas de soja la importancia de estos resultados radica en que constituyen los primeros registros de la acción de $B$. bassiana como endófito accionando en aspectos tanto morfológicos como reproductivos los cuales son deseados para mejorar la producción agrícola. 


\section{CAPÍTULO IV}

Efectos de Beauveria bassiana

como endófito en plantas de maíz y

soja sobre dos especies plaga

Spodoptera frugiperda y

Helicoverpa gelotopoeon

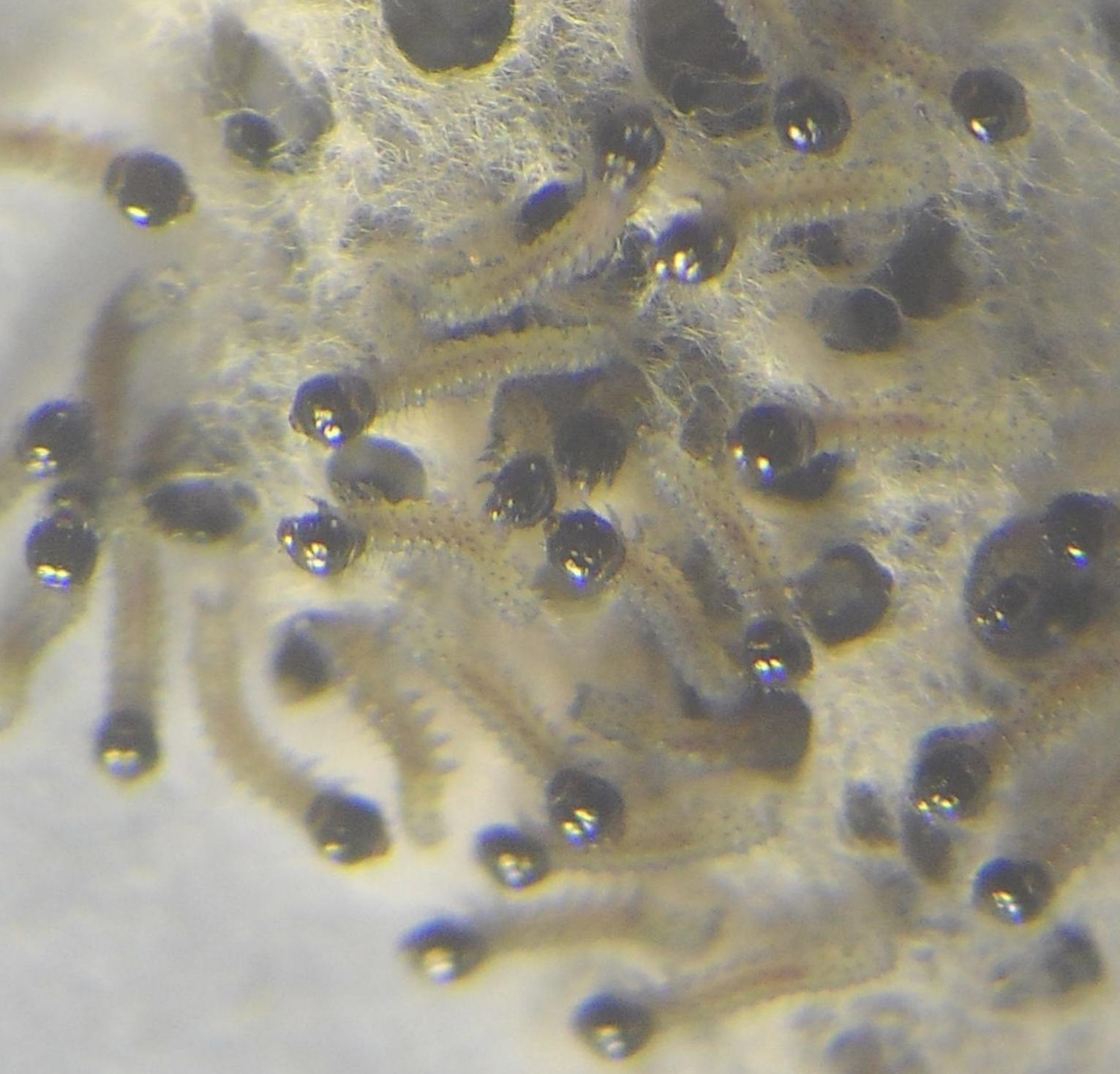




\section{Introducción}

Noctuidae constituye la familia más diversa dentro del Orden Lepidoptera e incluye el mayor número de especies de importancia agrícola (Specht et al. 2004).

S. frugiperda, conocida comúnmente como "gusano cogollero", es una especie con una amplia distribución geográfica en América, la cual va desde el sur de los Estados Unidos de Norteamérica hasta Argentina y Chile. Es un insecto polífago y es considerado la plaga más importante del cultivo del maíz, aunque también afecta en menor medida a los cultivos de soja, alfalfa, algodón, arroz, avena, caña de azúcar, cebolla, poroto, papa, sorgo, tomate y trigo. (Casmuz et al. 2010; Murúa et al. 2003; Murúa y Virla, 2004).

Deposita entre 40 y 600 huevos dispuestos en masa sobre las hojas y tallos, los mismos son cubiertos por una tela fina formada con las escamas del cuerpo de la hembra adulta. Los huevos recién depositados son verdosos y luego se tornan de color castaño con finas estrías. El período embrionario dura de 2 a 3 días y durante el desarrollo larvario son fáciles de reconocer porque las larvas poseen 4 puntos negros formando un trapecio en el dorso del antepenúltimo segmento abdominal. Los primeros estadios larvales son color verde claro y a partir del cuarto estadio adquiere tonalidades más oscuras. En el quinto estadio la sutura cefálica representa una "Y" invertida y la larva llega a medir 35-40 mm. Desarrolla 6 estadios larvales que duran aproximadamente entre 15 y 28 días, y luego empupan en el suelo (Caccia et al. 2014). Los adultos son grisáceos llegando a medir hasta $40 \mathrm{~mm}$ de expansión alar. El ciclo de vida de estos insectos oscila entre 19 y 48 días, lo cual depende de la temperatura, acortándose entre más elevada sea esta y sucediendo lo opuesto si esta disminuye (Urretabizkaya et al. 2010).

Debido a la particularidad de este lepidóptero de formar grandes poblaciones, la gran voracidad y desplazamiento de sus larvas y la alta tasa de dispersión de los adultos, $S$. frugiperda es considerada una plaga extremadamente peligrosa siendo una de las más destructivas del continente americano, produciendo una importante reducción sobre el rendimiento del cultivo de maíz (García y Clavijo, 1989).

Por otro lado, H. gelotopoeon, es conocida como "oruga bolillera". Se trata de una especie endémica de Argentina, Chile, Uruguay, Paraguay y Brasil. Es un lepidóptero polífago, plaga del cultivo de soja y daña principalmente vainas, hojas y 
tallos. También afecta al algodón, cebolla y girasol, entre otros cultivos (Pastrana, 2004; Specht et al. 2004; Fichetti et al. 2009).

Desde hace varios años sus poblaciones se han vuelto más abundantes en la región pampeana y viene generando problemas en el cultivo de soja, tanto en los primeros estadios vegetativos (V1-V3), como cuando el cultivo está formando sus granos (R5-R6) (Caccia et al. 2014).

La hembra llega a colocar de 300 a 1000 huevos en forma aislada sobre las hojas. Estos son hemisféricos, blancos perlados y con estrías que se unen en el ápice. El período embrionario se extiende de 5 a 10 días. Las larvas presentan 5 estadios que se desarrollan aproximadamente entre 15 y 25 días según la temperatura, son de color pardo a grisáceo oscuro, llegando a medir al final de su periodo larval entre 35 y $45 \mathrm{~mm}$. Empupan en el suelo y emergen los adultos, que miden de 28-35 mm. Su ciclo se completa en 40-45 días (Urretabizkaya et al. 2010).

El método de control comúnmente utilizado para ambas plagas es el uso de insecticidas, los cuales pueden tener efectos adversos sobre la salud humana, alteran las relaciones de las especies en el agroecosistema, matan los organismos benéficos y promueven que la plaga desarrolle poblaciones resistentes (Holguín y Bellotti, 2004; Bellotti et al. 2005; Valerio, 2006; Caccia et al. 2014). En consecuencia, se necesitan enfoques alternativos al el control químico y los hongos entomopatógenos se consideran uno de estos enfoques más prometedores como agentes de control biológico de muchas especies de insectos (Batta, 2013).

Los hongos entomopatógenos como endófitos pueden vivir dentro de las plantas y, en general, no causar daño evidente para el huésped (Van Bael et al. 2005, Cap. III de esta Tesis), aunque su uso como endófitos contra los insectos todavía es limitado. Se supone que la presencia de estos hongos en diferentes especies de plantas puede influir la dinámica de la población de herbívoros.

Algunas especies de hongos entomopatógenos como B. bassiana y M. anisopliae han sido introducidas en diferentes especies de plantas demostrando así el éxito de su capacidad endofítica contra diferentes plagas.

Hasta el momento, mediante ensayos de laboratorio e invernáculo se pudo demostrar la acción insecticida de $B$. bassiana como endófito para controlar a Sesamia calamistis Hampson (Lepidoptera: Noctuidae) en plantas de maíz (Cherry et al. 2004); Cosmopolites sordidus Germar (Coleoptera: Curculionidae) en plantas de banana (Akello et al. 2008b); Hypothenemus hampei Ferrari (Coleoptera: Curculionidae) en plantas de café (Vega et al. 2008); Iraella luteipes Thompson (Hymenoptera: Cynipidae) en plantas de P. somniferum L. (Quesada-Moraga et al. 2009); $H$. 
armigera en Vicia faba L. (Fabales: Fabaceae) (Jaber y Vidal 2010); dípteros en $V$. faba y en plantas de tomate (Akutse et al. 2013; Qayyum et al. 2015), Sesamia nonagrioides Lefebvre (Lepidoptera: Noctuidae) en plantas de sorgo (Mantzoukas et al. 2015); coleópteros en P. vulgaris (Mutune et al. 2016); y Helicoverpa zea Boddie (Lepidoptera: Noctuidae) en algodón (Castillo Lopez y Sword 2015). Por otro lado, M. anisopliae ha demostrado actuar contra Plutella xylostella L. (Lepidoptera: Plutellidae) en plantas de canola (Batta, 2013). En la mayoría de los estudios anteriormente mencionados la reducción en el daño causado por las plagas se ha atribuido a la acumulación de micotoxinas en los tejidos de la planta (Castillo Lopez y Sword 2015).

El objetivo de este capítulo fue evaluar aspectos biológicos, reproductivos, los principales parámetros poblacionales y la preferencia alimenticia, de dos especies plaga S. frugiperda y $H$. gelotopoeon de los cultivos de maíz y soja respectivamente, que presentaban el hongo entomopatógeno $B$. bassiana como endófito. 


\section{Materiales y Métodos}

\section{Selección de la cepa fúngica, preparación de la solución fúngica e inoculación de las plantas de maíz y soja}

Al igual que en el capítulo III se utilizó la cepa LPSc 1098 de B. bassiana de la colección de cultivos del Instituto Spegazzini, La Plata, Argentina. La elección de esta cepa fúngica se basó en su comprobada eficacia como biocontrolador de insectos plaga en ensayos de laboratorio (Pelizza et al. 2012 a, b) y principalmente en su alta tasa de colonización vegetal, tal como se pudo observar en el capítulo II.

La especie fúngica fue identificada a partir de datos morfológicos y moleculares. Para la identificación molecular, se obtuvo el ADN a partir de cultivos monospóricos según Stenglein y Balatti (2006). La reacción de PCR se llevó a cabo en un termociclador XP (Bioer Tecnología Co., Hangzhou, China) y se usaron pares de cebadores universales ITS 5-ITS 4 para amplificar la región ITS del ADNr (White et al. 1990). La reacción y la purificación del fragmento obtenido a partir de la reacción de PCR como el proceso de la secuenciación se realizaron de acuerdo a Canel et al. (2013). Similitudes del fragmento con las secuencias de datos previamente publicados fueron examinados con BLASTn (Altschul et al. 1990) en el Centro Nacional para la Información Biotecnológica (NCBI). La secuencia generada en este estudio se subió al GenBank (número de acceso KT163259) y fue comparada con las cepas de referencia (números de accesos KU726564, KU158472, KT443982), obteniendo como resultado un $\%$ de ID y cobertura del $100 \%$ y e-value $=0.0$.

La preparación de la solución de conidios e inoculación de las plantas de maíz y soja se realizó tal como se describió en el capítulo II. La solución de conidios se ajustó a $1 \times 10^{8}$ conidios/ml y las plantas de maíz y soja fueron inoculadas a través del método de aspersión de hojas que demostró previamente ser la técnica más efectiva para introducir la cepa de $B$. bassiana en ambas especies vegetales. 


\section{Cría de Lepidópteros}

Las especies S. frugiperda y $H$. gelotopoeon fueron criadas en bioterio bajo condiciones controladas de temperatura, humedad relativa y fotoperiodo $\left(25 \pm 2{ }^{\circ} \mathrm{C}\right.$, $70-75 \%$ HR y 14 L: 10 O) en el Instituto Spegazzini para utilizarlas en la realización de los bioensayos.

Los huevos (Figura IV.1a) para el inicio de la colonia de S. frugiperda fueron gentilmente provistos por la Empresa AgIdea, ubicada en la ciudad de Pergamino (www.agidea.com.ar).

Para la cría de S. frugiperda se utilizó el protocolo de Murúa et al. (2003): Ios huevos fueron colocados en recipientes de plástico de $500 \mathrm{~cm}^{3}$ conteniendo dieta artificial (Figura IV.2a) (Murúa et al. 2003, modificada) (ver anexo). A partir del tercer estadio (Figura IV.2b), las larvas fueron colocadas individualmente en tarros de 50 $\mathrm{cm}^{3}$, ya que luego del segundo estadio esta especie presenta canibalismo. Cuando llegaron a estado de pupa, se sexaron (Figura IV.3a, b), se esterilizaron (ver anexo) para eliminar la presencia de algún posible patógeno y se colocaron en tarros de plástico de $500 \mathrm{~cm}^{3}$ hasta la emergencia de los adultos.

Al emerger los adultos, tanto hembras como machos fueron transferidos a una jaula de copulación, la cual contenía en su interior papel plegado para permitir el reposo y la oviposición, permitiendo así, la manipulación de las masas de huevos. En la parte superior de la jaula se colocó un trozo de algodón impregnado con una solución azucarada (Greene et al. 1976) (ver anexo) que sirvió de alimento (Figura IV.4).

La recolección de los huevos y la reposición de la dieta de los adultos fueron realizadas diariamente.

Los huevos (Figura IV.1b) para el inicio de la colonia de $H$. gelotopoeon fueron provistos por el Instituto de Microbiología y Zoología Agrícola (IMYZA), del INTA Castelar.

Se utilizó como base la técnica de cría de Mihn modificada (1984). Los huevos fueron colocados en recipientes de plástico de $500 \mathrm{~cm}^{3}$ conteniendo dieta artificial (de la misma manera que para S. frugiperda) (Figura IV.1a) (Patana 1977 modificada) (ver anexo). Inmediatamente después de la muda al segundo estadio, las larvas se dispusieron en cajas plásticas con dieta artificial para evitar el canibalismo; para ello se colocó una larva por recipiente con un bloque de alimento de aproximadamente $2 \mathrm{~cm}^{3}$. Los recipientes fueron revisados cada tres días, retirando las heces $y$ reponiendo el alimento. Cuando se obtuvieron las pupas se sexaron (Figuras IV.3a, 
b), se esterilizaron (ver anexo) y se colocaron en tarros de plástico de $500 \mathrm{~cm}^{3}$ hasta la emergencia de los adultos.

Al emerger los adultos, tanto hembras como machos fueron transferidos a una jaula de copulación, la cual contenía en su interior papel plegado para permitir el reposo y la oviposición, permitiendo así, la manipulación de las masas de huevos. En la parte superior de la jaula se colocó un trozo de algodón impregnado con una solución azucarada (Greene et al. 1976) (ver anexo) que sirvió de alimento (Figura IV.4).

La recolección de los huevos y la reposición de la dieta de los adultos fueron realizadas diariamente. 


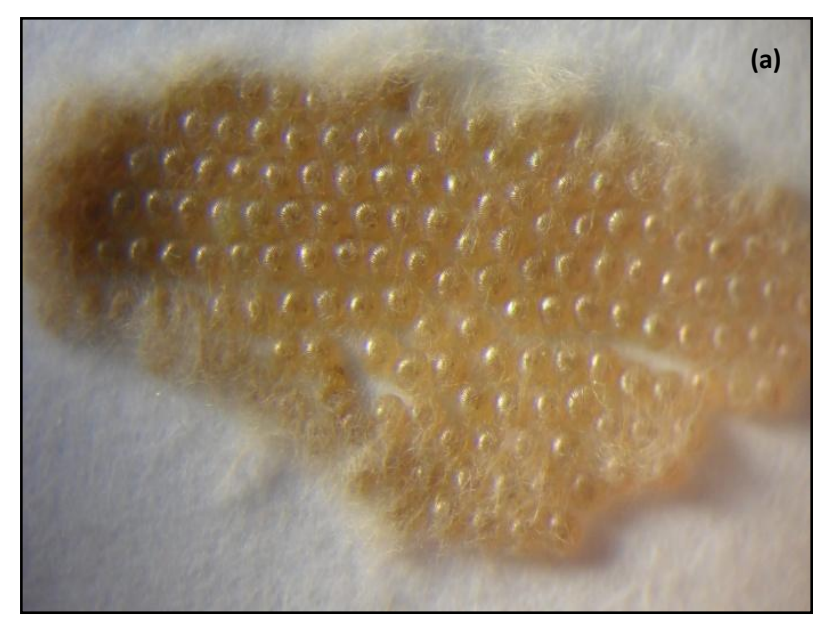

(b)

Figura IV.1. Huevos de Lepidópteros a) S. frugiperda, b) H. gelotopoeon

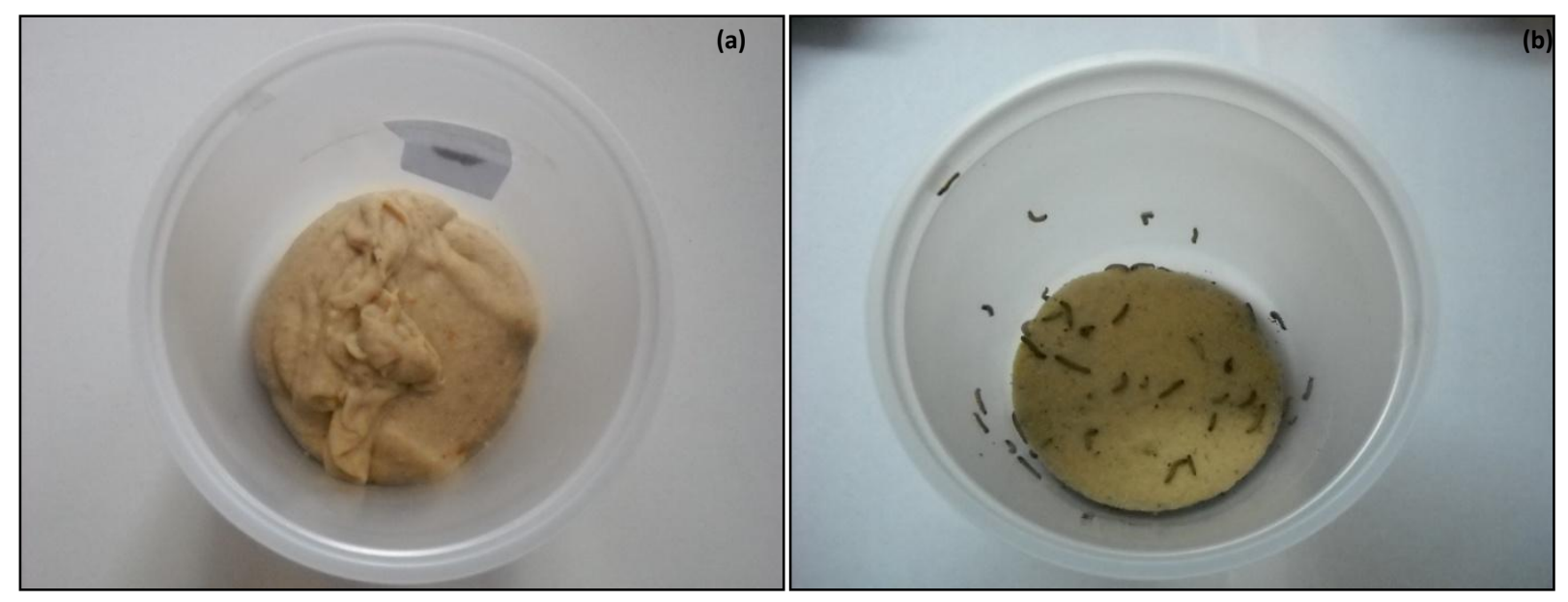

Figura IV.2. Recipientes con dieta artificial a) con huevos, b) con larvas 


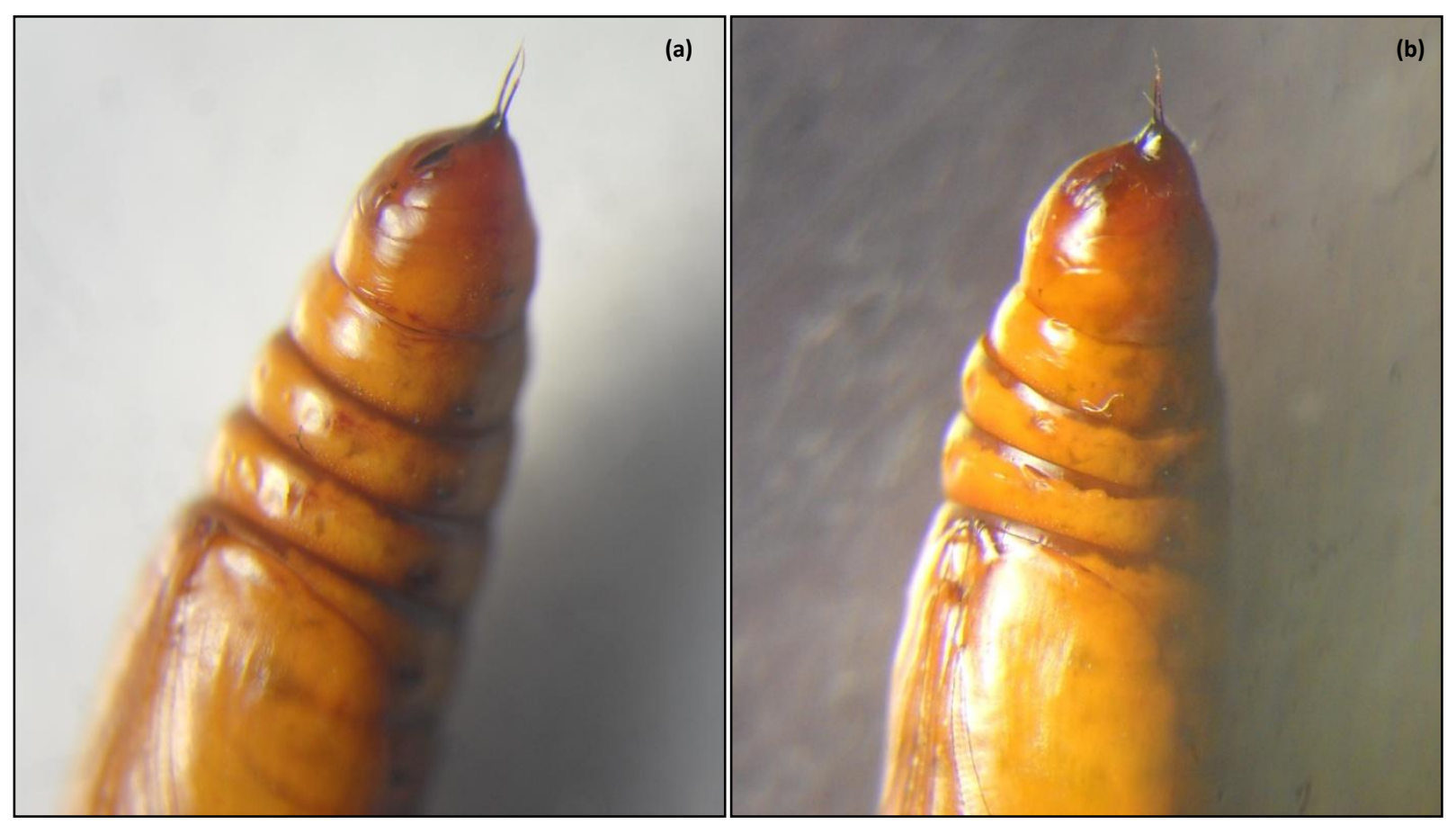

Figura IV.3. Pupas a) macho b) hembra

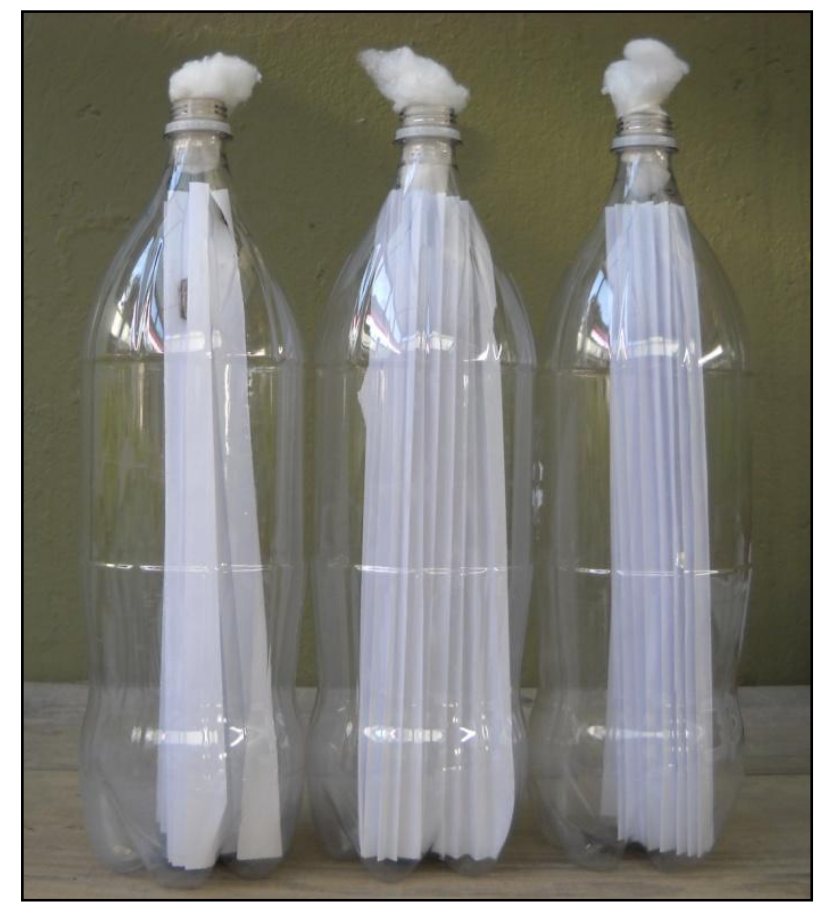

Figura IV.4. Jaulas de copulación 


\section{Efecto de Beauveria bassiana sobre el crecimiento y la reproducción de los insectos}

\section{Aspectos biológicos}

A partir de los huevos obtenidos en la primera generación de laboratorio se formaron 2 cohortes de cada especie de insecto, una para cada tratamiento, de esta manera se utilizaron dos grupos de 100 huevos de cada especie (200 huevos de $S$. frugiperda y 200 huevos de $H$. gelotopoeon) los cuales fueron individualizados y colocados cada uno en una caja de Petri para favorecer su alimentación y analizar la duración del ciclo de vida. Todos los insectos se mantuvieron en condiciones de laboratorio respetando la To, HR y fotoperíodo inherente a cada una de las especies.

Para alimentar a $S$. frugiperda se les ofreció plantas de maíz inoculadas con $B$. bassiana y no inoculadas (controles) y a $H$. gelotopoeon con plantas de soja inoculadas con $B$. bassiana y no inoculadas (controles). Las hojas tanto de soja como de maíz fueron ofrecidas a los 7 días posteriores a la inoculación y fueron renovadas diariamente.

Se observó el desarrollo y la duración de los diferentes estados del desarrollo (huevo, estadios larvales, pupa y adulto), la cantidad de individuos de edad x que se registraron $(\mathrm{nx})$, la mortalidad (proporción de la cohorte original que muere durante la edad $\mathrm{x})(\mathrm{dx})$, como así también la proporción de sexos resultante. Las larvas se revisaron diariamente para determinar la transición (muda) al siguiente estadio por la observación visual de las cápsulas cefálicas o la mortalidad. Las pupas fueron sexadas de acuerdo con la metodología descrita por Angulo y Weigert (1975) y transferidas a recipientes de $500 \mathrm{~cm}^{3}$ para favorecer el desarrollo de los adultos. Dichos adultos se colocaron en parejas (macho y hembra) y se transfirieron a recipientes de plástico transparente de $2000 \mathrm{~cm}^{3}$ como se describió más arriba para permitir la oviposición.

Los individuos que murieron fueron colocados en cámara húmeda para confirmar la muerte por acción del hongo entomopatógeno.

\section{Aspectos reproductivos}

Se estimaron los siguientes parámetros reproductivos:

Duración del periodo de oviposición. Tasa de supervivencia específica por edad (Ix): donde se registró la cantidad de días vividos por edad, tanto para los insectos 
alimentados con plantas tratadas como para los alimentados con las plantas control, desde su nacimiento hasta su muerte. Fecundidad especifica por edad (mx): calculada como el número de huevos producidos diariamente por individuos de edad $\mathrm{x}$ de acuerdo a Chi (1988). Fertilidad: calculada como: (huevos eclosionados / huevos puestos) x 100 (Schneider et al. 2009).

\section{Parámetros poblacionales}

Con los datos obtenidos se construyó una tabla de vida horizontal a partir de la cual se estimaron diferentes parámetros poblacionales.

Tasa Neta de Reproducción: [(Ro): $\Sigma(\mathrm{Ix} \mathrm{mx})$ ], número promedio de progenie hembra capaz de ser producida por cada hembra de la población durante toda su vida.

Tiempo generacional: $[T=\Sigma(x \mid x \quad m x) / R o]$, tiempo promedio entre dos generaciones sucesivas.

Tasa intrínseca de crecimiento natural: ( $r=\ln$ Ro/ T) capacidad de multiplicarse una población en el lapso de una generación.

Tasa finita de multiplicación: ( $\lambda$ : e r) número de individuos que se agregan a la población por individuo y por unidad de tiempo.

Donde Ix y $\mathrm{mx}$ corresponden a la supervivencia específica por edad y a la fecundidad específica por edad, respectivamente.

\section{Preferencia alimenticia}

La preferencia alimenticia de las larvas de $S$. frugiperda y $H$. gelotopoeon se evaluó de la siguiente manera: se les ofreció simultáneamente hojas inoculadas con B. bassiana utilizando la técnica de aspersión, en las cuales se corroboró previamente que el hongo entomopatógeno se había establecido como endófito, y hojas no inoculadas (controles).

Es importante mencionar que para evaluar la preferencia de $S$. frugiperda se utilizaron piezas de hojas de maíz de $6 \times 3 \mathrm{~cm}$ y para evaluar la preferencia alimenticia de $H$. gelotopoeon se utilizaron discos de hojas de soja de $4 \mathrm{~cm}$ de diámetro. Dicha actividad se determinó mediante el método de libre elección (Ling et al. 2008; Napal et al. 2009), donde ambas piezas de hojas (tratadas y controles) fueron escaneadas (para determinar su área inicial) y colocadas dentro de una caja de Petri con el fondo cubierto de un papel de filtro húmedo (Magrini et al. 2015). Luego 
se agregó una larva (L2) en el centro de cada caja, donde se las dejó durante 24 h (Figuras IV.5, 6). Se realizaron 3 repeticiones en el tiempo, de 30 individuos cada una, al final del ensayo los restos de hojas fueron escaneados nuevamente.

El área total consumida se calculó mediante la diferencia entre el área inicial de la hoja y el área restante luego de la alimentación (Milanovic et al. 2014). Dichas áreas se calcularon utilizando el Software Image] (Bailer, 2006).
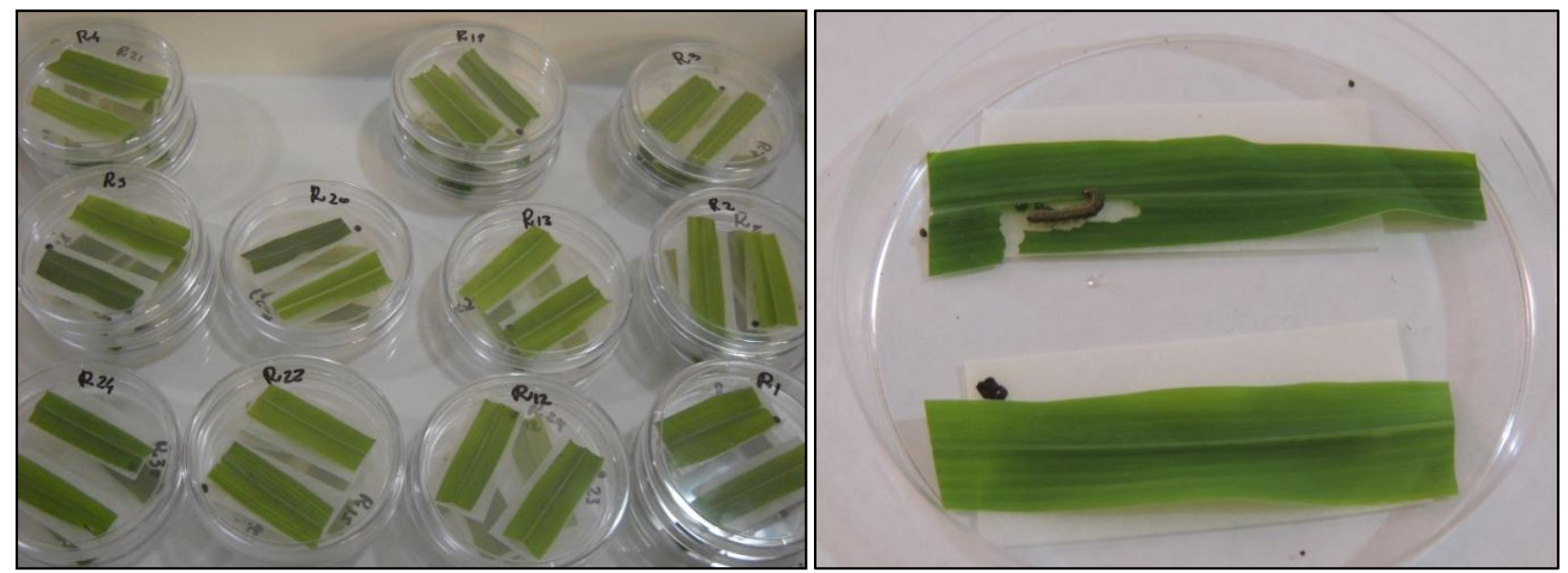

Figura IV.5. Cajas de Petri con piezas de hojas de maíz con una larva de S. frugiperda
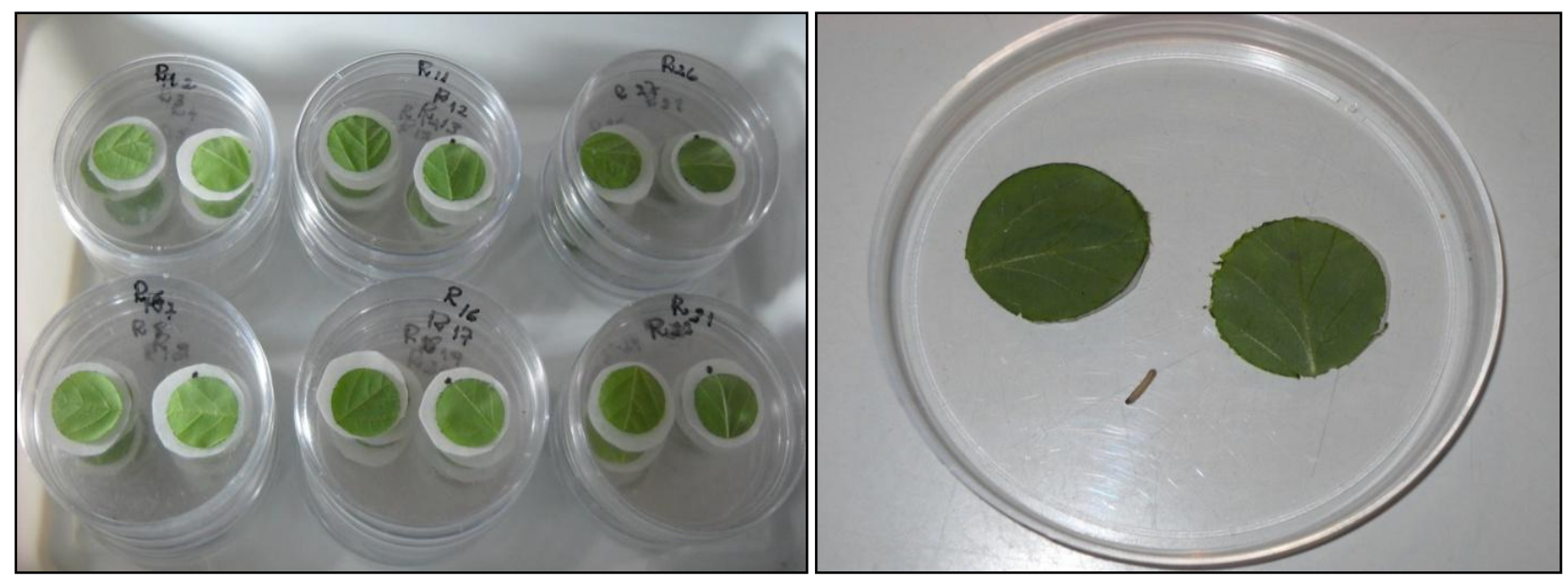

Figura IV.6. Cajas de Petri con piezas de hojas de soja con una larva de $H$. gelotopoeon 


\section{Análisis de los datos}

El análisis de supervivencia y fecundidad y los parámetros poblaciones de cada cohorte fueron estimados de acuerdo a Chi (1988) usando el software TWOSEX-MS Chart (Chi, 2008).

La duración de cada etapa (huevo, estadios larvales, pupa y adulto) de $S$. frugiperda y $H$. gelotopoeon, como así también la comparación de los aspectos reproductivos entre los diferentes tratamientos y el análisis de la prueba de preferencia se compararon mediante una test de $t(p<0,05)$. Todos los datos se analizaron con el programa InfoStat (2004). 


\section{Resultados}

\section{Aspectos biológicos y reproductivos de S. frugiperda}

En la Tabla IV.1 se registran los tiempos de desarrollo, la supervivencia y mortalidad de todos los estadios de dos cohortes de S. frugiperda (alimentadas con plantas de maíz inoculadas con $B$. bassiana y no inoculadas).

De las cohortes originales eclosionó el $100 \%$ de los huevos y el periodo larval transcurrió por seis estadios de los cuales el segundo registró el mayor número de muertes, a partir de ese momento la mortalidad disminuyó hasta alcanzar el estado de pupa donde en ambas cohortes la mortalidad volvió a aumentar, alcanzando el estado adulto el $85 \%$ y el $65 \%$ de la población de los tratamientos controles y tratados respectivamente (Tabla IV.1). Es importante mencionar que los insectos muertos que fueron alimentados con plantas inoculadas, se esterilizaron superficialmente y luego se colocaron en cámara húmeda, observando la aparición de micosis (Figura IV.7) en el 65 \% de los individuos. La identidad del entomopatógeno surgido a partir de los insectos muertos se confirmó por observación de las estructuras fúngicas bajo microscopio óptico.

Al establecer comparaciones entre ambos tratamientos puede señalarse que la duración media de los estadios L2, L4, pupa y adulto así como también la duración del ciclo fue significativamente mayor en individuos alimentados con hojas de maíz sin inocular (control) que en tratadas (Tabla IV.1) marcando diferencias significativas ( $p<0,0001, p=0,0073, p<0,0001, p<0,0001$ y $p=0,0013$ respectivamente). Al llegar al estado adulto la proporción de sexos fue de 1 hembra: 1,2 machos en el tratamiento control y de 1 hembra: 1,3 machos en $S$. frugiperda alimentada con maíz inoculado, mostrando un ligero predominio de machos sobre hembras. 


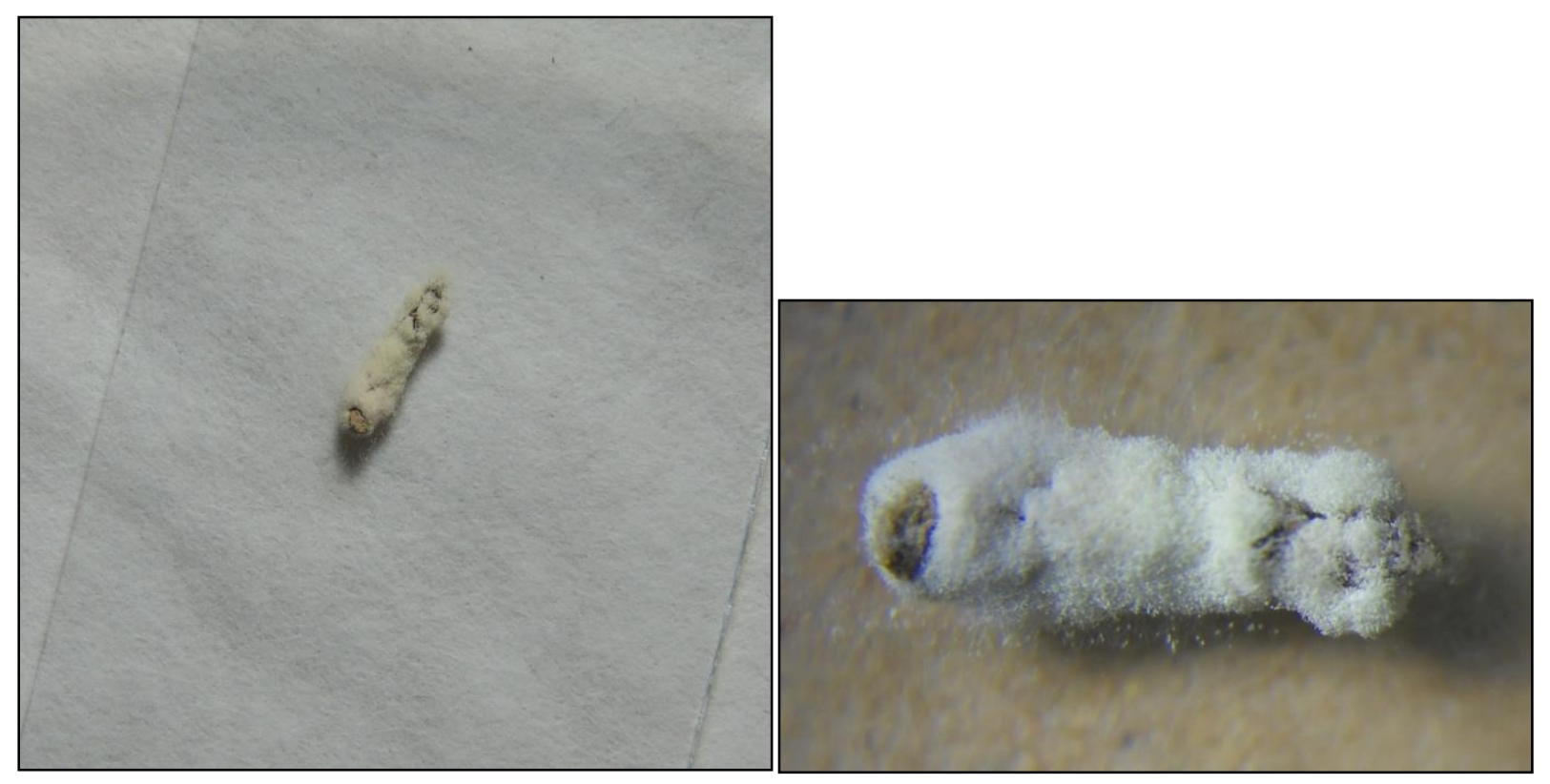

Figura IV.7. Larvas de S. frugiperda infectadas con B. bassiana

Tabla IV.1. Duración media en días, cantidad de individuos de edad $x$ que se registran ( $\mathrm{nx})$, supervivencia específica por edad (Ix), mortalidad de los diferentes estados de desarrollo ( $\mathrm{dx}$ ) de $S$. frugiperda alimentadas con maíz inoculado y no inoculado (control) con B. bassiana

\begin{tabular}{|c|c|c|c|c|c|c|c|c|}
\hline \multirow[b]{2}{*}{ Etapas del ciclo de vida } & \multicolumn{4}{|c|}{ Control } & \multicolumn{4}{|c|}{ Tratado } \\
\hline & Duración & $\mathrm{nx}$ & Ix & $d x$ & Duración & $\mathrm{nx}$ & Ix & $d x$ \\
\hline Huevo & $2,79 \pm 0,40 a$ & 100 & 1 & 0 & $2,7 \pm 0,46 \quad a$ & 100 & 1 & 0 \\
\hline L1 & $3,41 \pm 0,81 a$ & 100 & 1 & 3 & $3,43 \pm 0,51 \mathrm{a}$ & 100 & 1 & 6 \\
\hline L2 & $3,96 \pm 0,65 a$ & 97 & 0,96 & 4 & $3,21 \pm 1,06 b$ & 94 & 0,94 & 15 \\
\hline L3 & $3,81 \pm 0,87 a$ & 93 & 0,93 & 3 & $3,35 \pm 1,69 a$ & 79 & 0,79 & 2 \\
\hline L4 & $4,32 \pm 1,37$ a & 90 & 0,9 & 1 & $3,65 \pm 1,91 b$ & 77 & 0,77 & 2 \\
\hline L5 & $3,7 \pm 1,27 \quad a$ & 89 & 0,89 & 0 & $3,69 \pm 1,96 a$ & 75 & 0,75 & 0 \\
\hline L6 & $3 \pm 1,16 \quad a$ & 89 & 0,89 & 0 & $3,62 \pm 1,97 a$ & 75 & 0,75 & 0 \\
\hline Todos los estados larvales & $22,2 \pm 4,5 \quad a$ & 89 & 0,89 & 0 & $20,95 \pm 8,2$ a & 75 & 0,75 & 0 \\
\hline Pupa & $8,66 \pm 2,80 a$ & 89 & 0,89 & 3 & $6,45 \pm 1,34 b$ & 75 & 0,75 & 10 \\
\hline Adulto & $7,2 \pm 2,74 \quad a$ & 85 & 0,85 & 0 & $5,08 \pm 3,56 b$ & 65 & 0,65 & 0 \\
\hline Duración de ciclo & $40,85 \pm 9,28 a$ & & & & $35,18 \pm 15,05 b$ & & & \\
\hline Proporción de sexos H:M & $1: 1,2$ & & & & $1: 1,3$ & & & \\
\hline
\end{tabular}

Los valores seguidos por distinta letra dentro de una misma fila muestran diferencias significativas de acuerdo al test de $t(p<0,05)$.

Para los controles, el período de oviposición fue de 2,95 \pm 0,51 días y durante este periodo una hembra puso en promedio 848,35 huevos, con un rango de 500 a 1100 huevos (Figura IV.8). Mientras que para los insectos alimentados con plantas 
tratadas el periodo de oviposición fue de 2,2 \pm 0,89 días, depositando en promedio 495,7 huevos con un rango de 343 a 865 huevos (Figura IV.8).

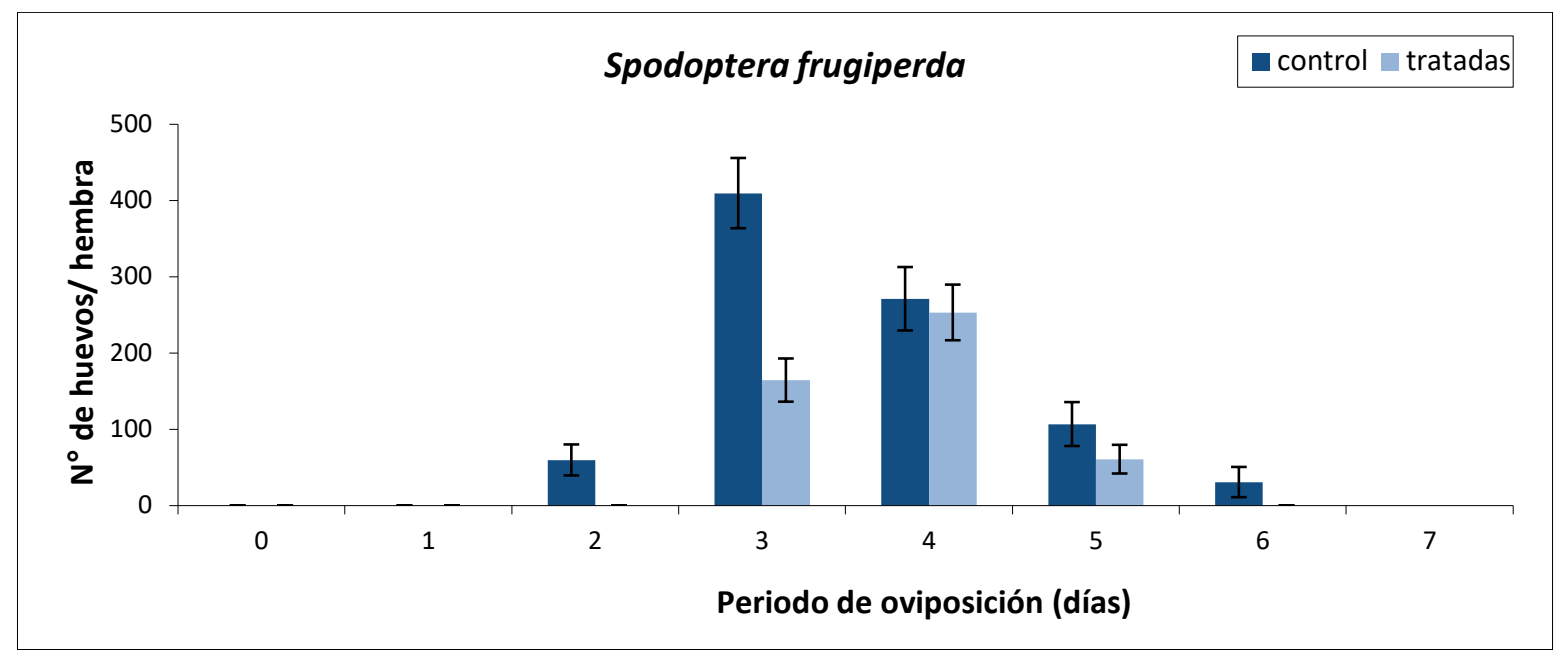

Figura IV.8. Número de huevos en función del periodo de oviposición de $S$. frugiperda alimentadas con maíz inoculado con $B$. bassiana y no inoculado (control).

La fertilidad fue de 92,60 $\pm 0,04$ registrándose los valores más altos al tercer día de puesta y de 43,04 \pm 0,41 registrándose los valores más altos el cuarto día de puesta para controles y tratadas respectivamente, mostrando diferencias significativas entre ambos tratamientos ( $p<0,0001)$ (Figura IV.9).

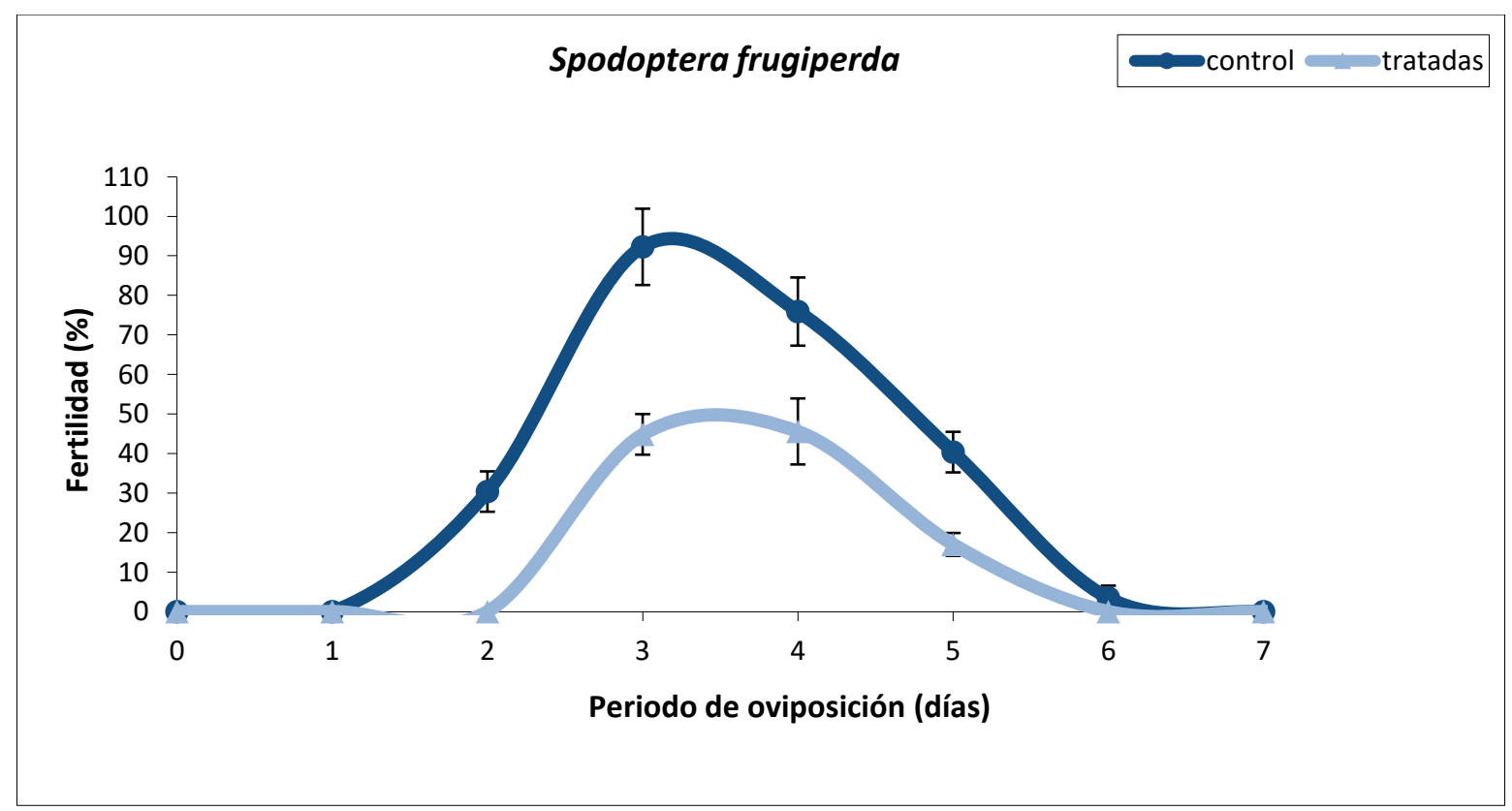

Figura IV.9. Fertilidad (huevos eclosionados/huevos totales)*100 en función del periodo de oviposición de $S$. frugiperda alimentadas con maíz inoculado con $B$. bassiana y no inoculado (control). Las barras indican el error estándar de la media. 
La supervivencia específica por edad (Ix) y la fecundidad específica por edad $(\mathrm{mx})$ de S. frugiperda se muestran en las Figuras IV.10, 11.

Los efectos negativos de $B$. bassiana sobre $S$. frugiperda se pueden observar en la Figura IV.11 donde la curva de supervivencia por edad disminuyó marcadamente a los 5 y 25 días.

La reproducción comenzó el día 37, alcanzando la tasa máxima de crecimiento poblacional durante el día 40 en insectos alimentados con plantas sin tratar (Figura IV.10), mientras que en insectos alimentados con plantas inoculadas la reproducción también comenzó el día 37 y alcanzó los picos poblacionales durante el día 42 (Figura IV.11).

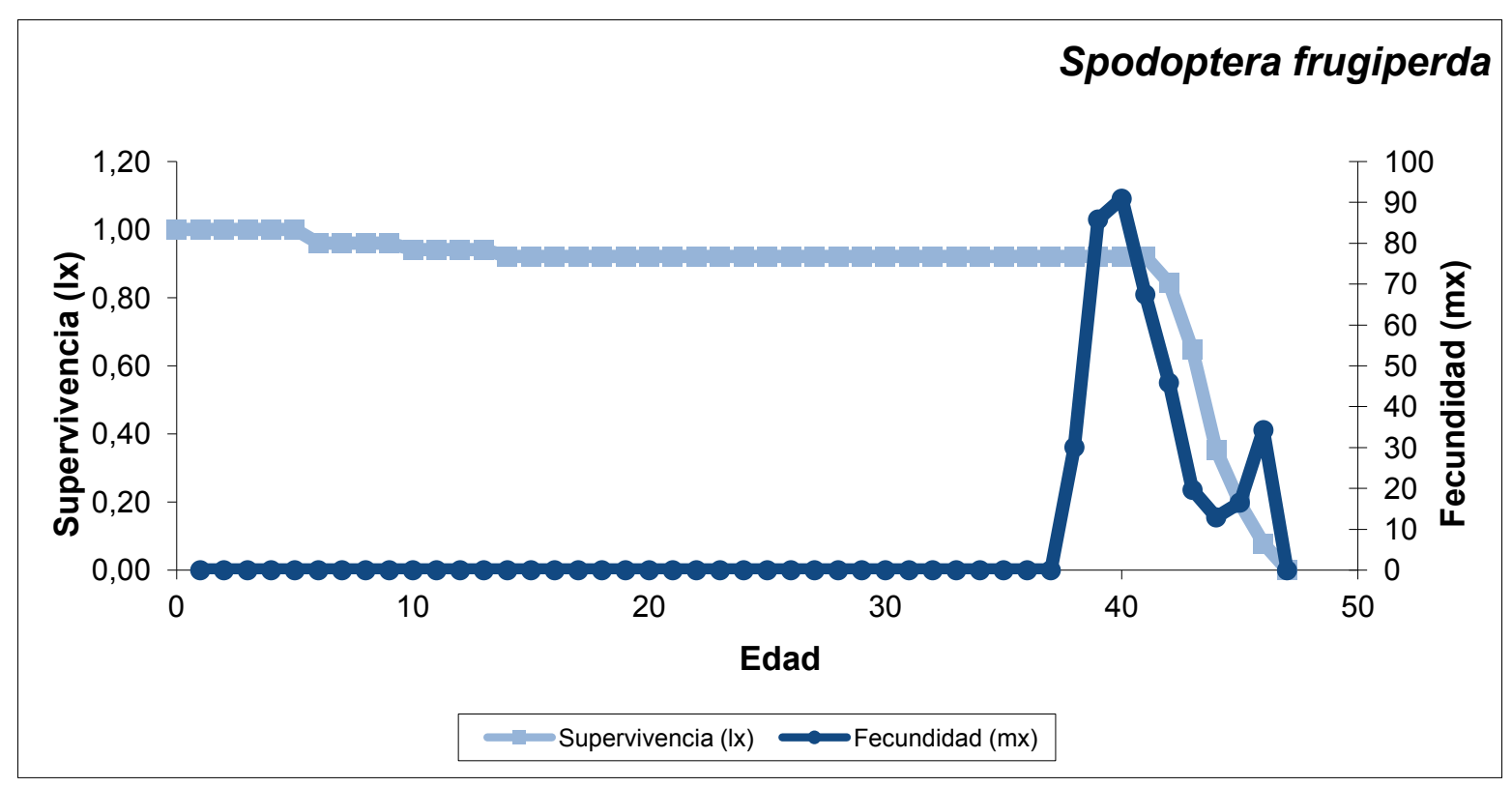

Figura IV.10. Curva de supervivencia (Ix) y fecundidad $(\mathrm{mx})$ de $S$. frugiperda, alimentada con maíz sin inocular en condiciones de laboratorio 


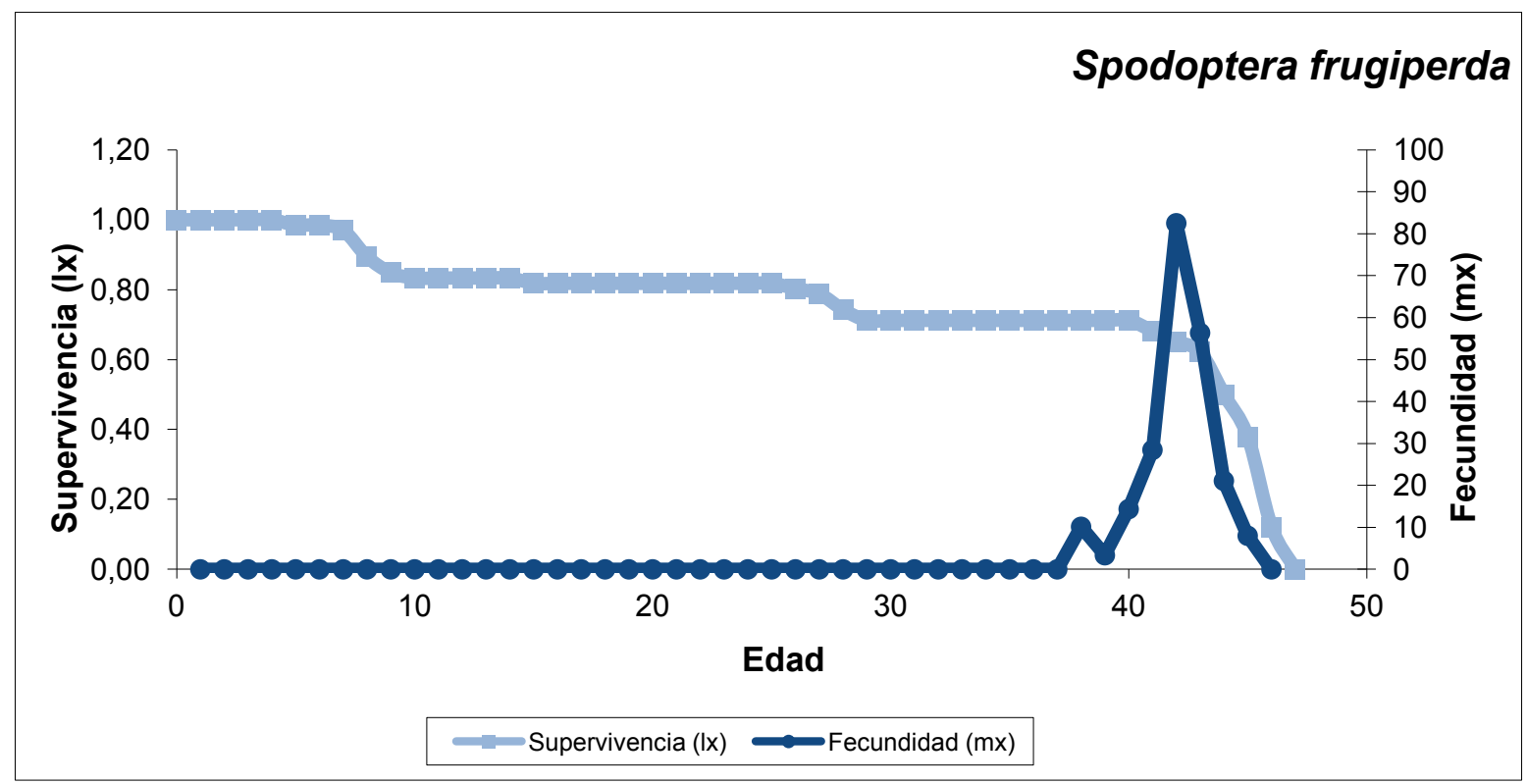

Figura IV.11. Curva de supervivencia $(I x)$ y fecundidad $(m x)$ de $S$. frugiperda, alimentada con maíz inoculado en condiciones de laboratorio

\section{Parámetros poblacionales}

El tiempo generacional $(T)$, la tasa intrínseca de crecimiento $(r)$, la tasa finita de crecimiento $(\lambda)$ y la tasa neta de reproducción (Ro) se muestran en la Tabla IV.2.

Tabla IV.2. Parámetros poblaciones de S. frugiperda alimentadas con maíz tratado con $B$. bassianay no tratado (control).

\begin{tabular}{lcccc}
\hline \hline & Ro & T & $\boldsymbol{r}$ & $\boldsymbol{\lambda}$ \\
\hline Control & 332,69 & 40,29 & 0,14 & 1,15 \\
Tratada & 150,21 & 41,85 & 0,12 & 1,12 \\
\hline \hline
\end{tabular}




\section{Aspectos biológicos y reproductivos de $\boldsymbol{H}$. gelotopoeon}

En la Tabla IV.3 se registran los tiempos de desarrollo, la supervivencia y mortalidad de todos los estadios de dos cohortes de $H$. gelotopoeon (alimentadas con plantas de soja inoculadas con $B$. bassiana y no inoculadas).

De las cohortes originales eclosionó el $100 \%$ de los huevos y el periodo larval transcurrió por cinco estadios, de los cuales el segundo registró el mayor número de muertes. A partir de ese momento la mortalidad disminuyó hasta alcanzar el estado de pupa, donde en ambas cohortes la mortalidad volvió a aumentar, alcanzando el estado adulto el $87 \%$ y el $62 \%$ de la población de los tratamientos controles y tratados respectivamente (Tabla IV.3). De la misma manera que en S. frugiperda, se observa la aparición de micosis en el $50 \%$ de los individuos muertos que fueron alimentados con plantas inoculadas, después de ser colocados en cámara húmeda (Figura IV.12).

Al establecer comparaciones entre ambos tratamientos puede señalarse que la duración media de los estadios L1, L2, L3, L4 y adulto, así como también la duración total del ciclo fue significativamente mayor en individuos alimentados con soja sin inocular (control) que en inoculados (Tabla IV.3) $(p<0,0001 p=0,0201, p=0,0005$, $p=0,0162, p=0,0006$ y $p=0,0068$ respectivamente). Al llegar al estado adulto, la proporción de sexos fue de 1 hembra: 1,05 machos en el tratamiento control y de 1 hembra: 1,10 machos en $H$. gelotopoeon alimentada con soja inoculada, mostrando una relación similar entre machos y hembras. 


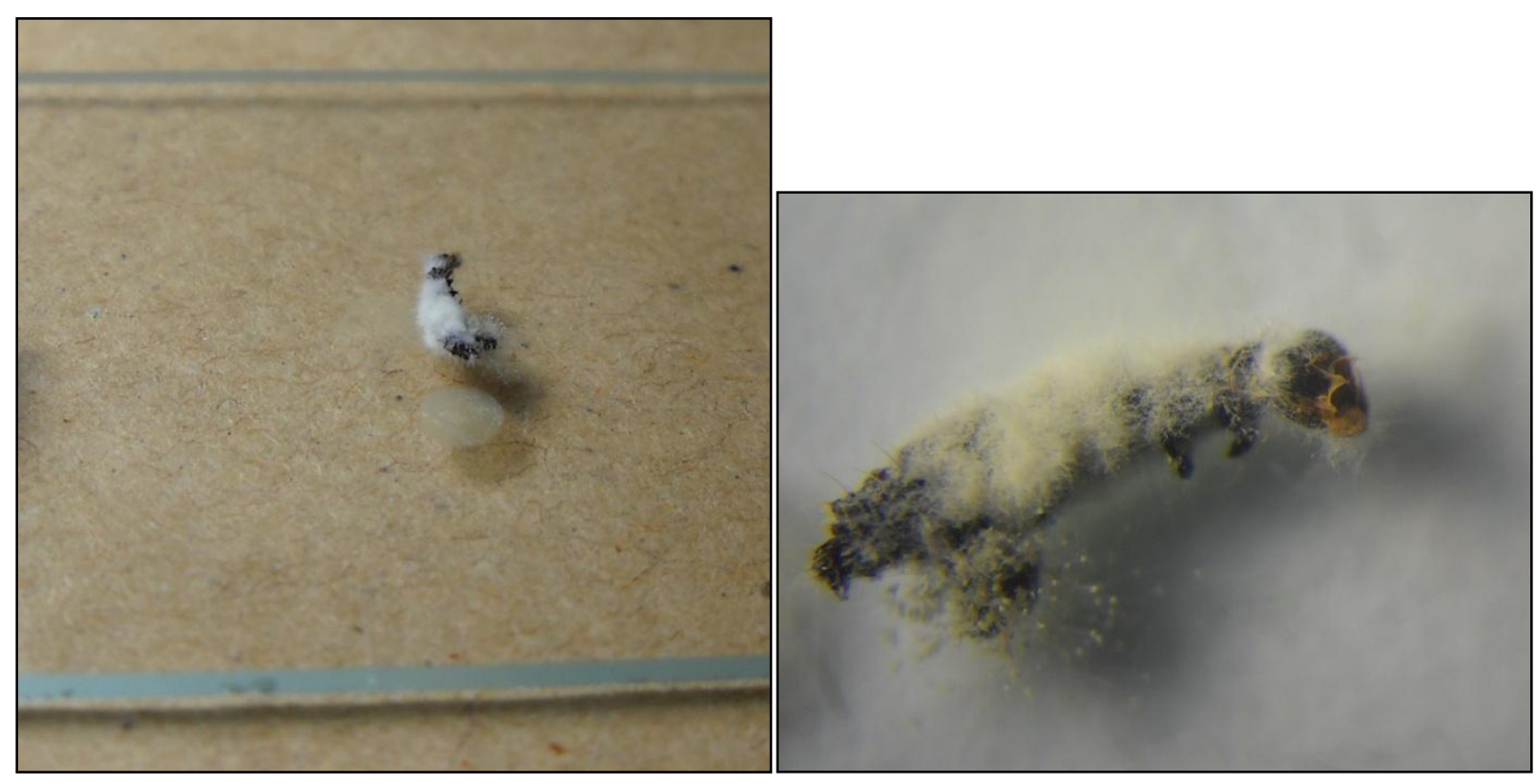

Figura IV.12. Larvas de $H$. gelotopoeon infectadas con $B$. bassiana

Tabla IV.3. Duración media en días, cantidad de individuos de edad $x$ que se registran $(\mathrm{nx})$, supervivencia específica por edad (Ix), mortalidad de los diferentes estados de desarrollo ( $\mathrm{dx}$ ) de $H$. gelotopoeon alimentadas con soja inoculada con $B$. bassiana y no inoculada (control).

\begin{tabular}{|c|c|c|c|c|c|c|c|c|c|}
\hline \multirow[b]{2}{*}{ Etapas del ciclo de vida } & \multicolumn{4}{|c|}{ Control } & \multicolumn{5}{|c|}{ Tratado } \\
\hline & Duración & $n x$ & Ix & $d x$ & Duración & & $n x$ & Ix & $d x$ \\
\hline Huevo & $5,42 \pm 0,49 a$ & 100 & 1 & 0 & $5 \pm 0,50$ & a & 100 & 1 & 0 \\
\hline L1 & $3,83 \pm 0,40 a$ & 100 & 1 & 3 & $3,38 \pm 0,48$ & $\mathrm{~b}$ & 100 & 1 & 4 \\
\hline L2 & $4,83 \pm 1,07 \quad a$ & 97 & 0,97 & 6 & $4,25 \pm 1,25$ & $b$ & 96 & 0,96 & 18 \\
\hline L3 & $4,59 \pm 1,57 \quad a$ & 91 & 0,91 & 1 & $3,38 \pm 1,63$ & $\mathrm{~b}$ & 80 & 0,78 & 2 \\
\hline L4 & $4,14 \pm 1,47 \quad a$ & 90 & 0,9 & 0 & $3,44 \pm 1,67$ & $b$ & 78 & 0,76 & 0 \\
\hline L5 & $3,59 \pm 1,35 a$ & 90 & 0,9 & 0 & $3,51 \pm 1,75$ & a & 78 & 0,76 & 0 \\
\hline Todos los estados larvales & $20,98 \pm 5,15 a$ & 90 & 0,9 & 0 & $17,96 \pm 6,09$ & $\mathrm{~b}$ & 78 & 0,76 & 0 \\
\hline Pupa & $6,18 \pm 2,47 \quad a$ & 90 & 0,9 & 3 & $8 \pm 2,88$ & a & 78 & 0,78 & 15 \\
\hline Adulto & $4,47 \pm 1,82 \quad a$ & 87 & 0,87 & 0 & $3,44 \pm 2,56$ & $\mathrm{~b}$ & 63 & 0,63 & 0 \\
\hline Duración de ciclo & $37,05 \pm 8,93 a$ & & & & $32,85 \pm 10,5$ & $59 \mathrm{~b}$ & & & \\
\hline Proporción de sexos H:M & 1: 1,05 & & & & 1: 1,10 & & & & \\
\hline
\end{tabular}

Los valores seguidos por distinta letra dentro de una misma fila muestra diferencias significativas de acuerdo al test $t(p<0,05)$.

Para los controles, el período de oviposición fue de 2,7 $\pm 0,73$ días y durante este periodo una hembra puso en promedio 743,45 huevos con un rango de 500 a 1071 huevos (Figura IV.13). Mientras que para los insectos alimentados con plantas tratadas el periodo de oviposición fue de 1,95 $\pm 1,23$ días, depositando en promedio 460,7 huevos con un rango de 231 a 898 huevos (Figura IV.13). 


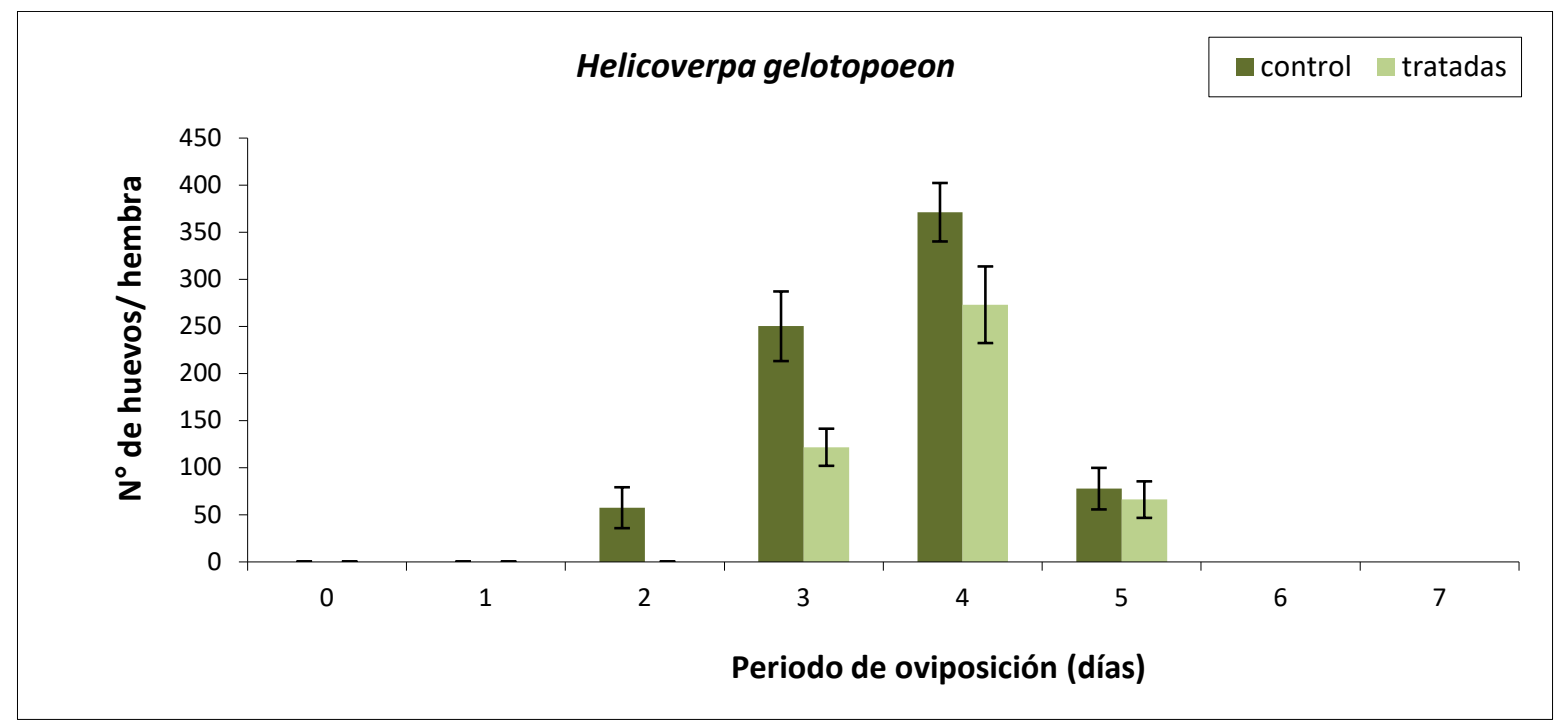

Figura IV.13. Número de huevos en función del periodo de oviposición de $H$. gelotopoeon alimentadas con soja inoculada con $B$. bassiana y no inoculada (control).

La fertilidad fue de 74,62 $\pm 0,32$ y de 45,25 $\pm 0,40$ registrándose los valores más altos el cuarto día de puesta para controles y tratadas respectivamente, mostrando diferencias significativas entre ambos tratamientos $(p<0,0001)$ (Figura IV.14).

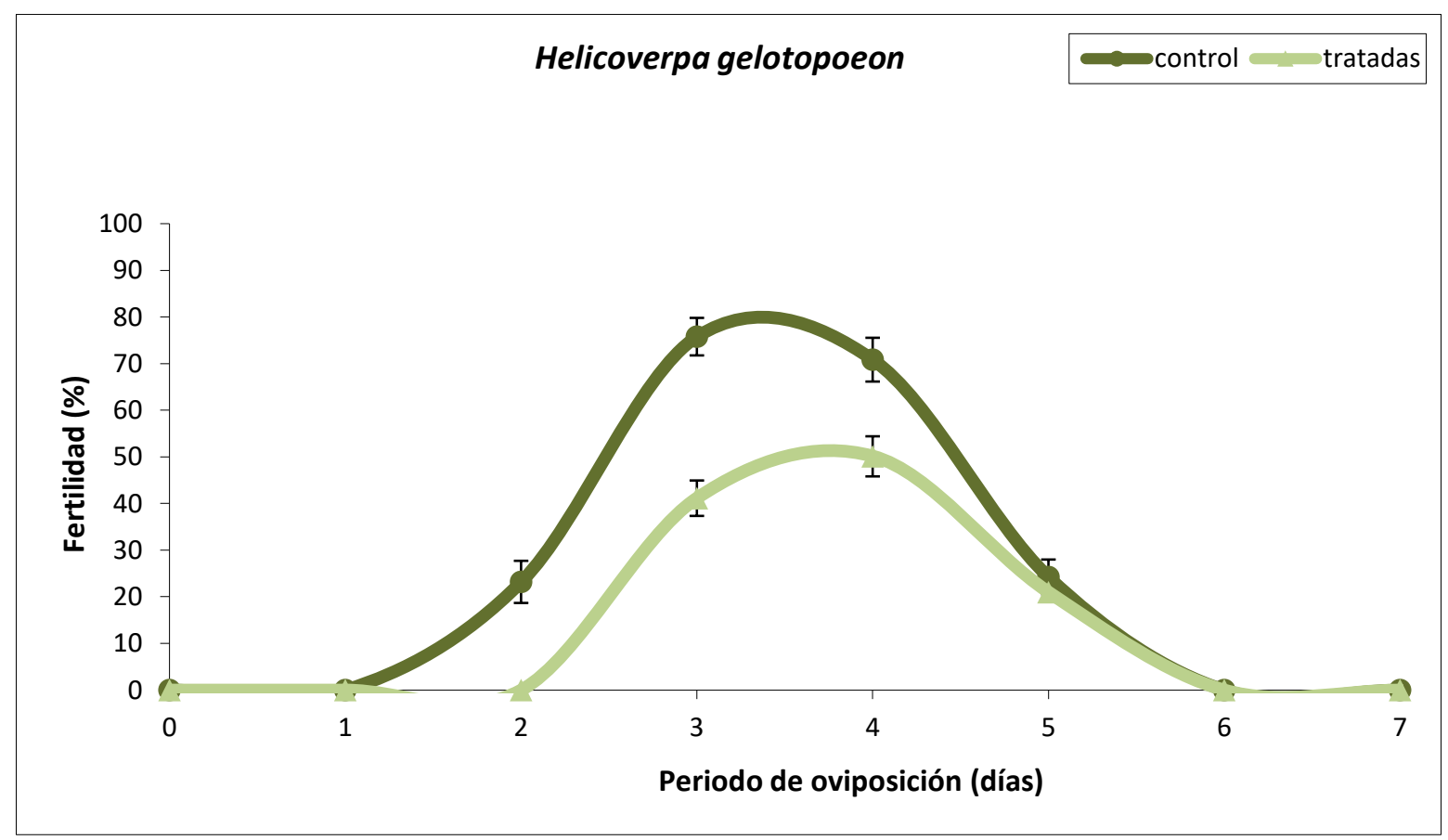

Figura IV.14. Fertilidad (huevos eclosionados/huevos totales)*100 en función del periodo de oviposición de Helicoverpa gelotopoeon alimentadas con soja inoculado con $B$. bassiana y no inoculado (control). Las barras indican el error estándar de la media. 
La supervivencia específica por edad (Ix) y la fecundidad específica por edad (mx) de $H$. gelotopoeon se muestran en las Figuras IV.15, 16 respectivamente.

La curva de supervivencia (Ix) muestra un mayor descenso en los insectos alimentados con plantas de soja inoculadas con $B$. bassiana, produciéndose la muerte del último de los individuos 3 días antes que en el tratamiento control.

La reproducción comenzó el día 37, se extendió por un periodo de una semana, alcanzando la tasa máxima de crecimiento poblacional durante el día 41 en insectos alimentados con plantas sin tratar (Figura IV.15). Por otra parte, los insectos alimentados con plantas inoculadas, además de mostrar tasas de fecundidad más bajas, su reproducción comenzó el día 36 extendiéndose por un periodo de 5 días y alcanzando los picos poblacionales durante el día 39 (Figura IV.16).

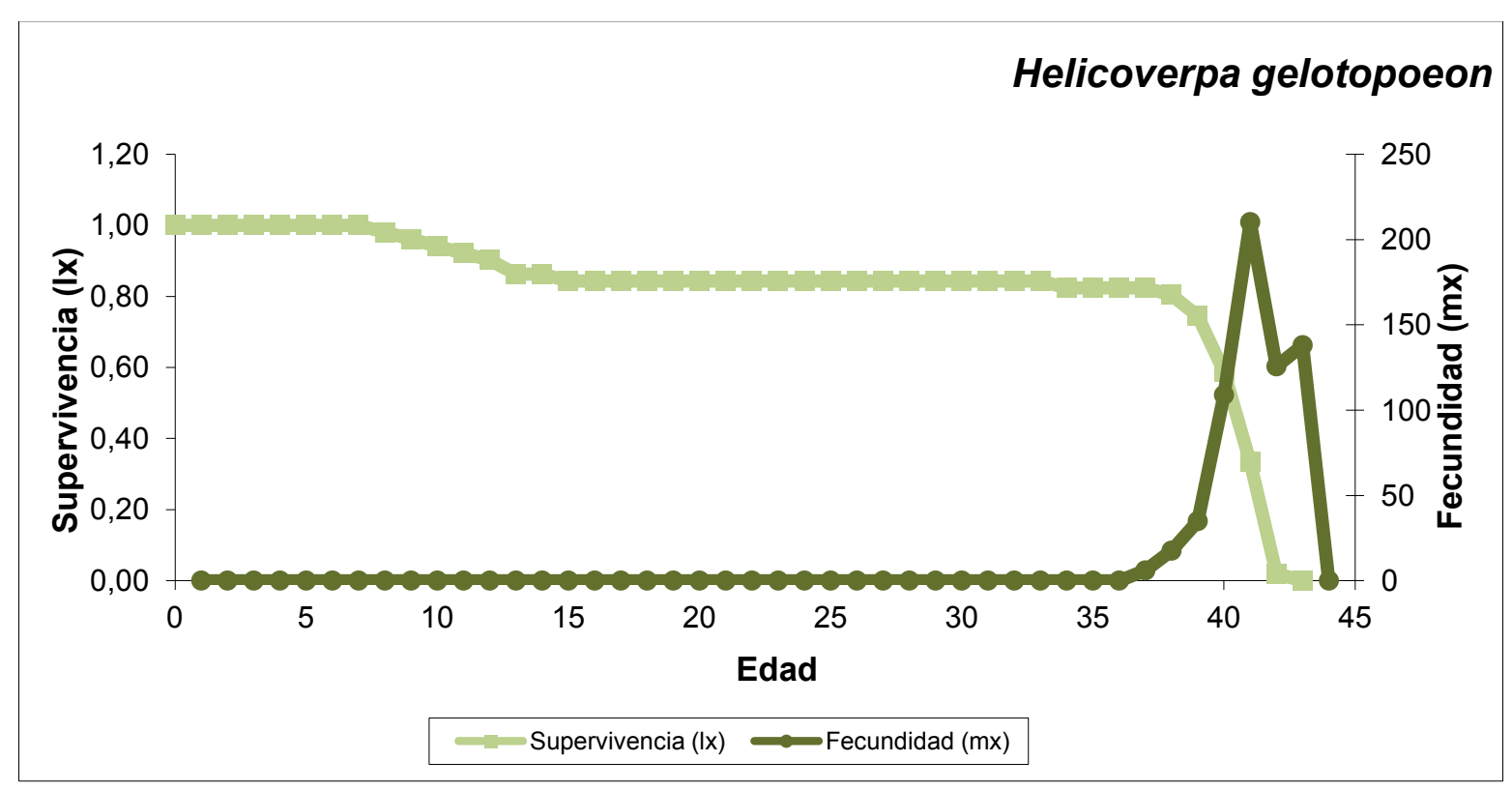

Figura IV.15. Curva de supervivencia $(\mathrm{Ix})$ y fecundidad $(\mathrm{mx})$ de $H$. gelotopoeon, alimentada con soja no inoculada en condiciones de laboratorio 


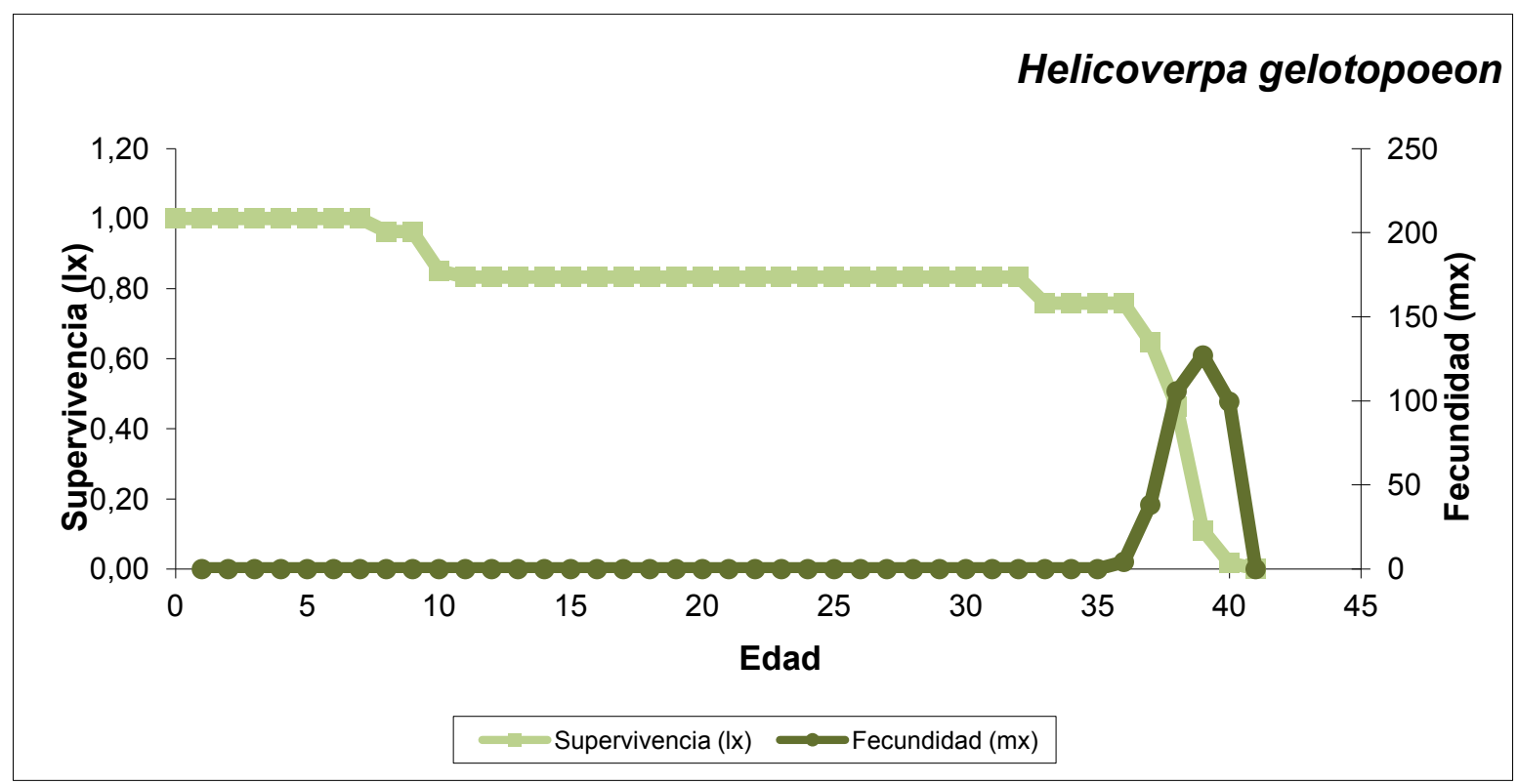

Figura IV.16. Curva de supervivencia $(\mathrm{Ix})$ y fecundidad $(\mathrm{mx})$ de $H$. gelotopoeon, alimentada con soja inoculada en condiciones de laboratorio

\section{Parámetros poblacionales}

El tiempo generacional $(\mathrm{T})$, la tasa intrínseca de crecimiento ( $\mathrm{r}$ ), la tasa finita de crecimiento $(\lambda)$ y la tasa neta de reproducción (Ro) se muestran en la Tabla IV.4.

Tabla IV.4. Parámetros poblacionales de $H$. gelotopoeon alimentadas con soja tratada con $B$. bassiana y no tratada (control)

\begin{tabular}{lcccc}
\hline \hline & Ro & T & r & $\boldsymbol{\lambda}$ \\
\hline Control & 296,69 & 40,39 & 0,14 & 1,15 \\
Tratada & 170,63 & 38,21 & 0,13 & 1,14 \\
\hline \hline
\end{tabular}




\section{Preferencia alimenticia}

Los resultados mostraron diferencias significativas $(p<0,0001)$ entre las plantas controles y las tratadas, demostrando que la presencia de B. bassiana como endófito, puede disminuir la preferencia, medida como el consumo de plantas de maíz y soja por parte de $S$. frugiperda y $H$. gelotopoeon respectivamente, consideradas las principales plagas de dichos cultivo (Figura IV.17, 18, 19, 20).

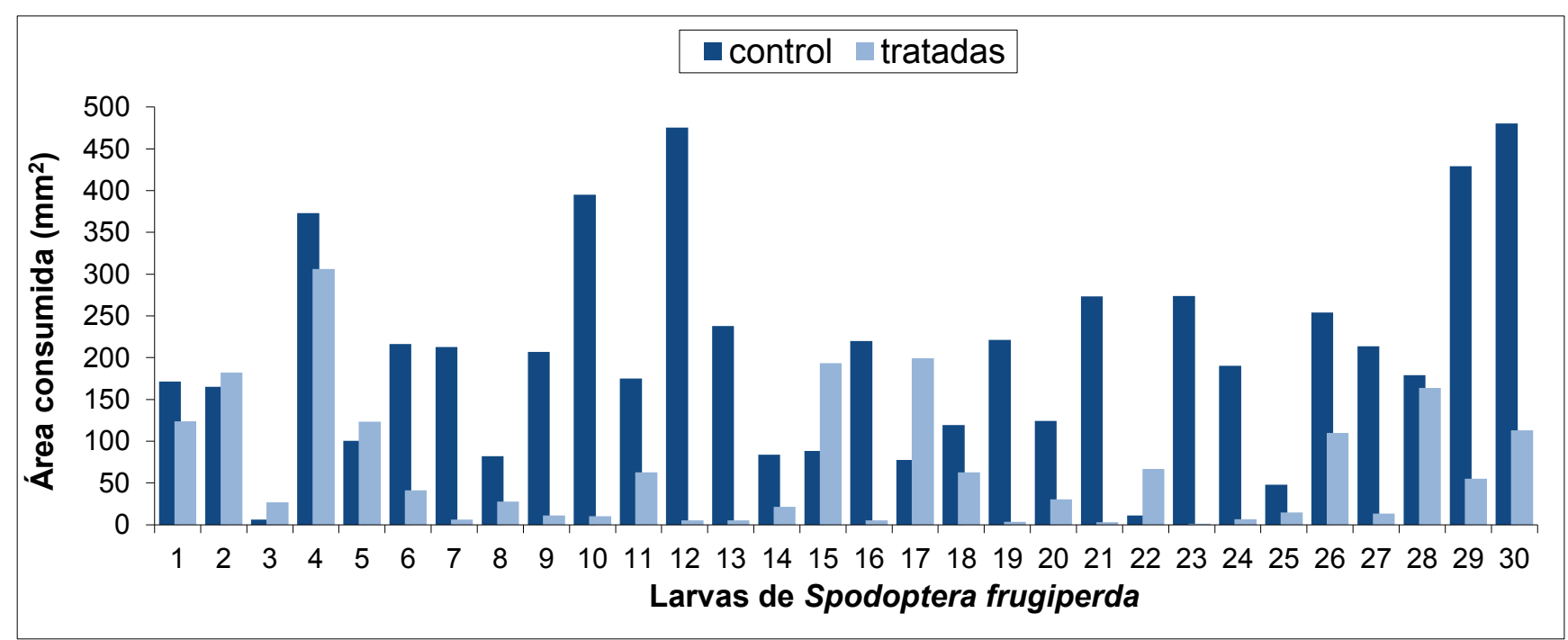

Figura IV.17. Preferencia alimenticia de $S$. frugiperda alimentadas con maíz inoculado con $B$. bassiana y maíz sin inocular (control).

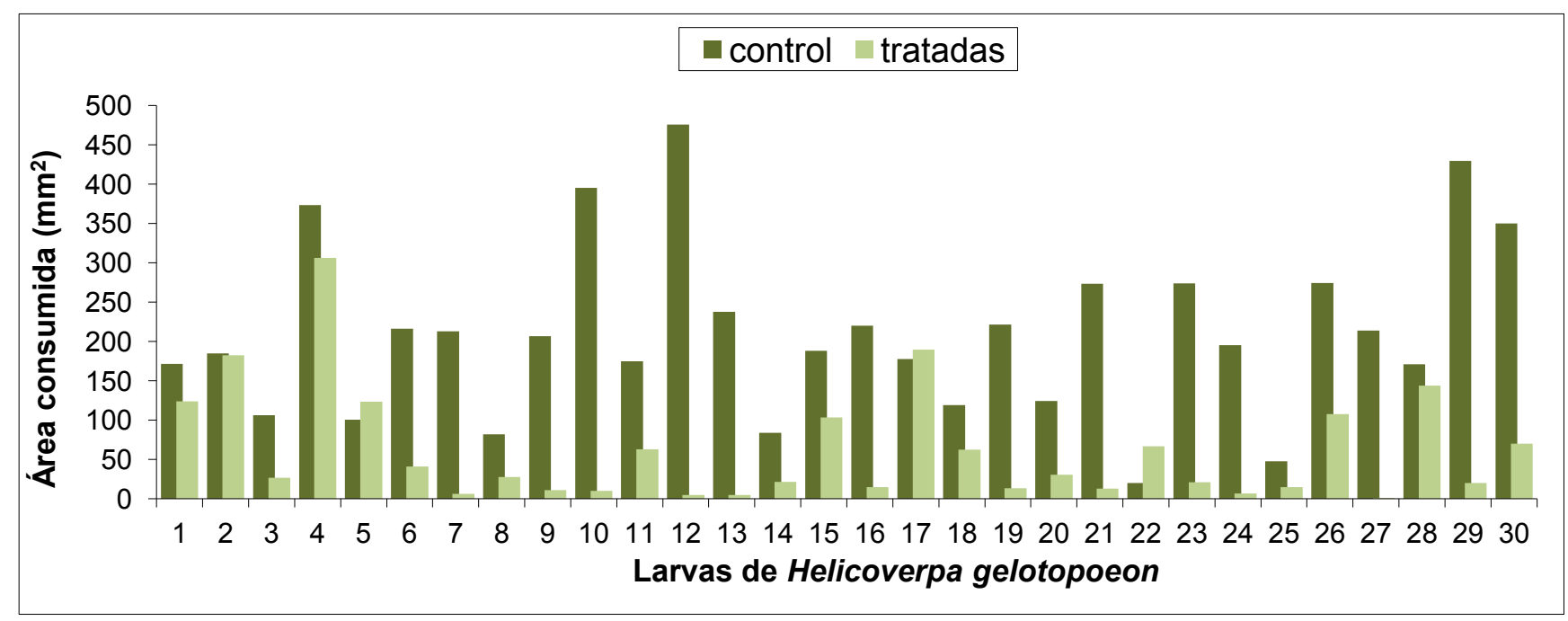

Figura IV.18. Preferencia alimenticia de $H$. gelotopoeon alimentadas con soja inoculada con B. bassiana y soja sin inocular (control). 


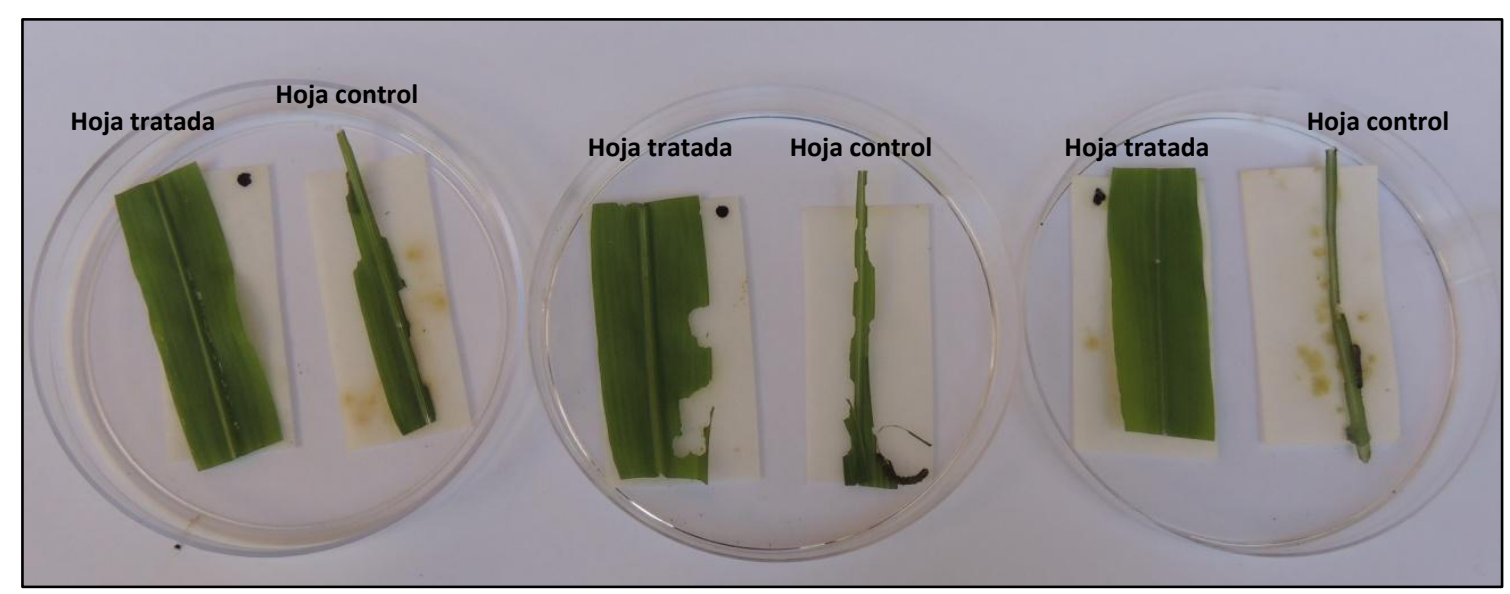

Figura IV.19. Preferencia alimenticia de S. frugiperda transcurridas 24 h.

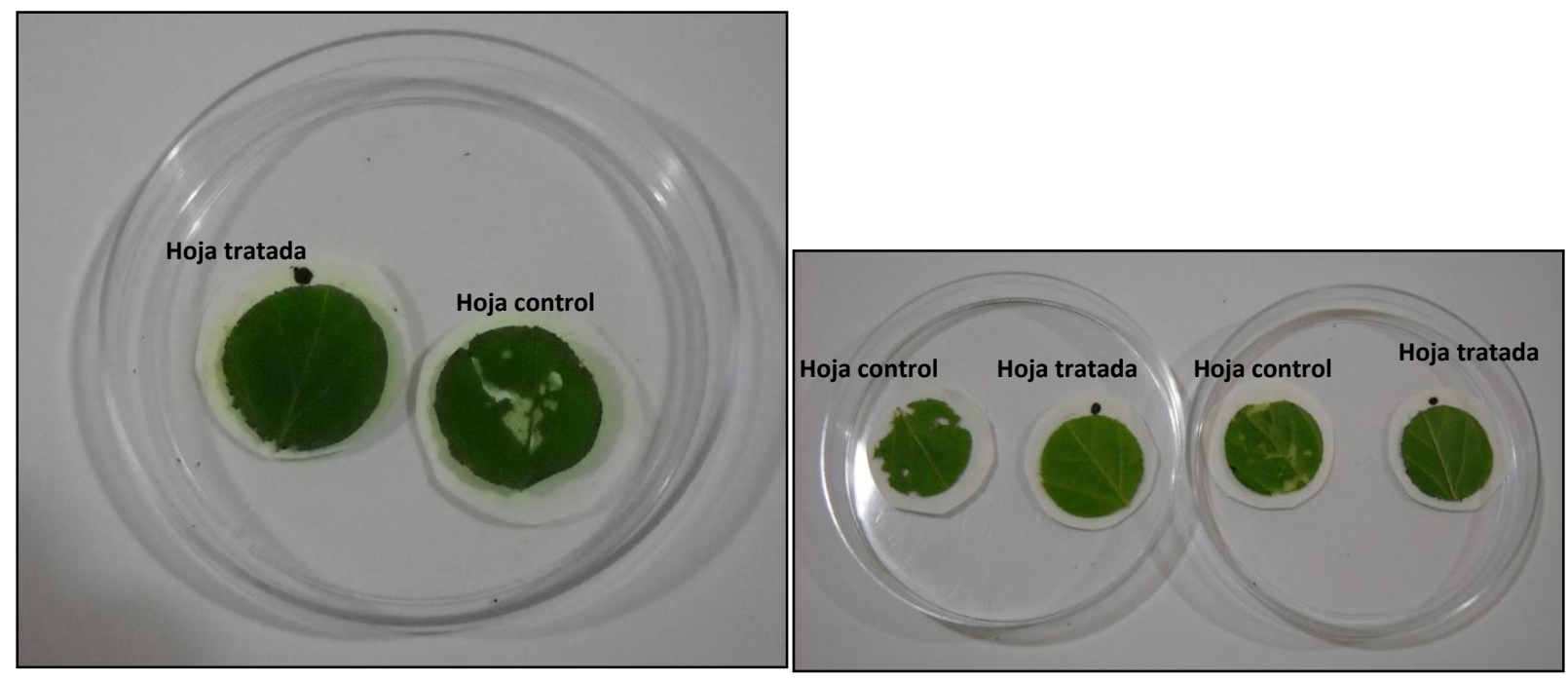

Figura IV.20. Preferencia alimenticia de H. gelotopoeon transcurridas $24 \mathrm{~h}$. 


\section{Discusión}

En este capítulo se evaluó la preferencia alimenticia como así también los diferentes efectos de patogenicidad producidos por el aislamiento de $B$. bassiana LPSc 1098 actuando como endófito sobre las principales especies de insectos plaga de los cultivos de maíz y soja. Los resultados mostraron que el hongo entomopatógeno $B$. bassiana afectó negativamente la supervivencia, la fecundidad, la fertilidad, la longevidad de adultos, la duración del ciclo de vida, el periodo de oviposición y la tasa neta de crecimiento (Ro) de las especies plagas (S. frugiperda y H. gelotopoeon), sin embargo los parámetros medidos de $T, r$ y $\lambda$ fueron similares para ambos tratamientos.

Estos resultados coinciden con los obtenidos por Castillo López y Sword (2015) y Powell et al. (2009), quienes observaron que Helicoverpa zea Boddie (Lepidoptera: Noctuidae) alimentadas con plantas de algodón y tomate que presentaban al hongo entomopatógeno $B$. bassiana como endófito, sufrieron una reducción en la supervivencia de los primeros estadios larvales. Resultados similares fueron obtenidos por Jaber y Vidal (2010) quienes constataron una reducción de la tasa de supervivencia de $H$. armigera cuando fueron alimentadas con plantas de $V$. faba inoculadas con B. bassiana.

En el presente estudio al igual que en los realizados por Powell et al. (2009) en larvas de $H$. zea, se observó la aparición de micosis en individuos muertos después de ser colocados en cámara húmeda, a diferencia de Castillo López y Sword (2015) y Jaber y Vidal (2010) quienes no detectaron dicha aparición y sostienen que la mortalidad de los insectos puede deberse a efectos indirectos producidos cuando el insecto consume la planta inoculada, incluyendo la producción de metabolitos secundarios o una respuesta sistémica inducida de defensa en la planta que le confiere resistencia a la alimentación de los insectos.

Al igual que Akutse et al. (2013) se notó que la longevidad de los adultos de las diferentes especies de insectos disminuyó considerablemente cuando se alimentaban de plantas inoculadas.

En cuanto a la fecundidad y fertilidad se observó que hubo una reducción en ambos parámetros reproductivos en aquellos insectos alimentados con plantas tratadas, en comparación con los que lo hicieron con plantas controles. Resultados similares fueron obtenidos por Mutune et al. (2016) quienes hallaron una reducción en 
la tasa de oviposición de Ophiomyia phaseoli (Tryon) (Diptera: Agromyzidae) alimentadas con plantas de $P$. vulgaris inoculadas con B. bassiana. Por otro lado, Akutse et al. (2013) observaron una reducción de la fertilidad en dípteros alimentados con $V$. faba y $P$. vulgaris que presentaban a $B$. bassiana como endófito. Estos resultados coinciden también con los obtenidos por Jaber y Vidal (2010) en $H$. armigera alimentadas con plantas de $V$. faba inoculadas con Acremonium strictum Gams (Hypocreales). A diferencia de Raps y Vidal (1998) que no detectaron diferencias significativas en la duración del ciclo de vida ni en la supervivencia de los adultos de Plutella xylostella L. (Lepidoptera: Plutellidae) alimentados con plantas de coliflor tratadas en comparación con plantas controles, en esta investigación se observó que en ambas especies de insectos alimentados con plantas tratadas, la proporción de sexos $(\mathrm{M}: \mathrm{H})$ fue mayor y el ciclo de vida fue más corto, indicando que la cantidad de días que permanecían en cada estadio larval y la longevidad de los adultos resultó ser inferior a los insectos alimentados con plantas control, de igual forma que Akutse et al. (2013) en dípteros y Thakur et al. (2013) en Spodoptera litura F. (Lepidoptera: Noctuidae) sobre plantas de coliflor.

Por otro lado, Akello y Sikora (2012) indicaron una reducción en el crecimiento de la población de áfidos alimentados con $V$. faba inoculadas con B. bassiana, mientras que en el presente trabajo se encontraron distintos valores solamente en la tasa neta de crecimiento (Ro), siendo menor en los insectos alimentados con plantas tratadas.

En cuanto a la preferencia alimenticia, S. frugiperda y $\mathrm{H}$. gelotopoeon disminuyeron la preferencia de las plantas que presentaban a $B$. bassiana como endófito en comparación con las plantas control. Resultados similares fueron obtenidos por Castillo López y Sword (2015) en H. zea alimentadas con plantas de algodón inoculadas con $B$. bassiana.

De esta manera podemos concluir que el hongo entomopatógenos $B$. bassiana actuando como endófito en plantas de maíz y soja, tiene el potencial para proteger a las plantas contra la acción de estas dos especies de insectos plaga, disminuyendo su preferencia y su consumo, evitando además la capacidad de dichas especies plagas de aumentar su población por disminución del número de individuos a causa de la ingesta de plantas inoculadas con $B$. bassiana. 


\section{Conclusiones generales y}

\section{perspectivas futuras}




\section{Conclusiones generales}

Treinta y cuatro taxa agrupados en 1601 aislamientos fúngicos fueron identificados a partir de siete variedades de maíz. De los 19 géneros y 15 especies que pudieron identificarse, los más relevantes por su abundancia fueron Arthrinium sp., F. graminearum, F. proliferatum y $P$. rubrum. Treinta y seis taxa agrupados en 3992 aislamientos fúngicos fueron identificados a partir de siete variedades de soja. De los 20 géneros y 16 especies que pudieron identificarse, los más relevantes por su abundancia fueron $A$. terreus, Fusarium sp. 15, Fusarium sp. 17, M. phaseolina y $P$. rubrum.

Las catorce cepas de $B$. bassiana inoculadas en maíz y soja mediante las técnicas de aspersión en hoja, inmersión de semilla e inmersión de raíz se asociaron endofíticamente con las plantas. Mientras que la cepa de M. anisopliae y M. robertsii solo se asociaron a las plantas mediante las técnicas de aspersión en hoja e inmersión de raíz.

Las tres cepas de L. lecanii y la cepa de $T$. cylindrosporum no fueron eficientes en establecerse como endófitos en las mismas plantas empleando las mismas técnicas de inoculación.

La cepa de $B$. bassiana (LPSc 1098) favoreció el crecimiento y el rendimiento de las plantas de maíz y soja, en condiciones de campo.

B. bassiana aumentó el poder germinativo de semillas obtenidas a partir de las plantas de soja inoculadas previamente, mientras que en maíz disminuyó el poder germinativo de semillas obtenidas a partir de las plantas inoculadas previamente.

Los aislamientos de $B$. bassiana evaluados en este estudio no fueron capaces de transmitirse verticalmente ni en maíz ni en soja.

Los insectos plaga de maíz $S$. frugiperda y de soja $H$. gelotopoeon no mostraron preferencia alimenticia por las hojas de plantas incoculadas con $B$. bassiana. 
La presencia de $B$. bassiana como endófito en las plantas estudiadas, afectó negativamente la supervivencia, la fecundidad y la fertilidad de $S$. frugiperda y $H$. gelotopoeon.

B. bassiana inoculada como endófito en maíz y soja no ocasionó síntomas de enfermedad en las plantas, las cuales se mantuvieron asintomáticas durante su crecimiento.

Las plantas que presentaron a $B$. bassiana como endófito mostraron mayor crecimiento, mayor rendimiento y aumento la resistencia frente al ataque de los insectos plagas $S$. frugiperda y $H$. gelotopoeon. 


\section{Perspectivas futuras}

A fines de complementar y continuar el estudio de la línea de investigación abordada en este trabajo de tesis doctoral, se propone tener en cuenta los siguientes puntos:

Evaluar mediante diferentes técnicas de tinción y microscopía el recorrido y alojamiento de los hongos entomopatógenos dentro de la planta.

Profundizar en la ecología de los hongos endófitos aislados de las plantas de maíz y soja, con el fin de evaluar si dichos aislamientos pueden actuar contra insectos plaga o microorganismos patógenos.

Realizar ensayos in vitro para evaluar el potencial antagónico de $B$. bassiana para controlar diferentes especies de hongos patógenos aislados como endófitos en plantas de maíz y soja.

Determinar en condiciones de laboratorio las causas por las cuales $B$. bassiana promovió el crecimiento en ambas especies de plantas, evaluando la capacidad de dicho hongo entomopatógeno de producir diferentes promotores de crecimiento. 


\section{Discusión general}

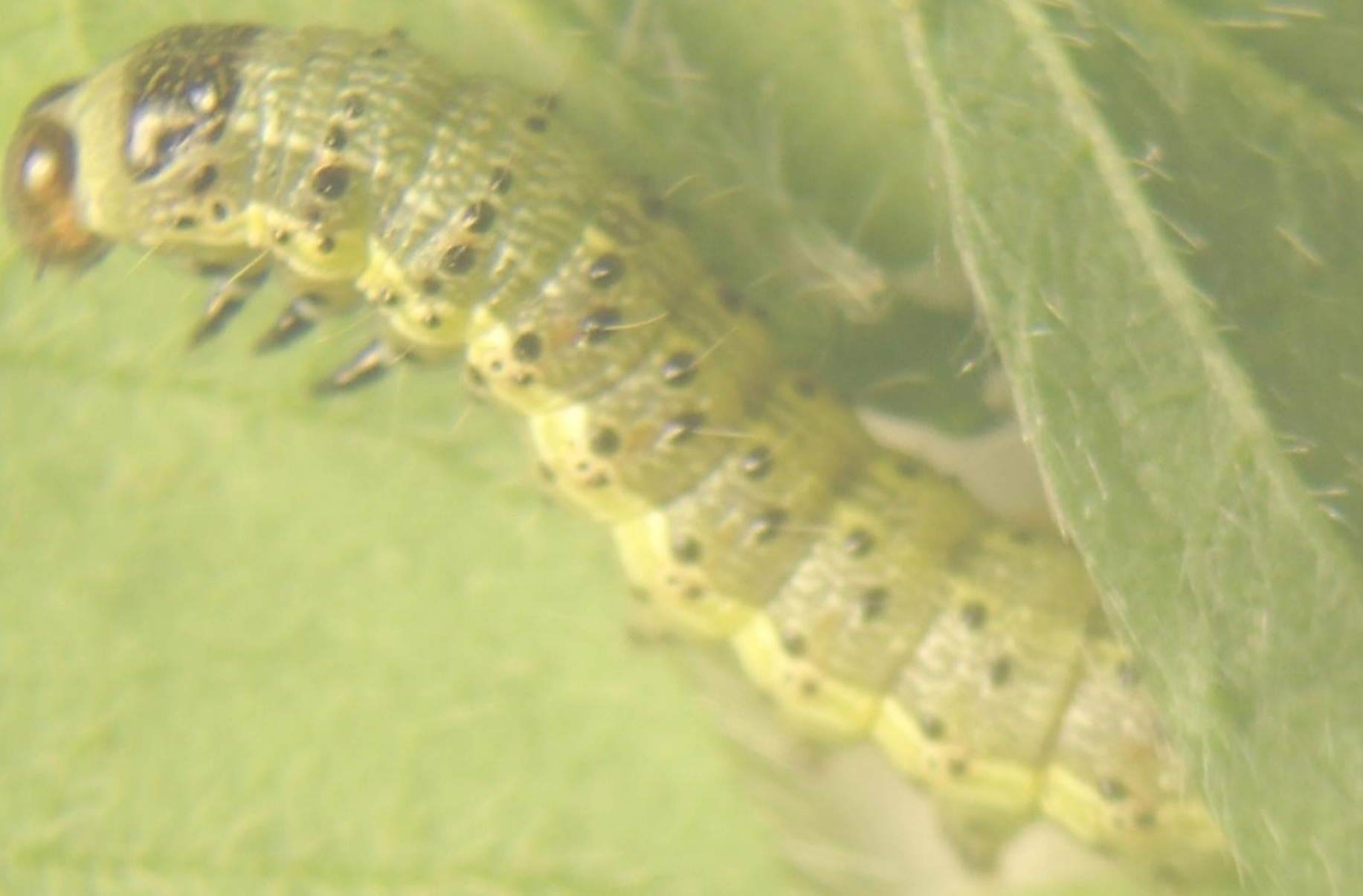




\section{Discusión general}

Como inicio de esta investigación se determinó la composición de comunidades fúngicas endófitas en raíces, tallos y hojas de siete variedades de maíz ( $Z$. mays) y siete variedades de soja (G. max) de zonas ubicadas en la Región Pampeana Argentina. Se encontró que ciertas especies sólo pudieron ser aisladas de determinadas variedades de plantas. En maíz, las especies Fusarium sp. 11 y $T$. harzianun sólo fueron aisladas de la variedad NK900 y Fusarium sp. 7 de la variedad DK699; mientras que en soja la especie Alternaria sp. sólo pudo ser aislada de la variedad DM4913, B. tetramera de la variedad DM4670, Nigrospora sp. de la variedad DM4210 y S. brevicaulis de la variedad DM3810. De este modo, al igual que Fisher et al. (1992), Pimentel et al. (2006), Implullitti y Malvick (2013), Nur (2013) y Fernandes et al. (2015), se reveló una tendencia en algunas especies fúngicas para colonizar determinadas variedades de plantas.

Además, se observó que el mayor número de aislamientos y el mayor número de especies fúngicas se obtuvieron a partir de los tallos. Pimentel et al. (2006) arribaron a idénticos resultados analizando plantas de soja.

Fernandes et al. (2015) encontraron que las especies de hongos endófitos detectadas en las plantas pueden estar influenciadas por varios factores (tipo de órgano de la muestra, las variedades, el clima en el que crecieron las plantas, si las plantas se cultivaron en un monocultivo o policultivo, edad de la planta, la historia de cultivos del campo, el estado nutricional y la cantidad de agua de la planta), haciendo a veces difícil establecer una relación directa entre los hongos aislados y los descriptos en otros estudios.

Por otro lado se evaluó la capacidad de los hongos entomopatógenos $B$. bassiana, M. anisopliae, M. robertsii, L. lecanii y T. cylindrosporum de establecerse en plantas de maíz y soja mediante diferentes técnicas de inoculación (aspersión en hoja, inmersión de raíz e inmersión de semilla). Al comparar las distintas técnicas de inoculación se encontró en primer lugar que $M$. anisopliae, M. robertsii y todas las cepas de $B$. bassiana probadas, pudieron permanecer en las plantas luego de la inoculación, siendo la técnica de aspersión la más eficiente en introducir a las distintas especies de hongos entomopatógenos. Resultados similares fueron observados en 
otras especies de plantas (Quesada-Moraga et al. 2006, Tefera y Vidal, 2009, Gurulingappa et al. 2010 y Parsa et al. 2013), además tanto este resultado como los resultados obtenidos por parte de los autores anteriormente mencionados demostraron que con dicha técnica el mayor porcentaje de reaislamiento se daba en las hojas. Por su parte, Brownbridge et al. (2012), Akutse et al. (2013), Landa et al. (2013), Quesada-Moraga et al. (2014 b) y Jaber y Enkerli (2016) observaron que la inoculación a través de las semillas fue la técnica con la que obtuvieron mejores resultados.

Por otro lado, se observó que a medida que transcurrió el tiempo luego de la inoculación, el porcentaje de reaislamiento fue disminuyendo encontrando las menores frecuencias de colonización a los 28 días posteriores a la inoculación. Similares resultados fueron observados por Jaber y Enkerli (2016) en plantas de $V$. faba, mientras que en otros estudios observaron que $B$. bassiana puede permanecer hasta ocho meses en plantas de café (Posada et al. 2007) y nueve meses en plantas de pino (Brownbridge et al. 2012).

Como ya se mencionó anteriormente, tanto las especies de Metarhizium como todas las cepas de $B$. bassiana fueron capaces de establecerse dentro de las plantas, destacando que la cepa LPSc 1098 de B. bassiana fue la más exitosa.

Una vez determinada la técnica más eficiente y el aislamiento fúngico que con mayor frecuencia se pudo aislar de las plantas tratadas bajo condiciones de laboratorio, se evaluó si dicho aislamiento produjo algún efecto (positivo o negativo) en el crecimiento y el rendimiento de las plantas. En las plantas de maíz y soja inoculadas con $B$. bassiana LPSc 1098 mediante la técnica de aspersión, se encontró que el hongo entomopatógeno promovió el crecimiento vegetal. Resultados similares fueron observados por Ownley et al. (2004), Griffin et al. (2005), Posada y Vega (2006), Ownley et al. (2008), Gurulingappa et al. (2010), Castillo López y Sword (2015) y Greenfield et al. (2016) en distintas especies de plantas, pero no concuerdan con los resultados obtenidos por Lewis et al. (2002) y Tefera y Vidal (2009) que no observaron diferencias en el crecimiento de las plantas. De igual modo en este estudio, el rendimiento de las plantas fue mayor en aquellas que presentaban a $B$. bassiana como endófito, similares resultados fueron observados por Kabaluk y Ericsson (2007).

Luego, se evaluó la preferencia alimenticia y los efectos patogénicos sobre los principales insectos plaga de los cultivos de maíz y soja que presentaban al hongo 
entomopatógeno B. bassiana como endófito. Se observaron efectos negativos en la supervivencia, fecundidad, fertilidad y en todo el ciclo de vida de los insectos plaga $S$. frugiperda y $H$. gelotopoeon cuando fueron alimentadas con plantas que presentaban a $B$. bassiana como endófito.

Cuando se evaluó el consumo y la preferencia alimenticia de dichas plagas, ambas especies de insectos disminuyeron la preferencia por aquellas plantas que presentaban a $B$. bassiana como endófito en comparación con las plantas control. Resultados similares fueron obtenidos por Castillo López y Sword (2015) en H. zea alimentadas con plantas de algodón inoculadas con $B$. bassiana.

Por último, los resultados obtenidos durante la realización del presente trabajo de tesis doctoral, mostraron que las plantas de maíz y soja tratadas con hongos entomopatógenos, se mantuvieron asintomáticas y sin mostrar ningún tipo de indicio de enfermedad durante todo el periodo de estudio. Además se observó que independientemente del punto de entrada en la planta y de la técnica de inoculación aplicada, el hongo puede aislarse de los diferentes tejidos de las plantas, indicando que los distintos aislamientos fúngicos utilizados pueden moverse dentro de ellas, produciéndose de esta manera la colonización endofítica de manera sistémica (Wagner y Lewis et al. 2000; Quesada-Moraga et al. 2006; Gurulingappa et al. 2010; Greenfield et al. 2016). 
Anexo 


\section{Cría de Lepidópteros}

\section{Dieta de larvas}

\section{S. frugiperda}

$\begin{array}{ll}\text { Agar-agar } & 20 \mathrm{~g} \\ \text { Harina de soja } & 75 \mathrm{~g} \\ \text { Germen de trigo } & 17,5 \mathrm{~g} \\ \text { Levadura de Cerveza } & 15 \mathrm{~g} \\ \text { Metilparabeno (Nipagínß) } & 1 \mathrm{~g} \\ \text { Ácido ascórbico } & 3 \mathrm{~g} \\ \text { Ácido sórbico } & 0,1 \mathrm{~g} \\ \text { Formol } & 1 \mathrm{ml} \\ \text { Complejo vitamínico (Vandermix } 囚) & 4 \mathrm{~g} \\ \text { Streptomicina } & 0,5 \mathrm{~g} \\ \text { Agua destilada } & 500 \mathrm{ml}\end{array}$

Calentar el agua destilada a $95^{\circ} \mathrm{C}$, agregar el agar disuelto previamente en agua destilada; calentar nuevamente a $95^{\circ} \mathrm{C}$. Luego agregar los ingredientes menos el antibiótico, el fungicida y las vitaminas y batir hasta que se forme una mezcla homogénea. Dejar en enfriar hasta $60^{\circ} \mathrm{C}$ y finalmente agregar el resto de los ingredientes y homogeneizar.

\section{H. gelotopoeon}

$\begin{array}{ll}\text { Harina de poroto } & 250 \mathrm{~g} \\ \text { Levadura de cerveza } & 50 \mathrm{~g} \\ \text { Metilparabeno (Nipagín }{ }^{\circledR} \text { ) } & 6 \mathrm{~g} \\ \text { Ácido ascórbico } & 7 \mathrm{~g} \\ \text { Ácido sórbico } & 2 \mathrm{~g} \\ \text { Streptomicina } & 2 \mathrm{~g}\end{array}$




$\begin{array}{ll}\text { Formaldehido } & 2 \mathrm{~cm}^{3} \\ \text { Complejo vitamínico (Vandermix } ®) & 4 \mathrm{~g} \\ \text { Agar } & 20 \mathrm{~g} \\ \text { Agua destilada } & 800 \mathrm{ml}\end{array}$

Calentar el agua destilada a $95^{\circ} \mathrm{C}$, agregar el agar disuelto previamente en agua destilada, dejar enfriar hasta $70^{\circ} \mathrm{C}$, añadir el formaldehido y posteriormente los productos sólidos previamente mezclados. Batir hasta que la temperatura descienda a $60^{\circ} \mathrm{C}$, aplicar el resto de los ingredientes y batir hasta lograr una mezcla homogénea.

\section{Dieta de adultos}

Miel $1 \mathrm{~g}$

Acido ascórbico $\quad 0,1 \mathrm{~g}$

Azúcar $6 \mathrm{~g}$

Agua 100ml

\section{Esterilización de pupas}

Hipoclorito de sodio (55g/L): agua (proporción 1:6) 


\section{Referencias bibliográficas}

Akello, J., Dubois, T., Coyne, D., Kyamanywa, S. 2008a. Effect of endophytic Beauveria bassiana on populations of the banana weevil, Cosmopolites sordidus, and their damage in tissue-cultured banana plants. Entomologia Experimentalis et Applicata. 129: 157-165.

Akello, J., Dubois, T., Coyne, D., Kyamanywa, S. 2008b. Endophytic Beauveria bassiana in banana (Musa spp.) reduces banana weevil (Cosmopolites sordidus) fitness and damage. Crop Protection. 27: 1437-1441.

Akello, J., Dubois, T., Gold, C. S., Coyne, D., Nakavuma, J., Paparu, P. 2007. Beauveria bassiana (Balsamo) Vuillemin as an endophyte in tissue culture banana (Musa spp.). Journal of Invertebrate Pathology. 96: 34-42.

Akello, J., Sikora, R. 2012. Systemic acropedal influence of endophyte seed treatment on Acyrthosiphon pisum and Aphis fabae offspring development and reproductive fitness. Biological Control. 61: 215-221.

Akutse, K.S., Maniania, N.K., Fiaboe, K.K.M., Van Den Berg, J., Ekesi, S. 2013. Endophytic colonization of Vicia faba and Phaseolus vulgaris (Fabaceae) by fungal pathogens and their effects on the life-history parameters of Liriomyza huidobrensis (Diptera: Agromyzidae). Fungal Ecology. 6: 293-301.

Altschul, S. F., Gish, W., Miller, W., Myers, E. W., Lipman, D. J. 1990. Basic Local Alignment Search Tool. Journal of Molecular Biology. 215: 403-410.

Alzugaray, R., Zerbino, M.S., Stewart, S., Ribeiro, A., Eilenberg, J. 1999. Epizootiología de hongos Entomophthorales. Uso de Zoophthora radicans (Brefeld) Batko (Zygomycotina: Entomophthorales) para el control de Epinotia aporema (Wals.) (Lepidoptera: Tortricidae) en Uruguay. Revista de la Sociedad Entomológica Argentina 58: $307-311$.

Anderson, C.M.T., McGee, P.A., Nehl, D.B, Mensah, R.K. 2007. The fungus Lecanicillium lecanii colonises the plant Gossypium hirsutum and the aphid Aphis gossypii. Australasian Mycologist 26:65-70. 
Angulo, A.O., Weigert. G.H. 1975. Estados inmaduros de lepidópteros nóctuidos de importancia económica en Chile y claves para su determinación (Lepidoptera: Noctuidae). Boletin de la Sociedad de Biología de Concepción. Publicación Especial (2): $153 \mathrm{pp}$.

Arnold, A.E. 2007. Understanding the diversity of foliar endophytic fungi: progress, challenges, and frontiers. Fungal Biology Reviews 21: 51-66.

Arnold, A.E, Henk, D.A, Eells, R.L., Lutzoni, F., Vilgalys, R. 2007. Diversity and phylogenetic affinities of foliar fungal endophytes in loblolly pine inferred by culturing and environmental PCR. Mycologia 99: 185-206.

Arnold, A.E., Lutzoni, F. 2007. Diversity and host range of foliar fungal endophytes: are tropical leaves biodiversity hotspots? Ecology 88: 541-549.

Arnold, A.E., Mejia, L.C., Kyllo, D., Rojas, E.I., Maynard, Z., Robbins, N., Herre, E.A. 2003. Fungal endophytes limit pathogen damage in a tropical tree. Proceedings of the National Academy of Sciences of the United States of America 100: 15649-15654.

Aruta, C., Carrillo, R., Gonzalez, S. 1974. Determinación para Chile de Hongos Entomopatógenos del género Entomophthora. Agro Sur 2: 62-70.

Aruta, C., Carrillo, R., Montealegre, J. 1984. Determinación para Chile del Orden Entomophthorales (Zygomycetes). Agro Sur 12: 36-42.

Bacon, C.W., Porter, J.K., Robins J.D., Lutrell, E.J. 1977. Epichloë typhina from 10 toxic tall fescue grass. Applied and Environmental Microbiology 34: 576-581.

Bailer, W. 2006. Writing ImageJ Plugins. A Tutorial. Version 1.71.

Barrios, M. B. 2011. Efecto del laboreo sobre el desarrollo de raíces y productividad. Grande, R.A. (Ed). Editorial Académica Española. España. 206 pp.

Barrios, M.B., Bujan, A., Debelis, S.P., Sokolowski, A.C., Blason, A.D., Rodriguez, H.A., López, S.C., De Gracia, J., Mazo, C.R., Gagey, M.C. 2014. Relación Biomasa de Raíz/ Biomasa total de soja (Glycine max) en dos sistemas de labranza. Terra Latinoamericana 32: 221-230. 
Batta, Y.A. 2013. Efficacy of endophytic and applied Metarhizium anisopliae (Metch.) Sorokin (Ascomycota: Hypocreales) against larvae of Plutella xylostella L. (Yponomeutidae: Lepidoptera) infesting Brassica napus plants. Crop Protection 44: 128-134.

Baudino, E., Villarreal, D. 2007. Orugas cortadoras que dañan cultivos de cosecha gruesa y pasturas de alfalfa en la región oriental de la provincia de La Pampa. Revisión bibliográfica. Revista de la Facultad de Agronomía UNLPam 18: 11-57.

Baverstock, J., Roy, H.E., Pell, J.K. 2010. Entomopathogenic fungi and insect behavior: from unsuspecting hosts to targeted vectors. BioControl 55: 89-102.

Bayat, F., Mirlohi, A., Khodambashi, M. 2009. Effects of Endophytic Fungi on Some Drought Tolerance Mechanisms of Tall Fescue in a Hydroponics Culture. Russian Journal of Plant Physiology 56 (4):510-516.

Bellotti, A.C., Melo, E.L., Arias, B., Herrera, C.J., Hernández, M.P., Holguín, C.M., Guerrero, J.M., Trujillo, H. 2005. Biological control in the neotropics: a selective review with emphasis on cassava. In: Proceedings of the Second International Symposium on Biological Control of Arthropods. Hoddle, M.S. (Ed.), USDA Forest Service publication. 206-227 pp.

Bhardwaj, D., Ansari, M.W.,Sahoo, R.K., Bhardwaj, N.T. 2014. Biofertilizers function as key player in sustainable agriculture by improving soil fertility, plant tolerance and crop productivity Microbial Cell Factories 13:1-66.

Bing, L., Lewis, L.C. 1991. Suppression of Ostrinia nubilalis (Hübner) (Lepidoptera: Pyralidae) by endophytic Beauveria bassiana (Balsamo) Vuillemin. Environmental Entomology 20: 1207-1211.

Bing, L.A., Lewis, L.C. 1993. Occurrence of the entomopathogen Beauveria bassiana (Balsamo) Vuillemin in different tillage regimes and in Zea mays L. and virulence towards Ostrinia nubilalis (Hiibner). Agriculture, Ecosystems and Environment 45: 147-156.

Biswas, C., Dey, P., Satpathy, S., Satya, P. 2012. Establishment of the fungal entomopathogen Beauveria bassiana as a season long endophyte in jute (Corchorus olitorius) and its rapid detection using SCAR marker. BioControl 57: 565-571. 
Boito, G.T., Giovanini, D., Crenna, A.C., Oddino, C., Giuggia, J.A., Gerardo, U.A. 2013. Desarrollo y validación de una escala para evaluación de daño por orugas defoliadoras en soja (Glycine max L.), para el sur de la provincia de Córdoba. Revista de la Facultad de Ciencias Agrarias - UNCuyo. 45(1): 91-104.

Brownbridge, M., Reay, S.D., Nelson, T.L., Glare, T.R. 2012. Persistence of Beauveria bassiana (Ascomycota: Hypocreales) as an endophyte following inoculation of radiata pine seed and seedlings. Biological Control 61: 194-200.

Brunstein, L., Digón, A., Licastro, S., Moreno I. 2009. Generalidades sobre plaguicidas y control de plagas. En: Plaguicidas. Información y estrategias para la gestión ecológicamente racional de plaguicidas de uso sanitario. Departamento de Salud Ambiental. Dirección Nacional de Determinantes de la Salud e Investigación. Ministerio de Salud de la Nación. Buenos Aires, Argentina. 11 pp.

Caccia, M.G., Del Valle, E., Doucet, M.E. Lax, P. 2014. Susceptibility of Spodoptera frugiperda and Helicoverpa gelotopoeon (Lepidoptera: Noctuidae) to the entomopathogenic nematode Steinernema diaprepesi (Rhabditida: Steinernematidae) under laboratory conditions. Chilean Journal of Agricultural Research 74(1):123-126.

Canel, R. S., Wagner, J. R., Stenglein, S. A., Ludemann, V. 2013. Indigenous filamentous fungi on the surface of Argentinean dry fermented sausages produced in Colonia Caroya (Córdoba, Argentina). International Journal of Food Microbiology 164: 81-86.

Cañedo, V., Ames, T. 2004. Manual de laboratorio para el manejo de hongos entomopatógenos. Centro Internacional de la Papa (CIP), Lima, Perú, 62 pp.

Cao, L.X., You, J.L., Zhou, S.N. 2002. Endophytic fungi from Musa acuminata leaves and roots in South China. World Journal of Microbiology \& Biotechnology 18: 169-171.

Carmona, M.A. 2014. Enfermedades de fin de ciclo y mancha ojo de rana en el cultivo de soja: Desarrollo y validadcion de de un sistema de puntuacion y determinacion del umbral de control. Trabajo de tesis doctoral. Facultad de Ciencias Agrarias y Forestales. UNLP. Buenos Aires.

Casmuz, A., Juárez Socías, M.G., Murúa, M.G., Prieto, S., S. Medina, E. W. 2010. Revisión de los hospederos del gusano cogollero del maíz, Spodoptera frugiperda 
(Lepidoptera: Noctuidae). Revista de la Sociedad Entomológica Argentina 69: 209231.

Castillo Lopez, D., Sword, G.A. 2015. The endophytic fungal entomopathogens Beauveria bassiana and Purpureocillium lilacinum enhance the growth of cultivated cotton (Gossypium hirsutum) and negatively affect survival of the cotton bollworm (Helicoverpa zea). Biological Control 89:53-60.

Chacón Castro, Y., Rojas, C.G., Cedeño, C.V., Velásquez, V.V. 2008. Desarrollo de una metodología de crianza en laboratorio del gusano cogollero del maíz Spodoptera frugiperda (Smith) como hospedante de insectos biocontroladores de interés agrícola. Centro de Investigación en Biotecnología. 51 pp.

Cherry, A.J., Banito, A., Djegui, D., Lomer, C. 2004. Suppression of the stem-borer Sesamia calamistis (Lepidoptera: Noctuidae) in maize following seed dressing, topical application and stem injection with African isolates of Beauveria bassiana. International Journal of Pest Management 50: 67-73.

Chi, H. 1988. Life-table analysis incorporating both sexes and variable development rates among individuals. Environmental Entomology 17: 26-31.

Chi, H. 2008. TWOSEX-MSChart: computer program for age-stage, two-sex life table analysis. http://140.120.197.183/Ecology.

Chouvenc, T., Su, N.Y., Elliott, M. 2008. Interaction Between the Subterranean Termite Reticulitermes flavipes (Isoptera: Rhinotermitidae) and the Entomopathogenic Fungus Metarhizium anisopliae in Foraging Arenas. Journal of Economic Entomology 101(3): 885-893.

Dalal, J.M., Kulkarni, N.S. 2014. Population variance and diversity of endophytic fungi in soybean (Glycine max (L) Merr). Research \& Reviews: Journal of Botanical Sciences 3(4): 33-39.

De Bary, H.A. 1884. Vergleichende Morphologie und Biologie der Pilze Mycetozoen und Bacterien. Verlag von Wilhelm Engelmann, Leipzig. 
Diestéfano, S.G., Gadbán, L.C. 2010. Efecto de la aplicación de fungicidas foliares de distintos grupos químicos en diferentes estadios fenológicos del cultivo de soja sobre la intensidad de "mancha ojo de rana" (Cercospora sojina) y los componentes del rendiemiento. INTA, Publicación Miscelánea. 118-144.

Distéfano, S. G., Lenzi, L., Gadbán, L. C., Fuentes, F. 2010. Intensidad y pérdida de rendimiento en cultivares de soja por "mancha ojo de rana". INTA. Informe de Actualización Técnica. 17: 53-64.

Domsch, K.H, Gams, W., Anderson, T.H. 2007. Compendium of soil fungi. 2nd ed. Eching: IHW Verlag, Germany, 672 pp.

Duperchy, E. 2003. Identification of up-regulated genes of the hyphomycete Beauveria bassiana, during the infection of Leptinoptarsa dicemlineata. Tesis de Doctorado. Universidad de Ruperto-Carola de Heidelberg. Alemania.

Edelstein, J.D., Lecuona, R.E. 2003. Presencia del hongo entomopatógeno Pandora gammae (Weiser) Humber (Zygomycetes: Entomophthorales) en el complejo de orugas medidoras de la soja (Lepidoptera: Plusiinae) en Argentina. Revista de Investigaciones Agronómicas. INTA. 32: 31- 38.

Edelstein, J.D., Trumper, E.V., Lecuona, R.E. 2005. Temperature-Dependent Development of the Entomopathogenic Fungus Nomuraea rileyi (Farlow) Samson in Anticarsia gemmatalis (Hübner) Larvae (Lepidoptera: Noctuidae). Neotropical Entomology 34(4):593-599.

Eilenberg, J., Hajek, A.E., Lomer, C. 2001. Suggestions for unifying the terminology in biological control. BioControl 46: 387-400.

Escande, A. 2012. Documento Base del Programa Nacional: Oleaginosas. INTA. 25 pp. Esposito, E., de Azevedo, J.L. 2004. Fungos: uma introdução à biologia, bioquímica e biotecnologia. Caxias do Sul: Editora da Universidade de Caxias do Sul (EDUCS). 510 pp.

Faeth, S.H. 2009. Asexual fungal symbionts alter reproductive allocation and herbivory over time in their native perennial grass hosts. American Naturalist 173: 554-565. 
Faeth, S.H., Fagan, W.F. 2002. Fungal endophytes: Common host plant symbionts but uncommon mutualists. Integrative and Comparative Biology 42(2): 360368.

Faeth, S.H., Saari, S. 2012. Fungal grass endophytes and arthropod communities: lessons from plant defence theory and multitrophic interactions. Fungal Ecology 5:364-371.

FAO 2010. Problemática del hambre y la nutrición mundial, por región y país. www.fao.org/hunger/hunger

FAO 2011. El Estado Mundial de la Agricultura y la Alimentación. Organización de las Naciones Unidas para la Agricultura y la Alimentación. www.fao.org/3/a-i2050s.pdf.

Fernandes, E.G., Pereira, O.L., da Silva, C.C., Bento, C.B.P., de Queiroz, M.V. 2015. Diversity of endophytic fungi in Glycine max. Microbiological Research 181: 84-92.

Fernandez, M.C., Gutierrez Boem, F.H., Rubio, G. 2009. Compared Phosphorus Efficiency in Soybean, Sunflower and Maize. Journal of Plant Nutrition 32: 2027-2043.

Ferraro, D., Ghersa, C., Sznaider, G. 2003. Evaluation of environmental impact indicators using fuzzy logic to assess the mixed cropping systems of the Inland Pampa, Argentina. Agriculture Ecosystems \& Environment 96: 1-18.

Fichetti, P., S. Avalos, V. Mazzuferi, and J. Carreras. 2009. Lepidóptera presentes en el cultivo de garbanzo en Córdoba, Argentina. Boletín de Sanidad Vegetal-Plagas 35:49-58.

Fisher, P.J., Petrini, O. 1992. Fungal saprobes and pathogens as endophytes of rice (Oryza sativa L.). New Phytologist 120: 137-143.

Fisher, P.J., Petrini, O., Scott, H.M.L. 1992. The distribution of some fungal and bacterial endophytes in maize (Zea mays L.). New Phytology 122: 299-305.

Fresa, R. 1971. El hongo Entomophthora grylli en tucuras. Revista de Investigaciones Agropecuarias, INTA, Serie Patología Vegetal 7(2): 83-88.

Fresa, R. 1979. Hongos entomopatógenos observados en larvas de lepidópteros perjudiciales para cultivos de la República Argentina. I.D.I.A. 373: 149-155.

Fröhlich, J., Hyde, K.D., Petrini, O. 2000. Endophytic fungi associated with palms. Mycological Research 104: 1202-1212. 
García García, M. A., Capello García, S., Lesher Gordillo, J. M., Molina Martinez, R.F. 2008. Hongos entomopatógenos como una alternativa en el control Biológico. Kuxulkab 27(15): 25-28.

García, J.E., Posadas, J.B., Perticari, A., Lecuona, R.E. 2011. Metarhizium anisopliae (Metschnikoff) Sorokin promotes growth and has endophytic activity in tomato plants. Advances in Biological Research 5: 22-27.

García, J.L., Clavijo, S. 1989. Efecto de la alimentación sobre la longevidad, fertilidad y fecundidad de Spodoptera frugiperda (Smith). Entomología 5 (6): 47-53.

Garcia, L.C., Raetano, C.G., Leite, L.G. 2008. Application technology for the entomopathogenic nematodes Heterorhabditis indica and Steinernema sp (Rhabditida: Heterorhabditidae and Steinernematidae) to control Spodoptera frugiperda (Smith) (Lepidoptera: Noctuidae) in corn. Neotropical Entomology 37: 305-311.

García López, A.M., Avilés, M., Delgado, A. 2013. Iron availability thresholds for the inoculation of cucumber with Trichoderma asperellum T34. Journal of Plant Nutrition and Soil Science 176: 867-875.

Gimenez Pecci, M.P., Laguna, G. Avila, A.O., De Remes Lenico, A.M.M., Virla, E., Borgogno, C., Nome, C.F. Paradell, S. 2002. Difusión del Corn Stunt Spiroplasma del maíz (Spiroplasma kunkelii) y del vector (Dalbulus maidis) en la República Argentina. Revista de la Facultad de Agronomía, La Plata 105 (1): 1-8.

Giorda, L. M., Baigorri. H. E. J. 1997. El cultivo de la soja en Argentina, Córdoba,Argentina. INTA. 142-150.

Glare, T. 2004. Biotechnological potencial entomopathogenic Fungi. In: Fungal Biotecnology in Agricultural, Food and Enviromental Applications. Marcel, D.K. (Ed.), Dekker Inc., New York, USA: (7): 79-90 pp.

Goettel, M.S., Inglis, G.D. 1997. Fungi: Hyphomycetes. In: Manual of Techniques in Insect Pathology. Lacey, L.A. (Ed.),Academic Press, London. 213-249 pp.

Gómez Vidal, S., Lopez Llorca, L.V., Jansson, H.B., Salinas, J. 2006. Endophytic colonization of date palm (Phoenix dactylifera L.) leaves by entomopathogenic fungi. Micron 37: 624-632. 
Gómez Vidal, S., Salinas, J., Tena, M., Lopez Llorca, L.V. 2009. Proteomic analysis of date palm (Phoenix dactylifera L.) responses to endophytic colonization by entomopathogenic fungi. Electrophoresis 30: 2996-3005.

González Castillo, M., Aguilar, C.N., Rodríguez Herrera. R. 2012. Control de insectosplaga en la agricultura utilizando hongos entomopatógenos: retos y perspectivas. Revista Científica de la Universidad Autónoma de Coahuila 4 (8): 42-55.

Gotz, M., Nirenberg, H., Krause, S., Wolters, H., Draeger, S., Buchner, A. 2006. Fungal endophytes in potato roots studied by traditional isolation and cultivationindependent DNA-based methods. FEMS Microbiology Ecology 58: 404-413

Greene, G.L., Leppla, N.C., Dickerson, W.A. 1976. Velvetbean catterpillar: a rearing procedure and artificial medium. Journal of Economic Entomology 69: 487-488.

Greenfield, M., Gómez Jiménez, M.I., Ortiz, V., Vega, F.E., Kramer, M., Parsa, S. 2016. Beauveria bassiana and Metarhizium anisopliae endophytically colonize cassava roots following soil drench inoculation. Biological Control 95: 40-48.

Greenfield, M., Pareja, R., Ortiz, V., Gómez Jiménez, M.I., Vega, F.E., Parsa, S. 2015. A novel method to scale up fungal endophyte isolations. Biocontrol Science and Technology 25(10): 1208-1212.

Griffin, M.R., Ownley, B.H., Klingeman, W.E., Pereira, R.M., 2005. Biocontrol ofRhizoctonia damping-off of cotton with endophytic Beauveria bassiana. Phytopathology 95- S36.

Gundel, P.E., Omacini, M., Sadras, V.O., Ghersa, C.M. 2010. The interplay between the effectiveness of the grass-endophyte mutualism and the genetic variability of the host plant in an agronomic context. Evolutionary Applications 3: 538-546.

Gurulingappa, P., Sword, G.A., Murdoch, G., McGee, P.A. 2010. Colonization of crop plants by fungal entomopathogens and their effects on two insect pests when in planta. Biological Control 55: 34-41.

Hatting, J.L., Humber, R.A., Poprawski, T.J., Miller, R.M. 1999. A survey of fungal pathogens from South Africa with special reference to cereal aphids. Biological Control 16: 1-12. 
Herrero Asensio, N., Sanchez Marquez, S., Zabalgogeazcoa, I. 2013. Mycovirus effect on the endophytic establishment of the entomopathogenic fungus Tolypocladium cylindrosporum in tomato and bean plants. BioControl 58: 225-232.

Herrero, N., Dueñas, E., Quesada-Moraga, E., Zabalgogeazcoa, I. 2012. Prevalence and diversity of viruses in the entomopathogenic fungus Beauveria bassiana. Applied and Environmental Microbiology 78 (24): 8523-8530.

Holguín, C.M., Bellotti, A.C. 2004. Efecto de la aplicación de insecticidas químicos en el control de la mosca blanca Aleurotrachelus socialis (Homoptera: Aleyrodidae) en el cultivo de yuca Manihot esculenta Crantz. Revista Colombiana de Entomología 30: 3742.

Huerga, M., San Juan, S. 2005. El control de las plagas en la agricultura argentina. Estudio Sectorial Agrícola Rural. Banco Mundial/Centro de Inversiones FAO, Argentina. $121 \mathrm{pp}$.

Humber, R.A. 1991. Fungal pathogens of aphids. In Aphid-Plant Interactions: populations to Molecules. Peters, D.C., Webster, J.A., Chlouser, C.S.(Eds.),Stillwater, Division of Agriculture, Oklahoma State University, USA. 45-56 pp.

Humber, R.A. 2008. Evolution of entomopathogenicity in fungi. Journal of invertebrate pathology 98: 262-266.

Humber, R.A. 2009. Fungi: Entomogenous fungi. In: Encyclopedia of Microbiology. Schaechter, M. (ed.), Elsevier, San Diego, USA.443-456 pp.

Humber, R.A. 2012a. Entomophthoromycota: a new phylum and reclassification of entomophthoroid fungi. Mycotaxon 120: 477-492.

Humber, R.A. 2012b. Identification of entomopathogenic fungi. In Manual of Techniques in Invertebrate Pathology. Lacey, L.A. (Ed.),The Netherlands: Academic Press. Amsterdam. 151-187 pp.

Hyde, K. D., Soytong, K. 2008. The fungal dilemma. Fungal Diversity 33: 163-173.

Impullitti, A.E, Malvick, D.K. 2013. Fungal endophyte diversity in soybean. Journal of Applied Microbiology 114(5):1500-1506. 
InfoStat 2004. InfoStat versión 2004, Argentina: Grupo InfoStat, Facultad Ciencias Agrarias, Universidad Nacional de Córdoba Primera edición. Editorial Brujas.

Inglis, G.D., Goettel, M.S., Butt, T.M., Strasser, H. 2001. Use of hyphomycetous fungi for managing insect pests. In: Fungi as Biocontrol Agents: Progress, Problems and Potential.Butt, T.M., Jackson, C., Magan, N. (Eds.), CABI Publishing, England. 23-69 pp.

ISTA 2007. International Seed Testing Association. Rules for Seed Testing, Zürich.

Jaber, L.R., Enkerli, J. 2016. Effect of seed treatment duration on growth and colonization of Vicia faba by endophytic Beauveria bassiana and Metarhizium brunneum. Biological Control 103: 187-195.

Jaber, L.R., Vidal, S. 2010. Fungal endophyte negative effects on herbivory are enhanced on intact plants and maintained in a subsequent generation. Ecological Entomology 35: 25-36.

Jani, A.J., Faeth, S.H., Gardner, D. 2010. Asexual endophytes and associated alkaloids alter arthropod community structure and increase herbivore abundances on a native grass. Ecology Letters 13: 106-117.

Kabaluk, J.T., Ericsson, J.D. 2007. Seed treatment increases yield of field corn when applied for wireworm control. Agronomy journal 99: 1377-1381.

Keller, S. 1997. The genus Neozygites (Zygomycetes: Entomophthorales) with special reference to species found in tropical regions. Sydowia 49: 118-146.

Kirk, P.M., Cannon, P.F., Minter, D.W., Stalpers, J.A. 2008. Dictionary of the Fungi, 10th Edición. CABI Europe - UK. 771pp.

Kovach W.L. 1999. MVSP - Multivariate Statistical Package, v.3.1. Kovach Computing Services, Pentreath.

Krings, M., Taylor, T.N., Hass, H. 2007. Fungal endophytes in a 400-million-yr-old land plant: infection pathways, spatial distribution, and host responses. New Phytologist 174: 648-657.

Kumar, D.D.S., Hyde, K.D. 2004. Biodiversity and tissue recurrence of endophytic fungi in Tripterygium wilfordii. Fungal Diversity 17: 69-90. 
Kumar, S., Kaushik, N. 2013. Isolation, characterization and bioactivity of endophytic fungi from Withania somnifera. Indian Phytopathology 66: 322-323.

Landa, B. B., López Díaz, C., Jiménez Fernández, D., Montes Borrego, M., Muñoz Ledesma, F. J., Ortiz Urquiza, A., Quesada Moraga, E. 2013. In-planta detection and monitorization of endophytic colonization by a Beauveria bassianastrain using a newdevelopednested and quantitative PCR-based assay and confocal laser scanning microscopy.Journal of Invertebrate Pathology 114: 128-138.

Lange, C. E. 1996. Melanoplinos (Orthoptera: Acrididae) afectados por micosis en la provincia de Buenos Aires, Argentina. Revista de la Sociedad Entomológica Argentina 55: $107-109$.

Larran, S., Monaco, C., Alippi, H.E. 2001. Endophytic fungi in leaves of Lycopersicon esculentum Mill. World Journal of Microbiology \& Biotechnology 17: 181-184.

Larran, S., Perello, A., Simon, M.R., Moreno, V., 2002a. Isolation and analysis of endophytic microorganisms in wheat (Triticum aestivum L.) leaves. World Journal of Microbiology \& Biotechnology 18: 683-686.

Larran, S., Rollan, C., Angeles, H.B., Alippi, H.E., Urrutia, M,I. 2002b. Endophytic fungi in healthy soybean leaves. Investigación agraria. Producción y protección vegetal 17(1): 174-178.

Leckie, B.M. 2002. Effects of Beauveria bassiana mycelia and metabolites incorporated into synthetic diet and fed to larval Helicoverpa zea, and detection of endophytic Beauveria bassiana in tomato plants using PCR and ITS. M.S. thesis, Department of Entomology, The University of Tennessee, Tennesse, USA. 75pp.

Leite, T.S., Cnossen-Fassoni, A., Pereira, O.L., Mizubuti, E.S.G., Araujo, E.F., Queiroz, M.V. 2013. Novel and highly diverse fungal endophytes in soybean revealed by the consortium of two different techniques. Journal of Microbiology 51: 56-69.

Leslie, J.F., Summerell, B.A. 2006. The Fusarium Laboratory Manual. Blackwell Publishing, Ames, Iowa, USA. 388 pp.

Lewis, L.C., Bruck, D.J., Gunnarson, R.D. 2002. On farm evaluation of Beauveria bassiana for control of Ostrinia nubilalis in Iowa, USA. BioControl 47: 167-176. 
Li, W.C., Zhou, J., Guo, S.Y. and Guo, L.D. 2007. Endophytic fungi associated with lichens in Baihua mountain of Beijing, China. Fungal Diversity. 25: 69-80.

Liao, X., O’Brien, T.R.,Fang, W., St. Leger, R.J. 2014. The plant beneficial effects of Metarhizium species correlate with their association with roots. Applied Microbiology and Biotechnology 98(16): 7089-7096.

Ling, B., Wang, G., Ya, J., Zhang, M., Liang, G. 2008. Antifeedant activity and active ingredients against Plutella xylostella from Momordica charantia leaves. Agricultural Sciences in China 7: 1466-1473.

López Lastra, C.C., Scorsetti A.C. 2006. Hongos Entomophthorales patógenos de insectos de la República Argentina. Revista de Biología Tropical 54: 311-315.

López Lastra, C.C., Siri, A., García, J.J., Eilenberg, J. Humber, R.A. 2006 Entomophthora ferdinandii (Zygomycetes: Entomophthorales) causing natural infections of Musca domestica (Diptera: Muscidae) in Argentina. Mycopathologia 161: 251-254.

Lopez, D.C., Sword, G.A. 2015. The endophytic fungal entomopathogens Beauveria bassiana and Purpureocillium lilacinum enhance the growth of cultivated cotton (Gossypium hirsutum) and negatively affect survival of the cotton bollworm (Helicoverpa zea). Biological Control 89: 53-60.

Lord, J.C. 2005. From Metchnikoff to Monsanto and beyond: the path of microbial control. Journal of Invertebrate Pathology 89(1):19-29.

Luna, M.J., Iannone, N. 2013. Efecto de la chinche de los cuernos "Dichelops furcatus" (F.) sobre la calidad de la semilla de soja. Revista de la Facultad de Agronomía, La Plata 112 (2): 141-145.

Maag, D., Kandula, D.R.W., Müller, C., Mendoza-Mendoza, A., Wratten, S.D., Stewart, A., Rosta, M. 2013. Trichoderma atroviride LU132 promotes plantgrowth but not induced systemic resistance to Plutella xylostella in oilseedrape. BioControl 59: 241252.

Magrini, F.E., Specht, A., Gaio, J., Girelli, C.P., Migues, I., Heinzen, H., Saldaña, J., Sartori, V.C., Cesio V. 2015. Antifeedant activity and effects of fruits and seeds extracts of Cabralea canjerana (Vell.) Mart. (Meliaceae) on the immature stages of the 
fall armyworm Spodoptera frugiperda (JE Smith) (Lepidoptera: Noctuidae). Industrial Crops and Products 65: 150-158.

Magurran, A. E. 1988. Ecological diversity and its measurement. Princeton University Press, New Jersey, USA.179 pp.

MAGyP 2012. Ministerio de Agricultura Ganadería y Pesca de la Nación. www.datos.magyp.gob.ar

Mantzoukas, S., Chondrogiannis, C., Grammatikopoulos, G. 2015. Effects of three endophytic entomopathogens on sweet sorghum and on the larvae of the stalk borer Sesamia nonagrioides. Entomologia Experimentalis et Applicata 154: 78-87.

McKinnion, A.C., Saari, S., Moran-Diez, M. E., Meyling, N. V., Raad, M., Glare, T. R. 2017. Beauveria bassiana as an endophyte: a critical review on associated methodology and biocontrol potential. BioControl 62: 1-17.

Medina Delgado, L. 2015, Dinamica de población de mosca de los estigmas (díptera: ulidiidae) de maíz (zea mays) L. utilizando trampas amarillas pegajosas en la comarca lagunera de Coahuila. Tesis de doctorado, universidad autónoma agraria, Mexico.

Meyling, N., Eilenberg, J. 2007. Ecology of the entomopathogenic fungi Beauveria bassiana and Metarhizium anisopliae in temperate agroecosystems: potential for conservation biological control. Biological Control 43: 145-155.

Meyling, N., Pell, J.K., Eilenberg, J., 2006. Dispersal of Beauveria bassiana by the activity of nettle insects. Journal of Invertebrate Pathology. 93: 121-126.

Milanovic, S., Lazarevic, J., Popovic, Z., Miletic, Z., Kostic, M., Radulovis, Z., Karadzic, D., Vuleta, A. 2014. Preference and performance of the larvae of Lymantria dispar (Lepidoptera: Lymantriidae) on three species of European oaks. European Journal of Entomology 111 (3): 371-378.

Mihn, J.A. 1984. Técnicas eficientes para la crianza masiva e infestación de insectos en la selección de plantas hospedantes para resistencia al gusano de la mazorca del maíz o elotero (Heliothis zea).Centro Internacional de Mejoramiento de Maíz y Trigo, México. 18pp. 
Miles, L.A., Lopera, C.A., González, S., Cepero de García, M.C., Franco, A.E., Restrepo, S. 2012. Exploring the biocontrol potential of fungal endophytes from an Andean Colombian Paramo ecosystem. BioControl 57: 697-710.

Murúa, M. G., Virla, E. 2004. Population parameters of Spodoptera frugiperda (Smith) (Lep.: Noctuidae) fed on corn and two predominant grasses in Tucumán (Argentina). A laboratory study. Acta Zoologica Mexicana 20 (1): 199-210.

Murúa, M.G., Virla, E.G., Defagó, V. 2003. Evaluación de cuatro dietas artifíciales para la cría de Spodoptera frugiperda (Lep.: Noctuidae) destinada a mantener poblaciones experimentales de himenópteros parasitoides. Boletín de Sanidad Vegetal-Plagas 29: 43-51.

Mutune, B., Ekesi, S., Niassy, S., Matiru, V., Bii, C., Maniania, N.K. 2016. Fungal endophytes as promising tools for the management of bean stem maggot Ophiomyia phaseoli on beans Phaseolus vulgaris. Journal of Pest Science. 89: in press.

Myles, T.G. 2002. Alarm, aggregation, and defense by Reticulitermes flavipes in response to a naturally occurring isolate of Metarhizium anisopliae. Sociobiology $40: 243-255$.

Napal, G.N.D., Carpinella, M.C., Palacios, S.M. 2009. Antifeedant activity of ethanolicextract from Flourensia oolepis and isolation of pino cembrin as its active principle compound. Bioresource Technology 100: 3669-3673.

Nielsen, C., Eilenberg, J., Dromph, K.M. 2001. Entomophthorales on cereal aphids: characterisation, growth, virulence, epizootiology and potential for microbial control. Copenhagen: Ministry of Environment. 75 pp.

Nur, A. 2013. Diversity of endophytic fungi from root of Maize var. Pulut (waxy corn local variety of South Sulawesi, Indonesia). International Journal of Current Microbiology and Applied Sciences 2(8): 148-154.

Nussenbaum, A.L., Lecuona, R.E. 2012. Selection of Beauveria bassiana sensu lato and Metarhizium anisopliae sensu lato isolates as microbial control agents against the boll weevil (Anthonomus grandis) in Argentina. Journal of Invertebrate Pathology 110: $1-7$. 
O'Donnell, K., Kistler, H.C., Cigelnik, E., Ploetz, R.C., 1998. Multiple evolutionary origins of the fungus causing Panama disease of banana: concordant evidence from nuclear and mitochondrial gene genealogies. Proceedings of the National Academy of Sciences, USA 95: 2044-2049.

Orole, O.O., Adejumo, T.O. 2009. Activity of fungal endophytes against four maize wilt pathogens. African Journal of Microbiology Research 3 (12): 969-973.

Orole, O. O., Adejumo, T. O. 2011. Bacterial and fungal endophytes associated with grains and roots of maize. Journal of Ecology and the Natural Environment 3(9): 298303.

Ownley, B.H., Griffin, M.R., Klingeman, W.E., Gwinn, K.D., Moulton, J.K., Pereira, R.M. 2008. Beauveria bassiana: endophytic colonization and plant disease control. The Journal of Invertebrate Pathology 98: 267-270.

Ownley, B.H., Pereira, R.M., Klingeman, W.E., Quigley, N.B., Leckie, B.M. 2004. Beauveria bassiana, a dual purpose biocontrol organism with activity against insect pests and plant pathogens. In: Emerging Concepts in Plant Health Management. Lartey, R.T., Cesar, A.J. (Eds.), Research Signpost, India. 255-269 pp.

Parodi, B.P. 2011. Caracterización espacial y temporal de la estructura genética del primer insecto blanco del maíz transgénico Bt en Argentina, el barrenador Diatraea saccharalis (Fabricius). Tesis Doctoral, Facultad de Ciencias Exactas y Naturales, Universidad de Buenos Aires.

Parsa, S., Ortiz, V., Vega, F.E. 2013. Establishing fungal entomopathogens as endophytes: towards endophytic biological control. The Journal of Visualized Experiments 74: e50360.

Pastrana, J.A. 2004. Los lepidópteros argentinos: sus plantas hospedadoras y otros sustratos alimenticios. Sociedad Entomológica Argentina 1-334.

Patana, R. 1977 Rearing selected western cotton insects in the laboratory. U.S. Department of Agriculture. Agricultural Research Service, ARS W-51. 8pp.

Pelizza, S. A., Elíades, L. A., Saparrat, M. C. N., Cabello, M. N., Scorsetti, A. C., Lange, C. E. 2012a. Screening of argentine native fungal strains for biocontrol of the grasshopper Tropidacris collaris: Relationship between fungal pathogenicity and 
chitinolytic enzyme activity. World Journal Microbiology and Biotechnology 28: 13591366

Pelizza, S. A., Eliades, L. A., Scorsetti, A. C., Cabello, M. N., Lange, C. E. 2012 b. Entomopathogenic fungi from Argentina for the control of Schistocerca cancellata (Orthoptera: Acrididae) nymphs: Fungal pathogenicity and enzyme activity. Biocontrol Science and Technology 22: 1119-1129.

Pell, J.K., Hannam, J.J., Steinkraus, D.C. 2010. Conservation Biological Control using fungal entomopathogens. BioControl 55: 187-198.

Pérez Moreno, I. 2000. Fundamentos teóricos del manejo integrado de plagas. Journal of Applied Entomology 27: 127-133.

Petrini, O., Stone, J., Carroll, F.E. 1982. Endophytic fungi in evergreen shrubs in western Oregon: a preliminary study. Canadian Journal of Botany 60: 789-796.

Pimentel, D. 2005. Environmental consequences and economic costs of alien species. En: Invasive plants: ecological and agricultural aspects. Indejit, A. (ed.). Birkäuser Verlag, Alemania. 269-276 pp.

Pimentel, I. C., Glienke-Blanco, C., Gabardo, J., Stuart, M. R., Azevedo, J. L. 2006. Identification and colonization of endophytic fungi from soybean (Glycine max (L.) Merril) under different environmental conditions. Brazilian archives of biology and technology 49(5): 705-711.

Pinruan, U., Rungjindamai, N., Choeyklin, R., Lumyong, S., Hyde K. D., Jones. E. G. 2010. Occurrence and diversity of basidiomycetous endophytes from the oil palm, Elaeis guineensis in Thailand. Fungal Diversity 41: 71-88.

Pocasangre, L.E., Sikora, R.A., Vilich, V., Schuster, R.P. 2000. Survey of banana endophytic fungi from Central America and screening for biological control of the burrowing nematode (Radopholus similis). Acta Horticulturae 531: 283-289.

Porras Alfaro, A., Bayman, P. 2011. Hidden Fungi, Emergent Properties: Endophytes and Microbiomes. Annual Review of Phytopathology 49: 291-315.

Posada, F., Aime, M.C., Peterson, S.W., Rehner S.A., Vega, F.E. 2007. Inoculation of coffe plants with the fungal entomopathogen Beauveria bassiana (Ascomycota Hypocreales). Mycological Research 111: 748-757. 
Posada, F., Vega, F.E. 2005. Establishment of the fungal entomopathogen Beauveria bassiana (Ascomycota: Hypocreales) as an endophyte in cocoa seedlings (Theobroma cacao). Mycologia 97: 1195-1200.

Posada, F., Vega, F.E. 2006. Inoculation and colonization of coffee seedlings (Coffea arabica L.) with the fungal entomopathogen Beauveria bassiana (Ascomycota: Hypocreales). Mycoscience 47: 284-289.

Posadas, J.B., Comerio, R.M., Mini, J., Nussenbaum, A.L., Lecuona, R.E. 2012. A novel dodine-free selective medium based on the use of cetyl trimethyl ammonium bromide (CTAB) to isolate Beauveria bassiana, Metarhizium anisopliaesensu lato and Paecilomyces lilacinus from soil. Mycologia 104: 974-980.

Powell, W.A., Klingeman, W.E., Ownley, B.H., Gwinn, K. 2009. Evidence of Endophytic Beauveria bassiana in Seed-treated Tomato Plants Acting as a Systemic Entomopathogen to Larval Helicoverpa zea (Lepidoptera: Noctuidae). Journal of Entomological Science 44(4): 391-396.

Promputtha, I., Lumyong, S., Dhanasekaran, V., McKenzie, E.H.C., Hyde, H.D., Jeewon, R.A. 2007. Phylogenetic evaluation of whether endophytes become saprotrophs at host senescence. Microbiology Ecology 53:579-590.

Pucheta Díaz, M., Flores Macias, A., Rodríguez Navarro, S., De la Torre, M. 2006. Mecanismos de acción de los Hongos Entomopatógenos. Interciencia 31(12): 856860.

Qayyum, M.A., Wakil, W., Arif, M.J., Sahi, S.T., Dunlap, C.A. 2015. Infection of Helicoverpa armigera by endophytic Beauveria bassiana colonizing tomato plants. Biological Control 90: 200-207.

Quesada Moraga, E., Herrero, N., Zabalgogeazcoa, I. 2014a.Entomopathogenic andnematophagous fungal endophytes. In: Advances in Endophytic Research. Verma, V.C., Gange, A.C. (Eds.), Springer, India. 85-99.

Quesada Moraga, E., Landa, B.B., Munoz-Ledesma, J., Jimenez-Diaz, R.M., Santiago Alvarez, C. 2006. Endophytic colonisation of opium poppy, Papaver somniferum, by an entomopathogenic Beauveria bassiana strain. Mycopathologia 161: 323-329. 
Quesada Moraga, E., López-Díaz, C., Landa, B.B. 2014b. The hidden habit of the entomopathogenic fungus Beauveria bassiana: First demonstration of vertical plant transmission. Plos One 9: e89278.

Quesada Moraga, E., Muuñoz-Ledesma, J., Santiago-Álvarez, C., 2009. Systemic Protection of Papaver somniferum L. against Iraella luteipes (Hymenoptera: Cynipidae) by an endophytic strain of Beauveria bassiana (Ascomycota: Hypocreales). Environmental Entomology 38: 723-730.

Raps, A., Vidal, S. 1998. Indirect effects of an unspecialized endophytic fungus on specialized plant herbivorous insect interactions. Oecologia 114: 541-547.

Rath, A.C. 2000. The use of entomopathogenic fungi for control of termites. Biocontrol Science and Technology 10:563-581.

Rathod, L.R., Pawar, N.B. 2013. In vitro seed treatment of fungicides for the control of seed borne fungi of soybean variety Durga. Global Journal for Research Analysis 2(10): 15-16.

Rodrigues Destéfano, R.H., Lanza Destéfano, S.A., Messias, C.L. 2004. Detection of Metarhizium anisopliae var. anisopliae within infected sugarcane borer Diatraea saccharalis (Lepidoptera, Pyralidae) using specific primers. Genetics and Molecular Biology. 27(2): 245-252

Rodríguez, R.J., White, J.F., Arnold, A.E., Redman, R.S. 2009. Fungal endophytes: diversity and functional roles. New Phytologist 182: 314-330.

Romero, F. 2004. Manejo Integrado de Plagas: las bases, los conceptos y su mercantilización. Chapingo, Tezcoco, México. 109 pp.

Roy, H.E, Brodie, E.L., Chandler, D., Goettel, M.S., Pell, J.K., Wajnberg, E., Vega, F.E. 2010. Deep space and hidden depths: understanding the evolution and ecology of fungal entomopathogens. BioControl 55: 1-6.

Roy, H.E., Steinkraus, D.C., Eilenberg, J., Hajek, A.E., Pell, J.K. 2006. Bizarre interactions and endgames: Entomopathogenic fungi and their arthropod hosts. Annual Review of Entomology 51: 331-357. 
Roy, K.W., Baird, R.E., Abney, T.S. 2000. A review of soybean (Glycine max) seed, pod, and flower mycofloras in North America, with methods and key for identification of selected fungi. Mycopathology 150: 15-27.

Russo, M.L., Pelizza, S.A., Cabello, M.N., Stenglein, S.A., Scorsetti, A.C. 2015. Endophytic colonisation of tobacco, corn, wheat and soybeans by the fungal entomopathogen Beauveria bassiana (Ascomycota, Hypocreales). Biocontrol Science and Technology 25: 475-480.

Russo, M.L., Pelizza, S.A., Cabello, M.N., Stenglein, S.A., Vianna, M.F., Scorsetti, A.C. 2016. Endophytic fungi from selected varieties of soybean (Glycine max L. Merr.) and corn (Zea mays L.) grown in an agricultural area of Argetina. Revista Argentina de Microbiología 48 (2): 154-160.

SAGPyA 2015. Secretaría de Agricultura, Ganadería, Pesca y Alimentos, Agricultura, Ministerio de Agricultura, Ganadería y Pesca de Argentina. Estimaciones Agrícolas, Informes por Cultivo.www.sagpya.mecon.gov.ar.

Sánchez Márquez, S., Bills, G.F., Domínguez Acuña, L., Zabalgogeazcoa, I. 2010. Endophytic mycobiota of leaves and roots of the grass Holcus lanatus. Fungal Diversity 41: 115-123.

Sanchez Marquez, S., Bills, G.F., Herrero, N., Zabalgogeazcoa, I. 2012. Non-systemic fungal endophytes of grasses. Fungal Ecology 5: 289-297.

Sánchez Márquez, S., Bills, G.F., Zabalgogeazcoa, I. 2007. The endophytic mycobiota of the grass Dactylis glomerata. Fungal Diversity 27:171-195.

Sánchez Márquez, S., Bills, G.F., Zabalgogeazcoa, I. 2008. Diversity and structure of the fungal endophytic assemblages from two sympatric coastal grasses. Fungal Diversity 33:87-100.

Sánchez-Fernández,R.E., Sánchez-Ortiz, B.L., Sandoval-Espinosa,Y.K.M., UlloaBenítez, A., Armendáriz-Guillén,B., García-Méndez, M.C., Macías-Rubalcava, M.L. 2013. Hongos endófitos: fuente potencial de metabolitos secundarios bioactivos con utilidad en agricultura y medicina. TIP Revista Especializada en Ciencias QuímicoBiológicas 16(2):132-146. 
Sánchez Rodríguez, A.R., Campillo, M.C., Quesada-Moraga, E. 2015. Beauveria bassiana: An entomopathogenic fungus alleviates Fe chlorosis symptoms in plants grown on calcareous substrates. Scientia Horticulturae 197: 193-202.

Santamaria, J., Bayman, P. 2005. Fungal epiphytes and endophytes of coffee leaves (Coffea arabica). Microbial Ecology 50: 1-8.

Santamaría, S., Girbal, J. 1996. Contribución al conocimiento de los Entomophthorales (Zygomycotina) Ibéricos. Revista Iberoamericana de Micología 13: 37-43.

Sarandón, S.J. 2011. Incorporando la Agroecología en las Instituciones de Educación Agrícola: Una necesidad para la Sustentabilidad Rural. En: La Agroecología en la construcción de alternativas hacia la sustentabilidad Rural. Hernández, J.M. (Ed.),Ediciones Siglo, InstitutoTecnológico de Estudios Superiores de Occidente, Guadalajara, México. 168-189 pp.

Sarandon, S.J., Flores, C.C. 2014. Agroecología: bases teóricas para el diseño y manejo de Agroecosistemas sustentables. Universidad Nacional de La Plata, Buenos Aires, Argentina. 466 pp.

Sasan, R.K., Bidochka, M.J. 2012. The insect-pathogenic fungus Metarhizium robertsii (Clavicipitaceae) is also an endophyte that stimulates plant root development. American Journal of Botany 99: 101-107.

Saucedo García, A., Anaya, A.L., Espinosa García, F.J., Gonzalez, M.C. 2014. Diversity and Communities of Foliar Endophytic Fungi from Different Agroecosystems of Coffea arabica L. in Two Regions of Veracruz, Mexico. Plos One 9(6):e98454.

Schardl, C.L., Leuchtmann, A., Spiering, M.J. 2004. Symbioses of grasses with seedborne fungal endophytes. Annual review of plant biology 55:315-340.

Schneider, M.I, Sanchez, N., Pineda, B., Chi, C., Ronco, A. 2009. Impact of glyphosate on the development, fertility and demography of Chrysoperla externa (Neuroptera: Chrysopidae): Ecological approach. Chemosphere 76: 1451-1455.

Schulz, B., Boyle, C. 2005. The endophytic continuum. Mycological Research 109: 661-686. 
Scorsetti, A.C., Humber, R.A., De Gregorio, C., Lopez Lastra, C. 2008. New records of entomopathogenic fungi infecting Bemisia tabaci and Trialeurodes vaporariorum, pests of horticultural crops, in Argentina. BioControl 53:787-796.

Scorsetti, A.C., Humber, R.A., García, J.J., López Lastra, C.C. 2007. Natural occurrence of entomopathogenic fungi (Zygomycetes: Entomophthorales) of aphid (Hemiptera: Aphididae) pests of horticultural crops in Argentina. Biocontrol 52: 641655.

Selim, K.A., El-Beih, A.A., Abdel-Rahman, T.M., El-Diwany, A.I. 2012. Biology of endophytic fungi. Current Research in Environmental \& Applied Mycology 2: 31-82.

Shah P.A., Pell J.K. 2003. Entomopathogenic fungi as biological control agents. Applied Microbiology and Biotechnology 61: 413-423.

Shapiro Ilan, D.I., Mizell, R.F., Cottrell, T.E., Horton, D.L. 2008. Control of plum curculio, Conotrachelus nenuphar with entomopathogenic nematodes: effects of application timing, alternate host plant, and nematode strain. Biological Control 44: 207-215.

Sieber, B. 2007. Endophytic fungi of forest trees: are they mutualists? Fungal Biology. 21:75-89.

Sosa-Gómez, D.R., López Lastra, C.C., Humber, R.A. 2010. An overview of arthropodassociated fungi from Argentina and Brazil. Mycopathologia 170: 61-76.

Specht, A., E.J.E. Silva, D. Link. 2004. Noctuídeos (Lepidoptera, Noctuidae) do museu entomológico Ceslau Biezanko, Departamento de Fitossanidade, Faculdade de Agronomia "Eliseu Maciel", Universidade Federal de Pelotas, Rio Grande do Sul. Revista Brasileira de Agrociência 10:389-409.

Spegazzini, C. 1880. Sporotrichum globuliferum. Fungi Argentini No 164. Anales de la Sociedad Científica Argentina 10: 278- 282.

Spegazzini, C. 1913. Mycetes argentinenses. Anales Museo Nacional de Historia Natural de Buenos Aires 20: 167-186.

St.Leger, R.J., Wang, C., Fang, W. 2011. New perspectives on insect pathogens. Fungal Biology Reviews 25: 84-88. 
Staples, J.A., Milner, R.J. 2000. A laboratory evaluation of the repellency of Metarhizium anisopliae conidia to Coptotermes lacteus (Isoptera: Rhinotermitdae). Sociobiology 36: 133-146.

Stenglein, S., Balatti P. 2006. Genetic diversity of Phaeoisariopsis griseola in Argentina as revealed by pathogenic and molecular markers. Physiological and Molecular Plant Pathology 68: 158-67.

Stenglein, S.A., Rodriguero, M.S., Chandler, E., Jennings, P., Salerno, G.L., Nicholson, P. 2010. Phylogenetic relationships of Fusarium poae based on EF-1a and mtSSU sequences. Fungal Biology 114: 96-106.

Stone, J.K., Bacon, C.W., White, J.F. 2000. An overview of endophytic microbes: endophytism defined. In: Microbial Endophytes,Bacon, C.W., White, J.F. (Eds.), Marcel Dekker, Inc., NY. 3-29 pp.

Stone, J.K., Polishook, J.D., White, J.F. 2004. Endophytic fungi. In: Biodiversity of fungi. Inventory and monitoring methods.Mueller, G.M., Bills, G.F., Foster, M.S. (eds.), Elsevier Academic Press, USA. 241-270 pp.

Sun, S.S., Chen, X.M., Guo, S.X. 2014. Analysis of endophytic fungi in roots of Santalum album Linn. and its host plant Kuhnia rosmarinifolia. Journal of Zheijang University Science B 15(2): 109-115.

Sun, X., Guo, L.D. 2012. Endophytic fungal diversity: review of traditional and molecular techniques. Mycology 3(1): 65-76.

Sunitha, V.H., Devi, D.N., Srinivas, C. 2013. Extracellular enzymatic activity of endophytic fungal strains isolated from medicinal plants. World Journal of Agricultural Sciences 9:1-2.

Tamagno, S., Greco, I., Almeida, H., Borras, L. 2015. Physiological differences in yield related traits between flint and dent Argentinean commercial maize genotypes. European Journal of Agronomy 68: 50-56.

Tanaka, A., Takemoto, D., Chujo, T., Scott, B. 2012. Fungal endophytes of grasses. Current Opinion in Plant Biology 15(4): 462-468. 
Tefera, T., Vidal, S. 2009. Effect of inoculationmethod and plant growth medium on endophytic colonization of sorghum by the entomopathogenic fungus Beauveria bassiana. BioControl 54: 663-669.

Tenguria, R.K., Firodiya, A. 2013. Diversity of endophytic fungi in leaves of Glycine max (L.) merr. From central region of Madhya Pradesh. World Journal of Pharmacy and Pharmaceutical Sciences 2(6): 5928-5934.

Thakur, A., Kaur, S., Kaur, A., Singh, V., 2013. Enhanced Resistance to Spodoptera litura in Endophyte Infected Cauliflower Plants. Environmental Entomology 42(2): 240-246.

Thompson, S. R., Brandenburg, R. L. 2005. Tunneling responses of mole crickets (Orthoptera: Gryllotalpidae) to the entomopathogenic fungus, Baeuveria bassiana. Environmental Entomology 34(1): 140-147.

Thrower, L.B. 1966. Terminology for plant parasites.Phythopathologische Zeitschrift 56: 258-259.

Toledo, A.V., Scorsetti, A.C., Dikgolz, V.E., López Lastra, C.C. 2004. Paecilomyces fumosoroseus y Nomuraea rileyi (Deuteromycotina: Hyphomycetes), hongos patógenos de insectos plaga de la agricultura en la Argentina. Boletín de la Sociedad Argentina de Botánica 39: 21-26.

Toledo, A.V., De Remes Lenicov, A.M.M., Lopez Lastra, C.C. 2008. Host range findings on Beauveria bassiana and Metarhizium anisopliae (Ascomycota: Hypocreales) in Argentina. Boletín de la Sociedad Argentina de Botánica 43(3-4): 211-220.

U'ren, J.M., Lutzoni, F., Miadlikowska, j., Arnold, A. E. 2010. Community analysis reveals close affi nities between endophytic and endolichenic fungi in mosses and lichens. Microbial Ecology 60:340-353.

Urretabizkaya, N., Vasicek, A., and Saini, E. 2010. Insectos perjudiciales de importancia agronómica. Lepidópteros. INTA. Universidad Nacional de Lomas de Zamora, Universidad Nacional de La Plata, Buenos Aires, Argentina. 77 pp.

Valerio, A. 2006. Evaluación de la incorporación de diferentes funguicidas y dosis en dietas artificiales para la reproducción de la broca del café con miras a la multiplicación masiva de sus parasitoides bajo condiciones controladas. Tesis de grado 
de bachiller en Ingeniería en Biotecnología. Instituto Tecnológico de Costa Rica. Cartago, Costa Rica.

Van Bael, S.A., Mejía, L.C., Bischoff, J.F., Rojas, E.I., Arnold, A.E., Robbins, N., Herre, E.A., Kyllo, D.A., Maynard, Z. 2005. Emerging perspectives on the ecological roles of endophytic fungi in tropical plants. In: The fungal community: its organization and the role in the ecosystem.Dighton, J., White, J., Oudemans, P. (eds.),CRC Press, London, UK. 181-191 pp.

Van Driesche, R.G., Hoddle, M.S., Center, T.D. 2007. Liberación aumentativa de enemigos naturales en cultivos exteriores. En: Control de Plagas y Malezas por Enemigos Naturales. USDA, US Forest Service, Forest Health Technology Enterprise Team, USA. 495-516 pp.

Vega, F.E. 2008. Insect pathology and fungal endophytes. Journal of Invertebrate Pathology 98: 277-279.

Vega, F.E., Goettel, M.S., Blackwell, M., Chandler, D., Jackson, M.A., Keller, S., Koike, M., Maniania, N.K., Monzón, A., Ownley, B.H., Pell, J.K., Rangel, D.E.N., Roy, E. 2009. Fungal entomopathogens: new insights on their ecology. Fungal Ecology 2: 149-159.

Vega, F.E., Meyling, N.V., Luangsa-ard, J.J., Blackwell, M. 2012. Fungal entomopathogens. In: Insect Pathology.Vega, F.E., Kaya, H.K. (Eds.), Academic Press, San Diego. 171-220.

Vega, F.E., Posada, F., Aime, M.C., Pava-Ripolli, M., Infante, F., Rehner, S.A. 2008. Entomopathogenic fungal endophytes. Biological Control 46: 72-82.

Vega, F.E., Simpkins, A., Aime, C., Posada, F., Peterson, S.W. 2010. Fungal endophyte diversity in coffee plants from Colombia, Hawai, Mexico and Puerto Rico. Fungal Ecology 3: 122-138.

Vidal, E., Jaber, L.R. 2015. Entomopathogenic fungi as endophytes: plant-endophyteherbivore interactions and prospects for use in biological control. Current Science 109 (1): 46-54.

Vilella, F., Senesi, S., Dulce, E., Pérez San Martín, R., Daziano, M. 2010. El sistema de agronegocios en la Argentina, su cadena y perspectivas para 2020. Horizonte A, Bs As, Argentina. 352 pp. 
Wagner, B.L., Lewis, L.C. 2000. Colonization of corn, Zea mays, by the entomopathogenic fungus Beauveria bassiana. Applied and Environmental Microbiology 66: 3468-3473.

Wearn, J.A., Sutton, B.C., Morley, N.J., Gange, A.C. 2012. Species and organ specificity of fungal endophytes in herbaceous grassland plants. Journal of Ecology 100: $1085-1092$.

White, T.J., Bruns, T.D., Lee, S., Taylor, J. 1990. Amplification and direct sequencing of fungal ribosomal rna genes for phylogenetics. In: PCR protocols: a guide to methods and applications. Innis, M.A., Gelfand, D.H., Sninsky, J.J., White, T.J. (Eds.), Academic Press,New York, USA. 315-22 pp.

www.trigoklein.com.ar/estacion-meteorológica

Yadav, A.S., Madelin, M.F. 1968. The ecology of microfungi on decaying stems of Urtica dioica. Transactions of the British Mycological Society 51 (2): 249-259.

Yan, J.F., Broughton, S.J., Yang, S.L., Gange, A.C. 2015. Do endophytic fungi grow through their hosts systemically? Fungal Ecology 13: 53-59.

Ybran, R.G., Lacelli, G.A. 2015. Informe estadístico mercado de la soja. INTA. 8pp.

Zabalgogeazcoa, I. 2008. Fungal endophytes and their interaction with plantpathogens. Spanish Journal of Agricultural Research 6: 138-146.

Zubek, S., Stojakowska, A., Anielska, T., Turnau, K. 2010. Arbuscular mycorrhizal fungi alter thymol derivative contents of Inula ensifolia L. Mycorrhiza 20: 497-504. 